\title{
ANÁLISE DE PAVIMENTOS DE EDIFÍCIOS DE CONCRETO ARMADO COM A CONSIDERAÇÃO DA NÃO-LINEARIDADE FÍSICA - MODELAGEM E METODOLOGIA DE APLICAÇÃO A PROJETOS
}

RICHARD SARZI OLIVEIRA

Tese apresentada à Escola de Engenharia de São Carlos, da Universidade de São Paulo, como parte dos requisitos para obtenção do Título de Doutor em Engenharia de Estruturas

ORIENTADOR: Prof. Dr. Márcio Roberto Silva Corrêa 
Ofereço este trabalho à minha esposa Adriana, e ao meu filho Pedro. 


\section{AGRADECIMENTOS}

À Deus, por tudo que tem me proporcionado.

À minha esposa Adriana e ao meu filho Pedro, pelos prazeres do convívio harmonioso que propiciaram o bom desenvolvimento deste trabalho. Em especial, agradeço à Adriana pelo pronto apoio e carinho nosmomentos difíceis.

Aos meus pais, Pedro e Noêmia, que me ensinaram os primeiros passos, e acreditaram na minha escalada.

À Suzy, Elaine e Sérgio pelo constante incentivo.

Aos ensinamentos e à amizade que pude desfrutar da convivência com o professor e orientador Márcio Corrêa, e com o professor e co-orientador Márcio Ramalho. Agradeço também ao professor Paulo Lourenço, da Universidade do Minho, Guimarães, pelas preciosas contribuições e edificante trabalho em terras portuguesas.

Ao amigo Daniel, pela companhia em muitas das reflexões que contribuíram para o bom andamento deste trabalho. Agradeço também a harmoniosa convivência com o amigo José Fernão.

Ao professor Sérgio P. B. Proença, pelas importantes colaborações com as formulações, e pela amizade.

À Sra. Maria Nadir Minatel, pela atenciosa ajuda com a bibliografia.

À todas as pessoas que contribuíram de alguma forma para a realização deste trabalho.

Ao Departamento de Engenharia de Estruturas da EESC-USP.

Ao CNPq, e à Fundação de Amparo à Pesquisa do Estado de São Paulo (FAPESP), pelas bolsas de estudos que tornaram possível minha dedicação à elaboração deste trabalho. 


\section{SUMÁRIO}

LISTA DE FIGURAS V V

LISTA DE TABELAS ix

LISTA DE SÍMBOLOS X $x$

RESUMO XV

ABSTRACT Xvi

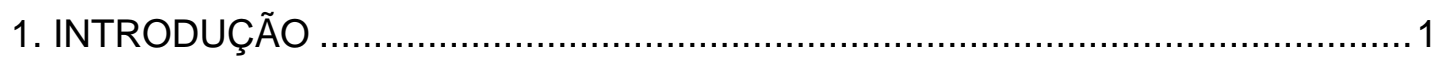

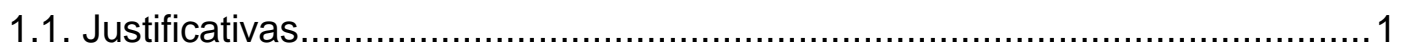

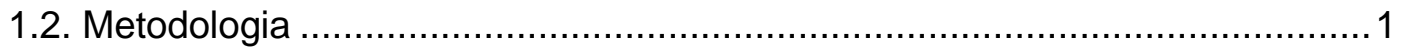

1.3. Descrição sucinta dos capítulos ......................................................... 2

2. ASPECTOS SOBRE A FORMULAÇÃO DOS ELEMENTOS ............................. 4

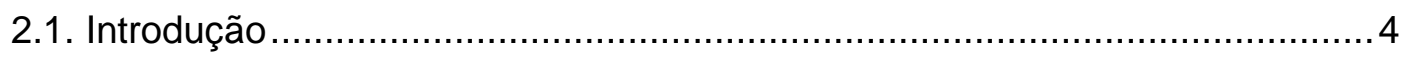

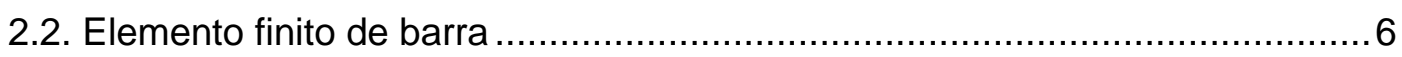

2.2.1. Modelos aplicados à análise de vigas.............................................. 10

2.2.1.1. Seção transversal não estratificada.............................................. 10

2.2.1.2. Seção transversal estratificada .................................................. 11

2.2.2. Modelos aplicados à análise de pilares............................................. 13

2.2.2.1. Seção transversal filamentada ................................................ 13

2.3. Elemento finito de placa delgada T3AF ................................................ 15

2.3.1. Seção transversal não estratificada ................................................ 18

2.3.2. Seção transversal estratificada ..................................................... 18

3. MODELOS CONSTITUTIVOS PARA OS MATERIAIS .....................................21

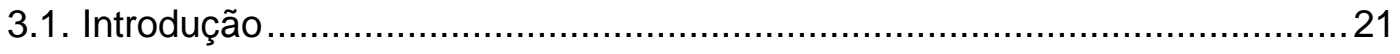

3.2. Formulação básica dos modelos elastoplásticos.....................................25

3.3. Aplicação ao aço das armaduras ..................................................... 27

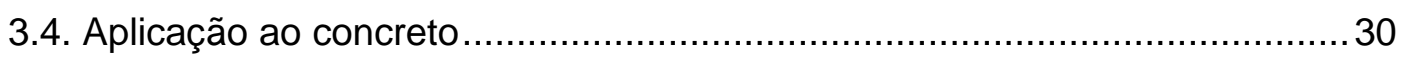

3.4.1. Estado multiaxial ....................................................................... 30 
3.4.1.1. Critérios de ruptura para materiais granulares............................. 37

3.4.1.2. Modelo de endurecimento ........................................................ 40

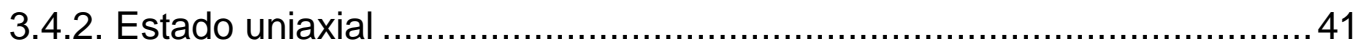

3.5. Modelo de dano de Mazars para o concreto ........................................... 45

3.5.1. Introdução .............................................................................. 45

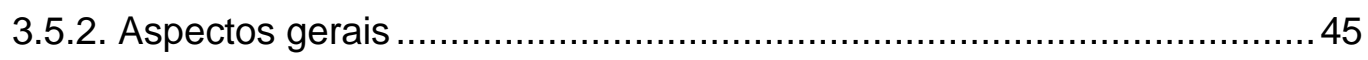

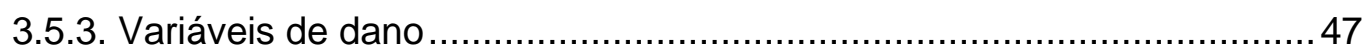

3.5.4. Modelo constitutivo de Mazars ........................................................ 47

3.5.5. Dano sob solicitação uniaxial (com uma e duas variáveis) .....................50

3.5.6. Dano sob solicitação pluriaxial (com duas variáveis) ............................ 51

3.6. Aplicação ao 'material' concreto armado .................................................. 53

3.7. Modelo para a aderência entre o aço e o concreto.....................................58

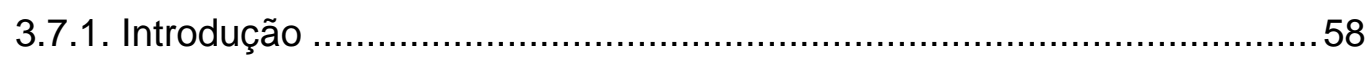

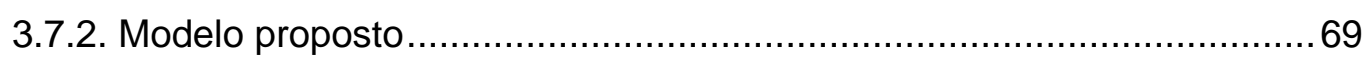

4. CONSIDERAÇÃO DOS EFEITOS DO TEMPO …........................................ 75

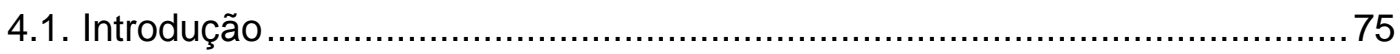

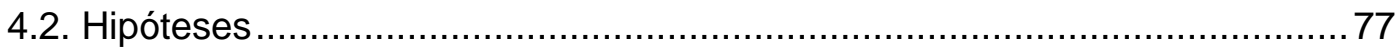

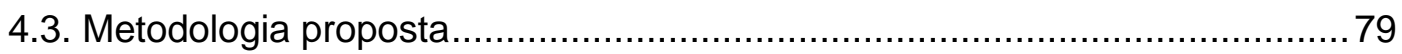

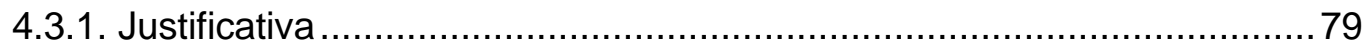

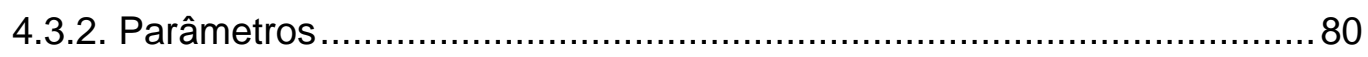

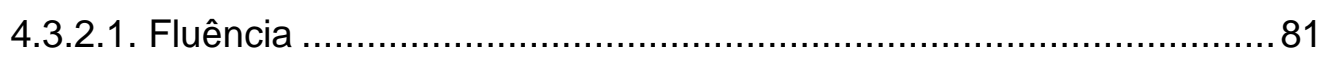

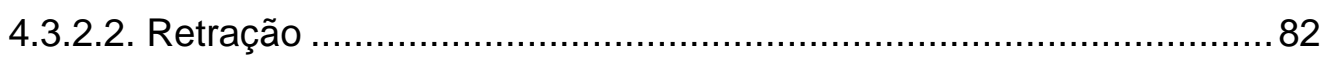

4.3.3. Metodologia - elementos lineares ................................................... 83

4.3.4. Metodologia - elementos de placa ................................................... 84

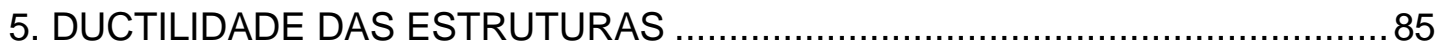

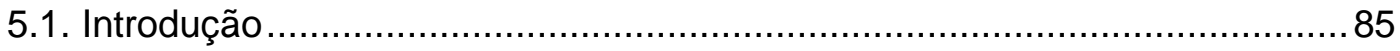

5.2. Fatores que influenciam a capacidade de rotação ................................... 86

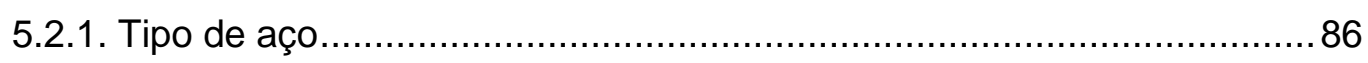

5.2.2. Profundidade da linha neutra ................................................... 86

5.3. Prescrições normativas sobre as máximas rotações permitidas.................. 87

5.4. Métodos para a determinação da capacidade de rotação ...........................90

5.5. Aferição do modelo mecânico implementado neste trabalho........................91

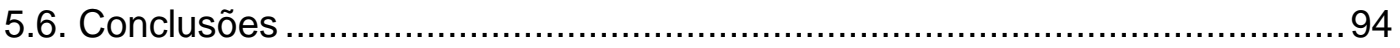

6. TÓPICOS SOBRE AS IMPLEMENTAÇÕES .............................................. 95

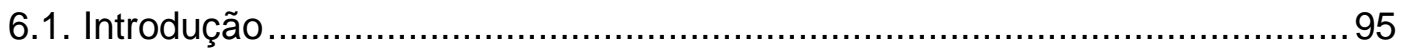




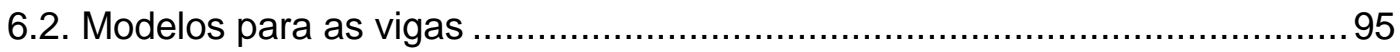

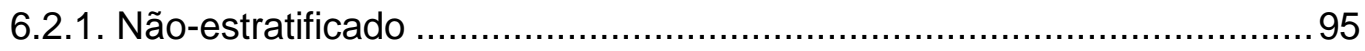

6.2.1.1. Formulação incremental do modelo elastoplástico .........................96

6.2.1.2. O procedimento incremental-iterativo ...................................... 97

6.2.2. Estratificado.......................................................................... 101

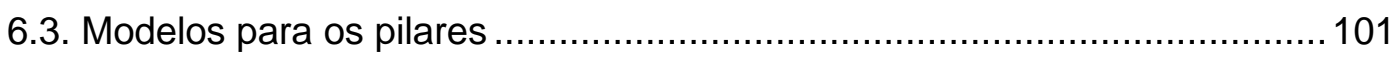

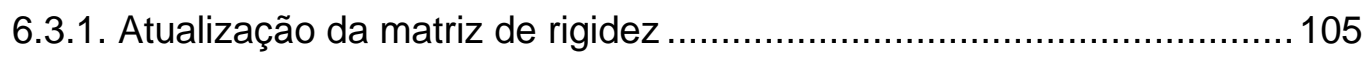

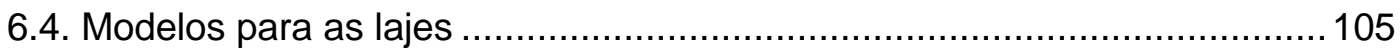

6.4.1. Formulação incremental do modelo de von Mises .............................. 106

6.4.1.1. Atualização da matriz de rigidez (von Mises) ................................ 112

6.4.2. Aspectos sobre a formulação da superfície de Rankine ...................... 112

6.4.2.1. Atualização da matriz de rigidez (Rankine) ............................... 115

6.4.3. Estratégia de implementação ...................................................... 116

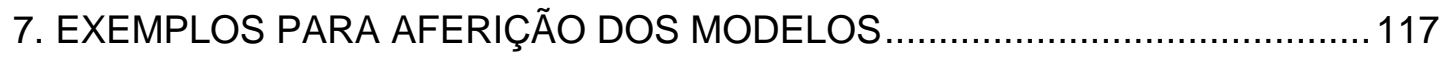

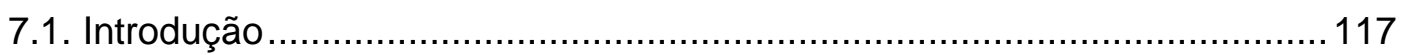

7.2. Modelos aplicados à análise de vigas ....................................................117

7.3. Exemplos de aferição do modelo de pilar ............................................... 121

7.4. Exemplo de aferição do modelo de aderência............................................. 123

7.5. Exemplo de aferição do modelo de fluência (teórico) ................................. 126

7.6. Exemplo de aferição do modelo de fluência (experimental) ....................... 127

7.7. Primeiro exemplo de aferição dos modelos para as lajes .......................... 131

7.8. Segundo exemplo de aferição dos modelos para as lajes......................... 133

8. ASPECTOS SOBRE O DIMENSIONAMENTO ........................................... 136

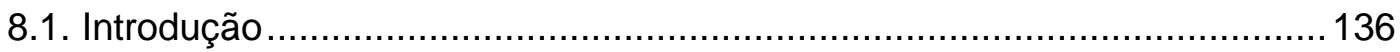

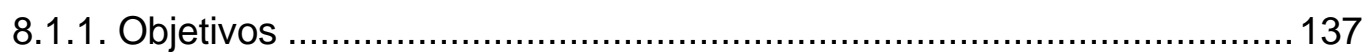

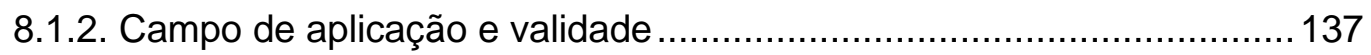

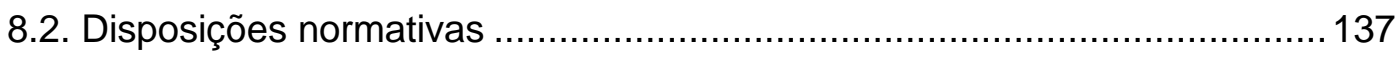

8.2.1. Ponderadores das ações ........................................................ 138

8.2.2. Ponderadores dos materiais .................................................... 139

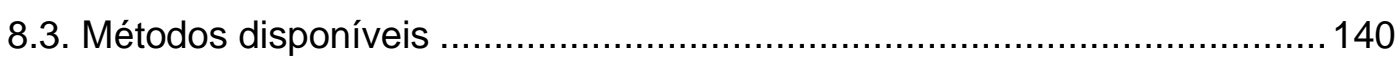

8.3.1. Método semi-probabilístico .......................................................... 140

8.3.1.1. Composição do carregamento ................................................ 141

8.3.1.2. Valores para as propriedades dos materiais .............................. 142

8.3.2. Propostas para o dimensionamento ............................................... 144

8.3.2.1. Proposta de alteração da rigidez inicial ..................................... 144 
8.3.2.2. Proposta da limitação da tensão máxima ................................... 145

8.3.3. Método dos coeficientes globais ................................................... 146

8.3.3.1. Particularização às lajes.................................................... 157

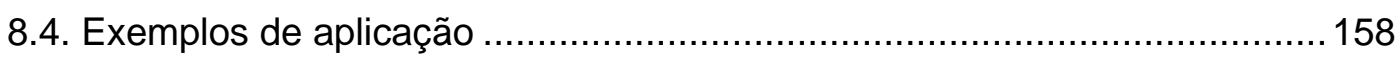

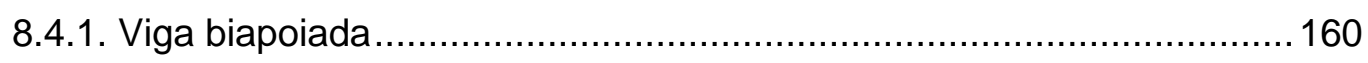

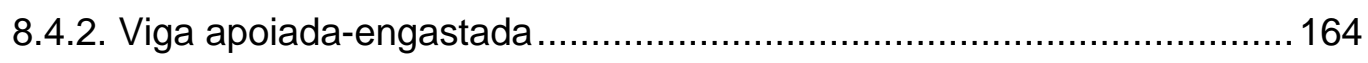

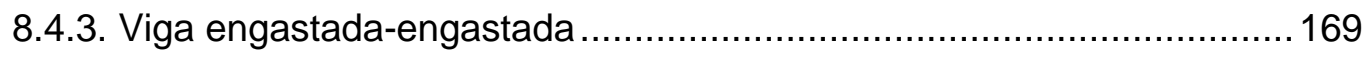

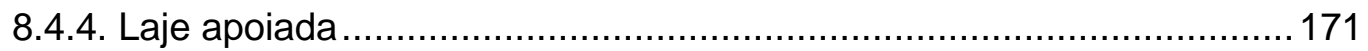

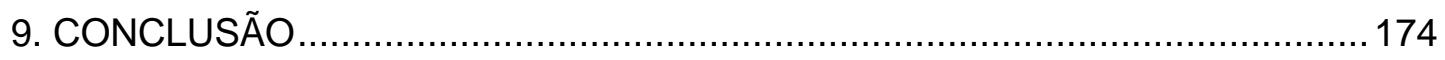

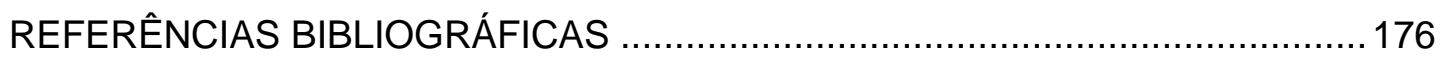

ANEXO A. INCORPORAÇÃO DAS DIMENSÕES DOS PILARES …................... 183

ANEXO B. ESTUDO DO COMPORTAMENTO DO COEFICIENTE $\gamma_{g \mid} \ldots \ldots \ldots \ldots \ldots . . . . . .193$ 


\section{LISTA DE FIGURAS}

Figura 2.1 - Elemento de barra de pórtico tridimensional - coordenadas locais ........6

Figura 2.2 - Elemento de viga estratificado; diagrama de deformações normais .... 11

Figura 2.3 - Elemento de pilar filamentado; diagrama de tensões normais .............. 13

Figura 2.4 - Elementos triangular T3AF, e quadrilateral - coordenadas locais ........ 15

Figura 2.5 - Localização dos pontos de integração no domínio dos elementos ...... 17

Figura 2.6 - Elemento de placa estratificado; diagrama de tensões normais ..........19

Figura 3.1 - Modelo de fissuração discreta - representação do caso biaxial ...........22

Figura 3.2 - Modelo de fissuras distribuídas - eixos principais (ortótropos) ..............23

Figura 3.3 - Representação gráfica do vetor fluxo plástico sobre o domínio elástico

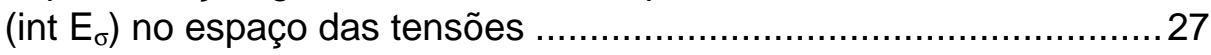

Figura 3.4 - Interpretação geométrica do critério de escoamento de von Mises .....28

Figura 3.5 - Relação elastoplástica perfeita - ilustração para o caso uniaxial ..........29

Figura 3.6 - Superfícies de plastificação e de ruptura (PROENÇA(1988)) ................30

Figura 3.7 - Deformação volumétrica do concreto (KUPFER et al.(1969)) ................33

Figura 3.8 - Curva carga distribuída-deslocamento: comparação do desempenho de diversas superfícies aplicáveis à análise do concreto (LABBANE et al.

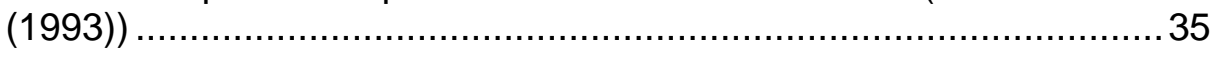

Figura 3.9 - Curvas de amolecimento (RANJBARAN;PHIPPS (1994)) ....................36

Figura 3.10 - Critérios de ruptura - comparação ilustrativa ....................................39

Figura 3.11 - Aspecto das superfícies de ruptura no plano octaédrico....................39

Figura 3.12 - Diagrama tensão efetiva-deformação efetiva.................................. 41

Figura 3.13 - Diagrama tensão-deformação para o concreto na compressão

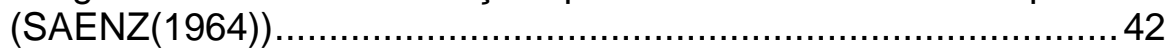

Figura 3.14 - Diagrama tensão-deformação para o concreto (CEB-FIP MC90) .......43

Figura 3.15 - Modelo para enrijecimento à tração............................................ 44

Figura 3.16 - Comparação entre diagramas tensão-deformação ........................... 45

Figura 3.17 - Experimentos uniaxiais: tração e compressão .................................. 45

Figura 3.18 - Modos básicos de solicitação de uma fissura ................................... 46

Figura 3.19 - Comportamento unilateral do concreto ....................................... 46 
Figura 3.20 - Superfícies de ruptura (PEREGO (1989)) …...................................49

Figura 3.21 - Microfissuração: tração e compressão …......................................50

Figura 3.22 - Leis constitutivas para o dano uniaxial de Mazars ............................53

Figura 3.23 - Diagramas momento-curvatura segundo Branson e Ghali \& Favre ...56

Figura 3.24 - Diagrama momento-curvatura segundo o CEB-FIP MC90 ................56

Figura 3.25 - Diagrama momento-curvatura segundo CORRÊA (1991) .................57

Figura 3.26 - Tensões em uma porção de concreto armado tracionado ..................59

Figura 3.27 - Distribuição esquemática do escorregamento relativo e das tensões em elemento tracionado fissurado (TASSIOS;YANNOPOULOS

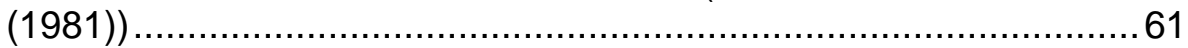

Figura 3.28 - Mobilização da aderência mecânica em barras corrugadas ..............63

Figura 3.29 - Relações tensão de aderência $\left(\tau_{b}\right)$ por escorregamento (s)...............64

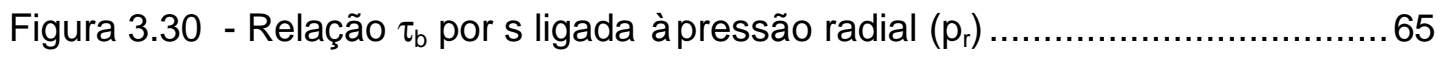

Figura 3.31 - Elemento de chapa com barra de treliça ........................................66

Figura 3.32 - Elemento de viga fissurado. Discretização …..................................70

Figura 3.33 - Evolução da tensão de aderência e do escorregamento com o carregamento ......................................................................... 71

Figura 3.34 - Estados de deformação e de tensão no elemento .............................. 72

Figura 4.1 - Deformação específica do concreto ao longo do tempo ......................77

Figura 4.2 - Influência da fluência sobre o modelo do concreto ............................... 83

Figura 4.3 - Estados de deformações e tensões nos instantes $t_{0}$ e t....................... 84

Figura 4.4 - Análise das deformações e tensões em $t_{0}$ e $t$..................................... 84

Figura 5.1 - Definição da capacidade de rotação plástica...................................... 85

Figura 5.2 - Capacidade de rotação plástica (aço tipo A). Resultados experimentais e proposta do CEB-FIP MC90 ..................................................... 87

Figura 5.3 - Capacidade de rotação plástica (aço tipo B). Resultados experimentais e proposta do CEB-FIP MC90 ................................................... 88

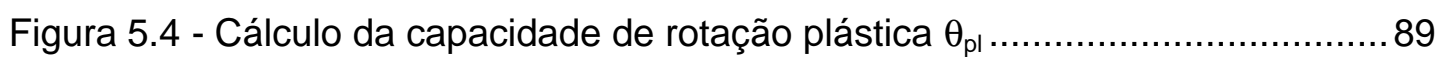

Figura 5.5 - Aproximação para a determinação da rotação $\theta$.................................92

Figura 5.6 - Capacidade de rotação plástica para a viga padrão: comparação entre os valores normativos, e os obtidos com o modelo mecânico .............93

Figura 6.1 - Procedimento incremental-iterativo para 0 modelo momento-

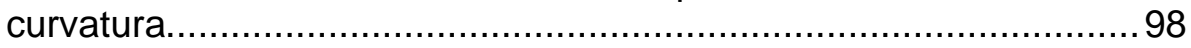

Figura 6.2 - Modelos constitutivos uniaxiais para o concreto e o aço..................... 102

Figura 6.3 - Estados de deformação, tensão e forças $\left(1^{a}\right.$ iteração do $1^{\circ}$

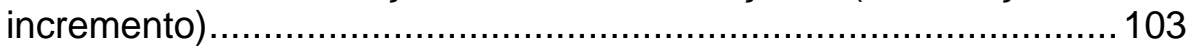

Figura 6.4 - Ilustração do vetor resíduo sobre o domínio da barra........................ 103

Figura 6.5 - Superfícies do modelo implementado: von Mises e Rankine .............. 105

Figura 6.6 - Retornos à superfície de Rankine (FEENSTRA;DE BORST(1995)) . 113 
Figura 6.7 - Procedimentos de retorno às superfícies - caso do vértice................. 114

Figura 7.1 - Esquema dos grupos de vigas (grupos I e II)..................................118

Figura 7.2 - Diagrama força-deslocamento para as vigas do grupo I.....................118

Figura 7.3- Diagrama força-deslocamento para as vigas do grupo II................... 119

Figura 7.4 - Posição da LN (modelo estratificado elastoplástico) ..........................119

Figura 7.5 - Estudo da dependência de malha - vigas do grupo I ........................ 120

Figura 7.6 - Ilustração do pilar típico de ABDEL-SAYED;GARDNER (1975) ......... 121

Figura 7.7 - Diagrama de força normal por deslocamento - pilar 1 ...................... 122

Figura 7.8- Diagrama de força normal por deslocamento - pilar 2 ........................ 123

Figura 7.9- Diagrama de força normal por deslocamento - pilar 3 ........................ 123

Figura 7.10 - Esquema da viga estudada por KWAK;FILIPPOU (1997)................ 124

Figura 7.11 - Deslocamentos para a viga de KWAK;FILIPPOU (1997).................. 124

Figura 7.12 - Estudo da dependência de malha - modelo de aderência ................ 125

Figura 7.13 - Abertura de fissuras para a viga de KWAK;FILIPPOU (1997) ......... 125

Figura 7.14 -Viga biapoiada (exemplo CEB-FIP MC90) .................................... 126

Figura 7.15 - Viga biapoiada analisada por BAKOSS et al. (1982) ....................... 128

Figura 7.16 - Posição da linha neutra (LN) nos instantes $t_{0}=28$ e $t=500$ dias ........ 130

Figura 7.17 - Deformação longitudinal da armadura tracionada........................... 130

Figura 7.18 - Laje simplesmente apoiada e malha inicial.....................................131

Figura 7.19 - Diagrama de força $Q$ por deslocamento transversal ....................... 132

Figura 7.20 - Estado de fissuração do fundo da laje, porém visto de cima

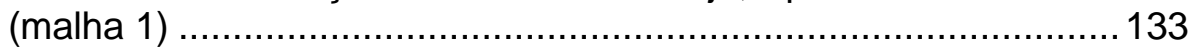

Figura 7.21 - Laje plana de Taylor. Ilustração da malha e do carregamento considerado para calcular o efeito da fluência .............................. 134

Figura 8.1 - Aspecto da majoração do esforço parcial de projeto $\left(\mathrm{M}_{\mathrm{d} \text {,parcial }}\right)$............ 141

Figura 8.2 - Aspecto da minoração do esforço característico $\left(M_{k}\right)$........................ 143

Figura 8.3 - Diagramas de momento fletor por curvatura para análise não-linear (CEB - Boletim n- 227) .......................................................... 144

Figura 8.4 - Diagrama tensão-deformação para o aço CA-50A …........................ 144

Figura 8.5 - Diagramas para o concreto C-30 (CEB-FIP MC90) ........................... 145

Figura 8.6 - Diagrama idealizado para o $\gamma_{\mathrm{gl}}$ esperado para uma estrutura de concreto armado submetida àflexão. Carregamento proporcional 147

Figura 8.7 - Desdobramento do coeficiente de segurança $\gamma_{c}=1,5 \ldots \ldots \ldots \ldots \ldots \ldots \ldots . . . . .148$

Figura 8.8 - Proporção entre os momentos de plastificação $\left(\gamma_{\mathrm{gl}}\right)$ : CEB-FIP .......... 149

Figura 8.9 - Geometria das seções analisadas .............................................. 149

Figura 8.10 - $\gamma_{\text {gl. }}$ Seção retangular sob flexão simples ...................................... 150

Figura 8.11 - $\gamma_{\mathrm{gl}}$. Seção T sob flexão simples................................................ 150 
Figura 8.12 - $\gamma_{\mathrm{gl}}$. Seção retangular sob FNC …............................................ 150

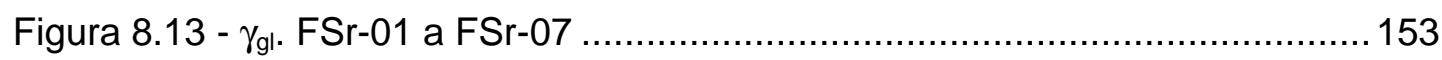

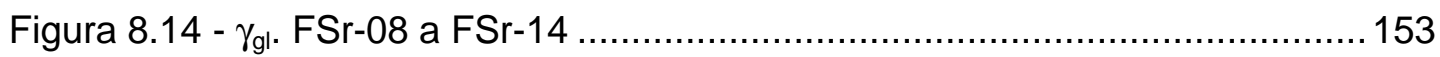

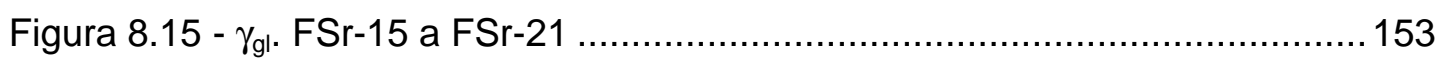

Figura 8.16 - $\gamma_{g \mid}$. FSr-22 a FSr-28 ....................................................... 154

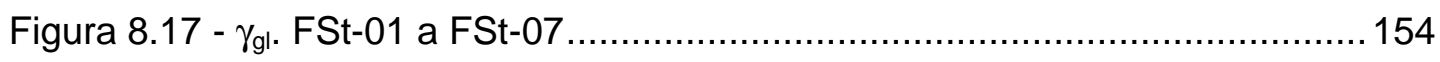

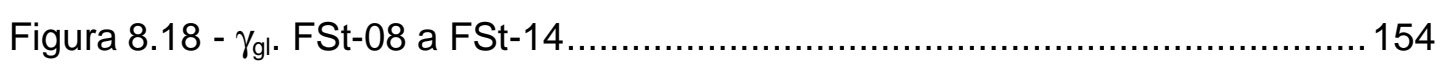

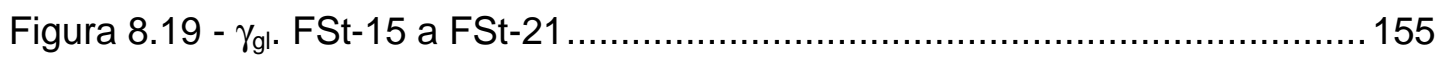

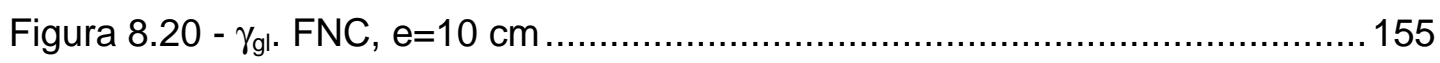

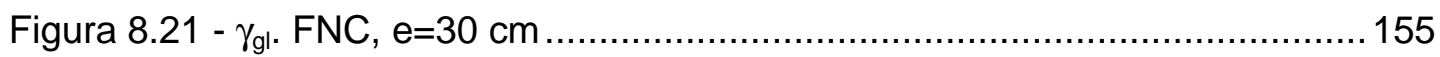

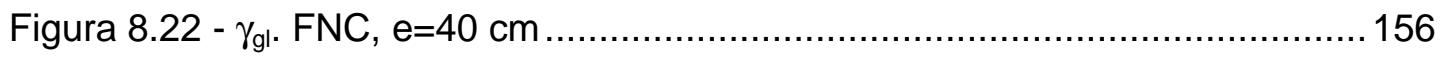

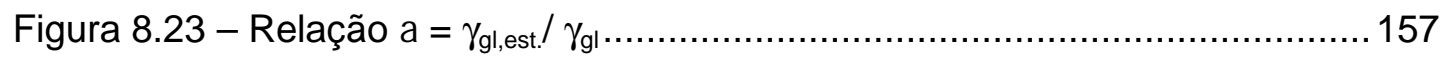

Figura 8.24 - $\gamma_{\mathrm{gl}}$ para uma laje quadrada apoiada ........................................... 158

Figura 8.25 - Viga biapoiada: exemplo 1 .................................................... 160

Figura 8.26 - Viga apoiada-engastada - exemplo 2 ......................................... 164

Figura 8.27 - Viga engastada-engastada - exemplo 3 ....................................... 169

Figura 8.28 - Laje apoiada nos quatro lados - exemplo 4 .................................. 172

Figura A.1 - Translação de coordenadas no espaço tridimensional ....................... 184

Figura A.2 - Translação dos graus de liberdade dos nós de fronteira do pilar........ 186

Figura A.3 - Viga engastada em pilar - $1^{\circ}$ exemplo ........................................... 188

Figura A.4 - Pavimento tipo: laje plana (medidas em cm) ................................... 189

Figura A.5 - Translação segundo o eixo z - apoios puntuais................................ 190

Figura A.6 - Momento fletor $M_{x}$ na região do P08 - apoios puntuais ...................... 190

Figura A.7 - Momento fletor $M_{y}$ na região do P08 - apoios puntuais ..................... 190

Figura A.8 - Translação segundo o eixo z - apoios extensos ............................... 191

Figura A.9 - Momento fletor $M_{x}$ na região do P08 - apoios extensos...................... 191

Figura A.10 - Momento fletor $M_{y}$ na região do P08 - apoios extensos................... 191

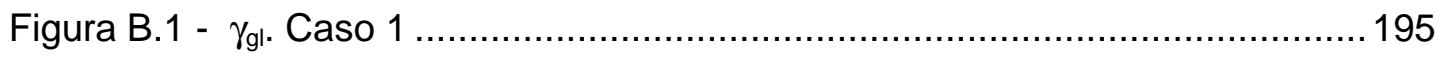

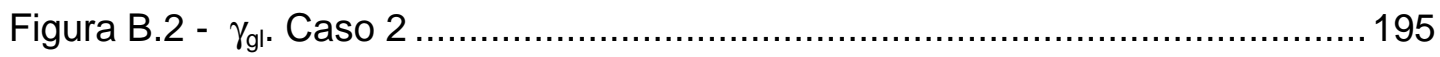

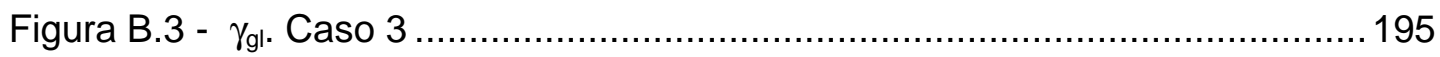

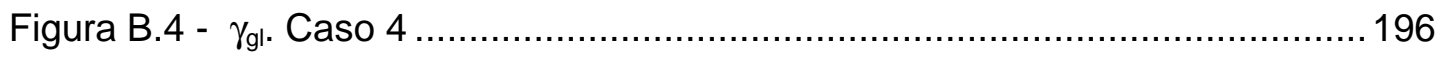

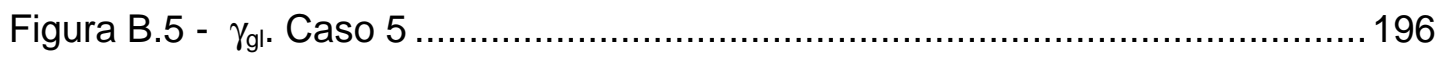

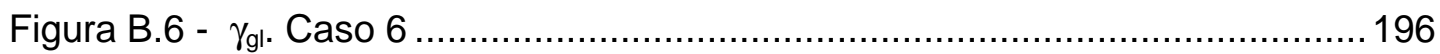

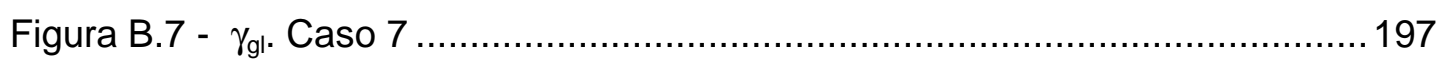




\section{LISTA DE TABELAS}

Tabela 3.1 - Parâmetros de escorregamento do CEB-FIP MC90 …......................65

Tabela 5.1 - Sinopse dos métodos para a determinação da rotação plástica .........90

Tabela 5.2 - Caracterização da presente metodologia comparativamente à Delft..92

Tabela 6.1 - Valores dos parâmetros do concreto e do aço.................................. 102

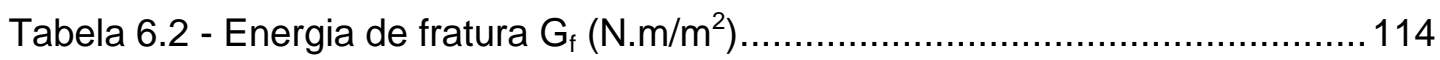

Tabela 7.1 - Parâmetros mecânicos dos materiais - experimentais ...................... 117

Tabela 7.2 - Comparativo entre os tempos de processamento (em segundos) .... 120

Tabela 7.3 - Excentricidades das forças normais nos pilares ............................. 123

Tabela 7.4 - Taxas de armadura e carregamentos (exemplo CEB-90) ................. 126

Tabela 7.5 - Deslocamentos para os instantes $t_{0}$ e t (exemplo CEB-FIP MC90) ... 127

Tabela 7.6 - Flechas máximas medidas e previstas para a viga biapoiada........... 129

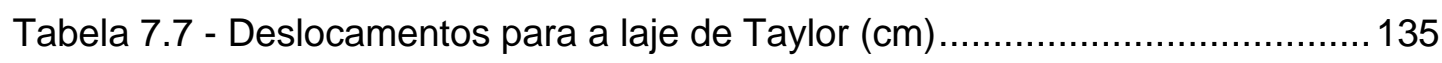

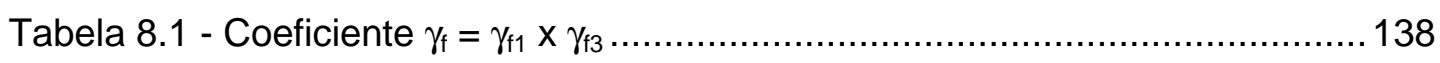

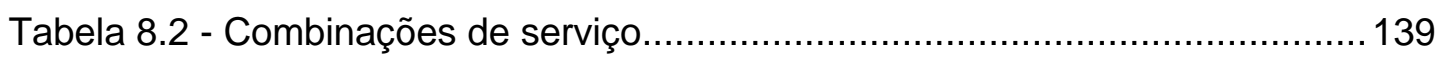

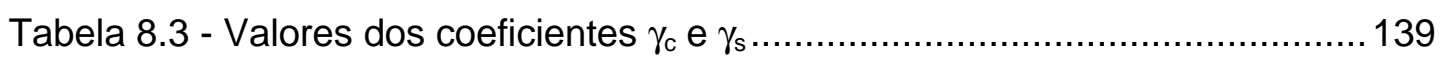

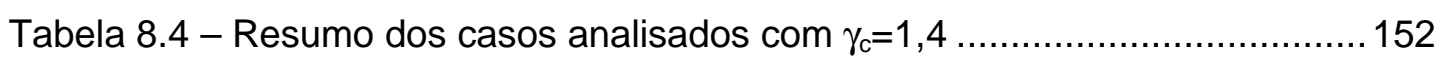

Tabela 8.5 - Características mecânicas dos materiais empregados nos exemplos 159

Tabela 8.6 - Abertura de fissuras para a viga apoiada-engastada (mm) ............... 168

Tabela 8.7 - Valores de $\gamma_{g l}$ para a viga apoiada-engastada................................ 169

Tabela 8.8 - Abertura de fissuras para a viga engastada-engastada (mm) ........... 171

Tabela 8.9 - Valores de $\gamma_{g l}$ para a viga engastada-engastada............................ 171

Tabela A.1 - Resultados obtidos para a estrutura.............................................. 188

Tabela A.2 - Resultados significativos das análises........................................... 192 


\section{LISTA DE SÍMBOLOS}

letras romanas maiúsculas:

A - área

$A_{c} \quad$ - área da seção transversal geométrica da peça

$A_{c}^{\prime} \quad$ - área da parte comprimida de $A_{c}$

$A_{s} \quad$ - área da seção transversal da armadura longitudinal tracionada

$A_{S}^{\prime} \quad$ - área da seção transversal da armadura longitudinal comprimida

[A] - matriz de mapeamento

[B] - matriz que relaciona deformações aos deslocamentos nodais

[C] - matriz (constante) dos módulos constitutivos de rigidez

$D_{\mathrm{n}} \quad$ - variável de dano

[D] - matriz que relaciona curvaturas aos momentos fletores de placa

$\left[D^{\mathrm{pl}}\right]$ - matriz que reúne os módulos plásticos de encruamento

E - módulo de deformação longitudinal

$\mathrm{E}_{\mathrm{c}}$ - módulo de deformação longitudinal do concreto

$E_{s} \quad$ - módulo de deformação longitudinal do aço

$\mathrm{E}_{\mathrm{T}} \quad$ - módulo de rigidez tangente àcurva tensão-deformação do concreto

$\left\{E_{\sigma}\right\} \quad$ - conjunto convexo e fechado das tensões admissíveis para o material

$\{F\} \quad$ - vetor de forças nodais

G - módulo de deformação transversal do concreto

$\mathrm{G}_{\mathrm{f}} \quad$ - energia de fratura (quantidade de energia requerida para criar uma área unitária de fissura contínua)

$\mathrm{H}$ - módulo de encruamento cinemático (constante)

I - momento de inércia

$\mathrm{I}_{1} \quad-1^{\circ}$ invariante do tensor das tensões

$J_{2} \quad-2^{\circ}$ invariante do tensor das tensões desviadoras

K - tensão de escoamento por cisalhamento puro

$\overline{\mathrm{K}} \quad$ - tensão octaédrica de cisalhamento no escoamento

$\mathrm{K}^{\backslash} \quad$ - coeficiente do critério de Drucker-Prager 
[K] - matriz de rigidez

Lin - espaço dos tensores de $2^{\mathrm{a}}$ ordem

M - momento fletor

$M^{\text {ef }} \quad$ - momento fletor efetivo proporcionado pelo critério de von Mises

$M_{\mathrm{r}} \quad$ - momento fletor de fissuração

$M_{u} \quad$ - momento fletor último

$M_{y} \quad$ - momento de escoamento

$\mathrm{N} \quad$ - força normal

[N] - matriz das funções de forma

[P] - matriz que relaciona o tensor das tensões $\sigma$ ao seu desviador incompleto

Q - carga acidental

$\mathrm{R} \quad$ - conjunto dos números reais

$R^{n} \quad$ - espaço vetorial real de ordem $n$

$R_{c} \quad$ - resultante das tensões de compressão na seção transversal

$R_{t} \quad$ - resultante das tensões de tração na seção transversal

$\mathrm{R}_{\mathrm{cc}} \quad$ - resultante das tensões de compressão no concreto

$R_{\mathrm{ct}} \quad$ - resultante das tensões de tração no concreto

$R_{s c} \quad$ - resultante das tensões de compressão na armadura longitudinal

$R_{s t} \quad$ - resultante das tensões de tração na armadura longitudinal

S - superfície

[S] - tensor das tensões desviadoras

[S*] - tensor incompleto das tensões desviadoras

$U \quad$ - energia

$\mathrm{V}$ - força cortante ou volume

W - trabalho

$Z_{p} \quad$ - módulo plástico da seção transversal

\section{letras romanas minúsculas:}

b - largura

$b_{f} \quad$ - largura da mesa das vigas de seção $T$

$b_{w} \quad$ - largura das vigas de seção retangular ou da alma das vigas de seção $T$

c - coesão; ou cobrimento da armadura

d - diâmetro; ou distância do ponto de aplicação da resultante das tensões de tração na armadura longitudinal ao ponto de maior encurtamento de uma seção transversal de peça fletida, medida normalmente àlinha neutra (altura útil) 
d' - distância do ponto de aplicação da resultante das tensões de compressão na armadura longitudinal ao ponto de maior encurtamento de uma seção transversal de peça fletida, medida normalmente àlinha neutra

f - função que exprime o critério de plastificação

$f_{c}$ - resistência àcompressão do concreto

$\mathrm{f}_{\mathrm{ck}} \quad$ - resistência característica do concreto àcompressão

$\mathrm{f}_{\mathrm{cm}} \quad$ - resistência média àcompressão do concreto

$\mathrm{f}_{\text {ctk }} \quad$ - resistência característica do concreto àtração

$\mathrm{f}_{\mathrm{ctm}} \quad$ - resistência média àtração do concreto

$f_{2 c}$ - resistência àcompressão biaxial do concreto

$\mathrm{f}_{\mathrm{t}} \quad$ - resistência àtração do concreto

$\mathrm{f}_{\mathrm{y}} \quad$ - resistência de escoamento do aço àtração

g - carga permanente uniformemente distribuída

h $\quad$ - altura da seção transversal; ou espessura de uma placa

$h_{f} \quad$ - espessura da mesa das vigas de seção $T$

$\mathrm{h}_{\mathrm{eq}} \quad$ - largura de domínio de uma fissura

\{h\} - vetor que define o tipo de encruamento.

k - módulo plástico do material (constante)

[k] - matriz de rigidez de um elemento finito

l - comprimento; ou vão teórico

$I_{b} \quad$ - comprimento de ancoragem

$l_{i} \quad$ - comprimento do elemento finito de barra

$\mathrm{n}_{\mathrm{e}} \quad$ - número de elementos finitos

\{p\} - vetor de forças de superfície

q - carga acidental uniformemente distribuída

\{q\} - vetor dos graus de liberdade nodais, ou vetor dos parâmetros e variáveis internas relacionadas ao encruamento

\{r\} - vetor direção do fluxo plástico

$\mathrm{S}_{\mathrm{r}} \quad$ - distância entre duas fissuras sucessivas

$t_{u} \quad$ - tolerância em deslocamentos preestabelecida

$t_{F} \quad$ - tolerância em forças preestabelecida

u - deslocamento

$\mathrm{w}_{\mathrm{r}} \quad$ - abertura de fissura

$\{w\} \quad$ - campo de deslocamentos transversais no domínio do elemento

x - distância da linha neutra ao ponto de maior encurtamento na seção transversal de uma peça fletida 


\section{letras gregas maiúsculas:}

$\partial$ - derivada parcial de uma função

$\Phi \quad$ - diâmetro da barra da armadura

$\Delta \quad$ - intervalo, variação

$\nabla^{\mathrm{s}} \quad$ - gradiente simétrico de um tensor

$[\Xi(\gamma)$ ] - matriz elástica tangente modificada

\section{letras gregas minúsculas:}

$\alpha \quad$ - variável interna relacionada ao encruamento isótropo

$\bar{\alpha} \quad$ - deformação plástica efetiva

$\alpha_{1} \quad$ - ponderador da ampliação do domínio elástico

$\alpha_{e} \quad$ - razão entre $E_{s}$ e $E_{c}$

$\beta \quad-\operatorname{arctg}(E)$

$\beta^{*} \quad-\operatorname{arctg}\left(E_{T}\right)$

$\sqrt{\beta_{\mathrm{b}}}$ - fator empregado no CEB90 para a redução do momento de fissuração

$\gamma \quad$ - deformação plástica acumulada no caso de encruamento por deformação

$\gamma_{f} \quad$ - coeficiente de segurança

$\gamma_{g l} \quad$ - coeficiente global de segurança relativo aos materiais

$\delta \quad$ - coeficiente de variação

$\varepsilon \quad$ - deformação específica

$\varepsilon_{\mathrm{c}} \quad$ - deformação específica do concreto àcompressão

$\varepsilon_{\mathrm{cc}} \quad$ - deformação lenta específica do concreto

$\varepsilon_{\mathrm{ct}} \quad$ - deformação específica do concreto àtração

$\varepsilon_{\mathrm{cs}} \quad$ - deformação específica do concreto por retração

$\varepsilon_{\mathrm{s}} \quad$ - deformação específica do aço

$\varepsilon_{\mathrm{y}} \quad$ - deformação específica de escoamento do aço

$\varepsilon_{\mathrm{st}} \quad$ - deformação específica do aço àtração

$\mu \quad$ - perímetro

$\eta_{\mathrm{b}} \quad$ - coeficiente de conformação superficial das barras da armadura

$\theta \quad$ - rotação

$v \quad$ - coeficiente de Poisson

$\rho \quad$ - taxa geométrica de armadura

$\sigma \quad$ - tensão normal 


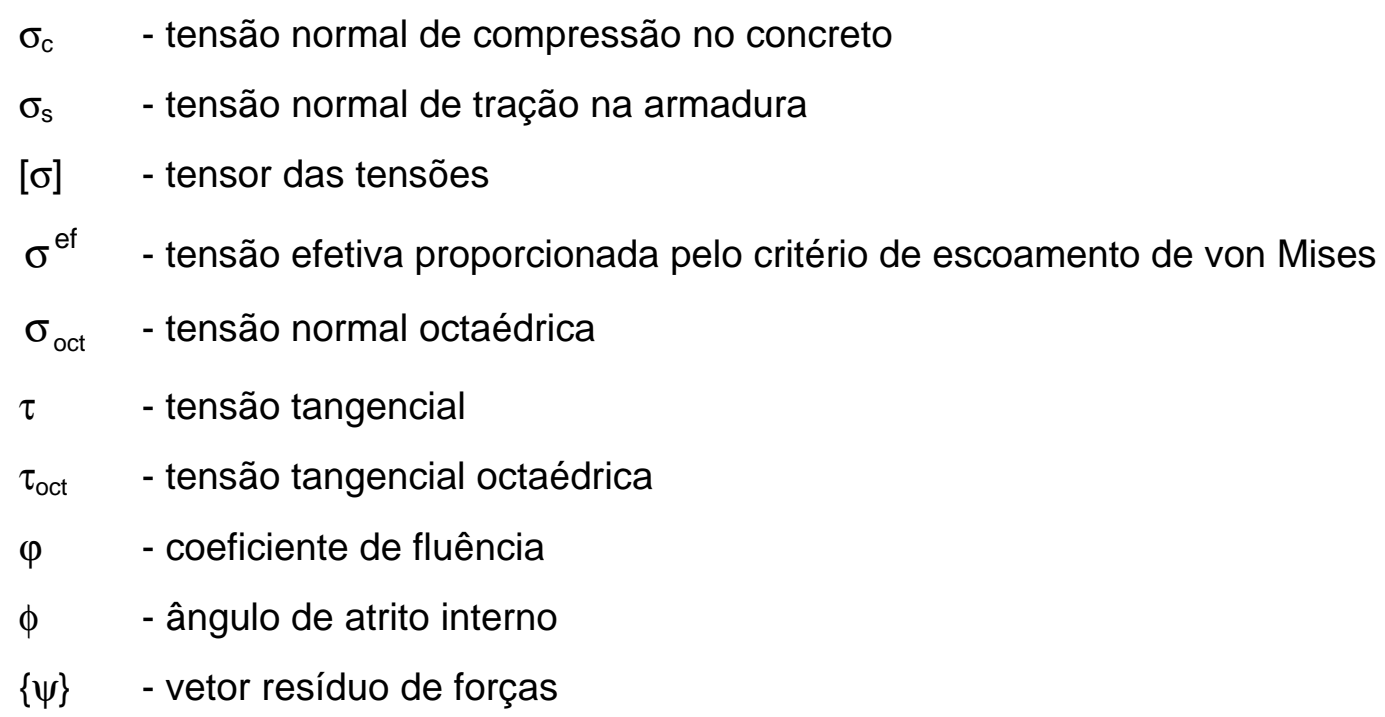




\section{RESUMO}

OLIVEIRA,R.S. Análise de pavimentos de edifícios de concreto armado com a consideração da não-linearidade física - modelagem e metodologia de aplicação a projetos. São Carlos, 2001. 197p. Tese (Doutorado) - Escola de Engenharia de São Carlos, Universidade de São Paulo.

Este trabalho trata da evolução natural do modelo de cálculo em regime elástico linear, largamente empregado no dimensionamento de pavimentos de concreto armado, para modelos com maior capacidade de representação.

Implementados a um sistema computacional, elementos finitos de barra de Euler são aplicados àrepresentação das vigas e dos pilares, e elementos finitos de placa de Kirchoff, à representação das lajes. A descrição do comportamento nãolinear físico desses elementos é introduzida por relações constitutivas atuais, e em dois campos: através das relações de momento fletor por curvatura incorporadas a elementos não-estratificados; e pela introdução de relações constitutivas uniaxiais para o concreto e o aço, a elementos estratificados.

As possíveis formas de emprego dos modelos não-lineares no dimensionamento estrutural, e os principais problemas envolvidos com esse tema são discutidos e, após um estudo crítico sobre algumas das propostas atualmente empregadas, apresenta-se uma abordagem original do problema. Ao final, o dimensionamento de elementos estruturais isolados possibilita uma comparação entre as propostas, e apresenta subsídios para a evolução dos procedimentos empregados no dimensionamento de pavimentos usuais de concreto armado.

Palavras-chave: pavimento, concreto armado, elementos finitos, não-linearidade física, plasticidade. 


\section{ABSTRACT}

OLIVEIRA,R.S. Analysis of reinforced concrete building slabs considering non-linear relations - modelling and design methodology. São Carlos, 2001. 197p. Tese (Doutorado) - Escola de Engenharia de São Carlos, Universidade de São Paulo.

This work deals with the natural evolution of the design model based on linear elasticity, widely employed on reinforced concrete floor designs, to an improved design model.

Both Euler beam finite elements employed to describe beam and column behavior and Kirchoff plate element applied to represent the slab behavior are implemented to a computational system. The description of the non-linear behavior to these elements is introduced by current constitutive relationships in two fields: through the moment-curvature relationships applied to non-layered elements and by introducing uniaxial constitutive relations to both concrete and steel reinforcement, applied to layered elements.

The possible ways of employing non-linear models to the structural design, and the main problems involved in that area are discussed and, after a critical study on some of the proposals currently employed, an original one is presented. Finally, the design of isolated structural elements enables one to establish a comparison among the proposals, and presents backgrounds for the evolution of the procedures employed to the design of usual reinforced concrete floors.

Keywords: floor, reinforced concrete, finite elements, non-linearity, plasticity. 


\section{INTRODUÇÃO}

\subsection{Considerações iniciais}

O meio científico tem desenvolvido, no decorrer dos últimos tempos, importantes ferramentas para o processamento da análise não-linear de elementos estruturais de concreto armado. Menos desenvolvida, no entanto, encontra-se a exploração dessas teorias no campo prático, notadamente no dimensionamento de estruturas correntes. Da mesma forma, os códigos modelo, responsáveis pela normalização do cálculo estrutural, não dispõem ainda de procedimentos seguros para o dimensionamento considerando o comportamento não-linear dos materiais.

A constatação desse panorama sugere a fundamentação deste trabalho em dois aspectos primordiais. O desenvolvimento de um sistema computacional para a análise de pavimentos de concreto armado em regime não-linear e, principalmente, o estudo crítico e a sugestão de procedimentos seguros para o dimensionamento.

\subsection{Objetivos}

A realização deste trabalho de doutoramento objetiva-se a colaborar no suprimento da carência de procedimentos para a aplicação dos modelos nãolineares ao dimensionamento estrutural. Para viabilizar os estudos relacionados ao dimensionamento, no entanto, houve a necessidade prévia de se estudar e implementar modelos constitutivos destinados à representação do comportamento mecânico dos elementos estruturais. A possibilidade de um dimensionamento amplo foi viabilizada com a representação do Estado Limite Último (ELU), aqui estabelecido como a perda da capacidade portante da estrutura, assim como a dos Estados Limites de Utilização (ELS) de formação e abertura de fissuras, e de deslocamentos excessivos ao longo do tempo. 
$\mathrm{Na}$ segunda parte do trabalho, voltada ao dimensionamento de pavimentos de concreto armado em regime não-linear físico, são apresentadas e discutidas as metodologias atualmente adotadas. O método semi-probabilístico é analisado quanto à sua aplicabilidade e, ao final, uma proposta original é apresentada. Em seguida, o método do coeficiente global de segurança é apresentado com maior ênfase, destacando-se os seus pontos favoráveis e desfavoráveis. São apresentados estudos originais envolvendo o comportamento do coeficiente global de segurança sob diversas solicitações de projeto.

\subsection{Descrição sucinta dos capítulos}

O presente texto compreende duas áreas do conhecimento do cálculo estrutural. Na primeira delas, dos capítulos 2 ao 7, são apresentados os aspectos relacionados àdiscussão, modelagem e implementação de modelos mecânicos que descrevem o comportamento dos elementos estruturais presentes em um pavimento de edifício. Na segunda parte, condensada no capítulo 8, são desenvolvidas as possíveis estratégias para a aplicação desses modelos ao dimensionamento.

Em resumo, o presente capítulo traz os aspectos preliminares do trabalho. O capítulo 2 aborda a formulação dos elementos finitos de barra e de placa estratificados e não estratificados. No capítulo 3, são apresentados e discutidos os vários modelos constitutivos empregados à análise dos elementos uni e bidimensionais de concreto armado. Em seguida, o capítulo 4 apresenta a influência que o tempo exerce sobre as estruturas de concreto armado, nomeadamente quanto aos aspectos da retração e da fluência. As características de ductilidade que envolvem o comportamento das estruturas de concreto armado são discutidas no capítulo 5 . Os resultados obtidos com os modelos implementados são amplamente discutidos sob o prisma da capacidade em absorver rotações plásticas. Nesse contexto, analisa-se a importância das imposições de deformações máximas do aço e do concreto sobre a segurança do dimensionamento. A implementação dos modelos desenvolvidos no capítulo 3 aos elementos finitos enfocados no capítulo 2, é realizada no capítulo 6. Os exemplos de aferição, tomados com o objetivo de certificar a validade das implementações efetuadas, são abordados no capítulo 7 .

O capítulo 8, que se constitui na segunda parte do trabalho, aborda as duas metodologias aplicáveis ao dimensionamento de pavimentos considerando-se as 
relações constitutivas não-lineares: o método semi-probabilístico, e o coeficiente global de segurança relativo aos materiais. As discussões sobre as principais vantagens e desvantagens da metodologia semi-probabilística puderam gerar a base para uma proposta original para o dimensionamento. $O$ estudo sobre 0 método do coeficiente global de segurança também apresenta aspectos de originalidade, na medida em que são caracterizados comportamentos do coeficiente global de segurança em diversas situações de projeto. Exemplos simples envolvendo ambos os conceitos são empregados na verificação e no dimensionamento de elementos estruturais de concreto armado.

O capítulo 9 trata as principais conclusões obtidas no desenvolvimento deste trabalho, e ainda apresenta as perspectivas para os estudos futuros relacionados ao tema.

O anexo A trata da implementação do pilar como apoio extenso na modelagem de um pavimento composto por laje plana segundo a técnica da translação dos graus de liberdade. Avaliações complementares sobre 0 comportamento do coeficiente global de segurança relativo aos materiais estão colocadas no anexo B. 


\section{ASPECTOS SOBRE A FORMULAÇÃO DOS ELEMENTOS}

\subsection{Introdução}

O objetivo deste capítulo é o de apresentar as formas de discretização do domínio de uma estrutura através do método dos elementos finitos (MEF), principalmente no que se refere à abordagem da seção transversal dos elementos. A escolha do MEF como ferramenta para a viabilização da análise de estruturas está fundamentada na sua ampla aceitação pelo meio técnico em detrimento de outros, como o método dos elementos de contorno, por exemplo.

$\mathrm{O} \mathrm{MEF}$, tal qual conhecemos atualmente, parece ter as suas origens com COURANT (1943) apud ASCE (1982) ${ }^{1}$ que, no início da década de 1940, aplica o princípio da energia potencial e a interpolação polinomial sobre sub-regiões triangulares para estudar o problema da torção de Saint-Venant. Alguns outros trabalhos se seguiram nessa linha sem, no entanto, apresentarem aplicabilidade prática devido à inexistência de ferramentas para a agilização do cálculo. Com o apoio da indústria aeronáutica norte americana e o advento do computador, LEVY (1953) apud ASCE (1982) $)^{2}$ escreve as equações de rigidez em forma de matriz e resolve o sistema em um computador digital. A partir de então, o método ganha notoriedade no meio científico, e passa a ser bastante estudado.

$\mathrm{Na}$ década de 1960, os trabalhos de NGO;SCORDELIS (1967), e de MARÇAL;KING (1967) marcam o início do emprego do MEF na análise não-linear de elementos estruturais. A partir de então a teoria sobre os elementos finitos e suas adaptações à análise não-linear passam a evoluir conjuntamente, como pode ser notado nos trabalhos de ZIENCKIEWICZ et al. (1969), que emprega o método das tensões iniciais na solução de problemas elastoplásticos, e de WHANG (1969)

\footnotetext{
${ }^{1}$ COURANT,R.(1943). Variational methods for the solution of problems of equilibrium and vibrations. Bulletin of the American Mathematical Society, v.49, p.1-23. apud ASCE (1982).

${ }^{2}$ LEVY,S.(1953). Structural analysis and influence coefficients for Delta wings. Journal Aero. Sciences, v.20, n.7, p.449-454. apud ASCE (1982).
} 
onde são analisadas placas e cascas de comportamento elastoplástico através de modelo estratificado (layered model).

BELYTSCHKO;VELEBIT (1972) utilizam elemento triangular de momento constante para a análise elastoplástica de placas. Ainda no início da década, os trabalhos de HAND et al. (1973) e de DOTREPPE et al. (1973) apresentam tentativas bem sucedidas de análise de lajes de concreto armado empregando-se relações elastoplásticas com o auxílio do MEF. Na segunda metade da década, merecem destaque os trabalhos de LIN;SCORDELIS (1975) e, especialmente, de BASHUR;DARWIN (1978) que, aplicando as idéias de Hand e colaboradores, estratificam os elementos estruturais em camadas de modo a viabilizar a representação de leis constitutivas distintas em uma seção transversal.

No início da década de 1980, destaca-se o livro de OWEN;HINTON (1980) sobre modelagem computacional, juntamente com a publicação do ASCE (1982) sobre aplicação do MEF na análise de estruturas de concreto armado (CA). Em seguida, FIGUEIRAS (1983) apresenta tese sobre análise limite de placas e cascas anisotrópicas e de concreto armado, com não-linearidades física e geométrica. $A$ nova edição de HINTON;OWEN (1986) sobre modelagem computacional de estruturas, juntamente com os algoritmos desenvolvidos por SIMO; HUGHES (1988) com o objetivo de promover a implementação de modelos viscoelásticos, viscoplásticos e elastoplásticos a um método de cálculo, constituem bibliografia básica sobre a aplicação do MEF àanálise não-linear física.

Na década de 1990, intensificam-se os trabalhos sobre a aplicação do MEF a problemas não-lineares, e uma nova publicação do ASCE (1990), com abordagem semelhante à anterior, é editada. Os livros de CRISFIELD (1991), e SKRZYPEK (1993) são importantes fontes de pesquisa sobre os conceitos da aplicação do MEF à análise não-linear. SATHURAPPAN et al. (1992) apresentam elemento finito de casca com armadura discretamente inserida como parte do elemento, e que contribui implicitamente na formulação da rigidez. Com o objetivo de modelar os efeitos da fissuração, FOSTER et al. (1996) apresentam elemento finito de chapa dotado de fissuras rotativas, e relação constitutiva para a aderência das armaduras longitudinais. KWAK;FILIPPOU (1997) incorporam a fibra de aço como uma barra de treliça ao elemento de chapa serendipity de oito nós.

No âmbito do departamento de Engenharia de Estruturas da EESC-USP, dentre outros, BALLAROTTI (1982) analisa o comportamento não-linear físico de pórticos planos retangulares sob carregamento monotonicamente crescente. Em dissertação de mestrado, KOMATSU (1985) expõe as premissas do cálculo 
elastoplástico de estruturas lineares de concreto armado. CORRÊA (1991) desenvolve um sistema computacional para análise elastoplástica de lajes de edifícios de concreto armado mediante elemento finito triangular não-estratificado. ÁLVARES (1993) aplica a teoria do dano de Mazars a elemento finito estratificado e determina, em laboratório, os parâmetros relativos ao concreto. Objetivando a aplicação prática dos modelos não-lineares, CARVALHO (1994) desenvolve um programa incorporando o diagrama momento fletor por curvatura proposto pelo CEB-FIP Model Code 1990. SILVA (1996) desenvolve a análise de pórticos de concreto armado aplicando relações constitutivas do concreto e do aço a um modelo estratificado. Seguindo as idéias de Corrêa, OLIVEIRA (1997) apresenta uma proposta para a análise não-linear de pavimentos de edifícios de concreto armado mediante o emprego de relações momento fletor por curvatura.

Dando continuidade aos desenvolvimentos supra citados pretende-se, com este trabalho, avançar na implementação de modelos não-lineares aplicáveis aos elementos estruturais que compõem o pavimento e, então, desenvolver uma metodologia consistente para a sua aplicação ao projeto estrutural.

\subsection{Elemento finito de barra}

Neste trabalho são empregados os elementos finitos de barra de Euler com seis graus de liberdade ( $g d l)$ por nó na representação dos elementos estruturais lineares de pórtico tridimensional, como mostrado na Figura 2-1.

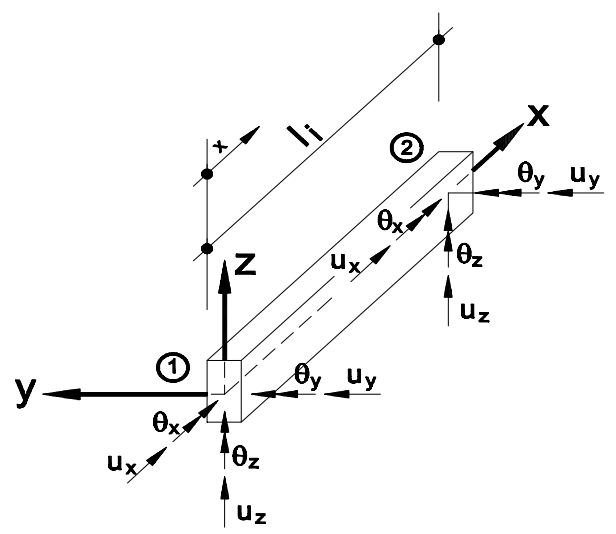

Figura 2-1 - Elemento de barra de pórtico tridimensional - coordenadas locais

onde: $u_{x}$ - translação segundo o eixo local $x$;

$u_{y}$ - translação segundo o eixo local y;

$\mathrm{u}_{\mathrm{z}}$ - translação segundo o eixo local z;

$\theta_{\mathrm{x}}$ - rotação em torno do eixo local $\mathrm{x}$; 
$\theta_{\mathrm{y}}$ - rotação em torno do eixo local y;

$\theta_{z}$ - rotação em torno do eixo local z;

$\mathrm{x}$ - coordenada genérica no domínio do elemento;

$I_{i}$ - comprimento do elemento finito.

Os elementos são dotados de campos de deslocamentos transversais $\left(\mathrm{u}_{\mathrm{y}} \mathrm{e}\right.$ $u_{z}$ ) cúbicos, e longitudinais $\left(u_{x}\right)$ lineares em seu domínio:

$$
\begin{aligned}
& u_{x}(x)=a_{1}+a_{2} x \\
& u_{y}(x)=b_{1}+b_{2} x+b_{3} x^{2}+b_{4} x^{3} \\
& u_{z}(x)=c_{1}+c_{2} x+c_{3} x^{2}+c_{4} x^{3}
\end{aligned}
$$

Por sua vez, as rotações $\theta_{x}$ são descritas através de um campo linear no domínio do elemento, enquanto que as demais são dependentes das derivadas dos respectivos deslocamentos transversais:

$$
\begin{aligned}
& \theta_{x}(x)=d_{1}+d_{2} x \\
& \theta_{y}(x)=c_{2}+2 \cdot c_{3} x+3 \cdot c_{4} x^{2} \\
& \theta_{z}(x)=b_{2}+2 \cdot b_{3} x+3 \cdot b_{4} x^{2}
\end{aligned}
$$

Em notação matricial, para um elemento finito genérico i, a relação entre os deslocamentos nodais e os deslocamentos no domínio do elemento é escrita como:

$$
\left\{u_{i}(x)\right\}=\left[N_{i}\right] \cdot\left\{q_{i}\right\}
$$

onde: $a_{i}, b_{i}, c_{i}, d_{i}$, com $i=1, \ldots, 4$ - constantes;

$\left\{u_{i}(x)\right\}$ - vetor deslocamentos em uma coordenada genérica $x$;

$\left[\mathrm{N}_{\mathrm{i}}\right]$ - matriz das funções de forma;

$\left\{q_{i}\right\}$ - vetor de deslocamentos nodais (graus de liberdade nodais).

O campo de deformações é obtido com as hipóteses de pequenos deslocamentos e pequenas deformações. Considera-se que as seções transversais permaneçam, com o decorrer do carregamento, planas e perpendiculares ao eixo longitudinal definido pelo centro de cisalhamento das seções transversais da viga:

$$
\left\{\varepsilon_{\mathrm{i}}(\mathrm{x})\right\}=\nabla\left\{\mathrm{u}_{\mathrm{i}}(\mathrm{x})\right\}=\left[\mathrm{B}_{\mathrm{i}}\right] \cdot\left\{\mathrm{q}_{\mathrm{i}}\right\}
$$

onde: $\nabla$ - operador diferencial de primeira ordem;

$\left[\mathrm{B}_{\mathrm{i}}\right]$ - matriz que relaciona deformações aos deslocamentos nodais. 
Aplicando o Princípio dos Trabalhos Virtuais (PTV) a um elemento finito de volume $\mathrm{V}$ e superfície $\mathrm{S}$, o equilíbrio desse elemento deve ser estabelecido com a condição de igualdade entre o trabalho realizado pelos esforços internos $\delta U$, e o trabalho realizado pelas forças externas $\delta \Omega$, como segue:

$$
\delta \mathrm{U}=\delta \Omega \Rightarrow \int_{\mathrm{V}}\left\{\delta \varepsilon_{\mathrm{i}}\right\}^{\top}\left\{\sigma_{\mathrm{i}}\right\} \mathrm{dV}=\int_{\mathrm{V}}\left\{\delta \mathrm{u}_{\mathrm{i}}\right\}^{\top}\left\{\mathrm{b}_{\mathrm{i}}\right\} \mathrm{dV}+\int_{\mathrm{S}}\left\{\delta \mathrm{u}_{\mathrm{i}}\right\}^{\top}\left\{\mathrm{p}_{\mathrm{i}}\right\} \mathrm{dS}
$$

Levando-se em consideração as equações 2.7 e 2.8, e reunindo-se os vetores dos graus de liberdade locais $\left\{q_{i}\right\}$ em um vetor global $\{q\}$ através de uma matriz de mapeamento adequada do tipo $\left\{q_{i}\right\}=[A]\{q\}$, tem-se:

$$
\int_{V}\{\delta q\}^{\top}\left[B_{i}\right]^{\top}\left\{\sigma_{i}\right\} d V=\int_{V}\{\delta q\}^{\top}\left[N_{i}\right]^{\top}\left\{b_{i}\right\} d V+\int_{S}\{\delta q\}^{\top}\left[N_{i}\right]^{\top}\left\{p_{i}\right\} d S
$$

onde: $\left\{b_{i}\right\}$ - vetor de forças por unidade de volume do elemento;

$\left\{p_{i}\right\}$ - vetor de forças por unidade de superfície do elemento;

$\{\delta \mathrm{q}\}=\forall$ - vetor de variação dos deslocamentos nodais globais.

Nota-se que o termo $\{\delta q\}^{\top}$ é comum a todas as parcelas, e que o termo `a esquerda da igualdade estabelecida na equação 2.10 origina a matriz de rigidez do elemento. Lembrando que a lei constitutiva no caso da elasticidade linear assume a forma da lei de Hooke generalizada, pode-se escrever:

$$
\left\{\sigma_{i}\right\}=\left[C_{i}\right]\left\{\varepsilon_{i}\right\}
$$

onde: $\left[C_{i}\right]$ - matriz constitutiva elástica linear do elemento i.

Aplicando-se as equações 2.11 e 2.8 ao termo da esquerda da expressão 2.10, escreve-se a matriz de rigidez do elemento finito $i\left[k_{i}\right]$ :

$$
\begin{aligned}
& \int_{V}\{\delta q\}^{\top}\left[B_{i}\right]^{\top}\left[C_{i}\right]\left\{\varepsilon_{i}\right\} d V \\
& \{\delta q\}^{\top} \int_{V}\left(\left[B_{i}\right]^{\top}\left[C_{i}\right]\left[B_{i}\right]\right) d V\{\delta q\}=\{\delta q\}^{\top}\left[k_{i}\right]\{\delta q\}
\end{aligned}
$$

As parcelas dos trabalhos realizados pelos esforços internos e pelas forças externas podem ainda ser rescritas: 


$$
\begin{aligned}
& \delta U=\{\delta q\}^{\top} \int_{V}\left(\left[B_{i}\right]^{\top}\left\{\sigma_{i}\right\}\right) d V=\{\delta q\}^{\top}\left\{f_{i}^{\text {int }}\right\} \\
& \delta \Omega=\{\delta q\}^{\top}\left(\int_{V}\left[N_{i}\right]^{\top}\left\{b_{i}\right\} d V+\int_{S}\left[N_{i}\right]^{\top}\left\{p_{i}\right\} d S\right)=\{\delta q\}^{\top}\left\{f_{i}^{\text {ext }}\right\}
\end{aligned}
$$

Através da contribuição de todos os elementos finitos, estabelece-se 0 equilíbrio da estrutura:

$$
\left\{F^{\text {int }}\right\}=\left\{F^{\text {ext }}\right\}
$$

onde: $\left\{F^{i n t}\right\}=\sum_{i=1}^{n}[A]\left\{f_{i}^{\text {int }}\right\} ; \quad$ e $\left\{F^{\text {ext }}\right\}=\sum_{i=1}^{n}[A]\left[f_{i}^{\text {ext }}\right\} \forall\{\delta q\} \in R^{n}$;

$R^{n}$ - espaço vetorial de ordem correspondente aos $n$ gdl da estrutura.

As integrações anteriormente descritas devem contemplar todo o volume do elemento. Para os elementos não-estratificados a seção transversal apresenta geometria constante ao longo do comprimento, e composta por um único material. Nesse caso, a integração é reduzida à coordenada $x$, relativa ao comprimento do elemento finito. Por outro lado, a hipótese de seção transversal estratificada implica na extensão do domínio de integração também sobre essa seção transversal.

Essa integração sobre a seção transversal pode ser obtida através do somatório discreto da contribuição de cada uma das camadas que, virtualmente, a compõem. Outra possibilidade seria o emprego de métodos numéricos, como a Quadratura de Gauss.

Apesar de ambos os procedimentos de integração serem bastante difundidos, muitas são, ainda, as discussões focadas sobre a representatividade de cada um deles. Com o objetivo de investigar os métodos de integração mais empregados: Gauss-Legendre, Gauss-Lobatto e somatório discreto; NOVOTNY et al. (1994) realizam um estudo sobre a previsão dos deslocamentos do ponto central de uma placa quadrada apoiada nos quatro lados, considerando-se um comportamento elastoplástico. As previsões de deslocamentos empregando-se as duas quadraturas ficaram bastante próximas, notando-se resultados um pouco melhores conseguidos com Gauss-Lobatto, como causa da incorporação dos extremos do domínio na integração. A integração por camadas, apesar de proporcionar resultados menos precisos que os obtidos com as quadraturas, pode ainda ser considerada suficientemente precisa para o emprego àanálise não-linear. $\mathrm{O}$ autor conclui que, em geral, o incremento do número de camadas leva à 
convergência a um mesmo resultado de forma monotônica. No pior caso estudado, para altos níveis de plastificação, o erro passa de no máximo 17\% empregando-se 4 camadas para um erro praticamente desprezível quando empregadas 10 camadas. Tal fato, no entanto não é observado com relação ao aumento do número de pontos de Gauss que pode levar àuma convergência não monotônica.

Esses resultados, a princípio, qualificam a aplicação de ambos os métodos de integração à análise não-linear, com a precaução de adotar-se, no modelo estratificado, algo em torno de 10 camadas. Essa afirmativa, relativa ao número mínimo de camadas empregadas, já havia sido feita por FIGUEIRAS (1983) quando da aplicação de modelo estratificado ao estudo das lajes de concreto armado.

\subsubsection{Modelos aplicados à análise de vigas}

Os modelos descritos a seguir apresentam a mesma gama de aplicabilidade com relação à geometria das vigas usuais de pavimento, ou seja, vigas de seção transversal retangular, e tê ( $\mathrm{T})$.

\subsubsection{Seção transversal não estratificada}

Esse modelo aborda o comportamento mecânico do elemento estrutural de viga segundo relações entre o esforço interno de momento fletor e a curvatura por ele produzida. Desse modo, impõe-se um padrão de comportamento mecânico a cada elemento finito de acordo com as suas características geométricas, físicas e de resistência, e em conformidade com as convenções normativas àqual deseja-se adequar o modelo. O CEB-FIP MC90, por exemplo, indica um diagrama trilinear para a relação momento fletor por curvatura, cujos pontos de inflexão são definidos pelos momentos fletores de fissuração e escoamento da seção transversal, sendo o momento fletor último definido pelo estado limite último. Já a NBR-6118 não aborda especificamente o assunto, mas, de acordo com CORRÊA (1991), o diagrama momento fletor por curvatura pode ser estabelecido, e os pontos de inflexão do diagrama trilinear, definidos com base nos limites dos estádios I, II e III do comportamento de uma seção de concreto armado. Esse assunto está apresentado com mais propriedade no item 3.6 deste trabalho.

Para o elemento não-estratificado, torna-se bastante simples a obtenção da matriz de rigidez e dos vetores de forças nodais equivalentes e forças internas, 
uma vez que o elemento apresenta seção transversal composta por apenas um tipo de material com características mecânicas constantes em todo o domínio:

$$
\begin{aligned}
& {\left[k_{i}\right]=\int_{V}\left[B_{i}\right]^{T}\left[C_{i}\right]\left[B_{i}\right] d V=\int_{0}^{l_{i}}\left[B_{i}\right]^{T} E \cdot I\left[B_{i}\right] \cdot d x} \\
& \left\{f_{i}^{\text {ext }}\right\}=\left\{f_{\text {conc, } i}^{\text {ext }}\right\}+\left(\int_{V}\left[N_{i}\right]^{\top}\left\{b_{i}\right\} d V+\int_{S}\left[N_{i}\right]^{\top}\left\{p_{i}\right\} d S\right) \\
& \left\{\mathrm{f}_{\mathrm{i}}^{\text {int }}\right\}=\int_{V}\left(\left[\mathrm{~B}_{\mathrm{i}}\right]^{\top}\left\{\sigma_{\mathrm{i}}\right\}\right)=\int_{0}^{\mathrm{i}_{\mathrm{i}}}\left[\mathrm{B}_{\mathrm{i}}\right]^{\top}\left\{\mathrm{M}_{\mathrm{i}}\right\} \cdot \mathrm{dx}
\end{aligned}
$$

onde: $\mathrm{E}$ - módulo de deformação longitudinal;

I - momento de inércia;

$\left\{f_{\text {conc,i }}^{\text {ext }}\right\}$ - vetor de forças concentradas aplicadas diretamente aos nós;

$\left\{M_{i}\right\}$ - campo de esforço interno de momento fletor do elemento i.

Apesar de simples, o modelo não-estratificado conduz a resultados tão bons como os obtidos por modelos mais refinados, como apontado nos trabalhos de CORRÊA (1991) e OLIVEIRA (1997), dentre outros.

\subsubsection{Seção transversal estratificada}

Além de permitir a aplicação de modelos constitutivos independentes para o aço e o concreto, essa modalidade abre espaço também à implementação consistente de relações de interação entre as camadas compostas por diferentes materiais. A Figura 2-2 ilustra uma viga de seção retangular.

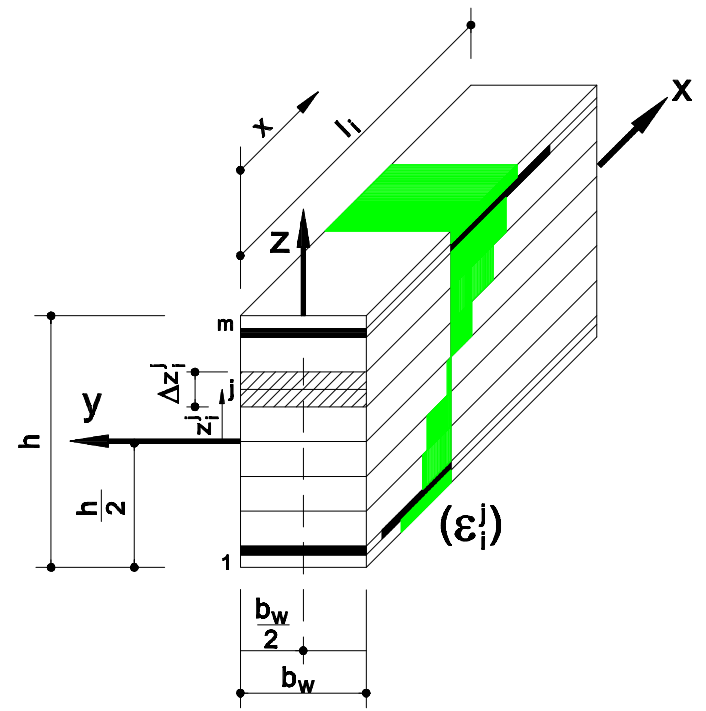

Figura 2-2 - Elemento de viga estratificado; diagrama de deformações normais 
A deformação normal, considerada constante em cada uma das camadas $\mathrm{j}$, é denominada por $\varepsilon_{i}^{j}$. A deformação em cada camada é calculada com base no produto da coordenada $z_{i}^{j}$ do seu ponto médio em relação ao eixo baricêntrico da seção transversal pela curvatura (1/r). Assim sendo, o diagrama de deformação normal resulta descontínuo junto às superfícies de separação das camadas, como se ilustra na Figura 2-2. Por conseguinte, aplicando-se as relações constitutivas dos materiais que compõem cada camada, determinam-se as respectivas tensões.

A integral de volume que origina a matriz de rigidez é desmembrada em uma integral no comprimento sobre um somatório discreto da contribuição de cada uma das camadas na rigidez da seção transversal. As propriedades físicas e mecânicas de cada camada geralmente não apresentam variação ao longo de sua largura, considerada constante ao longo do eixo $x$.

$$
\left[k_{i}\right]=\int_{V}\left[B_{i}\right]^{\top}\left[C_{i}\right]\left[B_{i}\right] d V=\int_{0}^{l_{i}} \sum_{j=1}^{m}\left(\left[B_{i}\right]^{\top}\left\{Z_{i}\right\}^{\top}\left[E_{i}^{j}\right]\left\{Z_{i}\right\}\left[B_{i}\right]\right) b . d x
$$

onde: $b=b_{w}, b_{f}$ - largura da alma e da mesa da viga, respectivamente;

$\left\{Z_{i}\right\}=\left\{\begin{array}{llll}1 & z_{i}^{j} & 0 & 0\end{array}\right\}$

$E_{i}^{j}$ - módulo de deformação longitudinal da camada j do elemento i.

O vetor de esforços (forças) internos do elemento pode ser expresso como:

$$
\left\{f_{i}^{\text {int }}\right\}=\int_{V}\left[B_{i}\right]^{\top}\left\{\sigma_{i}\right\} d V=\int_{0}^{l_{i}}\left(\left[B_{i}\right]^{\top}\left\{Z_{i}\right\}^{\top} \sum_{j=1}^{m}\left\{\sigma_{i}^{j}\right\}\right) d x
$$

Em cada um dos pontos de integração sobre o eixo $x$ do elemento são obtidos os esforços empregados na integração indicada em 2.20:

$$
\begin{aligned}
& N_{i, P G}=\int_{-h / 2}^{h / 2} \sigma(z) d z=\sum_{j=1}^{m} \sigma_{i, P G}^{j} \cdot A_{i}^{j} \\
& M_{i, P G}=\int_{-h / 2}^{h / 2} \sigma(z) \cdot z d z=\sum_{j=1}^{m} \sigma_{i, P G}^{j} \cdot A_{i}^{j} \cdot z_{i}^{j}
\end{aligned}
$$

onde: $\mathrm{N}_{\mathrm{i}, \mathrm{PG}}$ - esforço normal interno em um ponto de integração do elemento $\mathrm{i}$; $\mathrm{M}_{\mathrm{i}, \mathrm{PG}}$ - momento fletor interno em um ponto de integração do elemento $\mathrm{i}$; $A_{i}^{j}$ - área da camada j do elemento i (concreto ou aço); m - número total de camadas. 
Desconsiderando-se a parcela de forças por unidade de volume do elemento, $\left\{b_{i}\right\}$, pode-se reescrever o vetor de forças nodais equivalentes como:

$$
\left\{f_{i}^{\text {ext }}\right\}=\left\{f_{\text {conc, } i}^{\text {ext }}\right\}+b \cdot \int_{0}^{l_{i}}\left[N_{i}\right]^{\top} \cdot\left\{p_{i}\right\} \cdot d x
$$

Cabe ressaltar que, para este estudo, os esforços cortantes são estabelecidos a partir do equilíbrio estático do elemento.

\subsubsection{Modelos aplicados à análise de pilares}

A modelagem do comportamento mecânico dos pilares submetidos àflexão oblíqua composta, assim como no caso das vigas, pode se dar através de modelos não-estratificados, segundo diagramas de interação momento-normal-curvatura. Bons exemplos dessa aplicação são apresentados por DEBERNARDI (1989), ELMETWALLY;EL-SHAHHAT;CHEN (1989), CEB-FIP MC90, SFAKIANAKIS;FARDIS (1991), e GHALI;FAVRE (1994). Outra possibilidade seria a filamentação, ou seja, o emprego de estratificação simultânea da seção transversal segundo suas direções principais (ASSAN (1990)).

\subsubsection{Seção transversal filamentada}

A Figura 2-3 ilustra uma seção transversal filamentada típica.

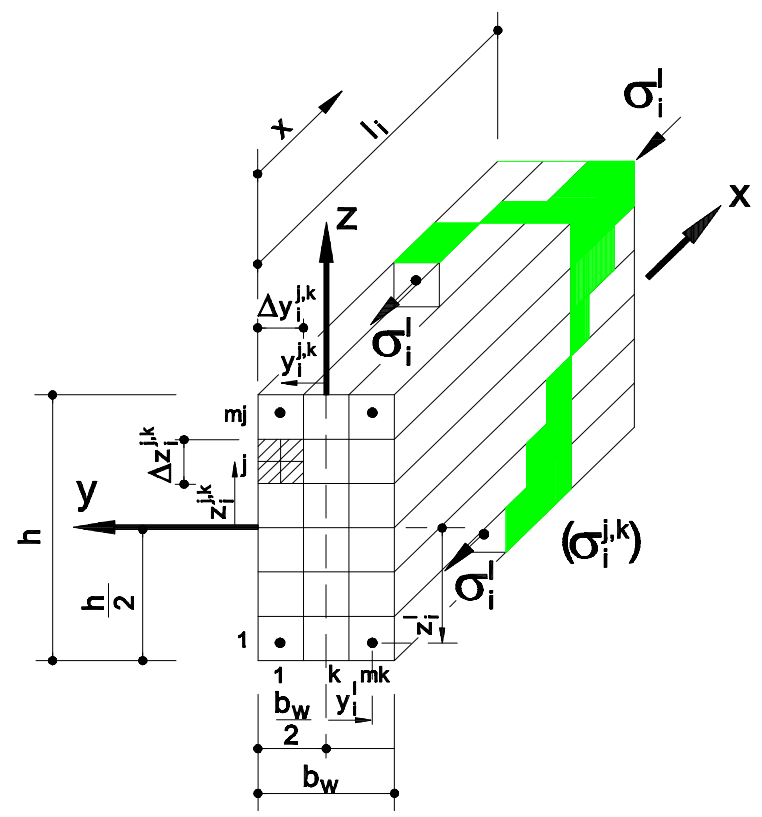

Figura 2-3 - Elemento de pilar filamentado; diagrama de tensões normais 
A diferença básica deste modelo para o estratificado diz respeito à consideração das barras da armadura longitudinal superpostas aos filamentos de concreto. Os efeitos dessa sobreposição da armadura longitudinal sobre o concreto foram estudados nas vigas, e na prática resultaram em acréscimos de rigidez não superiores a $5 \%$ para o caso extremo de uma viga superarmada.

\section{Matriz de rigidez de um filamento de concreto}

A partir da expressão 2.12, a matriz de rigidez para um filamento de concreto pode ser reescrita como:

$$
\left[k_{i}\right]=\int_{V}\left[B_{i}\right]^{T}\left[C_{i}\right]\left[B_{i}\right] d V=\int_{0}^{i}\left[B_{i}\right]^{\top}\left\{Z_{i}\right\}^{T}\left[E_{i}^{j, k}\right]\left\{Z_{i}\right\}\left[B_{i}\right] d x
$$

onde: $\left\{z_{i}\right\}=\left\{\begin{array}{llll}1 & z_{i}^{j, k} & 0 & y_{i}^{j, k}\end{array}\right\}$;

$\mathrm{E}_{\mathrm{i}}^{\mathrm{j}, \mathrm{k}}$ - módulo de deformação longitudinal do filamento j,k do elemento i;

$\mathrm{y}_{\mathrm{i}}^{\mathrm{j}, \mathrm{k}}$ - coordenada y do ponto médio do filamento j,k;

$z_{i}^{j, k}$ - coordenada $z$ do ponto médio do filamento j,k.

\section{Matriz de rigidez de um filamento de aço}

Lembrando que a seção transversal de um filamento de aço pode ser considerada puntual, a sua contribuição na matriz de rigidez do elemento pode ser obtida por procedimento análogo ao empregado ao filamento de concreto:

$$
\left[k_{i}^{\text {fs }}\right]=\int_{V}\left[B_{i}\right]^{T}\left[C_{i}\right]\left[B_{i}\right] d V=\int_{0}^{l_{i}}\left[B_{i}\right]^{T}\left[C_{i}^{s}\right]\left[B_{i}\right] d x
$$

onde: $\left[C_{i}^{s}\right]=E_{i}^{!} A_{i}^{!}\left[\begin{array}{cccc}1 & z_{i}^{!} & 0 & y_{i}^{!} \\ z_{i}^{!} & \left(z_{i}^{!}\right)^{2} & 0 & y_{i}^{!} z_{i}^{!} \\ 0 & 0 & 0 & 0 \\ y_{i}^{!} & y_{i}^{\prime} z_{i}^{!} & 0 & \left(y_{i}^{\prime}\right)^{2}\end{array}\right]$.

Do mesmo modo, escreve-se o vetor de forças internas do elemento:

$$
\left\{f_{i}^{i n t}\right\}=\int_{V}\left[B_{i}\right]^{\top}\left\{\sigma_{i}\right\} d V=\int_{0}^{l_{i}}\left[B_{i}\right]^{\top}\left\{Z_{i}^{j, k}\right\}^{\top} \sum_{j=1}^{m_{j}} \sum_{k=1}^{m_{k}}\left\{\sigma_{i}^{j, k}\right\}+\int_{0}^{l_{i}}\left[B_{i}\right]^{\top}\left[C_{i}^{s}\right] \sum_{l=1}^{m_{s}}\left\{\sigma_{i}^{!}\right\}
$$

Os esforços internos associados ao comportamento do pilar em flexão oblíqua composta, assim como no caso das vigas, são determinados através de 
somatório discreto. Neste caso, surgem dois momentos fletores $\left(M_{x, P G}\right.$ e $\left.M_{y, P G}\right)$ e uma força normal $\left(\mathrm{N}_{\mathrm{PG}}\right)$. O vetor de forças nodais equivalentes é calculado de modo análogo ao apresentado na expressão 2.23.

\subsection{Elemento finito de placa delgada T3AF}

Neste trabalho são empregados os elementos de formulação livre, anteriormente implementados por CORRÊA (1991). Estão disponibilizados elementos finitos triangulares que podem ser condensados, quatro a quatro, de modo a compor elementos quadrilaterais (OLIVEIRA (1998)). O elemento implementado (T3AF), foi inicialmente proposto por BERGAN; HANSSEN (1978), e figura como um dos primeiros elementos de formulação livre da história. A idéia básica da formulação livre é a de conceber o elemento finito impondo-se as condições do Patch Test na montagem da matriz de rigidez.

O elemento T3AF, cuja designação significa Triângulo com 3 gdl por nó, coordenadas de Área homogêneas, e ortogonalidade em Força, foi apontado por IRONS (1983) como o elemento triangular de melhor desempenho para a análise de placas delgadas. Essa afirmação, também comprovada e relatada por CORRÊA (1991) com o T3AF, qualifica o emprego desse elemento no presente trabalho. Coloca-se, na Figura 2-4, uma ilustração esquemática do elemento, bem como da composição do elemento quadrilateral através da condensação estática referente aos gdl pertencentes ao nó comum $(\mathrm{O})$ a quatro elementos triangulares.

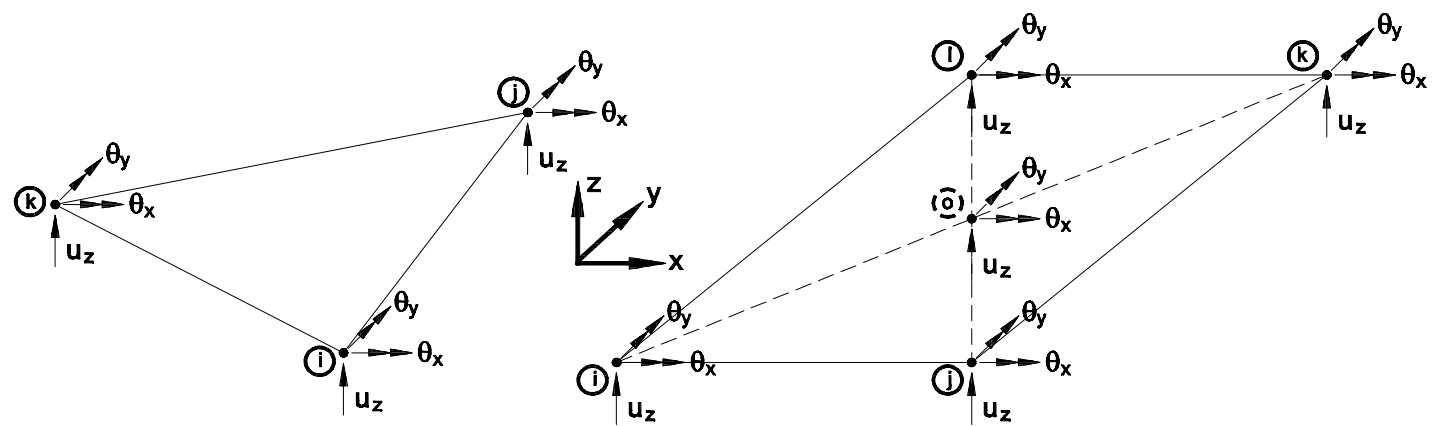

Figura 2-4 - Elementos triangular T3AF, e quadrilateral - coordenadas locais

O campo dos deslocamentos transversais $u_{z}$ no elemento é cúbico, e composto por um conjunto de modos básicos (responsáveis pela descrição do movimento de corpo rígido e da deformação constante) aliados a modos superiores (funções de forma de alta ordem, responsáveis pela descrição das variações da curvatura no domínio do elemento). 


$$
u_{\mathrm{z}}=\left[\mathrm{N}_{\mathrm{rc}}\right]\left\{\alpha_{\mathrm{rc}}\right\}+\left[\mathrm{N}_{\mathrm{h}}\right]\left\{\alpha_{\mathrm{h}}\right\}
$$

onde: $\mathrm{u}_{\mathrm{z}}$ - campo dos deslocamentos transversais no domínio do elemento;

$\left[\mathrm{N}_{\mathrm{rc}}\right]=\left[\begin{array}{lllllll}\xi_{1} & \xi_{2} & \xi_{3} & \xi_{1} \xi_{2} & \xi_{2} \xi_{3} & \xi_{3} \xi_{1}\end{array}\right]$ - polinômio completo até o grau que corresponde aos modos rígidos e de deformação constante;

$\left[N_{h}\right]=\left[\begin{array}{lll}\xi_{1} \xi_{2}\left(\xi_{1}-\xi_{2}\right) & \xi_{2} \xi_{3}\left(\xi_{2}-\xi_{3}\right) & \xi_{3} \xi_{1}\left(\xi_{3}-\xi_{1}\right)\end{array}\right]$ - conjunto de modos superiores;

$\left\{\alpha_{\mathrm{rc}}\right\},\left\{\alpha_{\mathrm{h}}\right\}$ - coeficientes associados;

$\xi_{i}$ - coordenadas homogêneas de área.

A relação entre os deslocamentos e as deformações no domínio do elemento é dada por:

$$
\nabla \mathrm{u}_{\mathrm{z}}=\nabla\left[\mathrm{N}_{\mathrm{rc}}\right]\left\{\alpha_{\mathrm{rc}}\right\}+\nabla\left[\mathrm{N}_{\mathrm{h}}\right]\left\{\alpha_{\mathrm{h}}\right\}=\left[\mathrm{B}_{\mathrm{rc}}\right]\left\{\alpha_{\mathrm{rc}}\right\}+\left[\mathrm{B}_{\mathrm{h}}\right]\left\{\alpha_{\mathrm{h}}\right\}
$$

onde: $\nabla$ - operador diferencial;

$\left[\mathrm{B}_{\mathrm{rc}}\right]$ - matriz que relaciona as deformações aos deslocamentos nodais (modo básico);

$\left[\mathrm{B}_{\mathrm{h}}\right]$ - matriz que relaciona as deformações aos deslocamentos nodais (modo superior);

Uma possibilidade para a montagem da matriz de rigidez generalizada $\left[\mathrm{k}_{\alpha, \mathrm{i}}\right]$ de um elemento finito i, consiste em utilizarem-se modos básicos completos em conjunto com modos superiores linearmente independentes, como:

$$
\left[k_{\alpha, i}\right]=\left[\begin{array}{cc}
{\left[k_{\alpha r c, i}\right]} & {\left[P_{r c}^{\top} G_{h}\right]} \\
{\left[G_{h}^{\top} P_{r c}\right]} & {\left[k_{\alpha h, i}\right]}
\end{array}\right]
$$

onde: $\left[\mathrm{k}_{\alpha r c, i}\right]=\int_{\mathrm{V}}\left[\mathrm{B}_{\mathrm{rc}}\right]^{\top}[\mathrm{C}]\left[\mathrm{B}_{\mathrm{rc}}\right] \mathrm{dV}$ - submatriz de rigidez referente ao modo básico;

$$
\begin{aligned}
& {\left[k_{\alpha h, i}\right]=\int_{V}\left[B_{h}\right]^{\top}[C]\left[B_{h}\right] d V \text { - submatriz de rigidez referente ao modo superior; }} \\
& {\left[G_{h}^{\top} P_{r c}\right]=\int_{V}\left[B^{r c}\right]^{\top}[C]\left[B_{h}\right] d V \text { - submatriz de rigidez que acopla o modo }}
\end{aligned}
$$
básico ao superior. Para o elemento T3AF, essa matriz apresenta coeficientes nulos devido à imposição da ortogonalidade em força (CORRÊA (1991)); 
$[G]=\left[G_{r c}\right]+\left[G_{h}\right]-$ matriz quadrada de ordem 9 que relaciona os parâmetros generalizados $\{\alpha\}$ aos deslocamentos nodais $\{u\}$ : $\{\mathrm{u}\}=[\mathrm{G}]\{\alpha\}$

$\left[P_{\mathrm{rc}}\right]=\left[\mathrm{k}_{\mathrm{u}, \mathrm{i}}\right]\left[\mathrm{G}_{\mathrm{rc}}\right]$.

Através da definição de cada submatriz, e efetuando as simplificações pertinentes ${ }^{\star}$, a matriz de rigidez passa a ser escrita como:

$$
\left[\mathrm{k}_{\alpha, \mathrm{i}}\right]=\left[\begin{array}{cc}
\mathrm{V} \cdot\left[\mathrm{B}_{\mathrm{rc}}\right]^{\top}[\mathrm{C}]\left[\mathrm{B}_{\mathrm{rc}}\right] & {[0]} \\
{[0]} & \int_{\mathrm{V}}\left[\mathrm{B}_{\mathrm{h}}\right]^{\top}[\mathrm{C}]\left[\mathrm{B}_{\mathrm{h}}\right] \mathrm{dV}
\end{array}\right]
$$

O vetor de forças nodais equivalentes às forças distribuídas no domínio do elemento i, pode ser escrito como:

$$
\left\{\mathrm{f}_{\mathrm{i}}^{\text {ext }}\right\}=\left\{\mathrm{f}_{\text {conc }, \mathrm{i}}^{\text {ext }}\right\}+\left(\int_{A}\left[\mathrm{~N}_{\mathrm{i}}\right]^{\top} \cdot\left\{\mathrm{p}_{\mathrm{i}}\right\} \cdot \mathrm{dA}-\int_{\mathrm{A}}\left[\mathrm{B}_{\mathrm{i}}\right]^{\top}\left\{\sigma_{0, i}\right\}\right)
$$

onde: $\left\{\mathrm{f}_{\mathrm{i}}^{\text {ext }}\right\}$ - vetor de forças nodais equivalentes do elemento i;

$\left\{\sigma_{0, i}\right\}$ - vetor das tensões iniciais no elemento.

Os esforços internos são obtidos de modo análogo ao caso das vigas e pilares, ou seja, pelo somatório da contribuição de cada camada.

$\mathrm{Na}$ análise não linear, no caso de elemento triangular, são utilizados os mesmos quatro pontos de Gauss com as seguintes coordenadas homogêneas $\xi_{\mathrm{i}}$ $(1 / 3,1 / 3,1 / 3 ; 3 / 5,1 / 5,1 / 5 ; 1 / 5,3 / 5,1 / 5 ; 1 / 5,1 / 5,3 / 5)$, enquanto que para 0 quadrilátero, as coordenadas referem-se ao centro de gravidade (CG) de cada triângulo $(1 / 3,1 / 3,1 / 3)$, como pode ser observado na Figura 2-5.

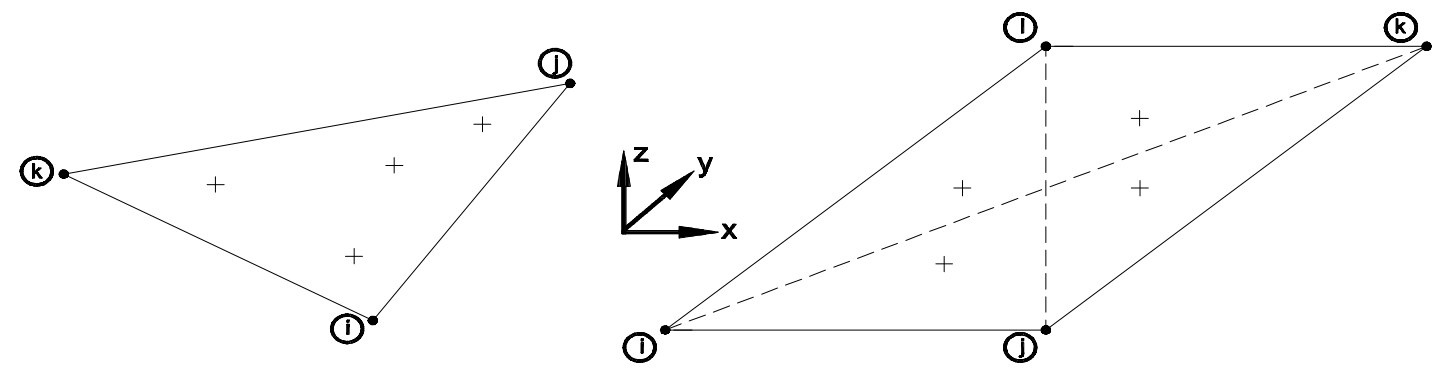

Figura 2-5 - Localização dos pontos de integração no domínio dos elementos

* a integral referente à submatriz dos modos básicos pode ser substituída por uma multiplicação no volume do elemento $(\mathrm{V})$, para o caso de ser [C] constante no domínio. 


\subsubsection{Seção transversal não estratificada}

O modelo de momento fletor por curvatura aplicado ao elemento de placa apresenta as mesmas características já comentadas no item referente à barra. Cabe apenas apresentar o desenvolvimento da matriz de rigidez e dos vetores de carga e de forças internas. A matriz $\left[B_{i}\right]$ passa a relacionar as 3 curvaturas aos deslocamentos nodais. $A$ matriz $\left[D_{i}\right]$, que relaciona os momentos fletores de placa, $M_{x}, M_{y}$ e $M_{x y}$ às respectivas curvaturas $\left(\frac{1}{r}\right)_{x} \cdot\left(\frac{1}{r}\right)_{y}^{\prime}\left(\frac{1}{r}\right)_{x y}$ considerando-se material ortótropo, é referida àseção transversal do elemento em cada ponto de integração.

$$
\left[D_{P G}\right]=\frac{h^{3}}{12}\left[C_{P G}\right]=\frac{h_{i}^{3}}{12}\left[\begin{array}{ccc}
\frac{E_{x, P G}}{1-v_{x, P G} v_{y, P G}} & \frac{v_{y, P G} E_{x, P G}}{1-v_{x, P G} v_{y, P G}} & 0 \\
\frac{v_{x, P G} E_{y, P G}}{1-v_{x, P G} v_{y, P G}} & \frac{E_{y, P G}}{1-v_{x, P G} v_{y, P G}} & 0 \\
0 & 0 & G_{P G}
\end{array}\right]
$$

onde: $E_{x, P G}$ - módulo de deformação longitudinal do concreto na direção $x$ em determinado PG do elemento i;

$E_{y, P G}$ - módulo de deformação longitudinal do concreto na direção y em determinado ponto de Gauss do elemento i;

$G_{P G}$ - módulo de deformação transversal do concreto em um PG do elemento i;

$v_{x, P G}$ - coeficiente de Poisson do concreto na direção $x$ em um PG do elemento i;

$v_{y, P G}$ - coeficiente de Poisson do concreto na direção y em um PG do elemento i;

$h_{i}$ - espessura do elemento de placa;

$\left[D_{i}\right]$ - matriz que relaciona os momentos fletores de placa às curvaturas.

\subsubsection{Seção transversal estratificada}

A Figura 2-6 ilustra um elemento genérico de placa de concreto armado estratificado. O sistema de coordenadas foi transladado para um dos vértices objetivando facilitar a compreensão das notações. Cada camada de concreto, em cada PG, apresenta uma matriz constitutiva particular $\left[\mathrm{C}_{\mathrm{PG}}^{j}\right]$. A matriz de rigidez referente à parcela do concreto $\left[D_{\mathrm{PG}}^{c}\right]$ é obtida por integração das matrizes constitutivas sobre a espessura da placa, através de somatório. 


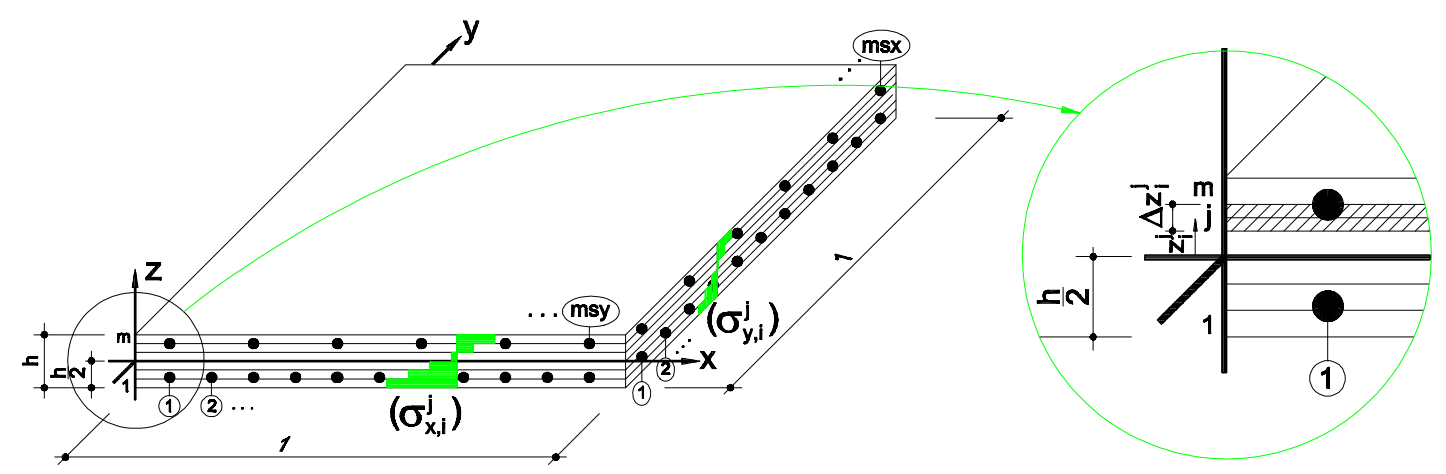

Figura 2-6 - Elemento de placa estratificado; diagrama de tensões normais

$$
\left[D_{P G}^{c}\right]=\sum_{j=1}^{m}\left(\left(\frac{1 \cdot\left(\Delta z_{i}^{j}\right)^{3}}{12}+\Delta z_{i}^{j} \cdot 1 \cdot\left(z_{i}^{j}\right)^{2}\right)\left[C_{P G}^{j}\right]\right)=\left[\begin{array}{ccc}
d_{11}^{c} & d_{12}^{c} & 0 \\
d_{21}^{c} & d_{22}^{c} & 0 \\
0 & 0 & d_{33}^{c}
\end{array}\right]
$$

As armaduras de flexão são compostas por barras discretas, dispostas de modo independente nas duas direções ( $x$ e y), e nas duas faces da laje (superior e inferior). Essas barras contribuem com a rigidez na direção de seu eixo longitudinal, ou seja, no primeiro e segundo termos da diagonal principal da matriz [D $\left.D_{P G}\right]$.

$$
\left[D_{P G}\right]=\left[\begin{array}{ccc}
d_{11}^{c}+d_{11}^{A_{s}, x} & d_{12}^{c} & 0 \\
d_{21}^{c} & d_{22}^{c}+d_{22}^{A_{s, y}} & 0 \\
0 & 0 & d_{33}^{c}
\end{array}\right]
$$

onde: $d_{11}^{A_{s, x}}=\sum_{k=1}^{m s x} A_{s, x}^{k} \cdot\left(z_{i}^{k}\right)^{2}$ - contribuição da armadura para a rigidez na dir. $x$;

$d_{22}^{A_{s, y}}=\sum_{k=1}^{m s y} A_{s, y}^{k} \cdot\left(z_{i}^{k}\right)^{2}$ - contribuição da armadura para a rigidez na dir. y;

msx - número de barras da armadura na dir. $x$;

msy - número de barras da armadura na dir. y.

Os esforços internos são, da mesma forma, determinados por integração sobre as camadas de concreto e as barras da armadura, através de somatório.

$$
\begin{aligned}
& M_{x, P G}=\int_{-h / 2}^{h / 2} \sigma_{x}(z) \cdot z \cdot d z=\sum_{j=1}^{m} \sigma_{y, P G}^{j} \cdot A_{i}^{j} \cdot z_{i}^{j}+\sum_{k=1}^{m s y} \sigma_{y, P G}^{k} \cdot A_{s, i}^{k} \cdot z_{i}^{k} \\
& M_{y, P G}=\int_{-h / 2}^{h / 2} \sigma_{y}(z) \cdot z \cdot d z=\sum_{j=1}^{m} \sigma_{x, P G}^{j} \cdot A_{i}^{j} \cdot z_{i}^{j}+\sum_{k=1}^{m s x} \sigma_{x, i} \cdot A_{s, i}^{k} \cdot z_{i}^{k}
\end{aligned}
$$




$$
M_{x y, P G}=\int_{-h / 2}^{h / 2} \tau_{x y}(z) \cdot z \cdot d z=\sum_{j=1}^{m} \tau_{x y, i}^{j} \cdot A_{i}^{j} \cdot z_{i}^{j}
$$

Os conceitos apresentados neste item constituem uma pequena introdução ao assunto, e tem a finalidade de apoiar a compreensão das implementações realizadas no capítulo 6 . Por se tratar de um assunto bem mais abrangente do que a breve formulação apresentada neste capítulo indica-se, a título de complementação bibliográfica, a leitura do trabalho de CORRÊA (1991). 


\section{MODELOS CONSTITUTIVOS PARA OS MATERIAIS}

\subsection{Introdução}

Este capítulo tem o objetivo de apresentar e discutir os modelos constitutivos usualmente empregados na representação do comportamento mecânico de elementos estruturais de concreto armado. O item 3.2 apresenta as bases da formulação dos modelos elastoplásticos. O enfoque dos itens 3.3 e 3.4 é dirigido à evolução das teorias da plasticidade e do fraturamento, bem como dos modelos mistos que envolvem aspectos dessas duas teorias. A mecânica do dano contínuo é apresentada com mais detalhes no item 3.5. Os modelos mecânicos baseados na relação momento fletor por curvatura estão colocados no item 3.6, e os modelos específicos sobre a aderência estão apresentados nos item 3.7.

Provavelmente deve-se a GRIFFITH (1920) ${ }^{1}$ apud SHAH et al. (1995) a primeira formulação consistente envolvendo o conceito de energia. O objetivo era descrever a propagação instável de uma fissura discreta em um material homogêneo com comportamento elastofrágil.

Por outro lado, os trabalhos de PRANDTL (1925) ${ }^{2}$ e de REUSS(1930) ${ }^{3}$ apud MENDELSON (1968) pode ser considerado o marco histórico da aplicação das relações constitutivas baseadas na teoria clássica da plasticidade. Pouco depois, KACHANOV (1958) ${ }^{4}$ apud PROENÇA (1988), motivado em modelar o efeito da fissuração distribuída na ruptura frágil de metais, inicia as formulações da teoria do dano. Essa teoria, entendida como uma particularização da mecânica da fratura,

\footnotetext{
${ }^{1}$ GRIFFITH,A.A.(1920). The fenomena of rupture and flow in solids. Philosophical Transactions of the Royal Society of London, series A221, p. 163-198. apud SHAH et al. (1995).

2 PRANDTL,L.(1925). Spannungsverteilung in plastischen Koerpern. Proc. Of the $1^{\text {st }}$ Int. Congress on Appl. Mech., Delft, Tech. Boekhandel en Druckerij, J. Waltman. p.43-54. apud MENDELSON (1968).

3 REUSS,E.(1930). Beruecksichtigung der elastischen formaenderungen in der plstizitaetstheorie, $Z$. Angew Math. Mech. n.10 p.266-274. apud MENDELSON (1968).

${ }^{4}$ KACHANOV,L.M.(1958). Time of the rupture process of non-linear solid mechanics. Otd. Tech. Nauk., v.8, p. 28-31. apud PROENÇA(1988).
} 
admite a possibilidade de existência de um estado de fissuração uniformemente distribuído (porém, não orientado) no domínio de análise.

A partir do final da década de 1950, as pesquisas sobre o comportamento mecânico dos materiais, no âmbito da plasticidade e da mecânica da fratura, têm sido desenvolvidas com grande intensidade. Do mesmo modo, as aplicações dos modelos mistos que contemplam as duas formulações, tem se apresentado bastante aplicável à modelagem de materiais que apresentam comportamento diferenciado de acordo com o tipo de solicitação àqual estejam submetidos.

A década de 1960 é marcada pela contribuição de excelentes trabalhos destacando-se, por exemplo, o livro publicado por PRAGER;HODGE (1963) sobre teoria da plasticidade. Já em 1967, NGO;SCORDELIS (1967) aplicam o conceito da fissuração discreta (discrete crack) à análise de vigas de concreto armado. Seguindo as idéias de Griffith, os autores aplicam conceitos básicos da mecânica da fratura para descrever o comportamento frágil da zona tracionada de concreto. As fissuras são pré-estabelecidas, e devem perfazer caminhos previamente estabelecidos, e definidos com nós duplos. A modelagem se dá individualmente para cada fissura através da desconexão dos deslocamentos e dos pontos nodais (localizados sobre as mesmas) que, no início da análise, ocupavam o mesmo lugar no espaço (Figura 3.1). Por esse motivo, a aplicabilidade do modelo na solução de problemas usuais torna-se bastante dificultosa, haja vista a impossibilidade de se conhecer, antemão, a localização das fissuras no domínio da estrutura.

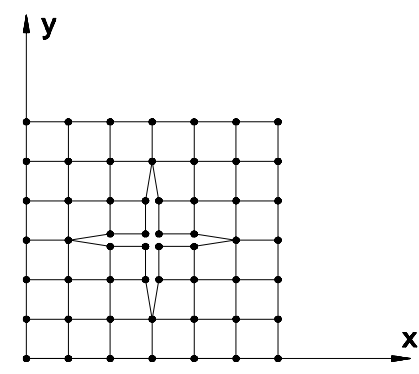

Figura 3.1 - Modelo de fissuração discreta - representação do caso biaxial

Utilizando pela primeira vez o conceito de fissuração distribuída, RASHID(1968) ${ }^{5}$ apud FEENSTRA;DE BORST(1995) passa a representar as fissuras de modo contínuo e orientado sobre o elemento. A formação das fissuras é verificada nos planos principais, mantidos com a mesma orientação até o final da análise, através do conceito das fissuras fixas (fixed crack). Rashid adota um

\footnotetext{
${ }^{5}$ RASHID,Y.R.(1968). Analysis of prestressed concrete pressure vessels. Nucl. Engrg. Design v.7, p. 334-344. apud FEENSTRA;DE BORST(1995).
} 
modelo elastofrágil para a direção principal $(\alpha)$ relativa àmaior tração $\left(\sigma_{1}\right)$. A tensão normal vai a zero imediatamente após a fissuração, assim como a resistência ao esforço de cisalhamento no plano da fissura $(\tau)$. Nessas condições, o concreto passa a apresentar ortotropia e, para o estado plano de tensões, a seguinte relação constitutiva incremental é empregada:

$$
\left\{\begin{array}{c}
d \sigma_{1} \\
d \sigma_{2} \\
d \tau
\end{array}\right\}=\left[\begin{array}{lll}
0 & 0 & 0 \\
0 & E & 0 \\
0 & 0 & 0
\end{array}\right]\left\{\begin{array}{c}
d \varepsilon_{1} \\
d \varepsilon_{2} \\
d \gamma
\end{array}\right\}
$$

onde: os índices 1 e 2 referem-se às direções principais que apresentam, respectivamente, o maior e o menor valor para as tensões normais.

Como o sistema de eixos principais permanece fixo, a formação de uma segunda fissura no ponto deverá se dar ortogonalmente àprimeira (Figura 3.2).

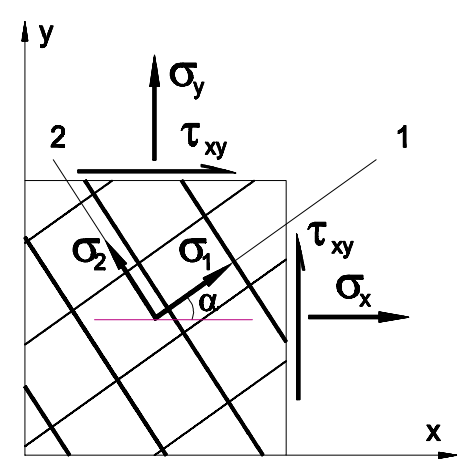

Figura 3.2 - Modelo de fissuras distribuídas - eixos principais (ortótropos)

O emprego de um modelo elastofrágil para descrever o comportamento do concreto simples à tração é consistente com o que se observa em ensaios uni e biaxiais mas, no entanto, conduz a resultados sensíveis ao refinamento da malha de elementos finitos. Por outro lado, em se tratando de concreto armado, existe uma contribuição do concreto íntegro entre duas fissuras sucessivas para a resistência aos esforços de tração. Esse fenômeno, conhecido como enrijecimento àtração (tension-stiffening), pode ser levado em consideração de modo aproximado através da inclusão de um ramo de amolecimento (softening) àcurva de tração do concreto pós ruptura. HILLERBORG;PATERSON (1976) e BAZANT (1976) propõem que a curva de amolecimento (softening) do concreto submetido à tração não seja uma característica do material, e sim da relação entre a energia de fratura $\left(\mathrm{G}_{\mathrm{f}}\right)$, definida como a quantidade de energia necessária para criar uma área unitária de uma fissura contínua, e da largura $h_{\text {eq }}$ de domínio da fissura. 
No início da década de 1980, COPE et al.(1980) apud FEENSTRA;DE BORST $(1995)^{6}$ aprimoram o modelo de fissuras distribuídas, permitindo a corotação dos eixos principais com a evolução do carregamento através de um modelo de fissuras rotativas (rotating crack). Iniciado o processo de fissuração, o modelo permite o surgimento de novas fissuras, denominadas secundárias, em direções não necessariamente ortogonais à direção da primeira fissura, e sim paralelas às direções principais orientadas para aquele instante.

Dando prosseguimento aos estudos de Kachanov, MAZARS (1984) apresenta uma formulação de dano para o concreto submetido a carregamento proporcional ou cíclico; a denominada mecânica do dano contínuo, mais tarde formalizada por LEMAITRE;CHABOCHE (1985), com base na termodinâmica dos processos irreversíveis. O dano contínuo admite um estado de fissuração disperso pelo material sem, no entanto, estabelecer as direções das fissuras. Os efeitos dessa fissuração são quantificados de modo indireto, através de alterações das características mecânicas do material, proporcionais ao dano acumulado.

A incorporação de teorias baseadas em critérios de energia é bastante importante na modelagem do concreto armado, pois tende a suprir a deficiência dos modelos elastoplásticos na representação da deterioração do concreto devido à abertura, propagação e união de microfissuras. TANABE;WU (1992) apresentam uma formulação da teoria da plasticidade com encruamento em que as superfícies de carregamento variam de dimensão e forma continuamente, de acordo com o dano acumulado, e CHEN et al. (1993) empregam uma série de modelos mistos de plasticidade e dano àanálise de estruturas de concreto armado.

FLOREZ-LÓPEZ (1993) estabelece os modelos de dano concentrado para a simulação numérica do colapso de pórticos planos. Nesse modelo, as barras obedecem ao regime elástico-linear, e o dano é considerado confinado aos nós.

FEENSTRA;DE BORST (1996) adotam o dano distribuído e representado por parâmetros internos. O modelo elastoplástico é regido pelo critério de DruckerPrager na compressão biaxial, e delimitado pelo critério de Rankine* nos estados envolvendo a tração. PARK; KLINGNER (1997) abordam modelos mistos para a análise de estruturas de concreto armado sob estado plano de tensões.

\footnotetext{
${ }^{6}$ COPE,R.J.;RAO,P.V.;CLARKE,L.A.;NORRIS,P.(1980). Modeling of reinf. concr. behaviour for finite element analysis of bridge slabs. In: TAYLOR,C.;HINTON,E.;TAYLOR,D.R.J.(1980), Num. Meth. for Non-linear Problems. Pineridge Press, Swansea, p. 457-470. apud FEENSTRA;DE BORST(1995).

* A composição do critério de Rankine com outros critérios, através do artifício denominado por cut-off, será abordada no decorrer deste capítulo.
} 


\subsection{Formulação básica dos modelos elastoplásticos}

Os itens ' $a$ ' a 'd' definem as hipóteses básicas de um modelo constitutivo elastoplástico, com base na generalização do caso uniaxial.

a) Decomposição aditiva do tensor das deformações totais

Devido à generalização para o estado triaxial de tensões, as deformações $\{\varepsilon\}$ e as tensões $\{\sigma\}$ são representadas por tensores, e a decomposição aditiva do tensor das deformações totais é expressa por:

$$
\{\varepsilon\}=\nabla^{s}\{u\} \rightarrow\{\varepsilon\}=\left\{\varepsilon^{e}\right\}+\left\{\varepsilon^{p}\right\}
$$

onde: $\nabla^{\mathrm{s}}\{\mathrm{u}\}$ - parcela simétrica do tensor gradiente dos deslocamentos;

$\left\{\varepsilon^{\mathrm{e}}\right\}$ - parcela elástica da deformação total;

$\left\{\varepsilon^{p}\right\}$ - parcela plástica da deformação total.

b) Critério de plastificação

O critério de plastificação baseia-se no valor de uma variável escalar, denominada tensão efetiva $\left(\sigma^{\text {ef }}\right)$. Para os casos uniaxiais, a tensão efetiva eqüivale àprópria tensão (normal ou de cisalhamento) atuante.

A função $f$ denomina o critério de plastificação. As tensões permitidas por esse critério pertencem a um conjunto $E_{\sigma}$, convexo e fechado tal que:

$$
\begin{aligned}
& f: \operatorname{Linx}^{m} \rightarrow R \\
& E_{\sigma}=\left\{(\{\sigma\},\{q\}) \in \operatorname{Linx}^{m} / f(\{\sigma\},\{q\}) \leq 0\right\}
\end{aligned}
$$

onde: $\mathrm{m}$ - número de componentes do vetor $\{q\}$ que reúne os parâmetros e as variáveis internas relacionadas com o encruamento;

Lin - espaço dos tensores de $2^{\mathrm{a}}$ ordem.

O interior de $E_{\sigma}(f<0)$ representa o domínio elástico, e o contorno $\partial E_{\sigma}(f=0)$, a superfície de plastificação do material.

$$
\begin{aligned}
& \operatorname{int} E_{\sigma}=\left\{(\{\sigma\},\{q\}) \in \operatorname{Linx}^{m} / f(\{\sigma\},\{q\})<0\right\} \\
& \partial E_{\sigma}=\left\{(\{\sigma\},\{q\}) \in \operatorname{Linx}^{m} / f(\{\sigma\},\{q\})=0\right\}
\end{aligned}
$$


c) Uma lei de evolução do tensor de deformações plásticas

A lei de plastificação, que expressa a variação da deformação plástica, é escrita em função do produto de um escalar $(\dot{\gamma})$ por um vetor direção:

$$
\left\{\dot{\varepsilon}^{p}\right\}=\dot{\gamma}\{r(\{\sigma\},\{q\})\}
$$

onde : $\left\{\dot{\varepsilon}^{\mathrm{p}}\right\}=\frac{\mathrm{d}\left\{\varepsilon^{\mathrm{p}}\right\}}{\mathrm{dt}}$ - representa a velocidade de deformação plástica;

$\{r\} \in \operatorname{Linx}^{\mathrm{m}} \rightarrow$ Lin - tensor que determina a direção do fluxo plástico;

$\dot{\gamma} \geq 0$ - escalar que obedece às condições de complementaridade (KuhnTucker), e de consistência.

As condições impostas a $\dot{\gamma}$ permitem avaliar os estados de carregamento e descarregamento. Tais situações, descritas na tese de PROENÇA(1988) e na dissertação de OLIVEIRA(1998), podem ser assim resumidas:

$$
\begin{aligned}
\mathrm{f}<0 \leftrightarrow(\{\sigma\},\{\mathrm{q}\}) \in \operatorname{int}\left(\mathrm{E}_{\sigma}\right) \rightarrow & \dot{\gamma}=0 \text { - carregamento elástico; } \\
\mathrm{f}=0 \leftrightarrow(\{\sigma\},\{\mathrm{q}\}) \in \partial \mathrm{E}_{\sigma}: \quad & \dot{\mathrm{f}}<0 \rightarrow \dot{\gamma}=0 \text { - descarregamento elástico; } \\
& \dot{\mathrm{f}}=0 \text { e } \dot{\gamma}>0 \text { - carregamento plástico; } \\
& \dot{\mathrm{f}}=0 \text { e } \dot{\gamma}=0 \text { - carregamento neutro. }
\end{aligned}
$$

O carregamento neutro é caracterizado pela modificação do estado de tensões mantendo-o, no entanto, sobre a mesma superfície de escoamento anterior ao estado de tensões atual (não há evolução do encruamento).

d) Uma lei de evolução do vetor que reúne os parâmetros de encruamento

Os parâmetros e as variáveis internas relacionados ao encruamento do material são dispostos em um vetor $\{q\} \in R^{m}$, cuja lei de evolução também é obtida em função do escalar $\dot{\gamma}$, e expressa por:

$$
\{\dot{q}\}=-\dot{\gamma}\{h(\{\sigma\},\{q\})\}
$$

onde: $\{h\} \in \operatorname{Linx}^{\mathrm{m}} \rightarrow \mathrm{R}^{\mathrm{m}}$ define o tipo de encruamento, e o sinal negativo dá consistência termodinâmica ao processo dissipativo (associado ao encruamento). 
Os tensores $\{h(\{\sigma\},\{q\})\}$ e $\{r(\{\sigma\},\{q\})\}$ podem ser associados æ̀s derivadas parciais da função $f(\{\sigma\},\{q\})$ através das leis associativas:

$$
\begin{aligned}
& \frac{\partial f}{\partial \sigma}=f_{\sigma}=\{r(\{\sigma\},\{q\})\}(\text { regra da normalidade }) \\
& D^{p l} \cdot \frac{\partial f}{\partial q}=D^{p l} \cdot f_{q}=D^{p l} \cdot\{h(\{\sigma\},\{q\})\}
\end{aligned}
$$

onde: $\quad D^{p l}=\left[\begin{array}{ll}k & 0 \\ 0 & H\end{array}\right]$ - matriz que reúne os módulos plásticos de encruamento;

k - módulo plástico de encruamento isótropo;

H - módulo plástico de encruamento cinemático (não abordado neste texto).

Esta associação, ilustrada na Figura 3.3, estabelece a perpendicularidade entre a direção do fluxo plástico e a superfície de escoamento $\left(\partial \mathrm{E}_{\sigma}\right)$.

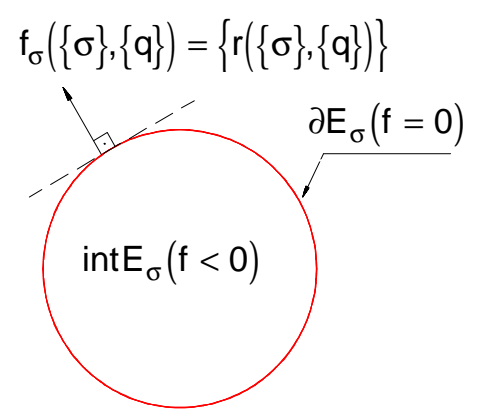

Figura 3.3 - Representação gráfica do vetor fluxo plástico sobre o domínio elástico (int $E_{\sigma}$ ) no espaço das tensões

\subsection{Aplicação ao aço das armaduras}

O aço empregado na construção civil se constitui em exemplo clássico de material dúctil, pois além de apresentar patamar de escoamento bem definido (aço conformado a quente), comporta-se equivalentemente tanto na tração como na compressão. Assim sendo, torna-se óbvia a conclusão de que um modelo elastoplástico seja o mais indicado à representação do seu comportamento mecânico. Sob a ação de esforços combinados esse comportamento é bem representado, desde 1913, pelo critério de escoamento de von Mises. Segundo von Mises, a plastificação de um ponto pertencente a um meio inicia-se quando a tensão octaédrica de cisalhamento $\left(\tau_{\text {oct }}\right)$ atinge o limite elástico $\overline{\mathrm{K}}$ do material: 


$$
\tau_{\text {oct }} \leq \overline{\mathrm{K}}
$$

Recorrendo à definição de $\tau_{\text {oct }}=\sqrt{\frac{2}{3} \mathrm{~J}_{2}}$, e relacionando $\overline{\mathrm{K}}$ com $\mathrm{K}$ (tensão de escoamento por cisalhamento puro), o critério assume a forma:

$$
\sqrt{J_{2}} \leq K
$$

onde: $\mathrm{J}_{2}-2^{\circ}$ invariante das tensões desviadoras.

A Figura 3.4 traz uma interpretação geométrica para o critério.

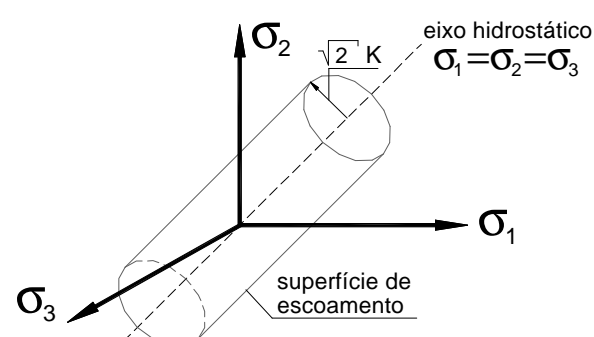

(a) estado triaxial de tensões

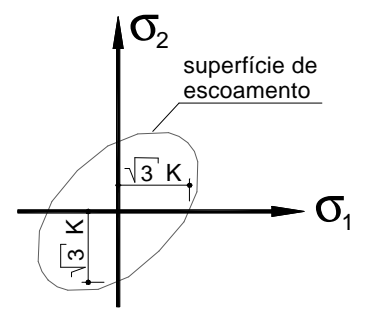

(b) estado biaxial de tensões

Figura 3.4 - Interpretação geométrica do critério de escoamento de von Mises

No entanto, as armaduras empregadas nas estruturas lineares, planas e tridimensionais de concreto armado são compostas por barras discretas. Isto sugere que, nesses casos, o emprego de um modelo elastoplástico uniaxial para a modelagem das armaduras fosse o mais indicado.

Cabe discutir agora a caracterização do modelo constitutivo mais adequado à representação do comportamento mecânico do aço. A literatura científica não consagra um modelo específico, porém, dois deles são amplamente empregados: o elastoplástico perfeito, e o dotado de encruamento positivo isótropo.

A NBR-6118 apresenta uma relação elastoplástica perfeita para o aço conformado a quente, com patamar de escoamento bem definido (classe A). Para o aço conformado a frio (classe B), é apresentada uma relação elastoplástica com encruamento positivo isótropo linear. No Brasil, no entanto, a grande maioria das barras de aço empregadas em obras correntes pertencem à classe $A$, estando a classe $B$ restrita apenas às bitolas de diâmetro igual ou inferior a 5,0 mm. O CEBFIP MC90 também adota diagramas tensão-deformação típicos da classe $A$ da norma brasileira, e propõe um modelo elastoplástico perfeito para a representação do comportamento mecânico de barras de aço solicitadas uniaxialmente.

Neste trabalho, o comportamento mecânico das barras de aço, empregadas em qualquer elemento estrutural, será representado por um modelo constitutivo 
uniaxial elastoplástico perfeito. Esse modelo constitutivo caracteriza-se por um comportamento elástico linear até que se atinja a tensão de escoamento, limite a partir do qual o material perde a capacidade de absorver acréscimos de tensões, como mostra a Figura 3.5.

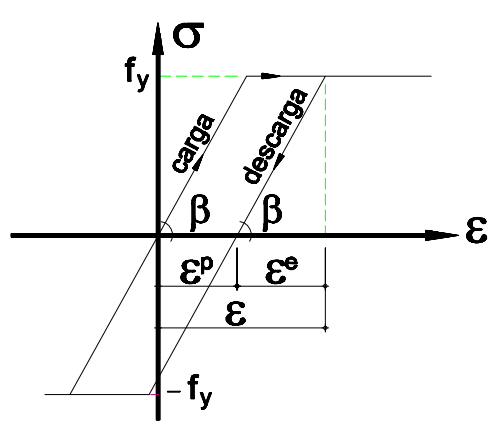

Figura 3.5 - Relação elastoplástica perfeita - ilustração para o caso uniaxial

Com base no diagrama da Figura 3.5, admite-se que as deformações normais possam ser decompostas aditivamente, como segue:

$$
\varepsilon=\varepsilon^{e}+\varepsilon^{p}
$$

deste modo, pode-se escrever:

$$
\sigma=\mathrm{E}_{\mathrm{s}} \cdot \varepsilon^{\mathrm{e}}=\mathrm{E}_{\mathrm{s}}\left(\varepsilon-\varepsilon^{\mathrm{p}}\right)
$$

onde: $\varepsilon$ - deformação total;

$\varepsilon^{p}$ - parcela de deformação plástica acumulada;

$\varepsilon^{\mathrm{e}}$ - parcela de deformação elástica;

$\sigma$ - tensão normal;

$\mathrm{f}_{\mathrm{y}}$ - resistência de escoamento do aço àtração;

$E_{s}=\operatorname{tg} \beta$ - módulo de deformação longitudinal do aço.

As grandezas $\varepsilon, \sigma$, e $\varepsilon^{p}$ devem ser expressas como funções variáveis com o tempo em um intervalo $[0, T] \subset R$ pois, deste modo, poderão representar a evolução da plastificação segundo um modelo elastoplástico adotado:

$$
\dot{\sigma}=\mathrm{E} \cdot \dot{\varepsilon}^{\mathrm{e}}=\mathrm{E} \cdot\left(\dot{\varepsilon}-\dot{\varepsilon}^{\mathrm{p}}\right)
$$

onde: $\quad \dot{\sigma}=\frac{\mathrm{d} \sigma}{\mathrm{dt}} ; \quad \dot{\varepsilon}^{\mathrm{e}}=\frac{\mathrm{d} \varepsilon^{\mathrm{e}}}{\mathrm{dt}} ; \quad \dot{\varepsilon}=\frac{\mathrm{d} \varepsilon}{\mathrm{dt}} ; \quad \dot{\varepsilon}^{\mathrm{p}}=\frac{\mathrm{d} \varepsilon^{\mathrm{p}}}{\mathrm{dt}}$.

A condição de plastificação é representada pela função $f$, onde os estados de tensão possíveis satisfazem a inequação: 


$$
f: R \rightarrow R / f(\sigma)=|\sigma|-\sigma_{y} \leq 0
$$

Define-se, também, um escalar positivo $\dot{\gamma}$ que corresponde ao valor absoluto da velocidade de deformação plástica que pode ocorrer quando atingido o limite de escoamento $(f(\sigma)=0)$. O escalar deve estar associado a um versor correspondente àdireção do fluxo plástico. Para o caso uniaxial, como a direção da velocidade de deformação plástica é única, verifica-se que o seu sentido passa a ser dado pelo sinal da tensão utilizada na análise.

$$
\varepsilon^{p}=\dot{\gamma} \cdot \sin (\sigma)
$$

onde: $\sin (\sigma)$ é uma função àqual atribui-se o sinal da tensão $\sigma$.

\subsection{Aplicação ao concreto}

\subsubsection{Estado multiaxial}

Como mencionado anteriormente, o concreto apresenta características mecânicas distintas de acordo com o tipo de solicitação à qual esteja submetido. Comporta-se como um material tipicamente frágil sob estados de tensões de tração e, por outro lado, apresenta características de material plástico sob estados de tensão compressivos. As amplas experimentações até hoje realizadas estabelecem um consenso sobre as formas das superfícies elástica e de ruptura do concreto no espaço das tensões principais, apresentadas na Figura 3.6.

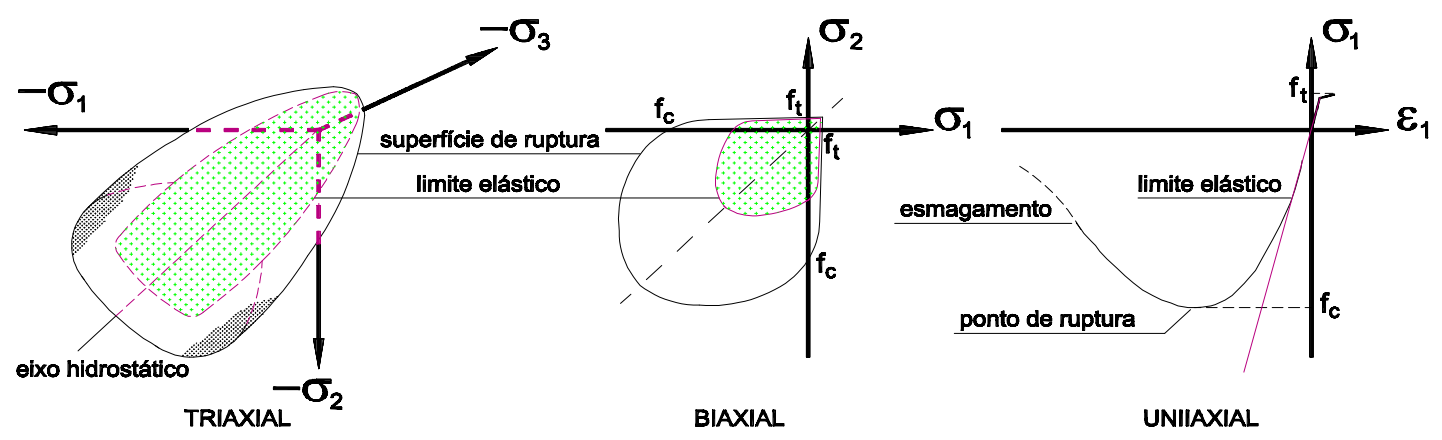

Figura 3.6 - Superfícies de plastificação e de ruptura (PROENÇA(1988))

De modo aproximado, considera-se um comportamento elástico linear do concreto até 0 início da plastificação (limite elástico). A partir desse limite 0 concreto apresenta características de encruamento positivo até que se atinja a 
ruptura que deve ser seguida, preferencialmente, por um ramo de amolecimento para os estados de tração. Para os estados compressivos, no entanto, a capacidade última é estabelecida pelo esmagamento do concreto em virtude do estado de deformação plástica excessiva.

Os primeiros estudos objetivando qualificar o comportamento mecânico do concreto surgiram no final do século passado, provavelmente com o pesquisador alemão FÖPPL $(1899,1900)^{7}$ apud KUPFER; HILSDORF;RÜSH (1969), que publica os resultados de ensaios em cubos de concreto para a determinação da sua resistência à compressão biaxial. A partir de então, seguem-se vários trabalhos na tentativa de estabelecer critérios de ruptura para o concreto submetido a estados de solicitação combinados sem a preocupação, ainda, com os aspectos relacionados ao comportamento não-linear propriamente dito, como a plastificação na compressão e o encruamento, que só seriam estudados posteriormente, após o desenvolvimento das teorias da plasticidade e da fratura. Alguns trabalhos nessa linha de pesquisa atingem repercussão internacional, como o critério triaxial de dois parâmetros proposto por LEON (1935) $)^{8}$ apud MENÉTREY;WILLAM (1995). Segundo esse critério, bastante parecido com o de Mohr-Coulomb, e que corresponde a uma generalização parabólica do critério de Drucker-Prager, a tensão de cisalhamento em um plano crítico é restrita por:

$$
\tau^{2} \leq \mathrm{C}_{1} \sigma+\mathrm{C}_{2}
$$

onde: $\tau$ - tensão de cisalhamento em um plano crítico;

$\sigma$ - tensão normal ao plano crítico;

$\mathrm{C}_{1}$ e $\mathrm{C}_{2}$ - são combinações do atrito interno e da coesão do material.

Reescrevendo o critério em termos das tensões principais, chega-se a:

$$
f\left(\sigma_{1}, \sigma_{3}\right)=\left(\frac{\sigma_{1}-\sigma_{3}}{f_{c}}\right)^{2}+m_{1} \frac{\sigma_{1}+\sigma_{3}}{f_{c}}-c_{l}=0
$$

Os parâmetros de coesão e atrito interno são calibrados a partir dos ensaios de tração e compressão simples:

$$
c_{I}=\frac{f_{c} \cdot f_{t}+\left(f_{t}\right)^{2}}{f_{c} \cdot f_{t}+\left(f_{c}\right)^{2}} ; m_{l}=\frac{3}{2} \cdot \frac{\left(f_{c}\right)^{2}-\left(f_{t}\right)^{2}}{f_{c} \cdot f_{t}+\left(f_{c}\right)^{2}}
$$

\footnotetext{
7 FÖPPL,A.(1899,1900). Reports from the laboratory for engineering mechanics. Technischen Hochschule, München, n.28, 29. apud KUPFER et al. (1969).

8 LEON,A.(1935). Uber die scherfestigkeit des betons. Beton und Eisen. V.34, p.130-135. apud MENÉTREY;WILLAM (1995).
} 
onde: $f_{c}$ - resistência àcompressão do concreto*;

$\mathrm{f}_{\mathrm{t}}$ - resistência àtração do concreto*.

BRESLER;PISTER (1958) ${ }^{9}$ apud KUPFER;HILSDORF;RÜSH (1969) analisam o comportamento do concreto sob tensões de cisalhamento e compressão combinadas, e apresentam um critério de ruptura para o concreto submetido ao campo tração-compressão. Para a tração e compressão biaxiais, no entanto, não houve uma proposta de curva teórico-experimental. A superfície de ruptura proposta por Bresler e Pister é expressa em termos das tensões de cisalhamento $\left(\tau_{\text {oct }}\right)$ e normal $\left(\sigma_{\text {oct }}\right)$ octaédricas:

$$
f\left(\sigma_{\text {oct }}, \tau_{\text {oct }}\right)=-A+B \frac{\sigma_{\text {oct }}}{\tau}-C\left(\frac{\sigma_{\text {oct }}}{\tau}\right)^{2}+\frac{\tau_{\text {oct }}}{\tau}=0
$$

As constantes $A, B$ e $C$ são determinadas através de 3 ensaios de ruptura:

tração uniaxial: $\quad \sigma_{1}=\mathrm{f}_{\mathrm{t}}, \sigma_{2}=\sigma_{3}=0$;

compressão uniaxial: $\sigma_{1}=\sigma_{2}=0, \sigma_{3}=-f_{c}$;

compressão biaxial: $\sigma_{1}=0, \sigma_{2}=\sigma_{3}=-f_{2 c}$.

onde: $\mathrm{f}_{2 \mathrm{c}}$ - resistência àcompressão biaxial do concreto.

Adotando as relações entre as resistências: $f_{t}=0,10 f_{c}, f_{2 c}=1,15 f_{c}$, as constantes do material passam a valer: $\mathrm{A}=0,098 ; \mathrm{B}=1,530 ; \mathrm{C}=-1,240$.

Em 1969, o extenso trabalho experimental elaborado por Kupfer, Hilsdorf e Rüsh (KUPFER;HILSDORF;RÜSH (1969)) apresenta resultados importantes para o estudo do concreto, destacando-se: a curva completa tensão-deformação para o caso de compressão uniaxial; a descrição das superfícies de limite elástico e de ruptura biaxial completa, incorporando os estados de tração e compressão biaxiais; a determinação da expansão volumétrica do concreto sob estados uni e biaxial de compressão (Figura 3.7); a quantificação do acréscimo de $16 \%$ na resistência do concreto sob um estado biaxial de tensões de compressão $\left(f_{2 c}\right)$ com relação à sua resistência à compressão uniaxial $\left(f_{c}\right)$; e a verificação da invariabilidade do valor da resistência do concreto submetido àtração uni e biaxial.

9 BRESLER,B.PISTER,K.(1958). Strength of concrete under combined stresses. ACI Journal, Proceedings v.55, n.3, p.321-345, September. apud KUPFER et al. (1969).

* Com o objetivo de unificar as notações, as nomenclaturas $f_{c}$ e $f_{t}$ estarão referidas às resistências convencionais do concreto, sem importar, pelo menos neste instante, o caráter estatístico desses valores. 


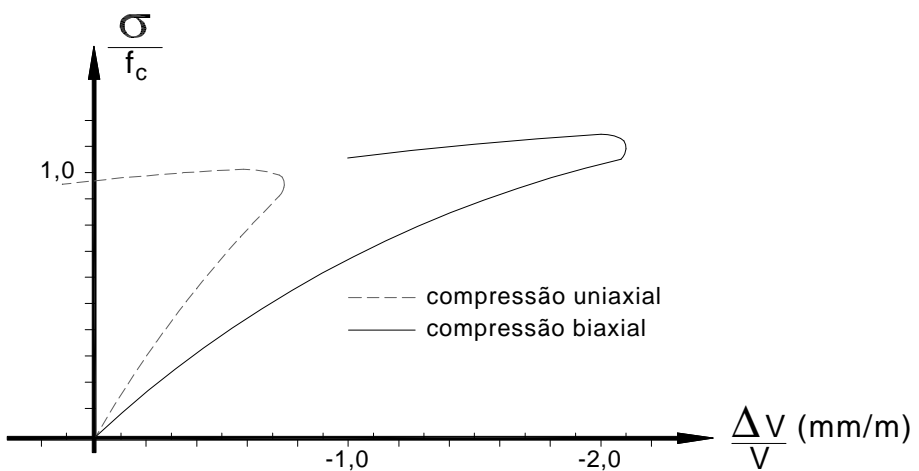

Figura 3.7 - Deformação volumétrica do concreto (KUPFER et al.(1969))

A extrapolação direta desses resultados dariam origem mais tarde, em 1973, àsuperfície teórica proposta por KUPFER; GERSTLE (1973):

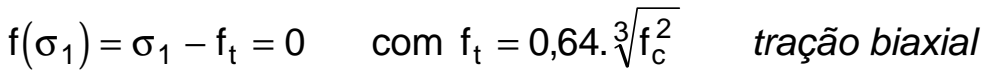

$$
\begin{aligned}
& f\left(\sigma_{1}, \sigma_{2}\right)=\left(\frac{\sigma_{1}}{f_{c}}+\frac{\sigma_{2}}{f_{c}}\right)^{2}+\frac{\sigma_{1}}{f_{c}}+3,65 \cdot \frac{\sigma_{2}}{f_{c}}=0 \text { compressão biaxial } \\
& \mathrm{f}\left(\sigma_{1}, \sigma_{2}\right)=\frac{\sigma_{2}}{\mathrm{f}_{\mathrm{t}}}-1-0,8 \cdot \frac{\sigma_{1}}{\mathrm{f}_{\mathrm{c}}}=0 \quad \text { tração-compressão }
\end{aligned}
$$

Seguindo essa mesma linha de raciocínio, surgem outros pesquisadores com propostas de critérios de ruptura para o concreto. É o caso, por exemplo, de WILLAM; WARNKE $(1974)^{10}$ apud LABBANE;SAHA;TING(1993) que, em 1974, propõem um complexo critério de ruptura (fratura plástica) para o concreto, baseado em estados de tensão tri e biaxiais. A superfície de ruptura é função dos invariantes $\sigma_{\mathrm{m}}, \tau_{\mathrm{m}}$, e envolve seis parâmetros:

$$
f\left(\sigma_{m}, \tau_{m}\right)=\sqrt{5} \cdot \tau_{m}-r=0
$$

onde: $\begin{aligned} r & =\frac{2 \cdot r_{c}\left(r_{c}^{2}-r_{t}^{2}\right) \cos \theta+r_{c}\left(2 \cdot r_{t}-r_{c}\right) \sqrt{4\left(r_{c}^{2}-r_{t}^{2}\right) \cos ^{2} \theta+5 \cdot r_{t}^{2}-4 \cdot r_{t} r_{c}}}{4\left(r_{c}^{2}-r_{t}^{2}\right) \cos ^{2} \theta+\left(r_{c}-2 \cdot r_{t}\right)^{2}} ; \\ & r_{t}=\sqrt{5} \cdot \tau\left[a_{0}+a_{1}\left(\frac{\sigma_{m}}{\tau}\right)+a_{2}\left(\frac{\sigma_{m}}{\tau}\right)^{2}\right] ; r_{c}=\sqrt{5} \cdot \tau\left[b_{0}+b_{1}\left(\frac{\sigma_{m}}{\tau}\right)+b_{2}\left(\frac{\sigma_{m}}{\tau}\right)^{2}\right] ;\end{aligned}$

10 WILLAM,K.J.;WARNKE,E.P. (1974). Constitutive models for the triaxial behavior of concrete. Int. Assoc. Bridge Struct. Eng. Sem. Concr. Struct. Subjected to Triaxial Stressses. apud LABBANE et al. (1993). 


$$
\begin{aligned}
& \tau_{\mathrm{m}}=\sqrt{\frac{2}{5} \cdot \mathrm{J}_{2}} ; \sigma_{\mathrm{m}}=\frac{1}{3} \cdot \mathrm{I}_{1} ; \\
& \mathrm{J}_{2}=\frac{1}{6}\left(\left(\sigma_{1}-\sigma_{2}\right)^{2}+\left(\sigma_{2}-\sigma_{3}\right)^{2}+\left(\sigma_{3}-\sigma_{1}\right)^{2}\right)-2^{\circ} \text { invariante do tensor } \\
& \quad \text { desviador; } \\
& \mathrm{I}_{1}=\sigma_{1}+\sigma_{2}+\sigma_{3}\left(1^{\circ} \text { invariante do tensor das tensões }\right) ; \\
& \mathrm{a}_{0}, \mathrm{a}_{1}, \mathrm{a}_{2}, \mathrm{~b}_{0}, \mathrm{~b}_{1}, \mathrm{~b}_{2}-\text { constantes do material; } \\
& \cos \theta=\frac{2 \cdot \sigma_{1}-\sigma_{2}-\sigma_{3}}{\sqrt{2\left[\left(\sigma_{1}-\sigma_{2}\right)^{2}+\left(\sigma_{2}-\sigma_{3}\right)^{2}+\left(\sigma_{3}-\sigma_{1}\right)^{2}\right]}}-\text { ângulo de similaridade. }
\end{aligned}
$$

As 6 constantes $a_{0}, a_{1}, a_{2}, b_{0}, b_{1}, b_{2}$ são obtidas através dos mesmos 3 ensaios de ruptura do concreto propostos para o critério de Bresler e Pister, juntamente com mais 2 ensaios de compressão triaxiais:

compressão triaxial confinada (meridiano de compressão): $\sigma_{\mathrm{m}}=-\sigma_{\mathrm{mc}} \quad, \mathrm{r}=\mathrm{r}_{\mathrm{c}}$ compressão triaxial confinada (meridiano de tração): $\sigma_{\mathrm{m}}=-\sigma_{\mathrm{mt}}, \mathrm{r}=\mathrm{r}_{\mathrm{t}}$

Assumindo as seguintes relações entre as resistências: $f_{t}=0,10 f_{c}$, $\mathrm{f}_{2 \mathrm{c}}=1,15 \mathrm{f}_{\mathrm{c}}, \sigma_{\mathrm{mc}}=1,95 \mathrm{f}_{\mathrm{c}}, \mathrm{r}_{\mathrm{c}}=2,77 \mathrm{f}_{\mathrm{c}}, \sigma_{\mathrm{mt}}=3,67 \mathrm{f}_{\mathrm{c}}, \mathrm{r}_{\mathrm{t}}=1,40 \mathrm{f}_{\mathrm{c}}$, determinam-se as constantes do material: $a_{0}=0,05347 ; a_{1}=-0,50731 ; a_{2}=-0,03826 ; b_{0}=0,09217$; $b_{1}=-0,86653 ; b_{2}=-0,14283$.

Hsieh, Ting e Chen propõem, em 1982 um critério de ruptura envolvendo quatro parâmetros:

$$
f\left(I_{1}, J_{2}\right)=A \frac{J_{2}}{\tau^{2}}+B \frac{\sqrt{J_{2}}}{\tau}+C \frac{\sigma_{1}}{\tau}+D \frac{I_{1}}{\tau}-1=0
$$

onde: $\sigma_{1}$ - maior tensão principal.

Os parâmetros A, B, C e D são constantes adimensionais do material determinadas através dos 3 ensaios de ruptura do concreto apresentados para o critério de Bresler e Pister, em conjunto com 1 ensaio de compressão triaxial.

compressão triaxial confinada: $\sigma_{1}=\sigma_{2}=-\mathrm{f}_{\mathrm{pc}} \quad, \sigma_{3}=-\mathrm{f}_{\mathrm{cc}}$.

Do mesmo modo, assumindo as relações entre as resistências: $f_{t}=0,10 f_{C}$, $\mathrm{f}_{\mathrm{bc}}=1,15 \mathrm{f}_{\mathrm{c}}, \sigma_{\mathrm{mc}}=1,95 \mathrm{f}_{\mathrm{c}}, \mathrm{f}_{\mathrm{pc}}=0,8 \mathrm{f}_{\mathrm{c}}, \mathrm{f}_{\mathrm{cc}}=4,2 \mathrm{f}_{\mathrm{c}}$, determinam-se as constantes do material: $A=2,0108 ; B=0,9714 ; C=9,1412 ; D=0,2312$. 
A superfície de ruptura é particularizada àde von Mises se as constantes $A$, C e D são levadas a zero, e àde Drucker-Prager quando A e D de anulam.

O critério de Figueiras-Owen (FIGUEIRAS(1983)) estabelece que a superfície de ruptura seja representada, para a compressão biaxial, em termos dos invariantes $I_{1}$ e $J_{2}$. Para os estados envolvendo a tração, vale a superfície de Rankine através do procedimento de cut-off.

$$
f\left(I_{1}, J_{2}\right)=\sqrt{\beta\left(3 \cdot J_{2}\right)+\alpha \cdot I_{1}}=f_{c}
$$

Os autores propõem ainda uma regra parabólica para a evolução do endurecimento misto do material. Essa descrição, convencionada como Parábola de Madrid é objeto de breves comentários a seguir, no item 3.4.1.2.

LABBANE;SAHA;TING (1993) publicam excelente trabalho, resultado de dez anos de pesquisas com modelos constitutivos para o concreto. Os autores analisam cinco superfícies de plastificação e de ruptura: von Mises; DruckerPrager; Hsieh et al.; Willam-Warnke e Bresler-Pister. Foram analisadas, ainda, as possíveis formas para o encruamento (por trabalho) das superfícies desde o final da sua fase elástica, continuamente, até a superfície de ruptura através das denominadas superfícies de carregamento (loading surfaces). Todas as superfícies analisadas foram compostas com o critério de Rankine através de cut-off, e o fenômeno do enrijecimento àtração foi negligenciado.

Os autores concluem ser os critérios de von Mises e de Drucker-Prager os mais indicados à análise de elementos de concreto armado submetidos ao estado plano de tensões compressivas, sendo que os demais mostraram-se mais rígidos do que o observado nos ensaios com lajes de concreto armado. A Figura 3.8 apresenta os resultados obtidos para uma laje de concreto armado quadrada, apoiada nos quatro lados, e submetida a carregamento uniformemente distribuído.

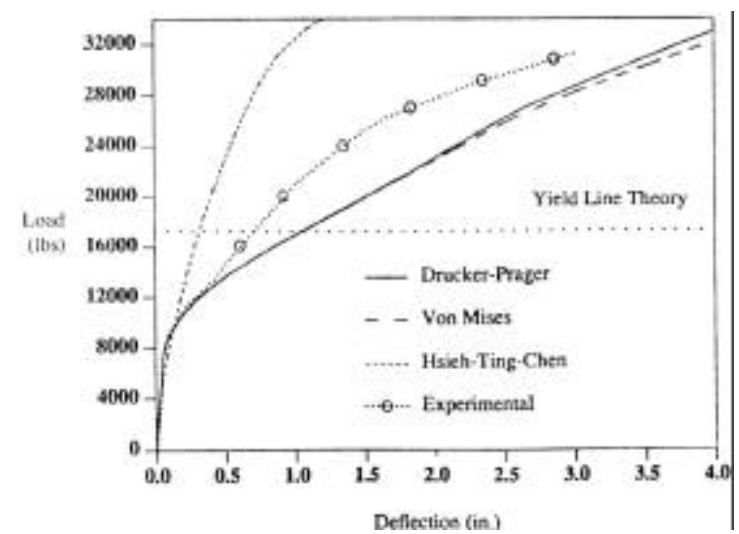

Figura 3.8 - Curva carga distribuída-deslocamento: comparação do desempenho de diversas superfícies aplicáveis à análise do concreto (LABBANE et al. (1993)) 
Os resultados obtidos com a superfície de von Mises são bastante próximos aos obtidos com a superfície de Drucker-Prager, e ambos relativamente próximos aos experimentais. Certamente, se o enrijecimento à tração tivesse sido contemplado na análise, os resultados poderiam ser ainda melhores, pois a queda na rigidez não seria tão acentuada após a fissuração (para a carga de 900 lbs).

Muitos são os trabalhos, surgidos a partir da década de 1990, que adotam modelos mistos de plasticidade e fratura (ou dano), geralmente acoplando superfícies de plastificação para representar o estado de compressão biaxial a modelos de fissuras dispersas fixas ou rotativas na representação dos estados envolvendo a tração. Nesse sentido, RANJBARAN;PHIPPS (1994) recuperam o modelo de RASHID (1968), e o aplicam a um elemento finito tridimensional dotado de armadura embutida. O critério de ruptura ainda é o de Rankine mas, para o ramo pós ruptura do concreto à tração, os autores propõem três variantes para o amolecimento, baseadas na energia de fratura $G_{f}$ (Figura 3.9).
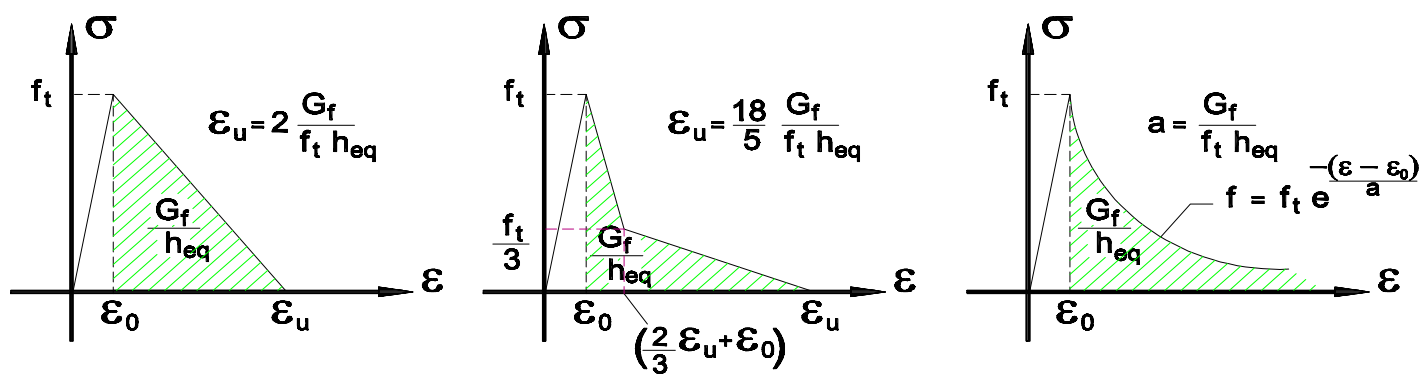

Figura 3.9 - Curvas de amolecimento (RANJBARAN;PHIPPS (1994))

onde: $G_{f}=h_{e q} \cdot g_{f}$;

$\mathrm{h}_{\text {eq }}$ - largura de domínio da fissura;

$\mathrm{g}_{\mathrm{f}}=\int \sigma . \mathrm{d} \varepsilon$ - energia de fratura por unidade de largura de domínio;

$\varepsilon_{0}$ - deformação equivalente àruptura por tração do concreto $\left(\varepsilon_{0}=\mathrm{f}_{\mathrm{t}} / \mathrm{E}_{\mathrm{c}}\right)$;

$\varepsilon_{\mathrm{u}}$ - deformação última à tração. Os autores a definem, alternativamente, equivalente àdeformação de escoamento do aço $\left(\varepsilon_{u}=f_{y} / E_{s}\right)$.

A maior dificuldade para a utilização dessas curvas incide sobre a definição do parâmetro $h_{\text {eq }}$ que, segundo diversos autores, pode variar com o tipo, a forma e o tamanho do elemento finito ao qual deseja-se aplicar o modelo.

Ranjbaran e Phipps incorporam também um modelo de transferência de tensões de cisalhamento no plano da fissura promovida pelo engrenamento dos agregados do concreto. $O$ efeito dessa transferência sobre a rigidez da região fissurada é estimado através da introdução do coeficiente $\beta_{c r}$ na expressão 3.1: 


$$
\left\{\begin{array}{c}
d \sigma_{1} \\
d \sigma_{2} \\
d \tau
\end{array}\right\}=\left[\begin{array}{ccc}
0 & 0 & 0 \\
0 & E & 0 \\
0 & 0 & \beta_{c r} \cdot G
\end{array}\right]\left\{\begin{array}{c}
d \varepsilon_{1} \\
d \varepsilon_{2} \\
d \gamma
\end{array}\right\}
$$

Esse coeficiente deve ser determinado experimentalmente. Na carência de ensaios experimentais, pode-se inferir valores entre 0,0 (para desconsiderar 0 efeito) e 0,4 (para considerá-lo integralmente).

PARK;KLINGNER (1997) implementam um modelo misto regido pelos critérios de Drucker-Prager ou von Mises na compressão biaxial e, para os estados biaxiais envolvendo a tração, os modelos de fissuração dispersa regidos pelo critério de Rankine. Cada um dos modelos elastoplásticos para a compressão biaxial (Drucker-Prager e von Mises) é composto aos modelos de fissuração dispersa (fixa e rotativa), gerando a possibilidade de análise através de quatro modelos mistos. A curva de amolecimento para o concreto em regime pós ruptura à tração é do tipo parabólica, muito próxima àapresentada na Figura 3.9, e a energia de fratura $G_{f}$ é determinada com base no CEB-FIP MC90. Os quatro modelos foram empregados na análise de uma viga parede biapoiada (relação altura/vão=0,5). Os resultados obtidos foram bastante próximos do experimental, notando-se uma melhor representatividade dos modelos de fissuras rotativas.

\subsubsection{Critérios de ruptura para materiais granulares}

No transcorrer deste capítulo foram mencionados vários critérios de ruptura desenvolvidos especialmente para a representação de materiais granulares coesivos como o solo, a rocha e, com o passar dos anos, o próprio concreto. Com o objetivo de abordá-los com um pouco mais de propriedade colocam-se, brevemente, aspectos relacionados àhistória e àcaracterização desses critérios.

Em 1773, Coulomb estabelece uma tensão de cisalhamento limite para a ruptura $(\tau)$ dependente da tensão normal $(\sigma)$ no seu plano de ação, do ângulo de atrito interno do material $(\phi)$, e da coesão (c).

$$
|\tau|=c-\sigma \cdot \operatorname{tg} \phi
$$

Já em 1882, Mohr demonstrou as relações propostas por Coulomb através de uma circunferência no espaço das tensões $(\sigma-\tau)$, denominado de Círculo de Mohr, e o critério passou a ser escrito em função das tensões principais $\sigma_{1}$ e $\sigma_{3}$ (responsáveis pelo $\tau_{\text {máx }}$ ), pois o diâmetro da circunferência é independente de $\sigma_{2}$. 


$$
\frac{\left|\sigma_{3}-\sigma_{1}\right|}{2 \cdot \cos \phi}+\frac{\left(\sigma_{1}+\sigma_{3}\right)}{2} \cdot \operatorname{tg} \phi=c
$$

Essa expressão pode ser rearranjada na forma:

$$
f\left(\sigma_{1}, \sigma_{3}\right)=\sigma_{1}(1+\operatorname{sen} \phi)-\sigma_{3}(1-\operatorname{sen} \phi)-2 \cdot \cos \cos \phi=0
$$

A representação do critério no espaço das tensões principais corresponde a uma superfície piramidal, cuja seção transversal é um hexágono. Esse critério apresenta o inconveniente de não prever limites para a pressão hidrostática (de compressão) suportáveis pelo material.

O critério de Drucker-Prager foi proposto em 1952 como uma aproximação do critério de Mohr-Coulomb, através de modificação do critério de von Mises. A influência da componente do estado hidrostático de tensão no critério de von Mises foi introduzida pelo invariante $I_{1}$, resultando:

$$
f\left(I_{1}, J_{2}\right)=a \cdot I_{1}+\sqrt{J_{2}}-K^{\backslash}=0
$$

onde: $a=\frac{2 \cdot \operatorname{sen} \phi}{\sqrt{3}(3 \pm \operatorname{sen} \phi)} ; K^{\prime}=\frac{6 \cdot \cos \phi}{\sqrt{3}(3 \pm \operatorname{sen} \phi)}$

Nas expressões 3.30, tomando-se o sinal positivo (+) ou o sinal negativo (-) no denominador, o Círculo de Drucker-Prager passa, respectivamente, pelos três vértices do hexágono de Mohr-Coulomb mais próximos ou mais afastados do eixo hidrostático.

Em 1858, Rankine estabelece um critério de ruptura bastante simples, baseado somente na resistência àtração uniaxial do material. Segundo Rankine, a ruptura do material em um ponto submetido a um estado de tensões qualquer ocorre quando a maior tensão principal atinge um valor igual àresistência à tração uniaxial $\left(\mathfrak{f}_{t}\right)$ do material. Para um estado triaxial de tensões principais não ordenadas, o critério pode ser expresso como:

$$
\sigma_{1} \leq \mathrm{f}_{\mathrm{t}}, \sigma_{2} \leq \mathrm{f}_{\mathrm{t}}, \sigma_{3} \leq \mathrm{f}_{\mathrm{t}}
$$

Para a análise de estruturas de concreto armado, a grande importância desse critério está na representação do concreto sob estados de tração, na formação dos modelos mistos (acoplados) através de cut-off.

A título comparativo, a Figura 3.10 ilustra no plano $\sigma_{1}-\sigma_{2}$ os diversos critérios de ruptura comentados neste capítulo. 


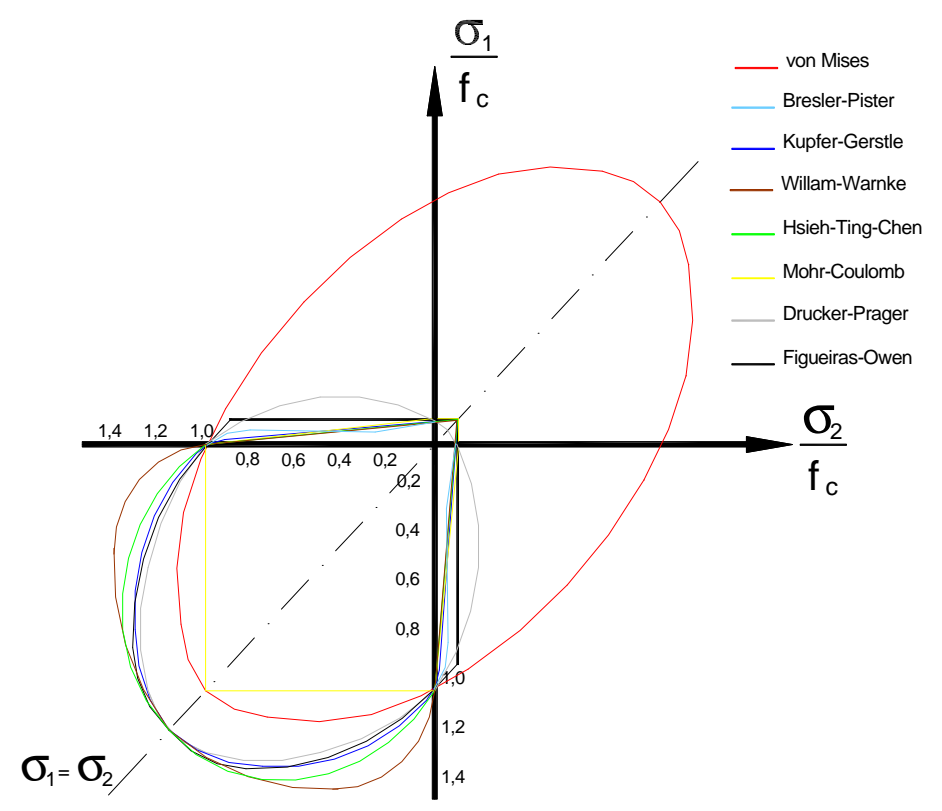

Figura 3.10 - Critérios de ruptura - comparação ilustrativa

$\mathrm{Na}$ região de compressão biaxial, a maioria das superfícies é contínua e convexa, exceção feita à de Mohr-Coulomb. Além disso, apresentam domínios bastante semelhantes, exceção feita à superfície de von Mises que imprime um caráter mais conservador à resistência. A representação dos estados envolvendo a tração (tração-compressão e tração biaxial) se dá de modo bastante similar pelos diversos critérios, através de segmentos de reta paralelos ou inclinados com relação aos eixos principais. Para essas regiões, a maior exceção se dá pelo critério de Drucker-Prager além, obviamente, da superfície de von Mises.

Cabe também uma comparação dos critérios de ruptura no plano octaédrico ( $\sigma_{\text {oct }}$ e $\tau_{\text {oct }}$ - Figura 3.11) de modo a serem observados os comportamentos para incrementos da pressão hidrostática (ou $\sigma_{\text {oct }}$ ). Basicamente, segundo o plano octaédrico, existem três tipos de comportamento principais quanto à evolução da superfície: constante (critério de von Mises), linear (Rankine, Mohr-Coulomb, Drucker-Prager e Figueiras-Owen), e parabólico (Leon, Hsieh-Ting-Chen, WillamWarnke e Bresler-Pister).

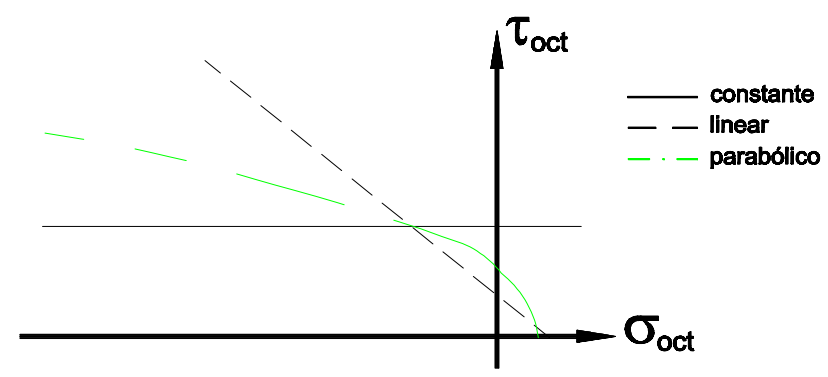

Figura 3.11 - Aspecto das superfícies de ruptura no plano octaédrico 


\subsubsection{Modelo de endurecimento}

Em um processo de carregamento monotônico crescente, a transição de estado é governada pelo endurecimento (encruamento), o qual promove a evolução contínua da superfície elástica inicial para a de ruptura continuamente. Convenciona-se adotar o início da plastificação do concreto a partir de uma tensão equivalente a cerca de $30 \%$ da tensão de ruptura à compressão simples mas, segundo CHEN;CHEN (1975), esse valor inicial pode ser situado entre 30 e $75 \%$. Existe ainda a possibilidade de se adotar a superfície elástica coincidente com a superfície de ruptura, o que na prática define o modelo elastoplástico perfeito (sem encruamento).

Segundo PROENÇA (1988), os modelos mistos de endurecimento são os mais indicados à análise do concreto. $O$ termo encruamento misto designa ambos os encruamentos convencionais: o isótropo, relativo à ampliação da superfície inicial; e o cinemático, que descreve o movimento da superfície em relação ao eixo hidrostático. Dentre vários modelos de encruamento conhecidos optou-se, neste trabalho, pelo emprego do modelo de Figueiras-Owen. Ajustando a superfície de ruptura de Figueiras-Owen aos dados experimentais de Kupfer et al. $\left(f_{2 c}=1,16 f_{c}\right)$, obtém-se os parâmetros $\alpha$ e $\beta$ da expressão 3.24:

$$
\alpha=0,355 \sigma^{\text {ef }} ; \quad \beta=1,355
$$

que passa a ser escrita, como:

$$
f\left(l_{1}, J_{2}\right)=\sqrt{4,065 \cdot J_{2}+0,355 \cdot \sigma^{\text {ef }} \cdot I_{1}}=\sigma^{\text {ef }}
$$

Nota-se, na expressão 3.32, que o termo que contém $l_{1}$ também é influenciado pela tensão efetiva $\left(\sigma^{\text {ef }}\right)$, o que impõe o caráter cinemático ao encruamento da superfície, como está melhor descrito em CHEN;HAN(1987) e PROENÇA(1988). FIGUEIRAS(1983) sugere ainda que seja estabelecida uma analogia com o caso uniaxial através dos conceitos de tensão efetiva ( $\sigma^{\text {ef }}$ ) e de deformação plástica efetiva ( $\Delta \gamma$ - equação 4.1 , capítulo 4 ), correlacionando-as de modo não-linear através da Parábola de Madrid.

$$
\sigma=\mathrm{E}_{0} \cdot \varepsilon-\frac{1}{2} \cdot \frac{\mathrm{E}_{0}}{\varepsilon_{0}} \cdot \varepsilon^{2}
$$

onde: $\mathrm{E}_{0}$ - módulo elástico inicial (tangente);

$\varepsilon$ - deformação total no instante analisado; 
$\varepsilon_{0}$ - deformação total para a tensão de ruptura uniaxial $\left(f_{c}\right)$.

Decompondo aditivamente a tensão total em suas parcelas elástica e plástica $\left(\varepsilon=\varepsilon^{e}+\varepsilon^{p}\right)$ e, substituindo a igualdade $\varepsilon^{e}=\sigma / E_{0}$, pode-se reescrever a expressão 3.33 já em termos da tensão e da deformação efetivas como:

$$
\sigma^{\text {ef }}=-E_{0} \cdot \Delta \gamma+\sqrt{2 \cdot E_{0}^{2} \cdot \varepsilon_{0} \cdot \Delta \gamma} \quad \text { para }\left(0,3 \cdot f_{c}<\sigma^{\text {ef }}<f_{c}\right)
$$

A Figura 3.12 traz uma ilustração para a regra de endurecimento proposta por Figueiras-Owen, e a compara aos resultados experimentais apresentados por KUPFER et al.(1969) para o caso de compressão uniaxial.

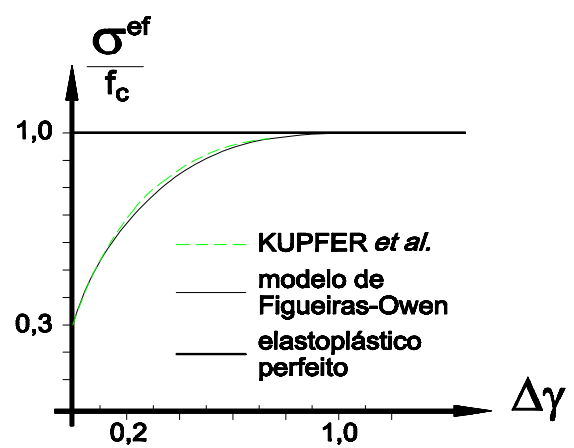

Figura 3.12 - Diagrama tensão efetiva-deformação efetiva

O módulo plástico do material $(\mathrm{k})$ pode ser determinado diretamente através da sua definição:

$$
k=\frac{d \sigma}{d \varepsilon^{p}}=\frac{d \sigma^{e f}}{d \Delta \gamma}=E_{0}\left(\sqrt{\frac{\varepsilon_{0}}{2 . \Delta \gamma}}-1\right)
$$

\subsubsection{Estado uniaxial}

A aplicação de relações constitutivas à análise de elemento finito uniaxial filamentado, como é o caso das vigas e dos pilares, exige o emprego de relações uniaxiais para a representação do comportamento mecânico dos materiais. Especificamente para o caso do concreto, apesar das inúmeras possibilidades, são destacadas, neste texto, apenas duas delas, julgadas as mais amplamente aplicadas: uma delas proposta por Saenz, e a outra pelo CEB-FIP MC90.

O modelo proposto por SAENZ (1964), aplicado à compressão uniaxial, é composto por dois trechos. Uma curva tensão-deformação não-linear, que se 
estende de zero à resistência à compressão do concreto $\left(f_{c}\right)$, é seguido por um trecho linear de amolecimento até o valor de $20 \%$ da resistência à compressão $\left(0,20 . f_{c}\right)$ para a deformação limite de compressão $\varepsilon_{\text {cu }}$ (Figura 3.13).

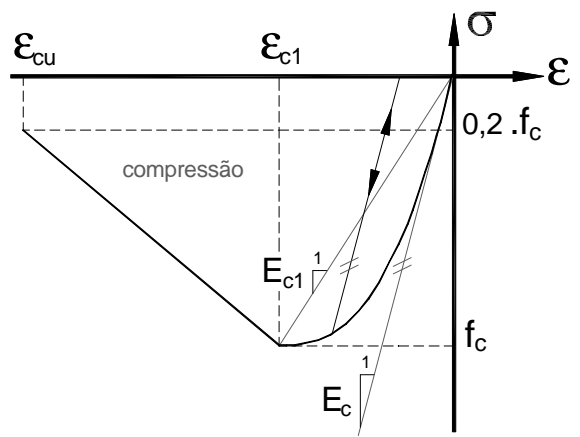

Figura 3.13 - Diagrama tensão-deformação para o concreto na compressão (SAENZ(1964))

A equação que rege 0 comportamento não-linear entre tensão e deformação para o primeiro trecho da curva é dada por:

$$
\sigma_{\mathrm{c}}=\frac{\varepsilon_{\mathrm{c}} \cdot \mathrm{E}_{\mathrm{c}}}{1+\left(\frac{\mathrm{E}_{\mathrm{c}}}{\mathrm{E}_{\mathrm{c} 1}}-2\right) \frac{\varepsilon_{\mathrm{c}}}{\varepsilon_{\mathrm{c} 1}}+\left(\frac{\varepsilon_{\mathrm{c}}}{\varepsilon_{\mathrm{c} 1}}\right)^{2}}
$$

onde: $\sigma_{\mathrm{c}}$ - tensão normal de compressão no concreto (correspondente a $\varepsilon_{\mathrm{c}}$ );

$\varepsilon_{\mathrm{C}}$ - deformação específica do concreto àcompressão;

$\mathrm{E}_{\mathrm{c}}$ - módulo de deformação longitudinal do concreto;

$\mathrm{E}_{\mathrm{c1}}$ - módulo de deformação longitudinal secante do concreto;

$\varepsilon_{\mathrm{c} 1}$ - deformação correspondente àf $\mathrm{c}_{\mathrm{c}}$;

$\varepsilon_{\mathrm{cu}}$ - deformação limite do modelo.

Saenz não trata de uma relação específica para o concreto tracionado, nem tampouco sobre hipóteses relativas à descarga e recarga, que seriam mais tarde incorporadas com sucesso por ASSAN (1990), que condicionou-as ao módulo de elasticidade inicial $\mathrm{E}_{\mathrm{c}}$ (Figura 3.13).

O Código Modelo CEB-FIP MC90 apresenta uma curva completa para o concreto sob solicitação uniaxial. O diagrama de compressão, em seu primeiro trecho, é semelhante ao apresentado por Saenz. O segundo trecho, relativo ao amolecimento, é não-linear e estende-se além do ponto correspondente à deformação $\varepsilon_{\mathrm{cu}}$. Convém observar que o trecho tracejado do diagrama, para deformações superiores (em módulo) a $\varepsilon_{\text {cu }}$, refere-se àextrapolação da curva com o objetivo de prever o comportamento do concreto no pós-esmagamento: 


$$
\begin{aligned}
& \sigma_{c}=-\frac{\frac{E_{c}}{E_{c 1}} \cdot \frac{\varepsilon_{c}}{\varepsilon_{c 1}}-\left(\frac{\varepsilon_{c}}{\varepsilon_{c 1}}\right)^{2}}{1+\left(\frac{E_{c}}{E_{c 1}}-2\right) \cdot \frac{\varepsilon_{c}}{\varepsilon_{c 1}}} \cdot f_{c} \text { para }\left|\varepsilon_{c}\right|<\left|\varepsilon_{c u}\right| \\
& \sigma_{\mathrm{c}}=-\frac{\mathrm{f}_{\mathrm{c}}}{\left[\left(\frac{1}{\frac{\varepsilon_{\mathrm{cu}}}{\varepsilon_{\mathrm{c} 1}}} \cdot \xi-\frac{2}{\left(\frac{\varepsilon_{\mathrm{cu}}}{\varepsilon_{\mathrm{c} 1}}\right)^{2}}\right) \cdot\left(\frac{\varepsilon_{\mathrm{c}}}{\varepsilon_{\mathrm{c} 1}}\right)^{2}+\left(\frac{4}{\frac{\varepsilon_{\mathrm{cu}}}{\varepsilon_{\mathrm{c} 1}}}-\xi\right) \cdot \frac{\varepsilon_{\mathrm{c}}}{\varepsilon_{\mathrm{c} 1}}\right]} \text { para }\left|\varepsilon_{\mathrm{c}}\right|>\left|\varepsilon_{\mathrm{cu}}\right|
\end{aligned}
$$

onde: $\varepsilon_{\mathrm{cu}}=\varepsilon_{\mathrm{c} 1}\left\{\frac{1}{2} \cdot\left(\frac{\mathrm{E}_{\mathrm{c}}}{2 \cdot \mathrm{E}_{\mathrm{c} 1}}+1\right)+\sqrt{\left[\frac{1}{4} \cdot\left(\frac{\mathrm{E}_{\mathrm{c}}}{2 \cdot \mathrm{E}_{\mathrm{c} 1}}+1\right)^{2}-\frac{1}{2}\right]}\right\}$ - deformação limite para a utilização entre as equações 3.37a e 3.37b (neste modelo, $\varepsilon_{\text {cu }}$ corresponde a uma tensão de módulo igual àmetade de $\mathrm{f}_{\mathrm{c}}$ );

$$
\xi=\frac{4 .\left(\left(\frac{\varepsilon_{\mathrm{cu}}}{\varepsilon_{\mathrm{c} 1}}\right)^{2} \cdot\left(\frac{\mathrm{E}_{\mathrm{c}}}{\mathrm{E}_{\mathrm{c} 1}}-2\right)+2 \cdot \frac{\varepsilon_{\mathrm{cu}}}{\varepsilon_{\mathrm{c} 1}}-\frac{\mathrm{E}_{\mathrm{c}}}{\mathrm{E}_{\mathrm{c} 1}}\right)}{\left(\frac{\varepsilon_{\mathrm{cu}}}{\varepsilon_{\mathrm{c} 1}} \cdot\left(\frac{\mathrm{E}_{\mathrm{c}}}{\mathrm{E}_{\mathrm{c} 1}}-2\right)+1\right)^{2}} \text { - parâmetro adimensional. }
$$

O comportamento do concreto sob tração uniaxial é representado por dois ramos lineares. O primeiro deles estende-se até $90 \%$ da resistência àtração $\left(\mathfrak{f}_{t}\right)$, e é seguido por um segundo trecho até o limite de deformação $\varepsilon_{t}=0,00015$, a partir do qual se dá a perda total da capacidade resistente (Figura 3.14).

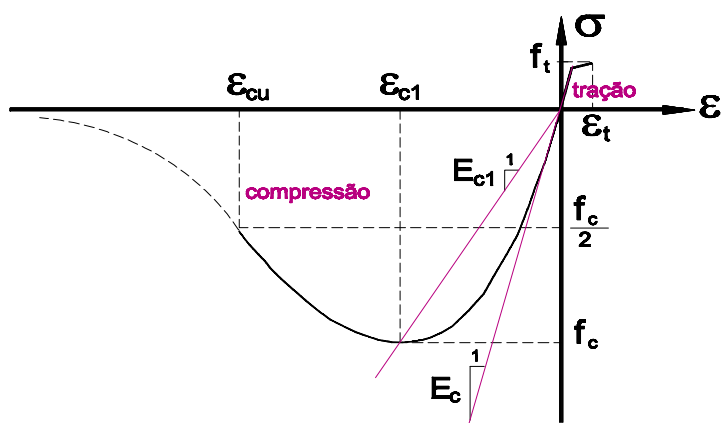

Figura 3.14 - Diagrama tensão-deformação para o concreto (CEB-FIP MC90)

O modelo não faz menção a comportamentos de descarga e recarga do material, e também não apresenta a possibilidade de modelagem (aproximada) do enrijecimento àtração através do diagrama de tração uniaxial. 
O termo enrijecimento à tração, como já colocado anteriormente, designa a contribuição que o concreto íntegro, entre duas fissuras sucessivas, exerce sobre a rigidez de um elemento de concreto armado fletido (ou tracionado) no estádio II. Apesar de estar fundamentado no fenômeno da aderência entre a armadura e o concreto, tal efeito pode ser quantificado, de maneira aproximada e indireta, através da inclusão de um ramo de amolecimento na curva do concreto tracionado, simulando uma perda progressiva de rigidez. A Figura 3.8 ilustra o bom modelo proposto por FIGUEIRAS (1983).

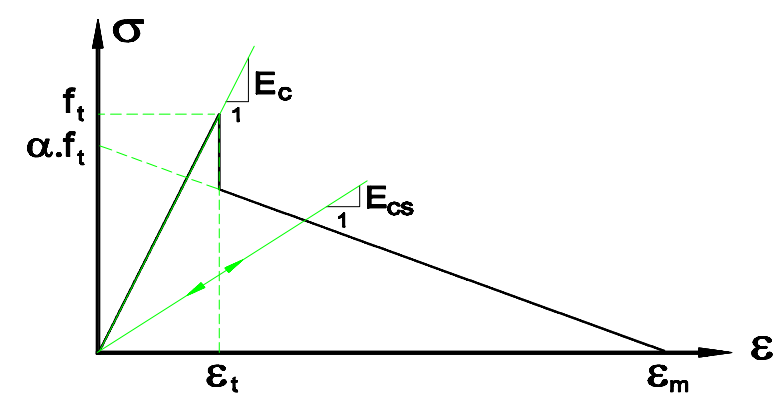

Figura 3.15 - Modelo para enrijecimento à tração

onde: $0,5 \leq \alpha \leq 0,7$ - coeficiente que impõe o grau de enrijecimento;

$\varepsilon_{\mathrm{m}}=0,0020$ - deformação específica limite do concreto àtração.

O modelo contempla as hipóteses de descarregamento e carregamento de acordo com a mecânica do dano contínuo, ou seja, através do módulo de deformação longitudinal secante do concreto $\left(E_{c s}\right)$. O enrijecimento àtração deveria ser ignorado para camadas de concreto suficientemente distantes da armadura tracionada e, por esse motivo, incapacitadas de trocar tensões de aderência com as armaduras. Na prática, a adoção do diagrama completo para todas as camadas produz bons resultados, e interfere menos intensamente sobre o comportamento do que a própria definição do parâmetro $\alpha$ entre seus valores limites. $O$ enrijecimento àtração pode ser ignorado forçando-se $\alpha=0$, ou $0<\varepsilon_{\mathrm{m}}<\varepsilon_{\mathrm{t}}$.

A Figura 3.16 ilustra uma comparação entre os modelos propostos por Saenz e pelo CEB-FIP MC90. Para viabilizar essa comparação, foi adotado $\varepsilon_{\mathrm{c} 1}=-0,0022$ e forçou-se, propositadamente, a passagem da reta de amolecimento de Saenz pelo ponto de inflexão da curva dada pelo CEB-FIP. A parte ascendente de ambas as curvas podem ser consideradas idênticas quanto ao aspecto, enquanto que na parte descendente reside a maior diferença entre as duas propostas. 


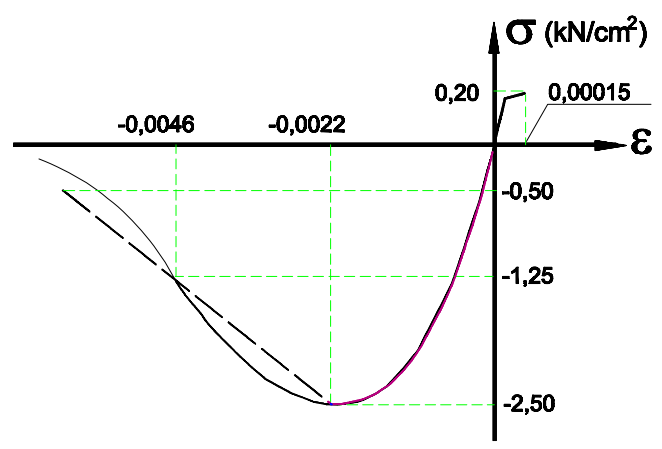

Figura 3.16 - Comparação entre diagramas tensão-deformação

\subsection{Modelo de dano de Mazars para o concreto}

\subsubsection{Introdução}

O dano no concreto é originado antes mesmo da sua solicitação (BUSSAMRA;PIMENTA(1995)). O inchaço da argamassa (cimento e areia) durante a hidratação do cimento, aliado à formação de "lentes" de água acumuladas ao redor dos agregados, favorecem o aparecimento de micro-fissuras tangenciais à interface argamassa-agregado. Desse modo, o comportamento mecânico do concreto é regido por um processo de deterioração do material, decorrente da abertura, propagação e união de microfissuras.

\subsubsection{Aspectos gerais}

Sob o ponto de vista macroscópico, os comportamentos típicos de um corpo-de-prova de concreto submetido a esforços de tração e de compressão (isoladamente) são os mostrados no diagrama da Figura 3.17.

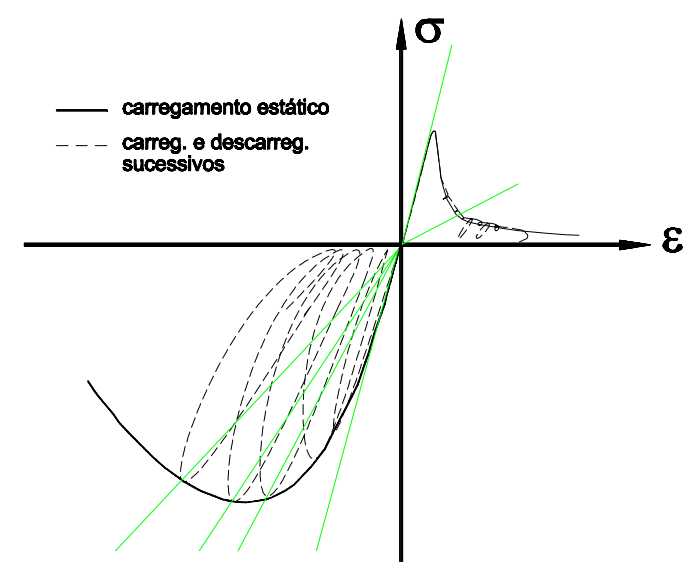

Figura 3.17 - Experimentos uniaxiais: tração e compressão 
O processo de danificação do concreto na compressão inicia-se ao redor dos agregados e dá-se, em média, a $45^{\circ}$ da linha de ação do carregamento. Por esse motivo, a fratura se propaga pelo modo II (Figura 3.18), já que se trata de um escorregamento entre as faces da fissura. Com o aumento do esforço, o dano cresce também na direção do plano perpendicular ao carregamento, sempre ao redor do agregado, resultando em dano segundo os modos I e II, podendo inclusive criar microfissuras paralelas ao carregamento.
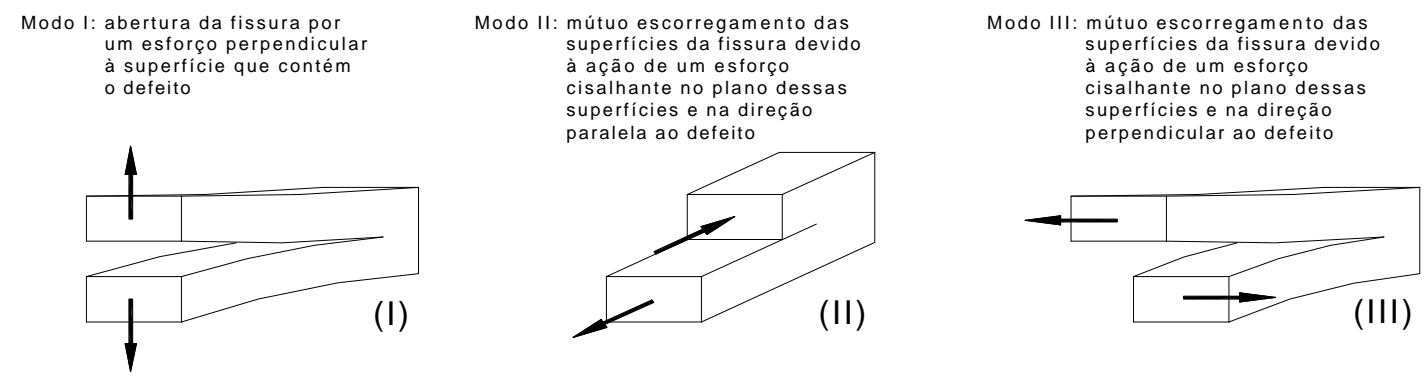

Figura 3.18 - Modos básicos de solicitação de uma fissura

Na tração, no entanto, o concreto apresenta um comportamento bastante diferente, uma vez que o crescimento das microfissuras se dá através do meio em direção perpendicular à da solicitação, pelo modo I de abertura. Existe uma fase elástico-linear até aproximadamente $80 \%$ da resistência, seguida de uma fase nãolinear até a tensão limite, e um amolecimento a partir desse ponto.

A partir dessas constatações é possível concluir que as microfissuras crescem predominantemente em modo I sempre que o material apresentar alongamento, e isso explica o denominado comportamento unilateral do concreto. Um corpo-de-prova de concreto submetido à tração uniaxial até atingir níveis elevados de danificação é descarregado e, em seguida, submetido a uma compressão uniaxial, apresenta a mesma rigidez inicial para tal solicitação (compressão), devido ao fechamento das microfissuras (Figura 3.19).

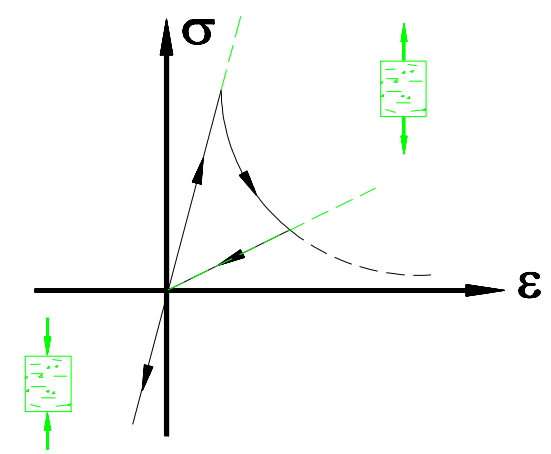

Figura 3.19 - Comportamento unilateral do concreto 


\subsubsection{Variáveis de dano}

Tomando-se um elemento de volume extraído de um sólido danificado suficientemente grande para conter uma imperfeição, mas que ainda possa ser considerado um ponto material do contínuo, o dano $\left(D_{n}\right)$, ou a densidade superficial do dano, é definida através da relação entre a superfície interna danificada $\left(S_{0}\right)$ e a superfície total (S):

$$
D_{n}=\lim _{s \rightarrow 0} \frac{S_{0}}{S}
$$

onde: $0 \leq D_{n} \leq 1$;

$D_{n}=0 \rightarrow$ material íntegro; $D_{n}=1 \rightarrow$ material inteiramente deteriorado;

n (sub-índice de D) - vetor direção normal àsuperfície considerada.

Esta formulação mais genérica, apresentada para a variável de dano $D$ em função da normal $n$, representa a danificação anisotrópica.

\subsubsection{Modelo constitutivo de Mazars}

A teoria do dano apresentada por MAZARS (1984) é também conhecida como dano isotrópico ou escalar, uma vez que considera uma distribuição uniforme (e independente da orientação da superfície considerada) dos microdefeitos no volume do sólido.

$$
\mathrm{D}_{\mathrm{n}}=\mathrm{D}, \quad \forall \mathrm{n}
$$

Para o desenvolvimento da teoria do dano contínuo devem ser adotadas as hipóteses básicas colocadas a seguir:

- o concreto tem um comportamento elástico e é passível de danificar-se, não existindo deformações permanentes, plásticas ou efeitos de viscosidade;

- o dano é causado somente por alongamentos nas direções principais $\left(\varepsilon_{1}>0\right)$, significando que prevalecem os desenvolvimentos das fissuras locais nos modos I e I+II;

- a evolução do dano só ocorre a partir de um certo valor limite de uma função fronteira (semelhante àfunção de plastificação): $f=f(\{\varepsilon\})$;

- o dano é considerado isotrópico, apesar de as análises experimentais evidenciarem que o dano conduz a uma anisotropia do concreto. Tal hipótese visa diminuir o número de variáveis do modelo e não implica, entretanto, na perda de assimetria de comportamento entre tração e compressão; 
- são considerados somente os carregamentos monotônicos crescentes, vedando assim a representação do comportamento unilateral do concreto neste modelo.

Assim como na teoria da plasticidade, faz-se necessária a introdução do conceito de deformação e tensão equivalentes de modo a compor os estados de solicitação pluriaxiais. Para a deformação equivalente, propõe-se:

$$
\tilde{\varepsilon}=\sqrt{\left\langle\varepsilon_{1}\right\rangle_{+}^{2}+\left\langle\varepsilon_{2}\right\rangle_{+}^{2}+\left\langle\varepsilon_{3}\right\rangle_{+}^{2}}
$$

onde: $\left\langle\varepsilon_{\mathrm{i}}\right\rangle_{+}$- parte positiva da deformação principal na direção i, definida como:

$$
\begin{array}{rlll}
\left\langle\varepsilon_{\mathrm{i}}\right\rangle_{+}=\frac{1}{2}\left[\varepsilon_{\mathrm{i}}+\left|\varepsilon_{\mathrm{i}}\right|\right] & & & \\
\text { desta forma: } & \left\langle\varepsilon_{\mathrm{i}}\right\rangle_{+}=\varepsilon_{\mathrm{i}} & \text { se } & \varepsilon_{\mathrm{i}}>0 ; \\
& \left\langle\varepsilon_{\mathrm{i}}\right\rangle_{+}=0 & \text { se } & \varepsilon_{\mathrm{i}} \leq 0 .
\end{array}
$$

Considere-se, por simplicidade, o caso unidimensional onde a tensão e a força aplicada em um elemento equilibrado de superfície $S$ relacionam-se por $\sigma=F / S$, e o estado de dano seja medido pelo escalar $D$. Neste caso, a área efetiva da seção $(\tilde{S})$ será:

$$
\tilde{S}=S-S_{0}=S \cdot(1-D)
$$

Desse modo, a tensão efetiva $\tilde{\sigma}$ deve valer:

$$
\tilde{\sigma}=\frac{F}{\tilde{S}} \quad \text { ou, para um estado multiaxial de tensões: }\{\tilde{\sigma}\}=\frac{\{\sigma\}}{(1-D)}
$$

Segundo LEMAITRE;CHABOCHE (1985): "O mesmo estado de deformações de um material com dano pode ser derivado do material íntegro onde a tensão usual é substituída pela tensão efetiva". Tal afirmação permite que se estabeleça uma relação constitutiva para o material com dano, escrita em função de um material íntegro pela seguinte relação:

$$
\{\varepsilon\}=\left[E_{c}\right]^{-1}\{\tilde{\sigma}\}=\left[E_{c}\right]^{-1} \frac{\{\sigma\}}{(1-D)}
$$

onde: $\left[E_{c}\right]$ - tensor de rigidez do material intacto.

Por outro lado, o mesmo estado de deformações pode ser expresso a partir de um tensor de rigidez do material danificado $\left[\tilde{E}_{\mathrm{c}}\right]$ : 


$$
\{\varepsilon\}=\left[\tilde{\mathrm{E}}_{\mathrm{c}}\right]^{-1}\{\sigma\}
$$

Igualando-se as expressões 3.43 e 3.44 , tem-se:

$$
\left[\tilde{\mathrm{E}}_{\mathrm{c}}\right]=(1-\mathrm{D})\left[\mathrm{E}_{\mathrm{c}}\right]
$$

A função fronteira do dano (f) é definida de tal modo que o processo de danificação só inicia-se a partir de um determinado valor limite para $\mathrm{S}_{0}$. A partir desse limite, tal processo evolui e é governado pela função $S=S(D)$. A função fronteira (critério de dano) passa a ter a seguinte forma:

$$
f(\tilde{\varepsilon}, D)=\tilde{\varepsilon}-S(D) \leq 0 \quad \text { com } S(0)=\varepsilon_{d 0}
$$

A forma da superfície inicial f no espaço das tensões principais é convexa, e não simétrica com relação àtração e compressão. A Figura 3.20 ilustra a superfície, juntamente com a curva experimental obtida por KUPFER et al.(1969).

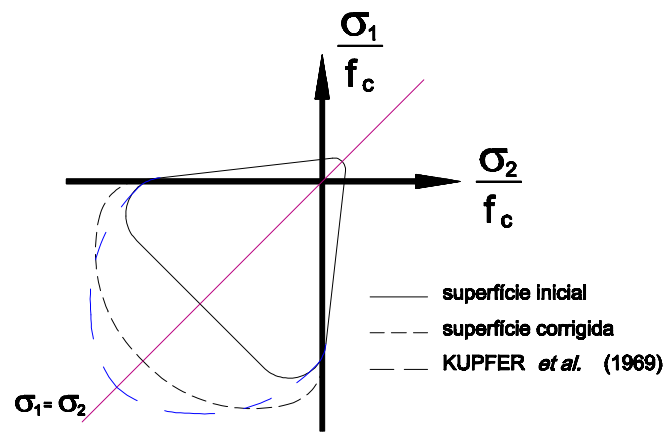

Figura 3.20 - Superfícies de ruptura (PEREGO (1989))

A relativa discrepância entre a curva experimental apresentada por Kupfer e colaboradores, e a curva do dano pode ser amenizada pela aplicação de um fator de correção $\eta \leq 1$ para a deformação equivalente $\tilde{\varepsilon}$, de modo que:

$$
\tilde{\varepsilon}_{\text {corrig }}=\eta\left(\sigma_{i}\right) \cdot \tilde{\varepsilon}
$$

onde: $\eta\left(\sigma_{i}\right)=\frac{\sqrt{\left\langle\sigma_{1}\right\rangle_{-}^{2}+\left\langle\sigma_{2}\right\rangle_{-}^{2}+\left\langle\sigma_{3}\right\rangle_{-}^{2}}}{\left\langle\sigma_{1}\right\rangle_{-}+\left\langle\sigma_{2}\right\rangle_{-}+\left\langle\sigma_{3}\right\rangle_{-}}$;

$\left\langle\sigma_{i}\right\rangle_{-}$- parte negativa da tensão principal $\sigma_{i}$.

A variável escalar de dano (D) obedece a uma lei de evolução que atende aos princípios da termodinâmica dos processos irreversíveis, de acordo com LEMAITRE;CHABOCHE (1985), e que é representada por: 


$$
\dot{D}=\left\{\begin{array}{c}
0, \text { se } f<0 \text { ou }(f=0 \text { e } \dot{f}<0) \\
F(\tilde{\varepsilon})\left(\dot{\tilde{\varepsilon}}_{+}\right), \text {se } f=0 \text { e } \dot{f}=0
\end{array}\right.
$$

onde: $F(\tilde{\varepsilon})$ - função positiva contínua determinada experimentalmente;

$$
(\cdot)=\frac{\partial()}{\partial \mathrm{t}} \text {, sendo t uma variável ordenadora do processo evolutivo. }
$$

\subsubsection{Dano sob solicitação uniaxial (com uma e duas variáveis)}

A função $F(\tilde{\varepsilon})$ deve respeitar o comportamento experimental do material, reproduzindo as curvas experimentais obtidas em ensaios uni, bi e triaxiais. No caso particular de uma prova uniaxial de tração na direção principal 1, tem-se:

$$
\tilde{\varepsilon}=\varepsilon_{1} \quad \text { e } \quad \dot{D}=F\left(\varepsilon_{1}\right) \cdot \varepsilon_{1}
$$

Supondo que o material esteja sujeito a uma solicitação monotonicamente crescente, o valor de $\mathrm{D}$ correspondente a um certo nível de deformação $\varepsilon_{\mathrm{M}}$ é:

$$
\mathrm{D}\left(\varepsilon_{\mathrm{M}}\right)=\int_{0}^{\varepsilon_{M}} F\left(\varepsilon_{1}\right) \cdot \mathrm{d} \varepsilon_{1}
$$

A evolução da microfissuração do concreto se dá de modo diferenciado, de acordo com o tipo de esforço, como pode ser observado na Figura 3.21. Na tração, as microfissuras se desenvolvem perpendicularmente à direção do esforço, enquanto na compressão esse desenvolvimento é paralelo ao esforço.
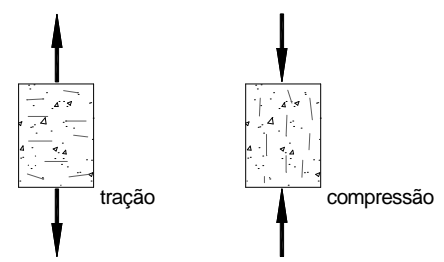

Figura 3.21 - Microfissuração: tração e compressão

Com o objetivo de descrever com mais exatidão esse aspecto diferenciado, foram definidas duas variáveis escalares, $D_{T}$ e $D_{C}$, no modelo isótropo. Tais variáveis são representativas, respectivamente, do dano na tração e na compressão, e possuem leis de evolução independentes.

$$
\dot{\mathrm{D}}_{\mathrm{T}}=\mathrm{F}_{\mathrm{T}}(\tilde{\varepsilon})\langle\dot{\tilde{\varepsilon}}\rangle_{+} \quad \text { (para a tração) }
$$




$$
\left.\dot{\mathrm{D}}_{\mathrm{C}}=\mathrm{F}_{\mathrm{C}}(\tilde{\varepsilon}) / \dot{\tilde{\varepsilon}}\right\rangle_{+} \quad \text { (para a compressão) }
$$

\subsubsection{Dano sob solicitação pluriaxial (com duas variáveis)}

Para analisar estados de tensões compostos, como tração e compressão em ação simultânea, Mazars propõe a decomposição da variável dano em duas parcelas escalares, $D_{T}$ e $D_{C}$, relativas respectivamente às parcelas de tração e de compressão. A composição das duas parcelas obedece àseguinte lei linear:

$$
\mathrm{D}=\alpha_{\mathrm{T}} \mathrm{D}_{\mathrm{T}}+\alpha_{\mathrm{C}} \mathrm{D}_{\mathrm{C}}
$$

onde: $\quad \alpha_{T}+\alpha_{C}=1, \quad \alpha_{T} \geq 0, \quad \alpha_{C} \geq 0$.

Os coeficientes da combinação linear, $\alpha_{T}$ e $\alpha_{C}$ variam entre 0 e 1 , e satisfazem æ̀s condições:

- tração uniaxial pura:

$$
\begin{aligned}
& \alpha_{T}=1 \quad \alpha_{C}=0 \Rightarrow D=D_{T} \\
& \alpha_{T}=0 \quad \alpha_{C}=1 \Rightarrow D=D_{C} \\
& \alpha_{T}+\alpha_{C}=1
\end{aligned}
$$

- compressão uniaxial pura:

- esforço genérico:

A obtenção dos coeficientes $\alpha_{T}$ e $\alpha_{C}$ requer a introdução de conceitos essenciais de particionamento de tensores. Uma deformação principal pode ser convenientemente separada em duas componentes $\varepsilon_{\mathrm{Ti}}$ e $\varepsilon_{\mathrm{Ci}}: \varepsilon_{\mathrm{i}}=\varepsilon_{\mathrm{Ti}}+\varepsilon_{\mathrm{Ci}}$.

Mazars propôs a seguinte separação do tensor de deformações principais:

$$
\begin{aligned}
& \left\{\varepsilon_{T}\right\}=\frac{1+v}{E_{c}}\langle\{\sigma\}\rangle_{+}-\frac{v}{E_{c}}\left\langle\sum_{i} \sigma_{i}\right\rangle_{+}[l] \\
& \left\{\varepsilon_{C}\right\}=\frac{1+v}{E_{c}}\langle\{\sigma\}\rangle_{-}-\frac{v}{E_{c}}\left\langle\sum_{i} \sigma_{i}\right\rangle_{-}[l]
\end{aligned}
$$

onde: $\{\sigma\}=\langle\{\sigma\}\rangle_{+}+\langle\{\sigma\}\rangle_{-}$;

$\operatorname{com}\left\langle\sigma_{i}\right\rangle_{+}=\frac{1}{2}\left(\sigma_{i}+\left|\sigma_{i}\right|\right) \quad$ e $\quad\left\langle\sigma_{i}\right\rangle_{-}=\frac{1}{2}\left(\sigma_{i}-\left|\sigma_{i}\right|\right)$

$\{\sigma\}$ - tensor das tensões principais obtido diretamente $\{\sigma\}=\left[E_{c}\right]\{\varepsilon\}$;

[I] - tensor identidade;

$\mathrm{E}_{\mathrm{c}}$ - módulo de deformação longitudinal do material íntegro.

Os coeficientes finalmente podem ser escritos, de acordo com Mazars: 


$$
\alpha_{T}=\sum_{i} H_{i} \frac{\varepsilon_{T_{i}}\left(\varepsilon_{T i}+\varepsilon_{C i}\right)}{\tilde{\varepsilon}^{2}} \quad \text { e } \quad \alpha_{C}=\sum_{i} H_{i} \frac{\varepsilon_{C i}\left(\varepsilon_{T i}+\varepsilon_{C i}\right)}{\tilde{\varepsilon}^{2}}
$$

onde: $H_{i}\left(\varepsilon_{i}\right)=\left\{\begin{array}{lll}1 & \text { se } & \varepsilon_{i}=\varepsilon_{T i}+\varepsilon_{C i}>0 \\ 0 & \text { se } & \varepsilon_{i}=\varepsilon_{T i}+\varepsilon_{C i}>0\end{array}\right.$ - função degrau de Heaviside.

PEREGO (1989), entretanto, propôs que os coeficientes fossem escritos de forma que somente os alongamentos (componentes positivas de $\varepsilon_{T}$ e $\varepsilon_{C}$ ) contribuíssem para a avaliação do dano, respeitando assim a hipótese que relaciona o surgimento e crescimento do dano em função das tensões de tração:

$$
\alpha_{T}=\alpha_{T}\left(\left\langle\varepsilon_{T}\right\rangle_{+}\right) \quad \text { e } \quad \alpha_{C}=\alpha_{C}\left(\left\langle\varepsilon_{C}\right\rangle_{+}\right)
$$

Os tensores de deformação sofrem a seguinte partição:

$$
\left\{\varepsilon_{\mathrm{T}}\right\}=\left\langle\left\{\varepsilon_{\mathrm{T}}\right\}\right\rangle_{+}+\left\langle\left\{\varepsilon_{\mathrm{T}}\right\}\right\rangle_{-} \quad \text { e } \quad\left\{\varepsilon_{\mathrm{C}}\right\}=\left\langle\left\{\varepsilon_{\mathrm{C}}\right\}\right\rangle_{+}+\left\langle\left\{\varepsilon_{\mathrm{C}}\right\}\right\rangle_{-}
$$

E os coeficientes são escritos da seguinte forma:

$$
\alpha_{T}=\frac{\sum_{i}\left\langle\varepsilon_{\mathrm{Ti}_{\mathrm{i}}}\right\rangle_{+}}{\varepsilon_{\mathrm{V}}^{+}} \quad \text { e } \quad \alpha_{\mathrm{C}}=\frac{\sum_{\mathrm{i}}\left\langle\varepsilon_{\mathrm{Ci}}\right\rangle_{+}}{\varepsilon_{\mathrm{V}}^{+}}
$$

onde: $\sum_{\mathrm{i}}\left\langle\varepsilon_{\mathrm{Ti}}\right\rangle_{+}+\left\langle\varepsilon_{\mathrm{Ci}}\right\rangle_{+}$- variável cinemática repr. do estado local de extensão.

A lei que governa a evolução do dano é análoga àquela com uma variável:

$$
\begin{array}{ll}
\dot{\mathrm{D}}_{\mathrm{T}}=\mathrm{F}_{\mathrm{T}}(\tilde{\varepsilon})\langle\dot{\tilde{\varepsilon}}\rangle_{+} & \text {(para tração) } \\
\dot{\mathrm{D}}_{\mathrm{C}}=\mathrm{F}_{\mathrm{C}}(\tilde{\varepsilon})\langle\dot{\tilde{\varepsilon}}\rangle_{-} & \text {(para compressão) }
\end{array}
$$

As expressões para as variáveis representativas do dano, $D_{T}$ e $D_{C}$, são estabelecidas a partir de resultados experimentais de tração e compressão uniaxiais de modo a reproduzir, com suficiente precisão, os andamentos das curvas experimentais respectivas e, em particular, os seus ramos de amolecimento. $O$ aspecto das relações constitutivas está ilustrado na Figura 3.22.

$$
\begin{aligned}
& D_{T}=1-\frac{\varepsilon_{d 0}\left(1-A_{T}\right)}{\tilde{\varepsilon}}-\frac{A_{T}}{\exp \left[B_{T}\left(\tilde{\varepsilon}-\varepsilon_{d 0}\right)\right]} \\
& D_{C}=1-\frac{\varepsilon_{d 0}\left(1-A_{C}\right)}{\tilde{\varepsilon}}-\frac{A_{C}}{\exp \left[B_{C}\left(\tilde{\varepsilon}-\varepsilon_{d 0}\right)\right]}
\end{aligned}
$$


onde: $A_{T}, B_{T}, A_{C}, B_{C}$ e $\varepsilon_{d 0}$ - parâmetros característicos do material obtidos experimentalmente.

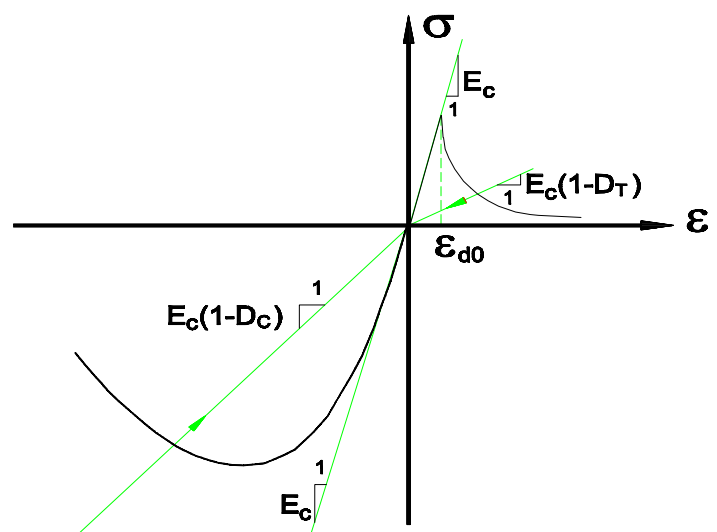

Figura 3.22 - Leis constitutivas para o dano uniaxial de Mazars

\subsection{Aplicação ao 'material' concreto armado}

A aplicação de relações elastoplásticas à representação do comportamento mecânico do material híbrido concreto armado só pode ser efetuada no espaço dos momentos fletores e das curvaturas. O comportamento conjunto de ambos os materiais constituintes (aço e concreto) deve obedecer a um modelo constitutivo único elaborado com base nas características mecânicas dos dois materiais, e na geometria da seção transversal. Esses modelos são, em geral, mais simples, pois contemplam uma única relação constitutiva.

São vários os modelos destinados à representação do concreto armado na flexão, como o proposto por GHALI;FAVRE (1986), DEBERNARDI $(1983,1989)$, CEB-FIP MC90, CORRÊA (1991), e o modelo empírico de BRANSON (1966).

Para a análise de deslocamentos de vigas de concreto armado, e a consideração da colaboração do concreto entre fissuras através da adoção de um momento de inércia efetivo ( $\left.\mathrm{I}_{\mathrm{e}}\right)$ constante em todo o vão (ou elemento), Branson propõe a seguinte formulação, baseada em resultados experimentais:

$$
\mathrm{I}_{e}=\left(\frac{M_{r}}{M}\right)^{m} I_{I}+\left[1-\left(\frac{M_{r}}{M}\right)^{m}\right] \cdot I_{\|} \quad \text { para }\left(M \geq M_{r}\right)
$$

onde: $\mathrm{I}_{\mathrm{e}}$ - momento de inércia efetivo;

$I_{1}$ - momento de inércia da seção no estádio I;

$I_{\|}$- momento de inércia da seção ideal no estádio II, em relação ao seu CG;

$M_{r}$ - momento de fissuração da seção; 


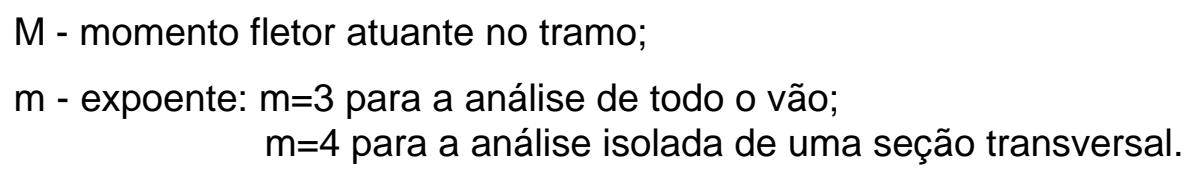

A expressão 3.64 é uma interpolação entre os momentos de inércia dos estádios I e II (Figura 3.23). Apesar de ter sido inicialmente aplicada aos elementos lineares fletidos, essa expressão teve, a posteriori, o emprego estendido às lajes.

No início da década de 1980, Debernardi apresenta um modelo rigoroso para análise de seções de concreto armado submetidas àflexo-compressão. Esse modelo, às vezes considerado como o mais rigoroso dentre os formulados no espaço momento-curvatura, considera os efeitos conjuntos da fissuração, fluência, retração, enrijecimento à tração, além de ser aplicável a seções transversais de formato qualquer. Ao contrário dos métodos apresentados por Branson e por Ghali e Favre, esse modelo não emprega a interpolação entre os valores das curvaturas obtidas para os estádios I e II. Debernardi utiliza a interpolação no cálculo da deformação média da armadura tracionada. O concreto também apresenta uma lei constitutiva linear, e escrita em função do tempo.

$$
\begin{aligned}
& \varepsilon_{\mathrm{sm}}=\frac{\sigma_{\mathrm{s} 2}}{\mathrm{E}_{\mathrm{s}}}-\beta_{1} \cdot \beta_{2} \cdot\left(\frac{\sigma_{\mathrm{sr}}}{\mathrm{E}_{\mathrm{s}}}-\varepsilon_{\mathrm{s} 1 \mathrm{r}}\right) \cdot \frac{\sigma_{\mathrm{sr}}}{\sigma_{\mathrm{s} 2}} \\
& \varepsilon_{\mathrm{c}\left(\mathrm{t}, \mathrm{t}_{0}\right)}=\sigma_{\mathrm{c}}\left(\mathrm{t}_{0}\right) \cdot \phi_{\left(\mathrm{t}, \mathrm{t}_{0}\right)}+\int_{\mathrm{t}_{0}}^{\mathrm{t}} \phi_{(\mathrm{t}, \tau)} \cdot d \sigma_{\mathrm{c}}\left(\mathrm{t}, \mathrm{t}_{0}\right)+\varepsilon_{\mathrm{cs}}\left(\mathrm{t}, \mathrm{t}_{0}\right)
\end{aligned}
$$

onde: $E_{s}$ - módulo de deformação longitudinal do aço;

$\varepsilon_{\mathrm{sm}}$ - deformação média da armadura tracionada;

$\varepsilon_{\text {s1r }}$ - deformação da armadura imediatamente antes da fissuração, devido à ação do momento de fissuração;

$\varepsilon_{\mathrm{cs}}$ - deformação específica do concreto por retração;

$\sigma_{\mathrm{s} 2}$ - tensão na armadura na seção da fissura após a fissuração (estádio II);

$\sigma_{\mathrm{sr}}$ - tensão na armadura devido ao momento de fissuração;

$\phi\left(t, t_{0}\right)$ - coeficiente de envelhecimento (GHALI;FAVRE (1986));

$\beta_{1}$ - coeficiente que depende das condições de aderência:

$\beta_{1}=1,0$ para barras de alta aderência $\left(\eta_{b} \geq 1,5\right)$;

$\beta_{1}=0,5$ para barras lisas $\left(\eta_{b}=1,0\right)$.

$\beta_{2}$ - coeficiente que depende das condições de carregamento:

$\beta_{2}=0,8$ para primeiro carregamento, ou cargas pouco repetitivas;

$\beta_{2}=0,5$ para carregamentos permanentes, ou com grande número de ciclos; 
$\eta_{\mathrm{b}} \quad$ - coeficiente de conformação superficial das barras da armadura.

A partir dos modelos constitutivos dos materiais, Debernardi estabelece as equações de equilíbrio (em regime elástico-linear) para a seção transversal não fissurada e fissurada, como está amplamente discutido nos trabalhos de MACHADO(1989) e SANCHES(1998). O aspecto do diagrama momento-curvatura para Debernardi é semelhante ao apresentado por Ghali e Favre (Figura 3.23).

GHALI;FAVRE (1986) propõem uma formulação mais simples, baseada na configuração média entre os estádios I e II, assim como na proposta apresentada por Branson. Considerando um elemento de viga submetido à flexão simples, a primeira fissura deverá surgir assim que o momento fletor atuante atinja o momento de fissuração $\left(M_{r}\right)$ :

$$
M_{r}=\frac{f_{t} \cdot I_{l}}{\left(h-x_{l}\right)}(\text { CEB }- \text { FIP MC90) }
$$

onde: $x_{1}$ - profundidade da linha neutra no estádio I.

Para um momento fletor $M>M_{r}$, a deformação na armadura tracionada, devido ao efeito do enrijecimento àtração, assume um valor médio $\left(\varepsilon_{\mathrm{sm}}\right)$. Esse valor médio pode ser descrito, ponderadamente, pelas deformações supondo o elemento de viga entre os estádios I $\left(\varepsilon_{\mathrm{s} 1}\right)$ e II $\left(\varepsilon_{\mathrm{s} 2}\right)$ :

$$
\varepsilon_{\mathrm{sm}}=(1-\zeta) \cdot \varepsilon_{\mathrm{s} 1}+\zeta \varepsilon_{\mathrm{s} 2}
$$

onde: $\zeta=1-\beta_{1} \cdot \beta_{2} \cdot\left(\frac{\sigma_{\mathrm{sr}}}{\sigma_{\mathrm{s} 2}}\right)^{2}=1-\beta_{1} \cdot \beta_{2} \cdot\left(\frac{\mathrm{M}_{\mathrm{r}}}{\mathrm{M}}\right)^{2}$ - ponderador;

$\beta_{1}$ e $\beta_{2}$ - coeficientes com as mesmas definições do modelo de Debernardi.

Assumindo as hipóteses de seções planas antes e após as deformações, e proporcionalidade entre tensões e deformações (lei de Hooke), da mesma forma, os autores propõem que a curvatura média seja função das curvaturas do estádio I

$$
\begin{aligned}
& \left(\frac{1}{r}\right)_{I} \text { e II }\left(\frac{1}{r}\right)_{I I} \text { puros: } \\
& \qquad\left(\frac{1}{r}\right)_{m}=(1-\zeta) \cdot\left(\frac{1}{r}\right)_{I}+\zeta \cdot\left(\frac{1}{r}\right)_{\|}
\end{aligned}
$$

A formulação proposta por Ghali e Favre, assim como a de Debernardi, pode ainda incorporar os efeitos do tempo. Uma ilustração do diagrama de 
momento fletor por curvatura para a formulação de Ghali e Favre está apresentada na Figura 3.23.

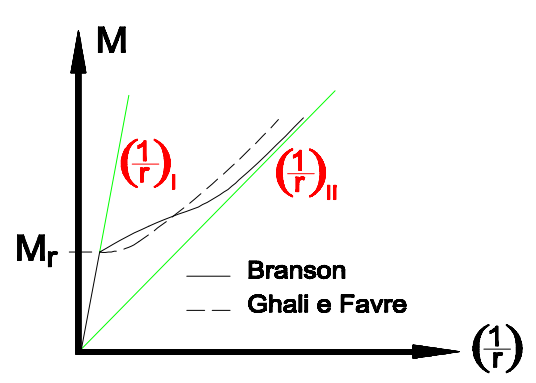

Figura 3.23 - Diagramas momento-curvatura segundo Branson e Ghali \& Favre

O CEB-FIP MC90 apresenta um diagrama momento-curvatura um pouco mais simplificado, considerando três estágios lineares de comportamento para as seções de concreto armado. O primeiro estágio configura o comportamento em regime elástico-linear, até que se atinja o momento de fissuração minorado $\left(\sqrt{\beta_{\mathrm{b}}} \cdot \mathrm{M}_{\mathrm{r}}\right)$ no final do estádio I. O segundo estágio exprime o comportamento da seção transversal até o seu escoamento, no final do estádio II $\left(\mathrm{M}_{\mathrm{y}}\right)$. Finalmente, o terceiro e último estágio configura, no seu final, a capacidade última da seção transversal $\left(\mathrm{M}_{\mathrm{u}}\right)$, com a diferença de que a sua inclinação $\left(\mathrm{k}_{\mathrm{III}}\right)$ assume o dobro do valor calculado, conforme ilustrado na Figura 3.24.

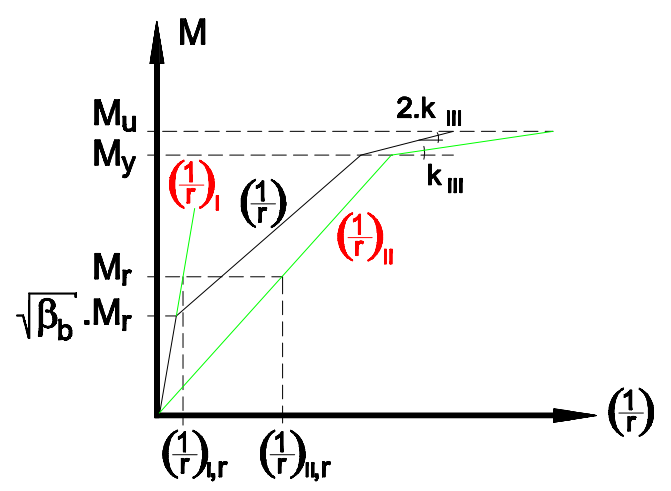

Figura 3.24 - Diagrama momento-curvatura segundo o CEB-FIP MC90

O momento de fissuração é calculado, através da expressão 3.67 , considerando-se a seção homogeneizada. $O$ coeficiente $\sqrt{\beta_{\mathrm{b}}}$ é tomado pela desigualdade $\beta_{b} \geq \beta_{1} \cdot \beta_{2}$, com $\beta_{1}$ e $\beta_{2}$ definidos anteriormente.

O momento de escoamento da seção transversal é de difícil definição, tanto que o CEB-FIP evita fazê-la. No entanto, CORRÊA (1991) propõe que o escoamento da seção transversal ocorra concomitantemente ao escoamento da 
armadura tracionada, desprezando-se a contribuição do concreto tracionado, e admitindo proporcionalidade entre tensões e deformações. Posteriormente, OLIVEIRA (1997) aplica a definição de Corrêa, e propõe uma distinção no cálculo de $M_{y}$ que pode ocorrer pelo escoamento da armadura tracionada, ou pelo esmagamento da fibra de concreto mais comprimida.

O valor do momento último é bem definido, e de modo análogo tanto pelo CEB-FIP MC90 como pela NBR-6118 (item 4.1.1). A sua determinação obedece a uma das três hipóteses: a) fibra de concreto mais comprimida sujeita àdeformação de $0,35 \%$, com deformação da armadura de tração sob valores inferiores a 1,00\% e superiores à deformação de escoamento; b) armadura tracionada com deformação de 1,00\%, com deformação da fibra de concreto mais comprimida entre os valores de 0,20\% e 0,35\%; c) armadura de tração com deformação igual a $1,0 \%$ sem que, no entanto, a fibra de concreto mais comprimida atinja o valor de $0,20 \%$. Nos dois primeiros casos considera-se o diagrama retangular de tensões em substituição ao parábola-retângulo, como permite a NBR-6118 no item 4.1.1.1, e no terceiro caso, adota-se diagrama linear de tensões no concreto comprimido.

De modo semelhante ao CEB-FIP MC90, Corrêa propõe um diagrama trilinear na análise não-linear de lajes de concreto armado. O modelo apresentado por Corrêa apresenta duas diferenças básicas com relação ao do CEB-FIP: o momento de fissuração não sofre qualquer tipo de minoração, e o terceiro trecho do diagrama não é majorado pelo fator multiplicativo 2 (Figura 3.12).

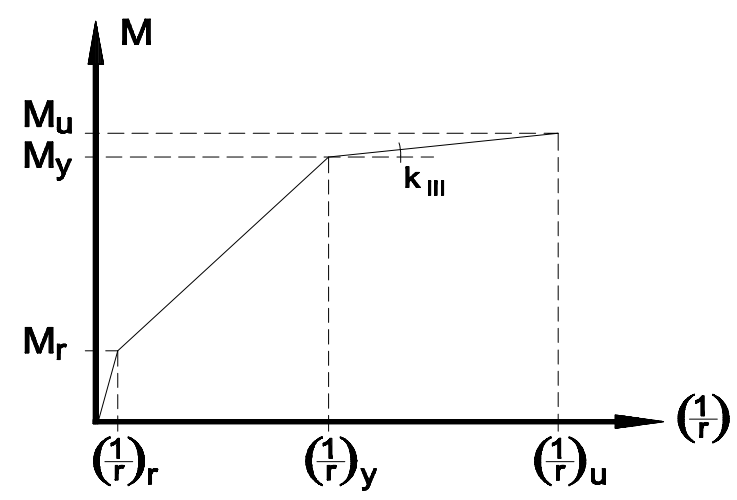

Figura 3.25 - Diagrama momento-curvatura segundo CORREA (1991)

O modelo proposto por Corrêa, e mais tarde também implementado por Oliveira, apresenta resultados bastante representativos do comportamento mecânico dos elementos de viga e de laje até o escoamento das armaduras. Atingido esse valor, o modelo passa a impor rigidez inferior à observada experimentalmente. 


\subsection{Modelo para a aderência entre o aço e o concreto}

\subsubsection{Introdução}

Em geral, os modelos físicos destinados àrepresentação das vigas e pilares admitem, implicitamente, uma perfeita interação entre as barras de aço e as porções de concreto que as envolvem. Para as solicitações, no entanto, esse comportamento perfeitamente solidário não se confirma, o que na prática propicia o surgimento de deslocamentos longitudinais relativos entre as barras da armadura e o concreto. No âmbito da engenharia, na aplicação a projetos de estruturas, o fenômeno da aderência é fundamental para o estudo do comprimento de ancoragem de barras tracionadas e comprimidas, e na determinação de emendas de barras de aço por traspasse. Na modelagem estrutural, através do método dos elementos finitos, a incorporação da aderência em conjunto com modelos constitutivos específicos para o concreto e o aço assume grande importância no estudo do enrijecimento à tração (tension-stiffening), e na avaliação do estado de fissuração de elementos estruturais.

De acordo com ELIGEHAUSEN;BALÁZS (1991), são vários os fatores que podem influenciar o comportamento do par tensão de aderência por escorregamento de barras de aço imersas em concreto: a conformação superficial das barras, a resistência do concreto, o cobrimento de concreto sobre a barra e a sua posição dentro do elemento estrutural e, finalmente, um fator externo, ligado à intensidade e ao tipo de carregamento (estático ou cíclico) ao qual esteja submetido o elemento estrutural. A identificação de vários desses fatores teve início na década de 1910, juntamente com as primeiras tentativas de se estabelecerem correlações entre a tensão de aderência e o escorregamento relativo das barras. ABRAMS (1913) ${ }^{11}$ apud ALLWOOD,BAJARWAN (1996), utilizando-se de ensaios de arrancamento de barras de aço isoladas imersas em blocos de concreto, estuda a aderência de barras lisas e de barras corrugadas.

\section{Em estudos posteriores, GLANVILLE (1930) ${ }^{12}$ apud ALLWOOD;} BAJARWAN (1996), pôde demonstrar a importância de um efeito até então não quantificado no estudo da aderência. Através da realização de ensaios de

\footnotetext{
${ }^{11}$ ABRAMS,D.A.(1913). Test of bond between concrete and steel. University of Illinois Bulletin, v.11, n.15, paper 71, 238p. apud ALLWOOD,R.J.;BAJARWAN,A.A.(1996).

${ }^{12}$ GLANVILLE,W.H.(1930). Studies in reinforced concrete-bond resistance. Building Research Technical Paper, n.10. apud ALLWOOD,R.J.;BAJARWAN,A.A.(1996).
} 
arrancamento à tração (pullout), e de arrancamento à compressão (pushout) em corpos de prova semelhantes, pôde-se verificar que a tensão de aderência mobilizada no ensaio de arrancamento à compressão é superior àquela do ensaio de tração, devido ao efeito de Poisson. A tensão de compressão longitudinal sobre a barra de aço provoca uma tendência de acréscimo no seu diâmetro, o que eleva sobremaneira a tensão radial e, por conseguinte, a força de atrito entre a barra e o concreto que a envolve. Com isso, pode ser demonstrado que o confinamento promovido pelo cobrimento de concreto, e também pela presença de armadura transversal contribui favoravelmente para o aumento da aderência. Esses estudos iniciais constituíram a base para o entendimento do fenômeno da aderência, responsável pelo equilíbrio de forças ilustrado na Figura 3.26 para uma porção de concreto $(\delta x)$ que compõe um tirante de concreto armado.

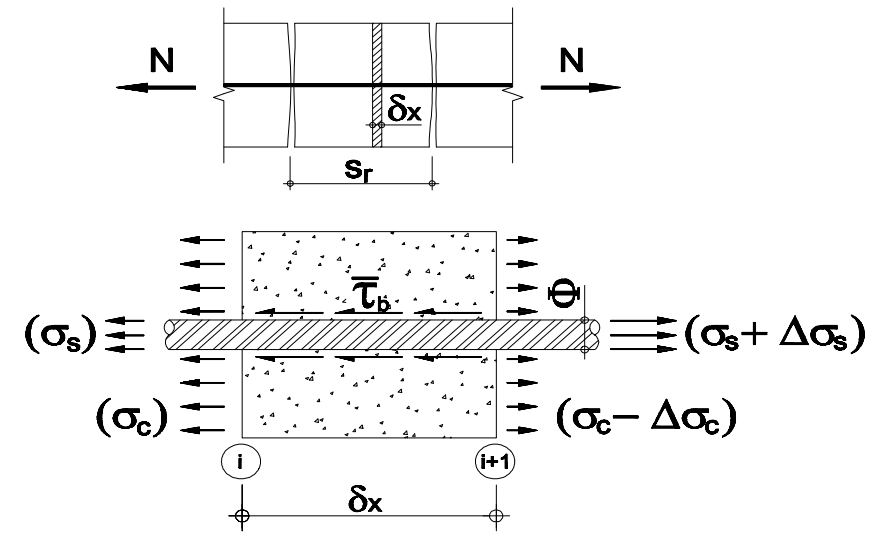

Figura 3.26 - Tensões em uma porção de concreto armado tracionado

Estabelecendo, respectivamente, o equilíbrio de forças na direção longitudinal da barra de aço submetida à tensão de aderência média $\left(\bar{\tau}_{\mathrm{b}}\right)$, e 0 equilíbrio da porção de concreto, conclui-se:

$$
\begin{aligned}
& \Delta \sigma_{\mathrm{s}}=\frac{4}{\Phi} \cdot \bar{\tau}_{\mathrm{b}} \cdot \delta \mathrm{x} \\
& \Delta \sigma_{\mathrm{c}}=\Delta \sigma_{\mathrm{s}} \cdot\left(\frac{\mathrm{A}_{\mathrm{s}}}{\mathrm{A}_{\mathrm{c}}}\right)
\end{aligned}
$$

onde: $\Delta \sigma_{\mathrm{s}}$ - parcela de tensão normal da barra de aço transmitida ao concreto por aderência;

$\Phi$ - diâmetro da barra da armadura longitudinal;

$\Delta \sigma_{c}$ - diferença entre as tensões normais no concreto nas duas seções;

$A_{c}$ - área da seção transversal geométrica de concreto;

$\mathrm{A}_{\mathrm{s}}$ - área da seção transversal da armadura longitudinal tracionada. 
A partir desses estudos iniciais, cujo objetivo único era o de estabelecer a tensão de aderência média na ruptura da ligação entre o aço e o concreto, o enfoque das pesquisas volta-se para a descrição do comportamento das variáveis tensão de aderência e escorregamento no domínio da barra. BRESLER;BERTERO $(1966)^{13}$ apud MIRZA;HOUDE (1979) foram os pioneiros na tentativa de descrição do comportamento do par tensão de aderência por escorregamento de uma barra de aço imersa em concreto. No ano seguinte, no entanto, NGO;SCORDELIS (1967) apresentam a primeira abordagem do fenômeno da aderência através de um método numérico. Os autores incorporam a rigidez da conexão entre os dois materiais através do emprego de molas discretas conectando o aço e o concreto em nós de uma malha de elementos finitos. Molas paralelas ao eixo da barra simulariam a rigidez ao escorregamento, enquanto molas perpendiculares ao eixo da barra modelariam o efeito Poisson. Segundo autores como ALLWOOD; BAJARWAN (1996), essa técnica requer um grande incremento do número de graus de liberdade ( $g d l)$ envolvidos na análise, o que a torna demasiadamente custosa, principalmente quando empregada uma relação constitutiva não-linear para o par tensão de aderência por escorregamento.

Seguindo a linha de raciocínio de Bresler e Bertero, mas com o intuito de apresentar valores para as constantes de mola longitudinal do modelo de $\mathrm{Ngo}$ e Scordelis, NILSON (1968) propõe uma relação cúbica entre tensão de aderência e o escorregamento (3.72). No final da década de 1970, em outro trabalho de destaque, MIRZA;HOUDE (1979) propõem uma correlação de grau 4 entre a tensão de aderência e o escorregamento relativo (3.73).

$$
\begin{aligned}
& \tau_{b}=3,606 \times 10^{6} \cdot s-5,356 \times 10^{9} \cdot s^{2}+1,986 \times 10^{12} \cdot s^{3} \quad(p s i) \\
& \tau_{b}=1,95 \times 10^{6} \cdot s-2,35 \times 10^{9} \cdot s^{2}+1,39 \times 10^{12} \cdot s^{3}-0,33 \times 10^{15} \cdot s^{4} \quad(p s i)
\end{aligned}
$$

onde: s - escorregamento relativo ("s" do inglês slip) em polegadas.

Ambos os trabalhos apresentam uma aproximação para a função de mola longitudinal não-linear, obtida diretamente através da derivada das expressões 3.72 ou 3.73 com relação a $s\left(\frac{d \tau_{b}}{d s}\right)$. Os aspectos dessas curvas podem ser observados na Figura 3.29 para um valor de $\tau_{\mathrm{b}, \max }$ unitário.

\footnotetext{
13 BRESLER,B.;BERTERO,V.(1966). Reinforced concrete prism under repeated load. In: RILEM Symposium on the effects of repeated loading on materials and structural elements, Mexico. Proceedings. apud MIRZA,S.M.;HOUDE,J.(1979).
} 
O escorregamento relativo (s) é uma grandeza vetorial cujo módulo pode ser mensurado a partir de sua própria definição como a diferença entre as deformações longitudinais de tração no aço $\left(\varepsilon_{\mathrm{s}}\right)$ e no concreto $\left(\varepsilon_{\mathrm{ct}}\right)$ naquele ponto:

$$
\frac{\mathrm{ds}}{\mathrm{dx}}=\varepsilon_{\mathrm{s}}-\varepsilon_{\mathrm{ct}}
$$

onde: $\frac{\mathrm{ds}}{\mathrm{dx}}$ - variação do escorregamento relativo na fissura com relação ao eixo $\mathrm{x}$; $\varepsilon_{\mathrm{s}}$ - deformação específica da barra de aço tracionada;

$\varepsilon_{\mathrm{ct}}$ - deformação específica do concreto à tração, na altura do centro de gravidade $(\mathrm{cg})$ da barra de aço.

Desse modo, o escorregamento segue uma função variável, dependente da diferença entre as deformações do aço e do concreto a cada ponto $\mathrm{x}$ do domínio do elemento. Para a porção infinitesimal $(\delta x)$ pode ser definido o escorregamento relativo aproximado, através do método das diferenças finitas:

$$
\delta s=\left(\bar{\varepsilon}_{\mathrm{s}}-\bar{\varepsilon}_{\mathrm{ct}}\right) \cdot \delta \mathrm{x}
$$

A completa descrição física do fenômeno da aderência exige, não só o relacionamento entre a tensão de aderência $\left(\tau_{b}\right)$ e o escorregamento (s) mas, antes de tudo, uma representação consistente da função escorregamento ao longo do domínio da barra tracionada imersa no concreto. O conhecimento desses dois comportamentos ao longo de toda a extensão de um elemento finito linear, aliado à imposição de condições de contorno, geralmente nas seções fissuradas, possibilita a completa descrição do fenômeno. Essa descrição deve contemplar os aspectos inerentes ao fenômeno, quais sejam: forte variação das tensões normais e de aderência nas barras de aço e no concreto, como ilustrado na Figura 3.27.

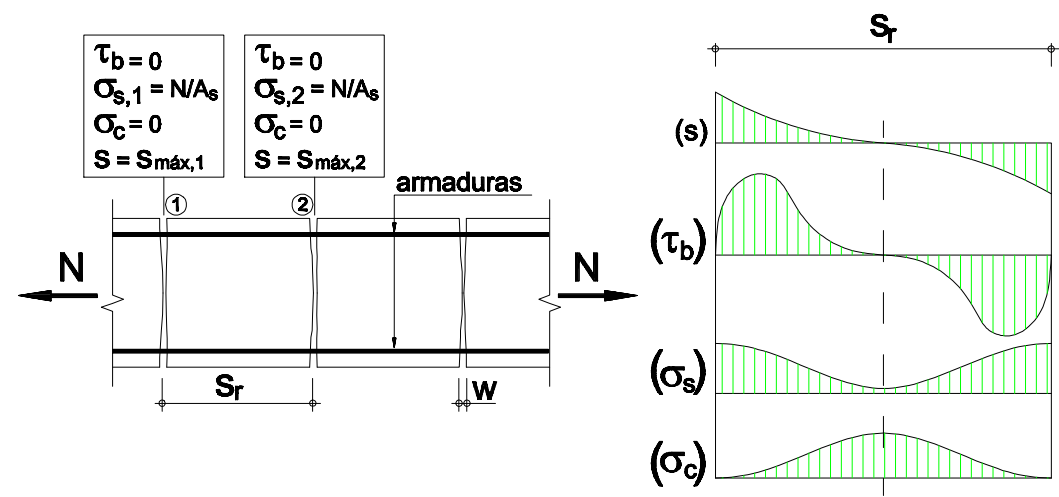

Figura 3.27 - Distribuição esquemática do escorregamento relativo e das tensões em elemento tracionado fissurado (TASSIOS; YANNOPOULOS (1981)) 
Com o objetivo de quantificar, através de um método numérico, a influência da aderência em ensaios de arrancamento e no comportamento mecânico de tirantes submetidos a carregamentos cíclicos, TASSIOS;YANNOPOULOS (1981) propõem um modelo eficiente para a determinação da distribuição do escorregamento relativo e das tensões de aderência, além das tensões normais nas barras de aço e no concreto. O espaçamento entre fissuras $\left(S_{r}\right)$ é adotado previamente, e deve corresponder ao comprimento do elemento finito. Assumindo $\bar{\tau}$ uniformemente distribuído em cada subdomínio $\delta x_{l} / l=1, . ., n$, os valores de $\mathrm{s}, \tau_{\mathrm{b}}, \sigma_{\mathrm{s}}$, e $\sigma_{\mathrm{c}}$ na seção I+1 são determinados com base nos valores da seção I, aplicando-se o método das diferenças finitas às relações 3.75, 3.70 e 3.71, consecutivamente. Como partida, são impostas condições de contorno na primeira fissura (1), ilustradas na Figura 3.27 para o caso de um tirante fissurado. Ao final do procedimento, atingida a seção $n+1$, a convergência é checada com base no valor da tensão normal na armadura $\sigma_{\mathrm{s}, \mathrm{n}+1}$, comparativamente àtensão $\sigma_{\mathrm{s}, 2}$.

$$
\begin{aligned}
& \mathrm{s}_{\mathrm{l}+1}=\mathrm{s}_{\mathrm{l}}-\left(\varepsilon_{\mathrm{s}, \mathrm{l}+1}+\varepsilon_{\mathrm{s}, \mathrm{l}}\right) \cdot \frac{\delta \mathrm{x}_{\mathrm{l}}}{2}+\left(\varepsilon_{\mathrm{c}, \mathrm{l}+1}+\varepsilon_{\mathrm{c}, \mathrm{l}}\right) \cdot \frac{\delta \mathrm{x}_{\mathrm{l}}}{2} \\
& \sigma_{\mathrm{s}, \mathrm{l}+1}=\sigma_{\mathrm{s}, \mathrm{l}}-4 \cdot\left(\frac{\tau_{\mathrm{b}, \mathrm{l}}}{\Phi}\right) \cdot \delta \mathrm{x}_{\mathrm{l}} \\
& \sigma_{\mathrm{c}, \mathrm{l}+1}=\sigma_{\mathrm{c}, \mathrm{l}}-\left(\sigma_{\mathrm{s}, \mathrm{l}+1}-\sigma_{\mathrm{s}, \mathrm{l}}\right) \cdot\left(\frac{\mathrm{A}_{\mathrm{s}, \mathrm{I}}}{\mathrm{A}_{\mathrm{c}, \mathrm{l}}}\right)
\end{aligned}
$$

Uma forma original de se incorporarem os efeitos da fissuração e do enrijecimento à tração na análise de tirantes de concreto armado é proposta por SOMAYAJI;SHAH(1981). Com a argumentação de que a determinação experimental da relação entre a tensão de aderência e o escorregamento está bastante sujeita a erros, é proposta uma distribuição da tensão de aderência ao longo da barra sem a prévia adoção de uma função para o escorregamento, ou mesmo para o relacionamento entre tensão de aderência e o escorregamento.

$$
\tau_{b}(x)=A \cdot e^{x}+B \cdot e^{-x}+C
$$

Impondo condições de contorno na região das fissuras e no centro do elemento finito entre duas fissuras, determinam-se as constantes da expressão 3.79. Em seguida, através de um procedimento de subparticionamento do elemento, análogo ao empregado por Tassios e Yannopoulos, procede-se a análise de todo o elemento. Os autores colocam que a distância entre fissuras $\left(S_{r}\right)$, 
imposta previamente à análise, deve variar entre os limites de 1 e 2 vezes o comprimento de ancoragem reta da barra $\left(\mathrm{l}_{\mathrm{b}}\right)$, obtido através de um ensaio de arrancamento àtração. Os resultados numéricos para um ensaio de arrancamento mostram que a adoção do limite inferior ou superior para o espaçamento entre fissuras pode levar a uma redução de até $45 \%$ no escorregamento calculado.

Dando continuidade aos trabalhos de Nilson, e de Mirza;Houde, ELIGEHAUSEN;POPOV;BERTERO (1983) apresentam uma nova relação entre a tensão de aderência e o escorregamento que mais tarde seria incorporada ao texto base do CEB-FIP MC90. O modelo, apesar de ser considerado bastante confiável, ignora a parcela de aderência química entre o concreto e o aço, e também não faz distinção entre arrancamento por tração ou por compressão. A Figura 3.29 ilustra, além das outras duas relações constitutivas mencionadas neste trabalho, 0 diagrama genérico adotado pelo CEB-FIP MC90, variável de acordo com as condições de aderência e de confinamento da barra (Tabela 3.1).

Convém lembrar, entretanto, que o comportamento da aderência de uma barra está intimamente ligado à sua conformação superficial, pois a essa superfície está relacionado o modo de ruptura da ligação entre o aço e o concreto. Segundo JIANG;SHAH (1994), a aderência de uma barra de aço corrugada ao concreto que a envolve deve-se, na sua maior parte, à ação mecânica das nervuras da barra contra os pequenos consolos de concreto situados entre duas nervuras sucessivas. Ao sacar a barra da massa de concreto que a envolve, mobiliza-se um estado de fissuração semelhante ao ilustrado na Figura 3.28. No caso dos elementos estruturais essencialmente fletidos, como é o caso das vigas, são formadas inicialmente as fissuras primárias decorrentes da ação do momento fletor de fissuração. O contato das nervuras com o concreto, aliado às tensões de tração no concreto ao redor da barra, resultam em um estado inadmissível de tensão que provoca a ruptura do concreto e faz surgir fissuras secundárias.

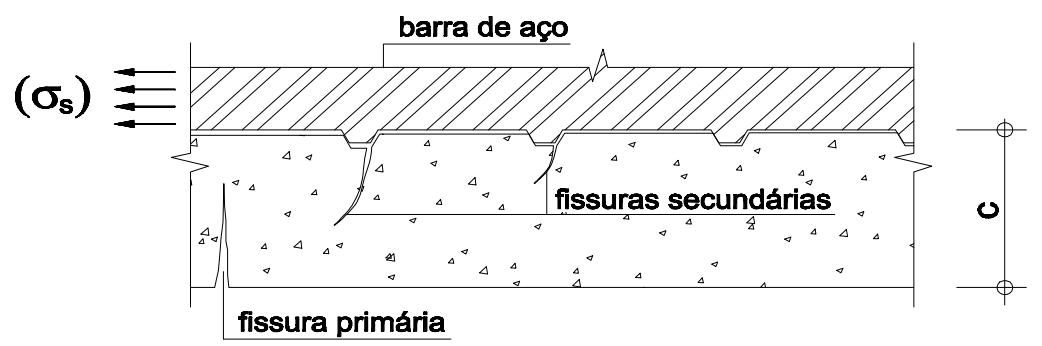

Figura 3.28 - Mobilização da aderência mecânica em barras corrugadas

A ruptura da aderência para as barras corrugadas pode ocorrer de dois modos distintos, de acordo com o confinamento do concreto que as envolve. $\mathrm{Na}$ 
hipótese de a barra estar imersa em concreto pouco confinado, a ruptura deverá ser por fendilhamento do concreto, como resultado da multiplicação e ampliação das fissuras secundárias. A primeira parte do diagrama da Figura 3.29 (trecho ascendente) corresponde ao estágio em que as nervuras da barra de aço estão penetrando no concreto adjacente, iniciando o processo de esmagamento e de fendilhamento desse concreto. Logo em seguida, o trecho descendente refere-se à redução da resistência à aderência devida ao estágio avançado de esmagamento, cisalhamento e fissuração do concreto entre nervuras consecutivas. O terceiro trecho (horizontal) representa a aderência residual.

Caso haja uma boa condição de confinamento, a ruptura deverá se dar exclusivamente pelo cisalhamento do concreto entre duas nervuras sucessivas. Neste caso, a curva apresenta um patamar de escorregamento, o que na prática corresponde ao esmagamento progressivo de todo o consolo de concreto. Os trechos descendente e horizontal são semelhantes ao caso do concreto não confinado, mas o valor residual se apresenta superior àquele caso.

As barras lisas apresentam ruptura de aderência pelo esgotamento da aderência química acrescida de uma pequena parcela de aderência mecânica, uma vez que não apresentam rugosidade relevante. O aspecto da curva tensão de aderência por escorregamento para esse tipo de barra é bastante próximo ao de barras corrugadas ancoradas em concreto não confinado, muito embora o valor de $\tau_{b, \max }$ seja bastante inferior. Não existe, no entanto, uma distinção clara entre a tensão máxima e a residual, o que torna a curva composta de um trecho ascendente, semelhante ao caso das barras corrugadas, seguido de um patamar de tensão de aderência residual constante.
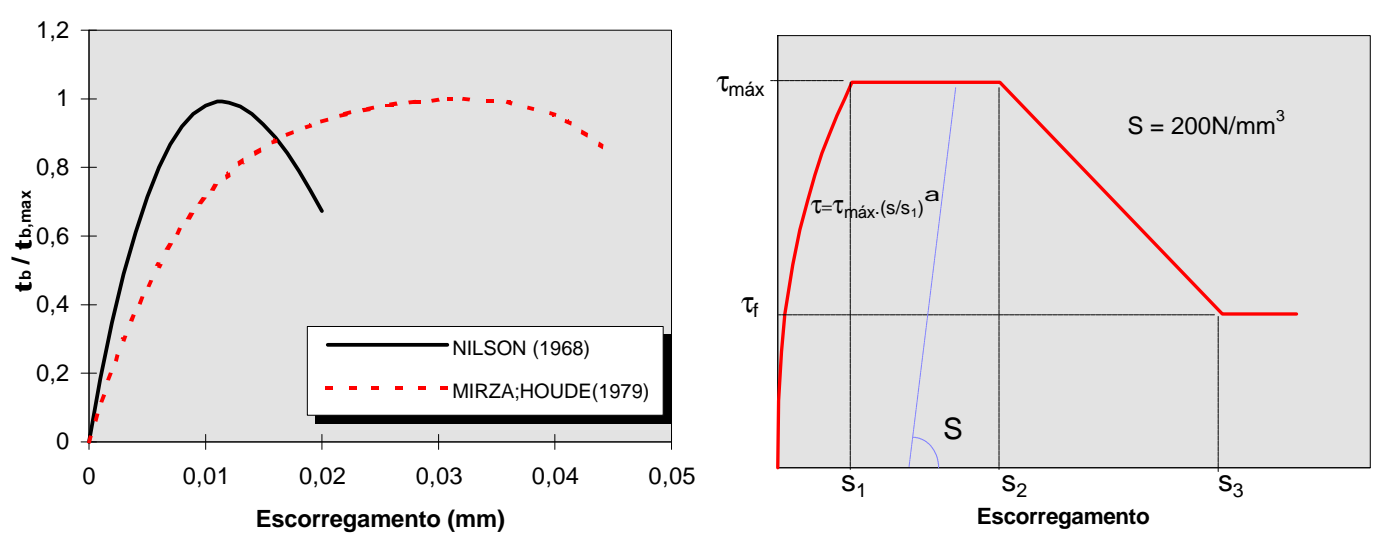

Figura 3.29 - Relações tensão de aderência $\left(\tau_{b}\right)$ por escorregamento (s)

onde: tensão de aderência normalizada $=\frac{\tau_{\mathrm{b}}}{\tau_{\mathrm{b}, \max }}$. 
Tabela 3.1 - Parâmetros de escorregamento do CEB-FIP MC90

\begin{tabular}{|c|c|c|c|c|c|c|c|c|}
\hline parâmetro & \multicolumn{4}{|c|}{ barras corrugadas } & \multirow{2}{*}{\multicolumn{2}{|c|}{$\begin{array}{c}\text { fios lisos } \\
\text { performados a } \\
\text { frio }\end{array}$}} & \multirow{2}{*}{\multicolumn{2}{|c|}{$\begin{array}{c}\text { barras lisas } \\
\text { performadas a } \\
\text { quente }\end{array}$}} \\
\hline & \multirow{2}{*}{\multicolumn{2}{|c|}{$\begin{array}{c}\text { concreto } \\
\text { não-confinado } \\
\begin{array}{c}\text { condição de } \\
\text { aderência }\end{array}\end{array}$}} & \multirow{2}{*}{\multicolumn{2}{|c|}{$\begin{array}{c}\text { concreto } \\
\text { confinado } \\
\text { condição de } \\
\text { aderência } \\
\end{array}$}} & & & & \\
\hline & & & & & $\begin{array}{l}\text { cono } \\
\text { ade }\end{array}$ & $\begin{array}{l}\text { o de } \\
\text { ncia }\end{array}$ & $\begin{array}{r}\text { cond } \\
\text { ade }\end{array}$ & $\begin{array}{l}\text { do de } \\
\text { ncia }\end{array}$ \\
\hline & boa & outras & boa & outras & boa & outras & boa & outras \\
\hline $\mathbf{s}_{1}$ & $0,6 \mathrm{~mm}$ & $0,6 \mathrm{~mm}$ & \multicolumn{2}{|c|}{$1,0 \mathrm{~mm}$} & \multicolumn{2}{|c|}{$0,01 \mathrm{~mm}$} & \multicolumn{2}{|c|}{$0,01 \mathrm{~mm}$} \\
\hline $\mathbf{S}_{2}$ & $0,6 \mathrm{~mm}$ & $0,6 \mathrm{~mm}$ & \multicolumn{2}{|c|}{$3,0 \mathrm{~mm}$} & \multicolumn{2}{|c|}{$0,01 \mathrm{~mm}$} & \multicolumn{2}{|c|}{$0,1 \mathrm{~mm}$} \\
\hline $\mathbf{S}_{3}$ & $1,0 \mathrm{~mm}$ & $2,5 \mathrm{~mm}$ & \multicolumn{2}{|c|}{ esp. entre mossas } & \multicolumn{2}{|c|}{$0,01 \mathrm{~mm}$} & \multicolumn{2}{|c|}{$0,1 \mathrm{~mm}$} \\
\hline$\alpha$ & \multicolumn{2}{|c|}{0,4} & \multicolumn{2}{|c|}{0,4} & \multicolumn{2}{|c|}{0,5} & \multicolumn{2}{|c|}{0,5} \\
\hline$\tau_{b, \text { máx }}$ & $2,0 \cdot \sqrt{f_{c k}}$ & $1,0 \cdot \sqrt{f_{c k}}$ & $2,5 \cdot \sqrt{f_{c k}}$ & $1,25 \cdot \sqrt{f_{c k}}$ & $0,1 \cdot \sqrt{f_{c k}}$ & $0,05 \cdot \sqrt{f_{c k}}$ & $0,3 \cdot \sqrt{f_{c k}}$ & $0,15 \cdot \sqrt{f_{c k}}$ \\
\hline$\tau_{f}$ & \multicolumn{2}{|c|}{$0,15 \cdot \tau_{\mathrm{b}, \text { máx }}$} & \multicolumn{2}{|c|}{$0,40 \cdot \tau_{b, \text { máx }}$} & $0,1 \cdot \sqrt{f_{c k}}$ & $0,05 \cdot \sqrt{f_{c k}}$ & $0,3 \cdot \sqrt{f_{c k}}$ & $0,15 \cdot \sqrt{f_{c k}}$ \\
\hline
\end{tabular}

Seguindo o raciocínio de SOMAYAJI;SHAH (1981), com o objetivo de desvincular a distribuição da tensão de aderência do escorregamento relativo, JIANG;SHAH (1994) propõem uma aproximação simples e, segundo os autores, suficientemente precisa para a formulação de elementos unidimensionais:

$$
\tau_{b}(x)=\tau_{b, \max } \cdot\left[1-\left(1-\frac{4 . x}{I_{b}}\right)^{2}\right]
$$

onde: $\quad \tau_{b}(x)$ - tensão de aderência em uma coordenada genérica $\left(0 \leq x \leq l_{b}\right)$;

$\tau_{b, \max }$ - tensão tangencial de referência (máxima) verificada a uma distância correspondente a $25 \%$ do comprimento de ancoragem $\mathrm{I}_{\mathrm{b}}$.

Apoiados na teoria de Mohr-Coulomb, ALLWOOD; BAJARWAN (1996) propõem um modelo no qual fundamentam a resistência de aderência em três fatores: adesão química, fricção e intertravamento mecânico dos agregados, de acordo com a expressão 3.81. Com isso, o valor da tensão de aderência máxima permanece vinculado ao nível de pressão radial $\left(p_{r}\right)$ sobre a barra de aço, como mostra a Figura 3.30.

$$
\tau_{\mathrm{b}}=\tau_{\mathrm{b}}^{0}+\mu \cdot \mathrm{p}_{\mathrm{r}}
$$

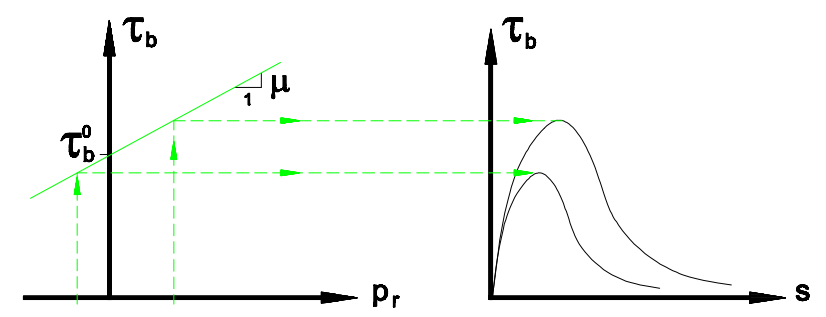

Figura 3.30 - Relação $\tau_{b}$ por s ligada à pressão radial (p) 
onde: $\tau_{\mathrm{b}}^{0}$ - tensão de aderência química;

$\mu$ - coeficiente de atrito entre a barra de aço e o concreto.

Os autores apresentam ainda uma nova abordagem do problema sob o enfoque do MEF, na qual substituem as molas longitudinais de Ngo e Scordelis por elementos de ligação (contato), enquanto as molas transversais são substituídas pelas intervenções no diagrama da Figura 3.30. De acordo com o modelo, empregado apenas para a análise numérica de ensaios de arrancamento, as matrizes de rigidez do concreto e do aço são obtidas separadamente. Os dois materiais são tratados isoladamente, supondo tensões de aderência distintas para o equilíbrio estático de cada um. Posteriormente, as duas soluções são forçadas a convergir, através de um método iterativo, para a solução que ajusta a tensão de aderência entre os dois materiais.

Dentro das possíveis abordagens do problema de escorregamento de armaduras, merece ainda destaque aquela em que o elemento finito, bi ou tridimensional, incorpora uma fibra de aço (ou de qualquer outro material diferente daquele que compõe o próprio elemento) implicitamente à formulação de sua rigidez. Um exemplo bastante representativo dessa classe de elemento finito devese a KWAK;FILIPPOU (1997), que incorpora uma barra de treliça ao elemento de chapa serendipity de oito nós (Figura 3.31). Os nós do elemento de barra não precisam necessariamente coincidir com os nós do elemento de chapa, nem tampouco apresentar compatibilidade de deslocamentos com o elemento em qualquer outro ponto além de seus nós. O comportamento do concreto, submetido a um estado biaxial de tensões, é regido pelas superfícies de plastificação e de ruptura descritas pelo critério de Kupfer. O modelo incorpora, ainda, conceitos da mecânica da fratura àhipótese de fissuras rotativas.

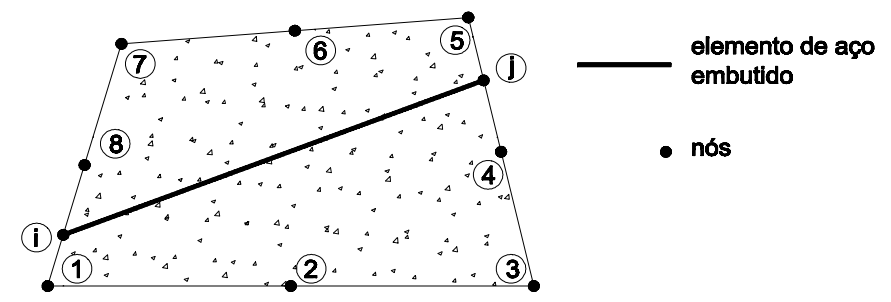

Figura 3.31 - Elemento de chapa com barra de treliça

Retomando as idéias de TASSIOS;YANNOPOULOS (1981), MANFREDI; PECCE (1998) apresentam um modelo para a análise de vigas contínuas de concreto armado considerando os efeitos do escorregamento da armadura. $O$ conceito de subparticionamento do elemento finito, e as equações básicas do 
equilíbrio de cada subelemento são os mesmos, havendo apenas uma mudança nas condições de contorno aplicadas junto à cada fissura. Duas fissuras consecutivas delimitam um elemento finito, e a cada uma dessas seções (nós) são impostas condições de equilíbrio de força normal $\left(\mathrm{N}_{\mathrm{i}, \text { no }}\right)$ e de momento fletor $\left(\mathrm{M}_{\mathrm{i}, \text { no }}\right)$ :

$$
\begin{aligned}
& N_{i, n o}=\int_{-h / 2}^{h / 2} \sigma(z) d z=\sum_{j c=1}^{m c} \sigma_{i, n o}^{j c} \cdot A_{i}^{j c}+\sum_{j s=1}^{m s} \sigma_{i, n o}^{j s} \cdot A_{i}^{j s}=0 \\
& M_{i, n o}=\int_{-h / 2}^{h / 2} \sigma(z) \cdot z d z=\sum_{j c=1}^{m c} \sigma_{i, n o}^{j c} \cdot A_{i}^{j c} \cdot z_{i}^{j c}+\sum_{j s=1}^{m s} \sigma_{i, n o}^{j s} \cdot A_{i}^{j s} \cdot z_{i}^{j s}
\end{aligned}
$$

onde: $b\left(b_{w}\right.$ ou $\left.b_{f}\right)$ - largura da alma ou da mesa da viga (constantes);

z - profundidade do cg da barra da armadura ou da camada de concreto;

$A_{i}^{j s}$ - área da barra da armadura longitudinal js pertencente ao elemento $i$;

$A_{i}^{j c}$ - área da camada de concreto jc pertencente ao elemento $i$;

$\sigma_{i, n o}$ - tensão normal na armadura ou no concreto.

Em seguida, são analisadas as $n+1$ seções transversais impondo-se as condições de equilíbrio de esforço normal e de momento fletor. Para estabelecer o equilíbrio, são computadas as resultantes das tensões normal e tangencial na armadura longitudinal, além das tensões normais no concreto. A abordagem numérica é assim resumida:

a) o espaçamento entre fissuras $\left(S_{r}\right)$ que delimitam cada elemento finito é arbitrado, e fixado antes do início do processo. Baseado em evidências experimentais, os autores propõem que essa distância seja equivalente àdistância entre os estribos, haja visto que nessas seções, o surgimento de fissuras primárias é favorecido por ocasião de um menor cobrimento. Em seguida, cada elemento finito é subdividido em $n$ subelementos (e $n+1$ seções transversais);

b) iniciando o processo, das expressões 3.82 e 3.83 obtém-se os valores das tensões normais na barra de aço em ambas as fissuras que delimitam o elemento $\left(\sigma_{\mathrm{s}, 1} ; \sigma_{\mathrm{s}, 2}\right)$, estabelecendo-se as condições de contorno do problema;

c) como os valores do escorregamento da armadura nas duas fissuras que delimitam o elemento finito são desconhecidos, é arbitrado um valor inicial para o escorregamento na primeira fissura: $s_{\max , 1}^{k}$. Para cada iteração " $k$ " do procedimento incremental determinam-se, para cada "seção l", sucessivamente, o valor do escorregamento (3.84), e a tensão de aderência média em $\delta x$ (Figura 3.29). Finalmente, a tensão na armadura é obtida através da expressão 3.77 ; 


$$
s_{I+1}^{k}=s_{I}^{k}+\delta x_{1} \cdot\left(\frac{\varepsilon_{s, l+1}^{\mathrm{k}}+\varepsilon_{s, l}^{k}}{2}-\frac{\varepsilon_{\mathrm{c}, I+1}^{\mathrm{k}}+\varepsilon_{\mathrm{c}, \mathrm{I}}^{\mathrm{k}}}{2}\right)
$$

d) após percorrer todos os subelementos, e determinar o valor da tensão normal na barra de aço tracionada na segunda fissura $\left(\sigma_{\mathrm{s}, \mathrm{n}+1}\right)$, compara-se este valor ao obtido no item b). O resultado compõe uma função resíduo f, cujo valor deve ser comparado àuma tolerância $\left(\mathrm{t}_{\mathrm{s}}\right)$ pré-estabelecida:

$$
f\left(s_{1}^{k}\right)=\sigma_{s, 2}-\sigma_{s, n+1} \leq t_{s}
$$

Caso não seja atendida a tolerância, inicia-se uma nova aproximação, pelo método tangente, para o escorregamento na primeira fissura:

$$
s_{1}^{k+1}=s_{1}^{k}-\frac{\sigma_{s, 2}-\sigma_{s, n+1}^{k}}{\sigma_{s, n+1}^{k-1}-\sigma_{s, n+1}^{k}}
$$

e) através das tensões médias nas armaduras em cada subelemento, determina-se a curvatura média do elemento finito:

$$
\left(\frac{1}{r}\right)_{m}=\frac{\varepsilon_{s, m}}{d-z_{c, m}}
$$

onde: $\varepsilon_{\mathrm{s}, \mathrm{m}}=\frac{\sum_{\mathrm{l}=1}^{\mathrm{n}+1} \varepsilon_{\mathrm{s}, \mathrm{l}}}{\mathrm{n}+1}$ - deformação média na armadura tracionada;

d - profundidade da armadura longitudinal de tração;

$\mathrm{z}_{\mathrm{c}, \mathrm{m}}$ - profundidade média da linha neutra.

f) com o valor médio da curvatura do elemento finito, e do momento fletor atuante $\left(\mathrm{M}_{\mathrm{m}}\right)$ determina-se o momento de inércia médio $\left(\mathrm{I}_{\mathrm{m}}\right)$ do elemento:

$$
\mathrm{I}_{\mathrm{m}}=\left(\frac{1}{\mathrm{r}}\right)_{\mathrm{m}} \cdot \frac{\mathrm{M}_{\mathrm{m}}}{\mathrm{E}_{\mathrm{c}}}
$$

e, a partir do valor médio do momento de inércia, são determinadas a nova matriz de rigidez e os novos vetores de forças internas a cada iteração do processo.

Cabe colocar que, a cada iteração do procedimento incremental-iterativo inerente à solução de um problema não-linear, são efetuadas as sub-iterações supra descritas dentro de cada elemento finito de modo a compatibilizar o 
escorregamento relativo, a tensão de aderência, e as tensões normais no aço e no concreto. Isso implica em um acréscimo sensível no tempo de processamento.

A integração do campo de tensões do elemento empregando-se o valor médio da curvatura, que equivale à integração do campo de curvaturas através de um ponto amostra pela quadratura de Gauss, empobrece a representatividade do modelo, geralmente aplicado àanálise de vigas sujeitas a campo de momento fletor variável.

\subsubsection{Modelo proposto}

Com o objetivo de descrever continuamente as variáveis envolvidas no fenômeno da aderência, propõe-se a eliminação do subparticionamento e a adoção de uma função contínua para o escorregamento no subdomínio de cada fissura $\left(l_{b, 1} ; l_{b, 2}\right.$ na Figura 3.33). Com a eliminação do caráter discreto, o procedimento de integração pode ser melhorado empregando-se, por exemplo, o método da quadratura de Gauss-Lobatto, com quatro pontos amostra (PGs).

Com base em resultados teóricos e observações experimentais (TASSIOS; YANNOPOULOS(1981); MARTINS(1991); MANFREDI;PECCE(1998)), propõe-se que o escorregamento seja expresso em termos de uma função linear ao longo do comprimento de ancoragem $\left(I_{b}\right)$, definido a partir da fissura para o centro do elemento finito. A tensão de aderência e a tensão normal na armadura longitudinal, surgem como conseqüência dessa função escorregamento. Em seguida, impondose o equilíbrio de força normal $(\mathrm{N}(\mathrm{x})=0)$, o estado de tensões no concreto pode ser estabelecido em qualquer coordenada $\mathrm{x}$ do elemento.

Por serem empregadas relações constitutivas não-lineares para os materiais, requer-se o emprego de um procedimento incremental-iterativo para a solução do sistema de equações. A cada iteração, são obtidas condições de contorno nas fissuras (nós do elemento) através do equilíbrio de força normal $\left(\mathrm{N}_{\mathrm{i}, n_{0}}=0\right)$. Para essas seções, adota-se um modelo elastofrágil para o concreto tracionado (Figura 3.15), limitado pelo valor de sua resistência àtração $\left(f_{c t}\right)$. Há que se notar, no entanto, que o equilíbrio de força normal promovido em uma coordenada genérica x não leva, necessariamente, ao equilíbrio de momento fletor. $\mathrm{Na}$ prática, existe uma parcela de momento fletor desbalanceado $(\Psi \mathrm{M}(\mathrm{x}))$ a ser integrado no domínio do elemento de modo a se estabelecer o resíduo de forças para a iteração seguinte: 


$$
\Psi M(x)=\left(\sum_{j c=1}^{m c} \sigma_{i, n o}^{j c} \cdot A_{i}^{j c} \cdot z_{i}^{j c}+\sum_{j s=1}^{m s} \sigma_{i, n o}^{j s} \cdot A_{i}^{j s} \cdot z_{i}^{j s}\right)-M(x)
$$

onde: $M(x)$ - momento fletor atuante.

O valor do escorregamento na seção da primeira fissura $\left(s_{\text {máx,1 }}\right)$ é obtido impondo-se $\left(\delta x=I_{b, 1}\right.$ e $\left.\varepsilon_{c}=\varepsilon_{c t}\right)$ àexpressão 3.75:

$$
\mathrm{s}_{\max , 1}=\mathrm{I}_{\mathrm{b}, 1} \cdot\left(\varepsilon_{\mathrm{s}}^{1}-\varepsilon_{\mathrm{ct}}\right)=\mathrm{I}_{\mathrm{b}, 1} \cdot\left(\frac{\sigma_{\mathrm{s}}^{1}}{\mathrm{E}_{\mathrm{s}}}-\varepsilon_{\mathrm{ct}}\right)
$$

e a função escorregamento é dada por:

$$
s\left(x_{1}\right)=s_{\max , 1} \cdot\left(1-\frac{x_{1}}{l_{b, 1}}\right)
$$

O mesmo raciocínio deve ser imposto à segunda fissura que delimita 0 elemento finito. Assim como proposto por Manfredi e Pecce, este modelo considera que as fissuras primárias surgem no instante em que a tensão na fibra de concreto mais tracionada, nas seções pré-definidas (seções dos estribos, por exemplo), atinja o valor de ruptura $\left(f_{\mathrm{ct}}\right)$, e desconsidera o surgimento das fissuras secundárias ao longo do processo de carregamento. Os nós do elemento finito devem, neste caso, coincidir com as seções sujeitas àfissuração.

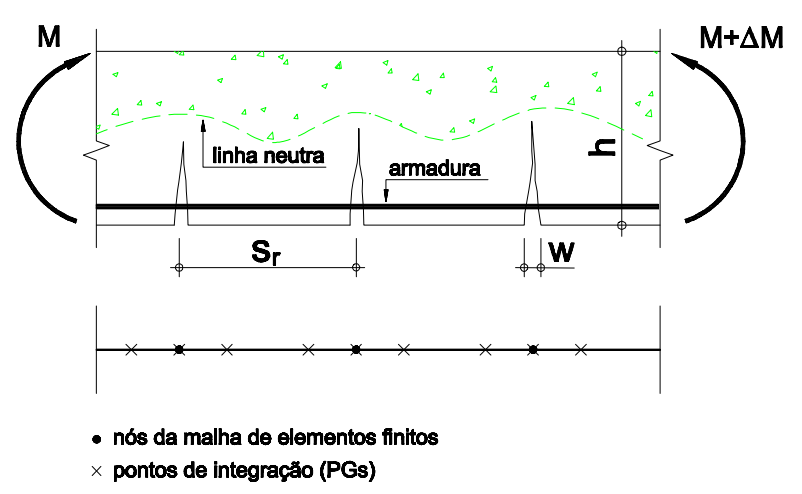

Figura 3.32 - Elemento de viga fissurado. Discretização

É importante colocar que o presente modelo, ao contrário do proposto por Manfredi e Pecce, não exige que ambas as extremidades do elemento estejam fissuradas para que a análise seja estabelecida. Isto só é possível porque os escorregamentos, descritos a partir de ambos os nós para o interior do elemento, possuem campos independentes, e relacionáveis apenas às tensões $\sigma_{\mathrm{s}, 1} ; \sigma_{\mathrm{s}, 2}$. 
Descritas as duas funções de escorregamento para os nós do elemento finito, torna-se imediata a obtenção da função tensão de aderência, e tensão na armadura ao longo do comprimento de ancoragem, tendo como base a relação proposta pelo CEB-FIP MC90 (Figura 3.29 e Tabela 3.1).

$$
\sigma_{s}\left(x_{1}\right)=\sigma_{s, 1}-\frac{4}{\Phi} \cdot \int_{0}^{x_{1}} \tau_{b}\left(x_{1}\right) \cdot d x_{1}
$$

Há que se notar que as funções de escorregamento evoluem com o carregamento, podendo atingir uma das configurações ilustradas na Figura 3.33, adaptada de MARTINS (1991) para o caso de vigas de concreto protendido.

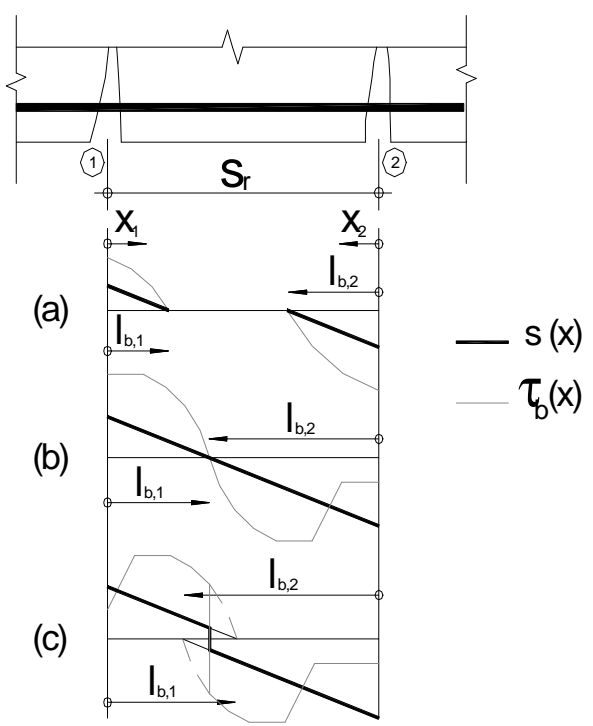

Figura 3.33 - Evolução da tensão de aderência e do escorregamento com o carregamento

Para cada uma das três configurações $(a, b, c)$ dadas na Figura 3.33, podese obter a respectiva distribuição da tensão normal na armadura longitudinal tracionada, aplicando-se a expressão 3.92 ao longo do respectivo $\mathrm{l}_{\mathrm{b}}$ com a parcela da integral adaptada a cada intervalo da curva proposta pelo CEB-FIP MC90.

Descritos os estados de tensão de aderência, e de tensões normais nas barras de aço estabelece-se, a cada iteração, e em qualquer ponto do domínio, o estado de tensões no concreto impondo-se o equilíbrio de força normal. Por integração discreta sobre as camadas de concreto e as barras de aço da seção transversal, estabelecem-se os esforços internos que, subtraídos dos externos solicitantes, resultam nos esforços desbalanceados $(\Psi \mathrm{M}(\mathrm{x}))$. Aplicando o método da quadratura de Gauss-Lobatto sobre os esforços desbalanceados nos pontos de integração, determina-se o resíduo de forças do elemento. O método da quadratura 
de Gauss-Lobatto é bastante oportuno neste caso, pois permite computar os esforços desbalanceados nos nós do elemento, e em seções internas ao seu domínio. Nos nós, considera-se a seção transversal fissurada, enquanto que nos outros dois pontos de integração, por hipótese, impõe-se a plastificação do concreto tracionado (BROMS (1965)), uma vez que o surgimento de fissuras secundárias não é contemplado pelo presente modelo. Nota-se, na Figura 3.3.34, que as deformações da armadura longitudinal nos PGs internos não são necessariamente iguais æ̀ deformações das fibras de concreto situadas, respectivamente, nas mesmas posições. Isto porque a tensão na armadura é descrita pela função escorregamento a partir do valor nodal da tensão na armadura. Na maioria dos casos, isso leva a deformações específicas diferentes daquelas que ocorrem na fibra de concreto adjacente à armadura seguindo a hipótese de Bernoulli (seções planas permanecem planas). Tal fato pode se dar tanto para valores superiores como para valores inferiores aos obtidos considerando-se o diagrama linear de deformações para o concreto. Esse fato é natural, uma vez que o modelo proposto permite representar o escorregamento.

(s)

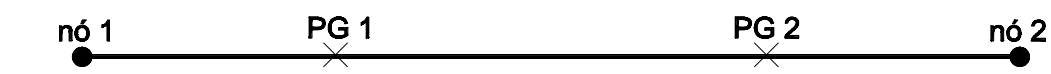

( $\varepsilon)$

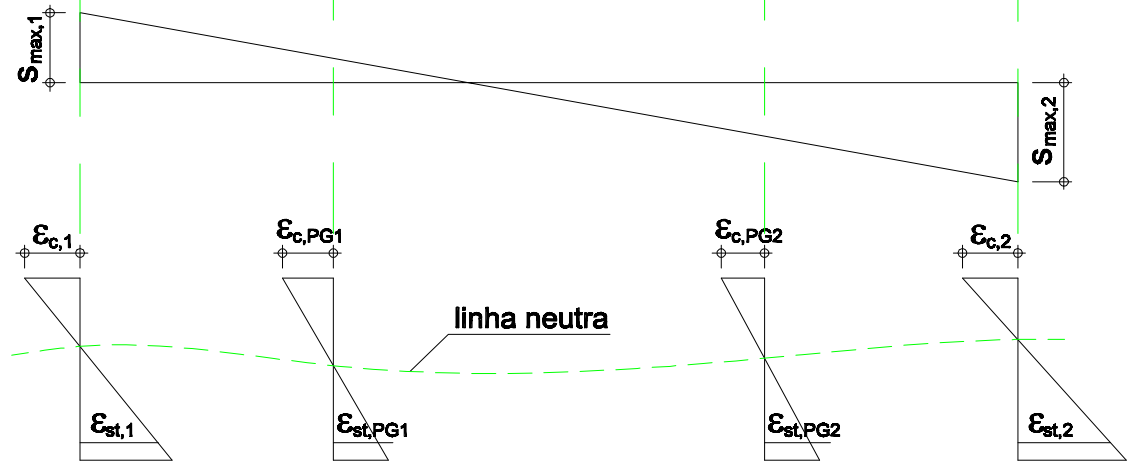

$(\sigma)$
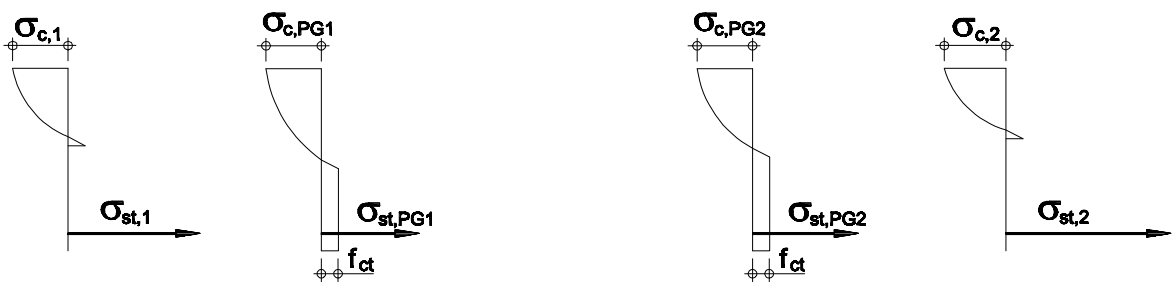

Figura 3.3.34 - Estados de deformação e de tensão no elemento

Obtidas as tensões no concreto e na armadura nas seções dos PGs (nós e pontos internos), todo o processo de integração para a obtenção da matriz de rigidez e do vetor de forças internas torna-se imediato. Em resumo, o procedimento numérico a ser aplicado a cada iteração pode ser assim descrito: 
a) divide-se a(s) viga(s) que compõe $(\mathrm{m})$ a estrutura em elementos situados entre duas fissuras consecutivas. Os nós de cada elemento finito devem ser colocados em seções com fissuração prevista;

b) das expressões 3.82 e 3.83 obtêm-se os valores das tensões normais na barra de aço em ambas as fissuras que delimitam o elemento finito $\left(\sigma_{\mathrm{s}, 1} ; \sigma_{\mathrm{s}, 2}\right)$;

c) impõe-se campo de escorregamento linear ao subdomínio de cada fissura, sendo o valor máximo (na fissura) calculado pela expressão 3.90. O valor máximo calculado ( $s_{\max , 1}$ para a fissura 1 , ou $s_{\max , 2}$ para a fissura 2 ) depende do respectivo comprimento de ancoragem $\left(l_{b, 1}\right.$ ou $\left.l_{b, 2}\right)$. A esse valor estará relacionado o número de partes do termo integral da expressão 3.92. Por exemplo, se $\mathrm{s}_{1}<\mathrm{s}_{\max , 1}<\mathrm{s}_{2}$ (com $\mathrm{s}_{1}, \mathrm{~s}_{2}$ e $\mathrm{s}_{3}$, da Figura 3.29), o termo integral deve ser composto do seguinte modo:

$$
\sigma_{s}\left(x_{1}\right)=\sigma_{s, 1}-\frac{4}{\Phi} \cdot \tau_{b, \max } \cdot \int_{0}^{\mathrm{b}_{\mathrm{b}, 11}}\left(\frac{\mathrm{s}\left(\mathrm{x}_{1}\right)}{\mathrm{s}_{1}}\right)^{\alpha} \cdot d \mathrm{x}_{1}-\frac{4}{\Phi} \cdot \tau_{\mathrm{b}, \max } \cdot \int_{\mathrm{b}, 11}^{\mathrm{b}, 1} \mathrm{~d} \mathrm{x}_{1}
$$

onde: $\mathrm{l}_{\mathrm{b}, 11}$ - comprimento de ancoragem (parcial) para $\mathrm{s}=\mathrm{s}_{1}$ referente apenas ao primeiro trecho (ascendente) do diagrama da Figura 3.29.

d) determinam-se os estados de tensão (na armadura e no concreto) nos PGs utilizando-se as hipóteses simplificadoras, e com isso, atualizam-se as matrizes e vetores através da integração pela quadratura de Gauss.

O modelo proposto, apesar de manter conceitos adotados por MANFREDI;PECCE (1998), apresenta melhorias dos aspectos ligados ao tempo de processamento e à precisão. $O$ fato de não requerer o subparticionamento do elemento finito, e a posterior análise seqüencial e iterativa de cada subelemento, reduz significativamente o esforço computacional e o tempo requerido para o processamento. A integração pela quadratura de Gauss-Lobatto, através de quatro pontos amostra, apresenta-se mais indicada e precisa para o tratamento de problemas envolvendo elementos finitos para a análise de vigas. Outro aspecto bastante importante, a ser observado no capítulo 7, refere-se à fraca dependência dos resultados com relação àmalha de elementos finitos adotada.

A abertura da fissura obtida através deste modelo é aquela referida ao nível médio da armadura longitudinal tracionada. No entanto, as aberturas de fissuras a que se referem os diversos códigos são aquelas medidas na face da viga. De acordo com MIRZA;HOUDE(1979), esses valores podem ser bastante distintos entre si. Os autores propõem uma relação aproximada entre as aberturas da 
fissura na superfície de concreto $\left(w_{c}\right)$ e no $\mathrm{cg}$ da armadura tracionada $\left(w_{s}\right)$, de acordo com a solicitação na armadura (Tabela 3.2).

Tabela 3.2 - Variação da abertura da fissura $\left(w_{d} / w_{s}\right)$ de acordo com $\sigma_{s}$

\begin{tabular}{|c|c|}
\hline $\begin{array}{c}\text { tensão no aço } \\
\left(\mathbf{k N} / \mathbf{c m}^{2}\right)\end{array}$ & $\begin{array}{c}\text { relação } \\
\left(\mathbf{w}_{\mathbf{c}} / \mathbf{w}_{\mathbf{s}}\right)\end{array}$ \\
\hline menor que 6,9 & $1,0-1,4$ \\
\hline 13,8 & 2,0 \\
\hline 41,2 & 3,3 \\
\hline
\end{tabular}

A influência que 0 escorregamento de armaduras exerce sobre 0 comportamento mecânico de vigas de concreto armado não se apresenta de forma constante para todos os tipos de elementos estruturais, nem a qualquer situação de carregamento, e pode assumir diferentes magnitudes de acordo com as condições de carregamento e com a quantidade de armadura longitudinal. Segundo KWAK;FILIPPOU(1997), "enquanto a resposta de vigas pouco armadas é sensível ao efeito do enrijecimento à tração, a resposta de estruturas de concreto armado nas quais a cortante exerce uma importante influência, como em vigas super armadas e em paredes, são mais afetadas pelo escorregamento das armaduras do que pelo efeito do enrijecimento àtração". 


\section{CONSIDERAÇÃO DOS EFEITOS DO TEMPO}

\subsection{Introdução}

Esta parte do trabalho é dirigida ao estudo dos efeitos do tempo sobre o comportamento mecânico dos elementos estruturais de concreto armado. O objetivo é a formulação de um modelo relativamente simples, mas suficientemente preciso para a análise da variação dos esforços, deslocamentos, tensões e deformações de uma estrutura ao final de um determinado período de tempo. Para fundamentar os modelos, e apresentar subsídios para o bom entendimento deste texto são colocadas, a seguir, algumas breves definições sobre os fenômenos estudados, obviamente, sem a pretensão de abordar o assunto na sua totalidade.

Os modelos já estudados neste trabalho, com o objetivo de analisar o comportamento dos elementos estruturais de concreto armado, são suficientes para uma análise no instante de tempo imediatamente posterior à aplicação do carregamento externo à estrutura (denominado por instante $t_{0}$ ). Sabe-se, entretanto, pelo menos desde a publicação do trabalho de WOOLSON (1905) ${ }^{1}$ apud NEVILLE et al. (1983), que o concreto, sob a ação de um campo de tensões, fica sujeito a acréscimos de deformações com o tempo pela manifestação do fenômeno da deformação lenta, ou fluência. O mesmo fenômeno pode ser observado quando o concreto, sujeito a um estado de deformações mantido constante ao longo do tempo, sofre uma relaxação do seu estado de tensões.

Segundo NEVILLE et al. (1983), a deformação lenta é um fenômeno intimamente associado à estrutura interna do concreto, e como tal, está condicionada a diversos fatores como: tipo de cimento (composição e finura) e de agregado (módulo de elasticidade, porosidade, forma e tamanho) utilizados na composição do concreto, aditivos (plastificantes e superplastificantes), fator

\footnotetext{
1 WOOLSON,I.H.(1905). Some remarkable tests indicating "flow" of concrete under pressure. Engineering News, v.54, n.18, p.459. apud NEVILLE, A.M. (1983).
} 
água/cimento, resistência do concreto e idade na qual ocorre a sua solicitação (idade em $\mathrm{t}_{0}$ ), temperatura e condições de cura e armazenagem ou exposição (vapor, úmida, natural). A magnitude da fluência depende ainda da condição de aplicação do carregamento ao longo do tempo (instantânea ou gradual).

Correntemente, a literatura científica aborda apenas a fluência do concreto sujeito a um estado de compressão uniaxial, mas torna-se interessante ressaltar que esse fenômeno manifesta-se sob diversos estados de solicitação, como a tração, o cisalhamento, a aderência, e os estados combinados.

Tomando a fluência na compressão como o fenômeno base para a apresentação das formulações, considere-se uma barra de concreto simples de seção transversal qualquer sujeita, em um instante inicial $t_{0}$, à æção de uma tensão de compressão uniforme mantida por um intervalo de tempo $(\Delta t)$ entre $t_{0}$ e o instante de interesse $t\left(t=t_{0}+\Delta t\right)$. Nos respectivos instantes, não havendo restrições às deformações específicas do concreto, as mesmas podem ser escritas como:

$$
\begin{aligned}
& \varepsilon_{c}\left(t_{0}\right)=\frac{\sigma_{c}}{E_{c}\left(t_{0}\right)} \\
& \varepsilon_{c}(t)=\varepsilon_{c}\left(t_{0}\right)+\varepsilon_{c c}\left(t, t_{0}\right)
\end{aligned}
$$

onde: $\varepsilon_{\mathrm{c}}\left(\mathrm{t}_{0}\right)$ - deformação instantânea em $\mathrm{t}_{0}$;

$\varepsilon_{\mathrm{c}}(\mathrm{t})$ - deformação no instante $\mathrm{t}$;

$\varepsilon_{\text {cc }}\left(t_{0}, t\right)$ - fluência específica do concreto entre $t_{0}$ e $t$;

$\sigma_{c}$ - tensão de compressão no concreto (constante entre $t_{0} e t$ );

$E_{c}\left(t_{0}\right)$ - módulo de deformação longitudinal do concreto em $t_{0}$.

A deformação do concreto no instante t também pode ser definida como a superposição da fluência ocorrida entre $t_{0}$ e $t$ com a deformação inicial em $t_{0}$, empregando-se o coeficiente de fluência:

$$
\varepsilon_{c}(t)=\varepsilon_{c}\left(t_{0}\right) \cdot\left[1+\varphi\left(t, t_{0}\right)\right]
$$

onde: $\varphi\left(t_{0}, t\right)$ - relação entre a deformação por fluência e a deformação inicial.

O comportamento genérico da deformação do concreto ao longo do tempo, para uma tensão normal de compressão constante, está idealizado no diagrama da Figura 4.1. 


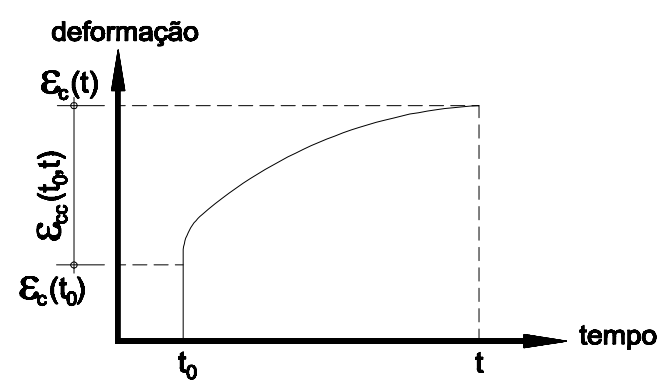

Figura 4.1 - Deformação específica do concreto ao longo do tempo

A movimentação de água entre uma peça de concreto e o ambiente ao qual esteja imersa pode, por si só, conferir variações de volume à mesma ao longo do tempo, mesmo na ausência de carregamento externo. Esse fenômeno, denominado genericamente por retração, pode ser caracterizado tanto por acréscimos (inchamento) como por decréscimos (contração) de volume para uma massa de concreto. $\mathrm{A}$ intensidade desse fenômeno está diretamente relacionada à umidade relativa do ar, e ao grau de carbonatação do concreto que, em muitos casos, pode levar à uma retração muitas vezes superior à própria fluência. Segundo GHALI;FAVRE(1994), a retração (contração) é mais significativa para o estudo das estruturas de concreto, pois apresenta valores muito superiores ao inchamento, além de ocorrer com maior freqüência.

Assim como no estudo da fluência, a retração no concreto é quantificada através de um modelo empírico, como o proposto pelo CEB-FIP MC90 para o caso da retração livre (sem impedimento).

$$
\varepsilon_{\mathrm{cs}}\left(\mathrm{t}, \mathrm{t}_{\mathrm{s}}\right)=\varepsilon_{\mathrm{cs} 0} \cdot \beta_{\mathrm{s}}\left(\mathrm{t}-\mathrm{t}_{\mathrm{s}}\right)
$$

onde: $\varepsilon_{\mathrm{cs}}\left(\mathrm{t}, \mathrm{t}_{\mathrm{s}}\right)$ - retração final no instante $\mathrm{t}_{\mathrm{s}}$;

$\varepsilon_{\text {cso } 0}$ - retração desde o instante $t_{s}$ até o tempo 'infinito' $(t=\infty)$;

$\beta_{s}\left(t-t_{s}\right)$ - função de retração;

$\mathrm{t}_{\mathrm{s}}$ - instante do início da retração (imediatamente após a cura úmida).

\subsection{Hipóteses}

A análise do comportamento mecânico de uma peça de concreto armado ao longo do tempo pode ser bastante complexa uma vez que, além da influência dos fenômenos já apresentados, a estrutura também está sujeita à variação das suas próprias características mecânicas, como as resistências à tração e compressão, e o módulo de deformação. Mesmo os fenômenos da fluência e da retração não são independentes, uma vez que a retração promove um aumento do módulo da 
fluência quando estas ocorrem simultaneamente. Com o objetivo de viabilizar um modelo teórico para a abordagem do problema, torna-se imprescindível a adoção de hipóteses simplificadoras. A primeira delas, de acordo com NEVILLE et al. (1983), consiste na superposição simples dos efeitos da fluência e da retração, e pode levar a resultados bastante satisfatórios.

A consideração da fluência à tração pode ser importante na estimativa da possibilidade de fissuração devido à retração, ou à variação da temperatra, e por isso, ter uma aplicabilidade mais relevante no dimensionamento de estruturas destinadas ao acúmulo de substâncias líquidas, como os reservatórios. Para uma baixa umidade relativa do ar, de aproximadamente 50\%, DAVIS et al. (1937) ${ }^{2}$ apud NEVILLE (1983) observaram uma fluência à tração cerca de $50 \%$ superior à de compressão. GLANVILLE;THOMAS $(1939)^{3}$ apud NEVILLE (1983) provaram que a fluência à tração e à compressão são praticamente iguais para o caso de solicitações de mesma intensidade, à umidade relativa variável. Como as tensões de tração no concreto observadas em uma seção transversal fissurada sujeita à flexo-compressão são pequenas quando comparadas às de compressão (até 10\%, na média), pode-se concluir que 0 efeito da fluência na tração sobre 0 comportamento do elemento estrutural seja bastante pequeno.

A análise dos amplos resultados experimentais disponíveis na literatura científica (CORLEY;SOZEN (1966), BAKOSS et al. (1982), CLARKE (1987) apud CLARKE et al. (1988)), permite constatar a pequena variabilidade da tensão na armadura tracionada no período de tempo entre $t_{0}$ e $t$. Transformada em hipótese simplificadora, essa observação foi utilizada com bastante sucesso por diversos autores, destacando-se CLARKE et al. (1988) e RAHMAN et al. (1998). Outra hipótese amplamente empregada é a desconsideração da relaxação das armaduras longitudinais de tração, uma vez que esse fenômeno só atinge níveis significativos nos cabos utilizados para protensão, geralmente sujeitos a tensões de tração muito maiores que as observadas nas armaduras passivas.

A data de aplicação do carregamento, por simplicidade, deverá coincidir com a idade de 28 dias do concreto ( $\mathrm{t}_{0}=28$ dias). Tal hipótese leva em consideração uma desforma da estrutura aos 14 dias, e a execução das alvenarias

2 DAVIS,R.E.;DAVIS,H.E.;BROWN,E.H. (1937). Plastic flow and volume changes of concrete. Proceedings ASTM, v.37, part 2, pp.317-330. apud NEVILLE, A.M.(1983).

${ }^{3}$ GLANVILLE,W.H.;THOMAS,F.G.(1939). Studies in reinforced concrete - IV. Further investigations on creep or flow of concrete under load. Building Research Technical Paper. n.21, 44p. London. apud NEVILLE, A.M.(1983).

${ }^{4}$ CLARKE,G.S. (1987). Long-term deflections of reinforced concrete flexural elements. MSc Thesis. University of the Witwatersrand, Johannesburg, 100p. apud CLARKE et al. (1988). 
nos 14 dias seguintes atingindo, aos 28 dias, aproximadamente $80 \%$ do carregamento final. Essa hipótese simplifica também a adoção das características mecânicas do concreto que, aos 28 dias já assume $80 \%$ das resistências à compressão e à tração, e cerca de $90 \%$ do módulo de elasticidade longitudinal esperado para o tempo infinito (segundo formulação do CEB-FIP MC90 para concreto preparado com cimento Portland comum, e submetido à cura normal).

Por fim, a hipótese clássica de Bernoulli-Navier sobre a manutenção das seções transversais planas após a deformação finaliza o escopo das hipóteses iniciais adotadas neste trabalho.

\subsection{Metodologia proposta}

Previamente ao estudo de uma metodologia específica, convém ressaltar a fundamental importância que as armaduras longitudinais exercem como agentes inibidores da retração e da fluência, e como responsáveis diretos pela redistribuição dos esforços internos nas estruturas hiperestáticas. Empregando o processo dos esforços, BAZANT (1972) prova que a redistribuição dos esforços internos em uma estrutura linear hiperestática, com armadura longitudinal constante, é nula desde que os elementos apresentem os mesmos coeficientes de fluência e retração. Conclui-se que a redistribuição origina-se dos diferentes impedimentos à fluência e à retração promovidos pelas diferentes taxas de armaduras longitudinais.

\subsubsection{Justificativa}

A implementação dos efeitos do tempo tem como base o modelo de fluência proposto pelo CEB-FIP MC90. A escolha está fundamentada no trabalho de BAKOSS et al. (1982), que realiza ensaios experimentais em vigas de concreto armado submetidas a diversos carregamentos aplicados durante um período de até 500 dias. Posteriormente, os autores comparam os resultados experimentais aos obtidos pelos métodos do ACl-209, norma britânica (CP 110:1972) e australiana (AS 1481-1978), além de resultados obtidos pelo método dos elementos finitos incorporando as propriedades de fluência e retração propostas pelo ACl-209 e CEB-FIP (1978). A conclusão, para uma pequena gama de corpos de prova (2 vigas biapoiadas, e 2 vigas contínuas), é de que o emprego das propriedades de fluência e retração propostas pelo CEB-FIP (1978) em uma análise pelo método dos elementos finitos, apresenta resultados de deslocamento ao longo do tempo 
bastante próximos aos obtidos pelo $\mathrm{ACl}-209$, ambos variando de 69 a $84 \%$ dos resultados experimentais (respectivamente, para as vigas contínua e apoiada). estudo mostra ainda que as propriedades de fluência e retração do concreto calculadas pelo ACl-209 e pelo AS 1481 ficaram bastante próximas.

Além dos estudos realizados por BAKOSS et al. (1982), a escolha do modelo do CEB-FIP MC90 justifica-se pela coerência mantida ao longo deste trabalho. Devido à norma brasileira relativa ao projeto das estruturas de concreb armado atualmente em vigor (NB1-78) ser fortemente influenciada pelo CEB-FIP MC90 opta-se, desde que não hajam prejuízos evidentes na representatividade, pela adoção do código modelo europeu.

\subsubsection{Parâmetros}

Anteriormente à formulação das propriedades de fluência e retração do concreto pelo modelo do CEB-FIP MC90, faz-se necessária a introdução de alguns conceitos pertinentes ao assunto. O primeiro deles refere-se ao grau de exposição do elemento estrutural ao meio ambiente, quantificado através da espessura equivalente $h_{0}(\mathrm{~cm})$. Como pode ser observado, o grau de exposição e, conseqüentemente, os efeitos da retração apresentam-se mais intensos quanto mais delgada for a seção transversal, obviamente considerando-se as mesmas condições de exposição.

$$
\mathrm{h}_{0}=\frac{2 \cdot \mathrm{A}_{\mathrm{c}}}{\mu}
$$

onde: $A_{c}$ - área da seção transversal geométrica da peça $\left(\mathrm{cm}^{2}\right)$;

$\mu$ - perímetro exposto ao meio ambiente $(\mathrm{cm})$.

Os dois conceitos seguintes estão ligados à velocidade com que o concreto amadurece. O primeiro deles relaciona-se à temperatura, considerada através do conceito da "idade fictícia" $\left(\mathrm{t}_{\mathrm{T}}\right)$ que teria o concreto na idade real $\mathrm{t}_{0}$, se submetido à ação de uma temperatura $(\mathrm{T})$ diferente de $20^{\circ} \mathrm{C}$ (referência) durante um determinado intervalo de tempo. O modelo implementado neste trabalho assume apenas um intervalo de tempo e, conseqüentemente, uma temperatura média [T(28)] no período entre 0 e 28 dias. 


$$
\left.\mathrm{t}_{\mathrm{T}}=28 . \mathrm{e}^{-\left[\frac{4000}{273+\frac{\mathrm{T}(28)}{\mathrm{T}_{0}}}-13,65\right.}\right]
$$

onde: $\mathrm{T}(28)$ - tempo de ocorrência da temperatura média (28 dias);

$\mathrm{T}_{0}=1^{\circ} \mathrm{C}$.

Outro agente importante, que influencia a maturidade do concreto, é o tipo de cimento empregado na sua produção. Para o cimento Portland comum, empregado na quase totalidade dos concretos estruturais utilizados no Brasil, essa influência é nula, pois parece que o modelo do CEB-90 deva ter sido calibrado para esse tipo de cimento. Vale ressaltar que o modelo do CEB-FIP MC90 é aplicável aos concretos estruturais correntes, com $12 \mathrm{MPa} \leq \mathrm{f}_{\mathrm{ck}} \leq 80 \mathrm{MPa}$. A aplicabilidade do modelo ainda se restringe a um campo de tensões de compressão no concreto de até $40 \%$ da sua resistência média na data $t_{0}$, a uma umidade relativa do ar (UR) entre 40 e $100 \%$, e à variação de temperatura entre 5 e $30^{\circ} \mathrm{C}$.

\subsubsection{Fluência}

Retomando a expressão 4.3, a hipótese para o instante $t_{0}=28$ dias, leva a um coeficiente de fluência $\left(\varphi_{28}\right)$ calculado pelo CEB-FIP MC90 como:

$$
\varphi_{28}\left(t_{0}, t\right)=\varphi_{0} \beta_{c}\left(t-t_{0}\right)
$$

onde: $\varphi_{0}=\varphi_{\mathrm{UR}} \cdot \beta\left(\mathrm{f}_{\mathrm{cj}}\right) \cdot \beta\left(\mathrm{t}_{0}\right)$;

$$
\begin{aligned}
& \varphi_{U R}=1+\frac{1-\frac{U R}{100}}{0,215 \cdot\left(\mathrm{h}_{0}\right)^{\frac{1}{3}}} ; \\
& \beta\left(\mathrm{f}_{\mathrm{cJ}}\right)=\frac{16,8}{\sqrt{\mathrm{f}_{\mathrm{cj}}}} ; \\
& \beta\left(\mathrm{t}_{0}\right)=\frac{1}{0,1+\left(\mathrm{t}_{0 \mathrm{f}}\right)^{0,2}} ;
\end{aligned}
$$

$\mathrm{t}_{\mathrm{T}}$ - idade inicial fictícia;

$\mathrm{f}_{\mathrm{cj}}$ - resistência média do concreto à compressão, prevista para os j dias;

$\mathrm{h}_{0}$ - espessura fictícia da peça.

O desenvolvimento da fluência com o tempo é descrito pela variável: 
$\beta_{c}\left(t, t_{0}\right)=\left[\frac{\frac{\left(t-t_{0}\right)}{t_{1}}}{\beta_{H}+\frac{\left(t-t_{0}\right)}{t_{1}}}\right]^{0,3}$

onde: $\beta_{H}=150 .\left[1+\left(1,2 \frac{U R}{100}\right)^{18}\right] \cdot \frac{h_{0}}{h_{\text {ref }}}+250 \leq 1500$;

(t- $\left.\mathrm{t}_{0}\right)$ - intervalo real em dias (não corrigido);

$\mathrm{h}_{\text {ref }}$ - espessura de referência $(=10 \mathrm{~cm})$;

$t_{1}=1$ dia.

\subsubsection{Retração}

Retomando a expressão 3.97 para a determinação da retração, cabe agora compreender cada um dos termos envolvidos no cálculo. A retração de referência $\left(\varepsilon_{\mathrm{cso}}\right)$ é determinada empiricamente em função de dois outros parâmetros.

$$
\varepsilon_{\mathrm{cs} 0}=\varepsilon_{\mathrm{c}}\left(\mathrm{f}_{\mathrm{cj}}\right) \cdot \beta_{\mathrm{UR}}
$$

onde: $\varepsilon_{c}\left(f_{c j}\right)=\left[160+10 \cdot \beta_{s c} \cdot\left(9-\frac{f_{c j}}{f_{c j 0}}\right)\right] \cdot 10^{-6}$;

$\mathrm{f}_{\mathrm{cj} 0}=10 \mathrm{MPa}$;

$\beta_{\mathrm{sc}}$ - parâmetro que leva em consideração o tipo de cimento (=5 para o cimento Portland comum).

$\beta_{\mathrm{UR}}$ - parâmetro que leva em consideração a umidade relativa do ar:

$$
\beta_{\mathrm{UR}}=\left\{\begin{array}{l}
-1,55 .\left[1-\left(\frac{\mathrm{UR}}{100}\right)^{3}\right] \text { para } 40 \% \leq \mathrm{UR} \leq 99 \% \\
+0,25 \text { para } \mathrm{UR} \geq 99 \%
\end{array}\right.
$$

O desenvolvimento da retração está relacionado diretamente ao intervalo de tempo decorrido, e inversamente com a espessura fictícia.

$$
\beta_{s}\left(t-t_{s}\right)=\left[\frac{t-t_{s}}{350 \cdot\left(\frac{h_{0}}{h_{\text {ref }}}\right)^{2}+\frac{\left(t-t_{s}\right)}{t_{1}}}\right]
$$




\subsubsection{Elementos lineares}

A metodologia empregada neste trabalho baseia-se na decalagem do diagrama tensão-deformação do concreto entre os instantes $t_{0}$ e t. Com a hipótese da independência entre o coeficiente de fluência $(\varphi)$ e a respectiva tensão no concreto $\left(\sigma_{c}\right)$, FUSCO,P.B.(1981) sugere que, por efeito da fluência, o diagrama tensão-deformação do concreto deva sofrer uma transformação afim, de razão $\varphi$, paralelamente ao eixo de $\varepsilon_{\mathrm{c}}$ (Figura 4.2). Com o objetivo de facilitar a compreensão das conseqüências de tal transformação do diagrama, toma-se o exemplo de uma seção transversal pertencente a uma estrutura isostática. A nova distribuição de tensões na seção transversal, referida ao instante de tempo $t$, passaria a ser empregada no estabelecimento do equilíbrio da estrutura, determinando-se os estados de tensões, deformações, esforços internos e deslocamentos correspondentes ao instante t.

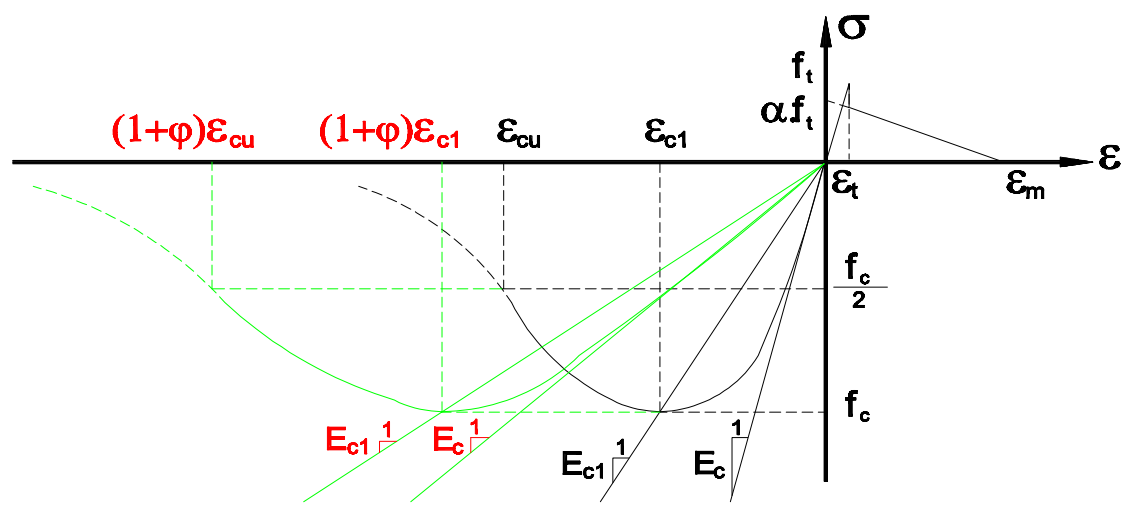

Figura 4.2 - Influência da fluência sobre o modelo do concreto

Com o emprego do novo diagrama para o equilíbrio do elemento estrutural (hipoteticamente isostático) deve ocorrer, aliado a um aumento significativo da curvatura, uma migração da linha neutra no sentido da armadura longitudinal de flexão tracionada que, no instante $t$, deve apresentar uma tensão de tração aproximadamente igual à verificada no instante to (Figura 4.3). Com a movimentação da $\mathrm{LN}$, as fibras de concreto tracionadas localizadas abaixo da $\mathrm{LN}\left(\mathrm{t}_{0}\right)$ no instante $\mathrm{t}_{0}$, sofrem uma inversão de solicitação, e passam a estar sujeitas à compressão no instante t. Conseqüentemente, o diagrama de deformações de tração migra em direção à armadura tracionada, porém sem encontrar fibras intactas resistentes à tração (fibras cujas deformações já tenham ultrapassado o limite de ruptura do concreto), ele praticamente se extingue. Por esse motivo, neste trabalho ignora-se a existência de tal diagrama no instante t (Figura 4.4). 

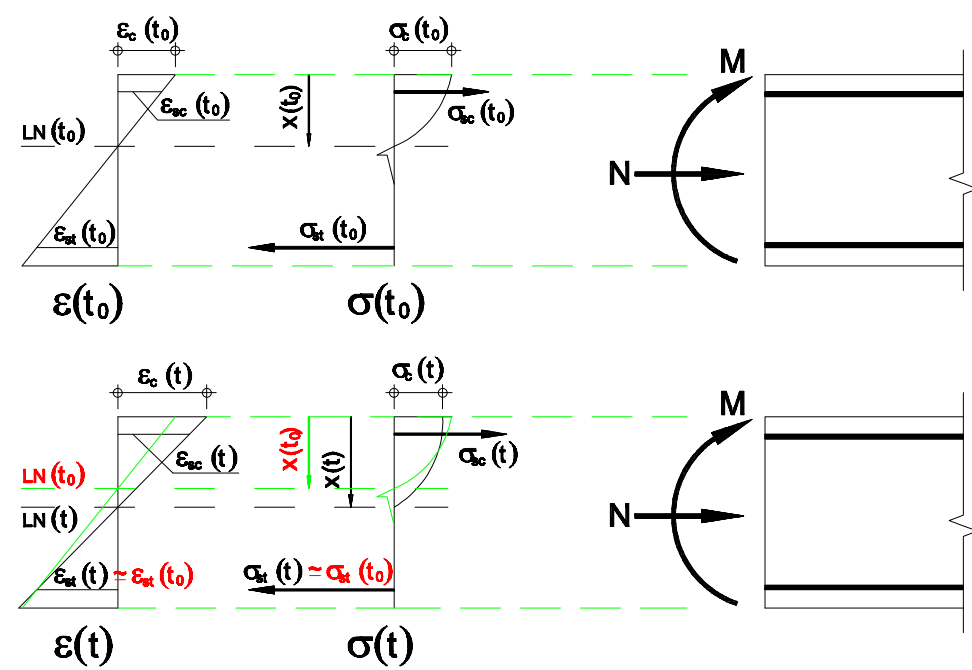

Figura 4.3 - Estados de deformações e tensões em to e $t$ (caso isostático)

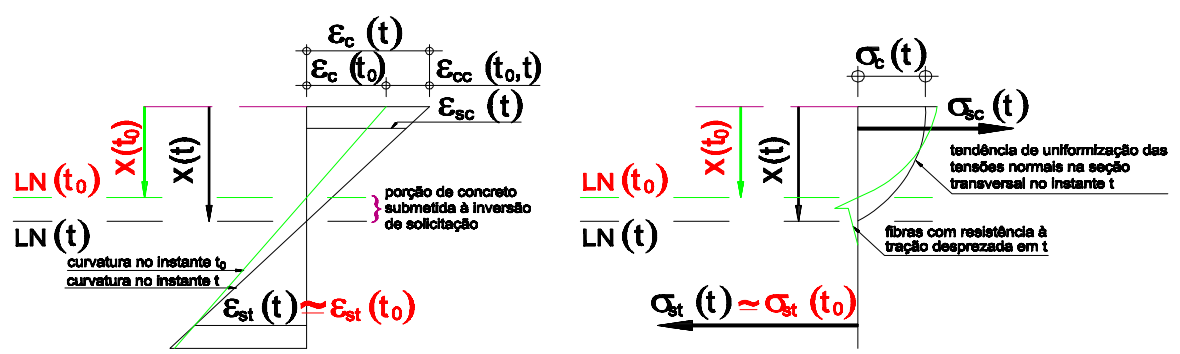

Figura 4.4 - Análise das deformações e tensões em to e $t$ (caso isostático)

\subsubsection{Elementos de placa}

Para a análise dos elementos de placa submetidos aos efeitos da fluência, foram mantidas as mesmas premissas adotadas para os elementos lineares. As relações constitutivas que exprimem os comportamentos típicos de estado plano (tração-tração, tração-compressão e compressão-compressão), têm apenas alterada a rigidez no que concerne ao módulo de deformação longitudinal $(E)$. Os estados desacoplados (tração+tração e tração+compressão) seguem as mesmas leis constitutivas uniaxiais apresentadas no item 4.3.3.

A solução adotada para as lajes é propositadamente simples, uma vez que o objetivo desta parte do trabalho dirige-se à elaboração de rotinas que permitam a análise não-linear que, mesmo simples, permita inferir não só sobre os estados limites últimos, como nos relacionados ao comportamento da estrutura em serviço. 


\section{DUCTILIDADE DAS ESTRUTURAS}

\subsection{Introdução}

Os estudos desenvolvidos nos capítulos anteriores sugerem que a capacidade portante das estruturas seja uma função exclusiva de aspectos mecânicos relacionados aos elementos estruturais. Para que seja atingida essa capacidade portante, plena com relação às características mecânicas dos materiais que compõem a estrutura, há que ser desenvolvido um estado de deslocamentos compatível, função das relações constitutivas adotadas. Conseqüentemente, surgem deformações plásticas cujos valores devem atender a limites máximos para que seja assegurado o bom desempenho da estrutura relativamente à sua capacidade de deformação, designada por ductilidade. Correntemente, a capacidade de rotação plástica de uma rótula pode ser quantificada pela diferença entre a rotação total e aquela para a qual inicia-se o escoamento da armadura longitudinal de flexão tracionada (Figura 5.1).

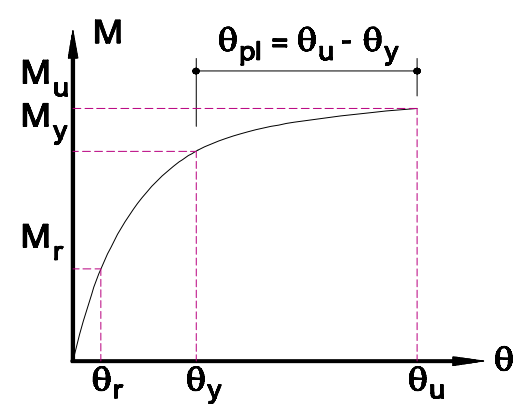

Figura 5.1 - Definição da capacidade de rotação plástica

Esse conceito, estendido a toda uma região plastificada de comprimento $I_{p}$, define a integral:

$$
\theta_{p l}=\int_{0}^{|p|} \frac{1}{d-x(a)}\left[\varepsilon_{s m}(a)-\varepsilon_{s m, y}\right] d a
$$


onde: $I_{p l}$ - é o comprimento da região plastificada, na qual a deformação da armadura de flexão tracionada é superior àde escoamento;

$x(a)$ - é a profundidade da zona de concreto comprimida;

$\varepsilon_{\mathrm{sm}}(\mathrm{a})$ - deformação média no aço;

$\varepsilon_{\mathrm{sm}, y}$ - é a deformação de escoamento do aço (para $\sigma_{\mathrm{s}}=\mathrm{f}_{\mathrm{yk}}$ );

$a$ - é a abcissa $\left(0 \leq a \leq I_{p l}\right)$ para a viga padrão.

Resumidamente, pode-se afirmar que são dois os limites a serem verificados nos dimensionamentos de estruturas de concreto armado que envolvam a redistribuição de esforços: um limite mecânico, imposto aos materiais, e um limite de deformação, imposto æ̀ rótulas ou regiões plastificadas.

\subsection{Fatores que influenciam a capacidade de rotação}

De acordo com o CEB: Bulletin d'Information $n^{\circ}$ 242, muitos são os fatores que exercem influência sobre a capacidade de rotação de uma seção ou região plastificada de concreto armado. A seguir, comentam-se aqueles julgados de maior relevância para o bom entendimento deste trabalho.

\subsubsection{Tipo de aço}

A limitação das deformações plásticas das estruturas de concreto armado tem como principal objetivo resguardar as deficiências da armadura tracionada em se deformar após atingido o limite de escoamento. Ao longo dos últimos anos, a tecnologia de produção do aço experimentou um grande avanço que se refletiu na melhoria de diversas de suas propriedades, como o limite de escoamento e de ruptura, e a aderência. Aliadas a esse avanço agregaram-se uma série de outras propriedades menos desejáveis sob o aspecto da ductilidade, como a redução da capacidade de encruamento, e a diminuição da deformação na ruptura.

\subsubsection{Profundidade da linha neutra}

A profundidade da linha neutra foi escolhida pelo CEB Model Code 1990 (CEB-FIP MC90), assim como pela NB1-revisão 2000, como o parâmetro para a verificação da rotação plástica permitida para uma seção ou região. Esse parâmetro torna-se bastante interessante pois, através dele, possibilita-se a 
quantificação indireta da influência que outras variáveis possam exercer sobre a capacidade de rotação. Como exemplo, citam-se: o confinamento do concreto comprimido, e as taxas de armaduras longitudinais (tração e compressão), que sabidamente afetam a capacidade de rotação e, por sua vez, também exercem influência sobre o posicionamento da linha neutra.

A profundidade da linha neutra está intimamente relacionada ao tipo de ruptura das seções transversais de concreto armado submetidas essencialmente à flexão. Caracteristicamente, os diagramas que exprimem a capacidade de rotação, propostos tanto pelo CEB-FIP MC90 como pela NBR 6118 rev. 2000 apresentam uma relação $(x / d)^{*}$ para a qual a capacidade de rotação é máxima. Esse valor máximo é caracterizado pela ocorrência simultânea das máximas deformações no concreto comprimido $(-3,5 \%)$ e na armadura tracionada $(10 \%)$. Para valores de $\mathrm{x} / \mathrm{d}$ inferiores a $(\mathrm{x} / \mathrm{d})^{*}$, a ruptura se dá pela armadura tracionada, e valores de $\mathrm{x} / \mathrm{d}$ superiores a $(x / d)^{\star}$ definem a ruptura pelo concreto.

\subsection{Prescrições normativas sobre as máximas rotações}

As rotações plásticas observadas no estado limite último (ELU) devem satisfazer aos valores indicados pelos códigos-modelo, de acordo com o tipo (classe) do aço empregado na análise. Particularmente, o CEB-FIP MC90 apresenta os valores limites através de um diagrama cujas abcissas correspondem à profundidade da linha neutra, e as ordenadas, àcapacidade de rotação plástica. $A$ Figura 5.2 ilustra o diagrama para o aço classe A, e a Figura 5.3, o classe B.

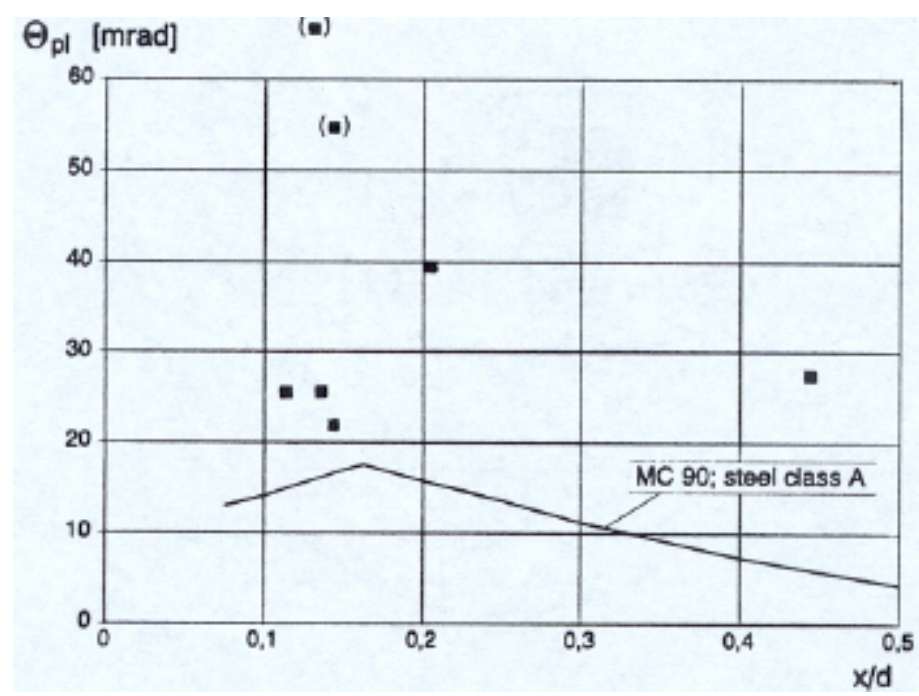

Figura 5.2 - Capacidade de rotação plástica (aço tipo A). Resultados experimentais e proposta do CEB-FIP MC90 


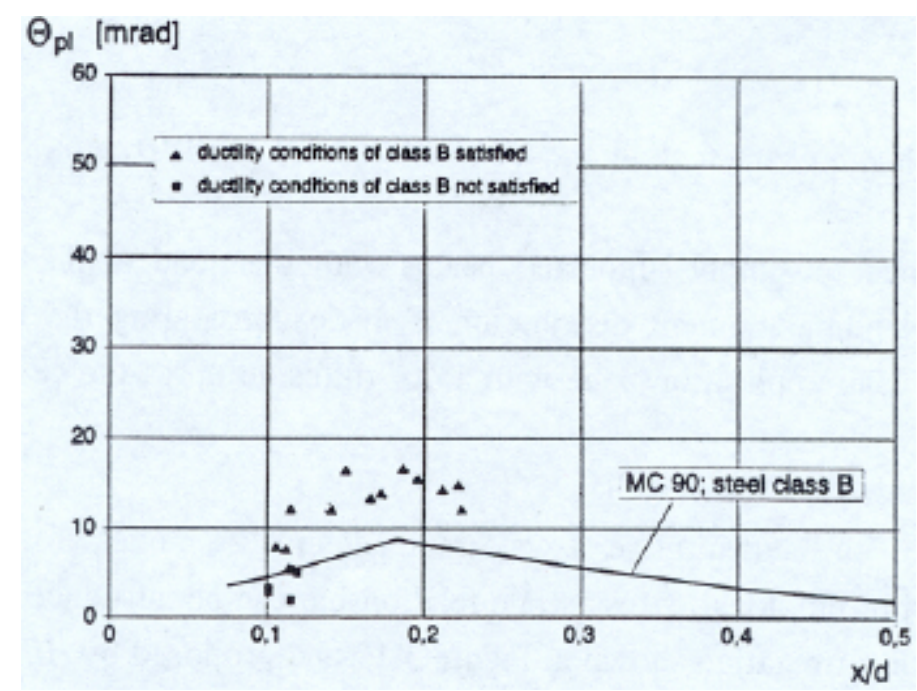

Figura 5.3 - Capacidade de rotação plástica (aço tipo B). Resultados experimentais e proposta do CEB-FIP MC90 ${ }^{1}$

É importante destacar que as classes A e B definidas pelo CEB-FIP MC90 não relacionam-se à classificação da NBR-6118. Ambas as classes do código europeu apresentam encruamento, e diferenciam-se pela ductilidade, estabelecida através de dois critérios: relação entre as tensões características de ruptura e de escoamento $\left(\mathfrak{f}_{\mathrm{t}} / \mathrm{f}_{\mathrm{y}}\right)_{\mathrm{k}}$; deformação característica total máxima $\left(\varepsilon_{\mathrm{u}}\right)_{\mathrm{k}}$. Os aços pertencentes à classe $\mathrm{A}$ apresentam maior ductilidade que os da classe $\mathrm{B}$, pois apresentam mais encruamento $\left(\mathrm{f}_{\mathrm{t}} / \mathrm{f}_{\mathrm{y}}\right)$, e uma maior deformação na ruptura $\left(\varepsilon_{\mathrm{u}}\right)$.

$$
\begin{array}{ll}
\left(f_{t} / f_{y}\right)_{k} \geq 1,08 \text { e } \varepsilon_{u k} \geq 5 \% & \text { aço classe A (CEB-FIP MC90) } \\
\left(f_{t} / f_{y}\right)_{k} \geq 1,05 \text { e } \quad \varepsilon_{u k} \geq 2,5 \% & \text { aço classe B (CEB-FIP MC90) }
\end{array}
$$

Os limites dados pelos diagramas da Figura 5.2 e da Figura 5.3 estão referidos ao quantil com probabilidade de $5 \%$ de ser ultrapassado, e foram obtidos a partir de ensaios com 'viga padrão', cujos dados básicos são os seguintes:

a) análise da região do apoio interno de uma viga contínua de 2 tramos, entre os 2 pontos de momento nulo;

b) a influência das fissuras de cisalhamento é considerada para forças cortantes maiores que os valores que causam fissuras inclinadas;

c) a ruptura é assumida quando o momento fletor atinge o pico, isto é, se o aço atinge a deformação relativa à ruptura, ou a zona comprimida de concreto atinge a sua capacidade resistente;

d) a viga ou laje de concreto armado (com $\mathrm{h}=30 \mathrm{~cm}$, e $\left.\mathrm{I}^{*} / \mathrm{d}=6\right)$.

\footnotetext{
1 Os resultados marcados (na Figura 5.3) com quadriláteros referem-se àqueles em que o aço empregado apresentou características inferiores æ̀ mínimas para a classe B.
} 
onde: I* - comprimento definido na Figura 5.4 (de acordo com o CEB-FIP MC90) ${ }^{2}$.

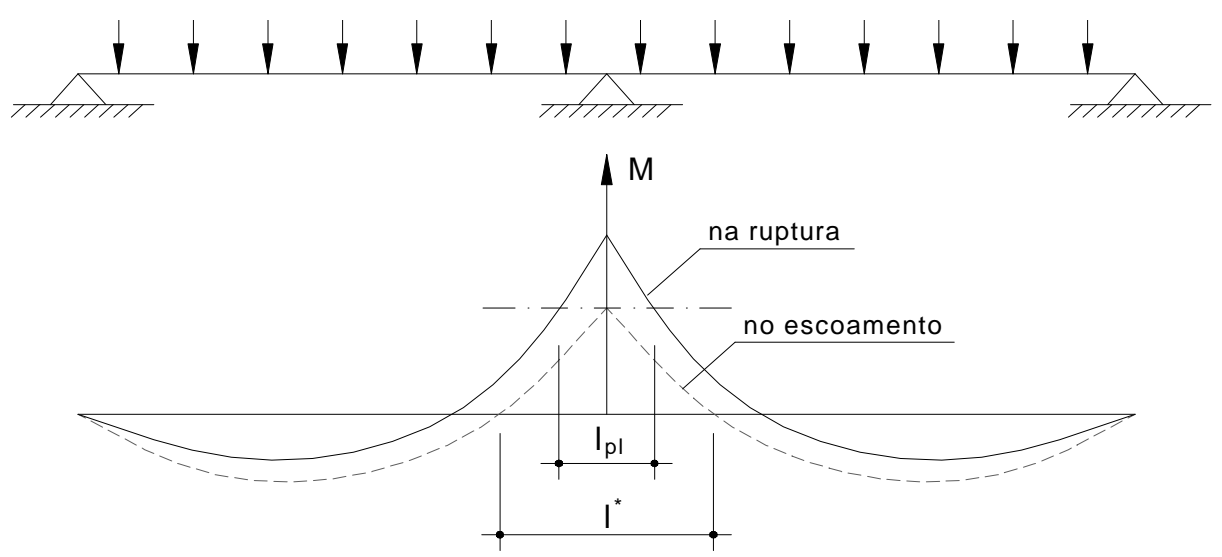

Figura 5.4 - Cálculo da capacidade de rotação plástica $\theta_{p l}$

Apesar de o CEB ter instituído a viga padrão, a maioria dos resultados experimentais que haviam disponíveis (EIFLER;PLAUK (1974), LANGER (1987), CLARKE (1990), CALVI et al. (1990) ${ }^{3}$ apud CEB Bulletin d'Information $\mathrm{n}^{\circ} 242$ e, inclusive pelo próprio ELIGEHAUSEN et al. (1993) ${ }^{4}$ apud CEB Bulletin d'Information $\mathrm{n}$ ㄴ 242), haviam sido obtidos com vigas cujas características dimensionais diferiam daquelas da viga padrão (por exemplo, a viga de Eligehausen apresenta $b_{w}=55 \mathrm{~cm}$ e $\mathrm{h}=18 \mathrm{~cm})$. Para que os resultados pudessem então ser incorporados, foi empregada a seguinte relação proporcional:

$$
\theta_{\mathrm{pl}, \text { test }}^{*}=\theta_{\mathrm{pl}, \text { test }} \cdot \frac{\theta_{\mathrm{pl}, \text { calc., ref.beam }}}{\theta_{\mathrm{pl}, \text { calc. }}}
$$

onde: $\theta_{\text {pl,test }}^{\star}$ - capacidade de rotação plástica para a viga padrão;

$\theta_{\mathrm{pl}, \text { test }}$ - capacidade de rotação plástica medida para a viga ensaiada;

\footnotetext{
${ }^{2}$ No CEB-FIP MC90 (Fig. 3.7.1), a mesma figura apresenta um equívoco quanto a definição de $I_{p l}$.

3 EIFLER,H.;PLAUK,G.(1974). Drehfahigkeit plastischer gelenke in biegebeanspruchten stahlbetonkonstruktionen, Bericht der Bundesanstalt für Materialprüfung (BAM) zum Forschungsvorhaben BAM: vh 221.2.221, Berlin, p.163. apud CEB Bulletin d'Information $\mathrm{n}^{\circ} 242$ Ductility of reinforced concrete structures.

CLARKE,J.L. (1990). The ductillity of reinforcement and its influence on the rotation capacity of concrete sections, Project report $n^{\circ}$ RE1.019.00.2, Project for fabric reinforcement development association, British cement association, p. 20. apud CEB Bulletin d'Information $\mathrm{n}^{\circ} 242$ - Ductility of reinforced concrete structures.

CALVI,G.M.;CANTÙ,E.;MACCHI,G.;MAGENES,G.(1990). Experimental investigation on the rotation capacity of concrete slabs reinforced with welded wire meshes, Rapporto $n^{\circ} 34$, Dipartimento di meccanica Strutturale dell'Universita de Pavia. apud CEB Bulletin d'Information nำ 242 - Ductility of reinforced concrete structures.

${ }^{4}$ ELIGEHAUSEN, R.; FABRITIUS, E.; LI, L; ZHAO, R. (1993). An analysis of rotation capacity tests. CEB Bulletin d'Information no 218, Comité Euro-International du Béton, Lausanne, p. 251-273. apud CEB Bulletin d'Information nำ 242 - Ductility of reinforced concrete structures.
} 


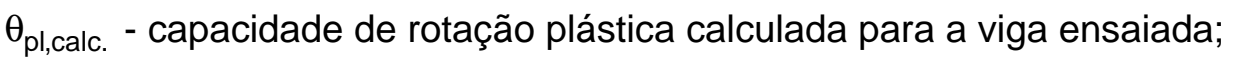

$\theta_{\text {pl,calc.,ref.beam }}$-capacidade de rotação plástica calculada para a viga padrão.

\subsection{Métodos para a determinação da capacidade de rotação}

O CEB: Bulletin d'Information $n^{0} 242$ faz uma breve introdução aos métodos para a determinação da rotação plástica disponível em elementos lineares de concreto armado, onde critica aqueles baseados na curvatura de uma seção transversal (a mais solicitada) com o argumento de que acabam por negligenciar efeitos como o espalhamento da região plastificada, o enrijecimento àtração, e a influência da força cortante. Em seguida, apresenta outros modelos mais recentes, que incorporam relações constitutivas atuais. Cada um desses modelos, brevemente comentados na da Tabela 5.1, leva o nome da cidade onde supostamente foram desenvolvidos.

Tabela 5.1 - Sinopse dos métodos para a determinação da rotação plástica

\begin{tabular}{|c|c|c|c|}
\hline modelo & precursores & ano & obtenção de $\theta=\theta_{\mathrm{el}}+\theta_{\mathrm{pl}}$ \\
\hline Stuttgart & $\begin{array}{l}\text { Langer } \\
\qquad \mathrm{Li}\end{array}$ & $\begin{array}{l}1987 \\
1995\end{array}$ & $\begin{array}{l}\text { Modelos: tensão por deformação; } \\
\text { Incorpora: interação aço-concreto e a influência da } \\
\text { força cortante; } \\
\text { Obtenção de } \theta \text { : integração do campo de } \\
\text { curvaturas entre dois pontos de momento nulo; } \\
\text { Nota: foi empregado para a obtenção das curvas } \\
\text { do CEB-FIP MC90 que, posteriormente, foram } \\
\text { calibradas com resultados experimentais. }\end{array}$ \\
\hline Naples & $\begin{array}{l}\text { Cosenza; } \\
\text { Greco; } \\
\text { Manfredi } \\
\text { Manfredi }\end{array}$ & $\begin{array}{l}1991 \\
1997\end{array}$ & $\begin{array}{l}\text { Modelos: tensão por deformação; } \\
\text { Incorpora: enrijecimento à tração e a influência da } \\
\text { força cortante; } \\
\text { Obtenção de } \theta \text { : integração do campo de } \\
\text { curvaturas entre dois pontos de momento nulo. }\end{array}$ \\
\hline $\begin{array}{l}\text { Darmstadt- } \\
\text { Leipzig }\end{array}$ & $\begin{array}{l}\text { Pommerening } \\
\text { Tue; Qian; } \\
\text { Pommerening }\end{array}$ & $\begin{array}{l}1996 \\
1996\end{array}$ & $\begin{array}{l}\text { Modelos: momento fletor por curvatura. } \\
\text { Incorpora: enrijecimento à tração indiretamente } \\
\text { através da lei constitutiva para o aço, e a influência } \\
\text { da força cortante; } \\
\text { Obtenção de } \theta \text { : ponderação entre os momentos } \\
\text { fletores de fissuração, escoamento, e último para a } \\
\text { seção transversal com as respectivas curvaturas, e } \\
\text { a distância entre o ponto de momento nulo e o } \\
\text { apoio sobre o qual plastifica-se a armadura. }\end{array}$ \\
\hline Zürich & $\begin{array}{c}\text { Sigrist; Marti } \\
\text { Sigrist }\end{array}$ & $\begin{array}{l}1994 \\
1995\end{array}$ & $\begin{array}{l}\text { Modelos: tensão por deformação e modelo de } \\
\text { bielas e tirantes; } \\
\text { Incorpora: enrijecimento àtração; } \\
\text { Obtenção de } \theta \text { : integração do campo de } \\
\text { curvaturas entre os dois pontos extremos que } \\
\text { definem uma região plastificada. }\end{array}$ \\
\hline Delft & $\begin{array}{c}\text { Bigaj } \\
\text { Bigaj; } \\
\text { Walraven }\end{array}$ & $\begin{array}{l}1992 \\
1993\end{array}$ & $\begin{array}{l}\text { Modelos: tensão por deformação; } \\
\text { Incorpora: interação aço-concreto; } \\
\text { Obtenção de } \theta \text { : integração do campo de } \\
\text { curvaturas entre os dois pontos extremos que } \\
\text { definem uma região plastificada }\end{array}$ \\
\hline
\end{tabular}


A maioria dos modelos relacionados na Tabela 5.1 incorpora a influência que a força cortante exerce sobre a rotação plástica disponível. Essa influência pode ser entendida admitindo-se, inicialmente, uma determinada rotação plástica associada a um elemento linear de concreto armado fissurado exclusivamente pela ação do momento fletor. Supondo que essa região passe a estar submetida, também, à influência de uma força cortante de tal magnitude que, às fissuras de flexão se sobreponham aquelas típicas de esforço cortante (fissuras a $45^{\circ}$ ), o efeito seria de ampliação da região plastificada inicialmente (por efeito exclusivo do momento fletor) com um conseqüente aumento da rotação plástica disponível. Tal raciocínio sugere que, simplificadamente, a rotação plástica disponível possa ser decomposta em uma parcela devida ao momento fletor e outra àforça cortante.

$$
\theta_{\mathrm{pl}, \mathrm{tot}}=\theta_{\mathrm{pl}, \mathrm{M}}+\theta_{\mathrm{pl}, \mathrm{V}}
$$

onde: $\theta_{\text {pl,tot }}$ - capacidade de rotação total disponível;

$\theta_{\mathrm{pl}, \mathrm{M}}$ - parcela da capacidade de rotação devida ao momento fletor;

$\theta_{\mathrm{pl}, \mathrm{V}}$ - parcela da capacidade de rotação devida àforça cortante.

\subsection{Aferição do modelo mecânico implementado}

O modelo mecânico implementado neste trabalho teve a sua eficiência aferida através de vários exemplos descritos neste trabalho. O mesmo deverá, agora, ser aferido sob o prisma da ductilidade. Com esse objetivo, procede-se uma análise comparativa da viga padrão preconizada pelo CEB-FIP MC90. Além das características mencionadas anteriormente, torna-se necessário apresentar as propriedades dos materiais que a constituem. O aço, é do tipo A da NBR-6118, com patamar de escoamento definido em $f_{y}=500 \mathrm{MPa}$. O concreto, C-30 ( $f_{c k}=30$ $\mathrm{MPa}$ ) é não confinado, com diagrama tensão-deformação definido pelo próprio $\mathrm{f}_{\mathrm{ck}}$ como valor para a tensão máxima. Assim como no modelo Delft, a influência da força cortante é negligenciada com a justificativa de se estudarem os elementos submetidos a esforços onde a força cortante não exerça a fissuração. O ELU é admitido quando atingidas as hipóteses convencionais: $\varepsilon_{\mathrm{s}}=10 \%$ ou $\varepsilon_{\mathrm{c}}=-3,5 \%$.

O método empregado, neste trabalho, para a determinação da capacidade de rotação plástica no ELU é bastante semelhante ao proposto pelo modelo Delft. Uma breve caracterização de ambos os métodos é dada na Tabela 5.2. 
Tabela 5.2 - Caracterização da presente metodologia comparativamente àDelft

\begin{tabular}{|c|c|c|}
\hline característica & presente método & Delft \\
\hline fissuras & por ação do momento fletor & por ação do momento fletor \\
\hline $\begin{array}{c}\text { espaçamento entre } \\
\text { fissuras }\end{array}$ & $\begin{array}{c}\text { arbitrado e fixo (igual ao } \\
\text { espaçamento entre estribos, por } \\
\text { exemplo) }\end{array}$ & $\begin{array}{c}\text { calculado com base nas } \\
\text { relações de aderência }\end{array}$ \\
\hline relação $\tau \times \mathrm{s}$ & ausente & presente \\
\hline $\begin{array}{c}\text { determinação de } \\
\theta_{\text {tot }}, \theta_{\mathrm{el}} \text { e } \theta_{\mathrm{pl}}\end{array}$ & $\begin{array}{c}\text { rotação relativa entre os dois pontos } \\
\text { que delimitam a região plastificada } \\
\text { (vide Figura 5.5) }\end{array}$ & $\begin{array}{c}\text { integral da curvatura entre } \\
\text { dois pontos que limitam a } \\
\text { região plastificada }\end{array}$ \\
\hline
\end{tabular}

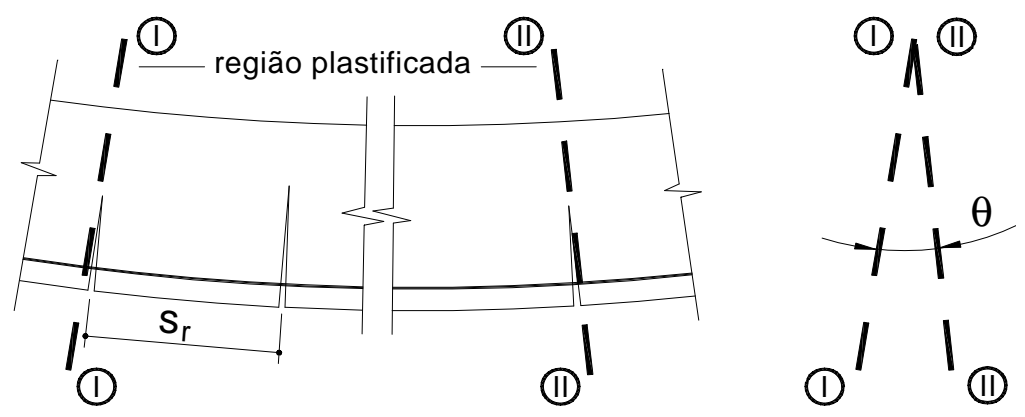

Figura 5.5 - Aproximação para a determinação da rotação $\theta$

As verificações de ductilidade efetuadas nesta parte do trabalho não contemplam o modelo de escorregamento descrito no capítulo 3 em virtude da sua utilização unicamente nas análises relativas aos Estados Limites de Serviço (ELS).

Outro aspecto de relevada importância para a análise da capacidade rotação plástica refere-se a um tipo dependência de malha um pouco diferente daquele relacionado ao comportamento mecânico dos elementos estruturais. Como pode ser observado na Figura 5.5, a localização dos dois pontos que delimitam a região plastificada é sempre coincidente com a de uma seção transversal fissurada que, na maioria dos casos refere-se a um nó da malha de elementos finitos. Assim sendo, se os nós da malha não forem coincidentes com o início e o final da região plastificada, ter-se-á uma estimativa da rotação (total e plástica) não condizente com a 'realidade do modelo'. Na obtenção dos resultados com a viga padrão apresentados na Figura 5.6, tomou-se a precaução de, sempre que necessário, refinar a malha de elementos finitos de modo que os extremos da região plastificada sempre coincidissem com dois nós (não necessariamente consecutivos) dessa malha. Esses resultados estão apresentados juntamente àqueles preconizados pelo CEB-FIP MC90 e pela NBR-6118 rev. 2000. 


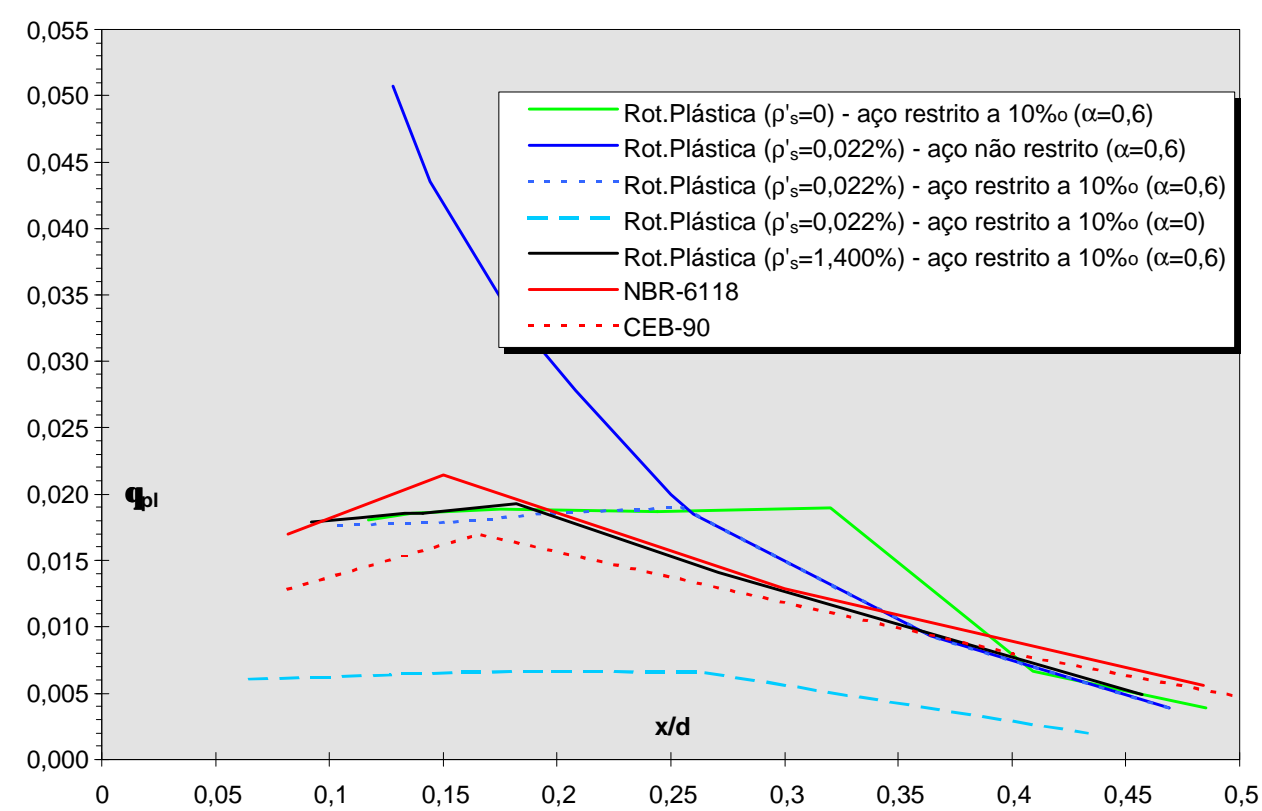

Figura 5.6 - Capacidade de rotação plástica para a viga padrão: comparação entre os valores normativos, e os obtidos com o modelo mecânico

onde: $\rho_{\mathrm{s}}^{\prime}-$ taxa geométrica de armadura de compressão;

$\alpha$ - coeficiente do modelo de tension-stiffening de FIGUEIRAS (1983).

A análise do diagrama da Figura 5.6 revela uma série de importantes constatações relacionadas ao projeto das estruturas de concreto armado, destacando-se a importância da imposição da deformação máxima da armadura tracionada em $10 \%$. No caso analisado, para valores de $x / d$ inferiores a 0,25 , tal imposição exerce papel fundamental na restrição das deformações dos elementos estruturais, mantendo-os próximos dos níveis limites (vide as curvas para $\rho_{s}^{\prime}=0,22 \%$ com aço não restrito, e aço restrito à deformação de $10 \%$ ). Outra importante observação relaciona-se à melhora no comportamento do elemento estrutural relativamente à sua capacidade de rotação promovida pelo incremento da taxa de armadura de compressão. Para uma mesma taxa de armadura de tração, o incremento da armadura comprimida impõe uma redução da profundidade da linha neutra, o que corresponde àtranslação do diagrama para regiões onde as rotações plásticas são mais permissíveis (para variações de $x / d$ de 0,08 até, aproximadamente, 0,15). Com o objetivo de quantificar tal efeito, apresentam-se três análises distintas. Na primeira delas, a viga padrão está desprovida de armadura negativa. Nota-se que esse diagrama é o que apresenta o pico segundo a maior abcissa $(\mathrm{x} / \mathrm{d})$. Em seguida, os resultados referentes a uma armadura de compressão bastante reduzida, equivalente à de um porta-estribos composto por $2 \Phi 8 \mathrm{~mm}\left(\rho_{\mathrm{s}}^{\prime}=0,22 \%\right)$, revelam um deslocamento do diagrama no eixo das abcissas 
no sentido da diminuição da relação x/d. Para valores de $\rho_{s}^{\prime}$ próximos a 1,40\%, os resultados apresentados pelo modelo implementado situam-se dentro dos valores permitidos pela NBR-6118 rev. 2000. De qualquer forma, uma análise preliminar dos diagramas da Figura 5.6 permite supor que, para as taxas de armadura negativa que não permitem um comportamento dentro da região estipulada pela NBR-6118 rev. 2000, os valores experimentais (Figura 5.2 e Figura 5.3) indicam uma capacidade de rotação acima dos limites indicados. Esse fato pode ser levado em consideração na tentativa de validar os resultados apresentados pelo presente modelo mecânico nos casos onde as taxas de armadura negativa forem inferiores a $1,40 \%$.

Por último, cabe analisar o efeito que o parâmetro de enrijecimento àtração impõe sobre a ductilidade dos elementos de viga. Como já esperado, a desconsideração de tal efeito impõe um decréscimo na ductilidade disponível pelo modelo, uma vez que a armadura inicia o escoamento a carregamentos praticamente idênticos àqueles considerando-se um enrijecimento máximo $(\alpha=0,6)$ mas, porém, a rótula plástica fica restrita a extensões inferiores àquelas proporcionadas com a consideração de $\alpha=0,6$. Para os casos analisados, as regiões plastificadas estiveram em torno de $20 \mathrm{~cm}$ (para $\alpha=0,6$ ), e de $4 \mathrm{~cm}$ para $(\alpha=0)$. Conseqüentemente, ambas as curvas ( $\alpha=0$ e $\alpha=0,7)$ obtidas com $\rho_{s}^{\prime}=0,22 \%$, e aço restrito a $10 \%$ apresentaram-se bastante distintas.

\subsection{Conclusões}

A breve análise sobre a capacidade de deformação dos elementos estruturais lineares apresentada neste capítulo já permite concluir sobre a sua importância na limitação da plastificação das estruturas de concreto armado. A imposição da deformação limite de $10 \%$ à armadura longitudinal de flexão tracionada desempenha papel importante não só para o controle da abertura de fissuras, como também na limitação da deformação plástica.

Apesar da grande importância que a ductilidade exerce sobre 0 comportamento das estruturas, a extensão dos conceitos aqui apresentados ao estudo das lajes de concreto armado encontra-se pouco desenvolvida. Diante desse panorama, e na falta de trabalhos que, neste momento, norteiem uma análise aplicada ̀̀ lajes, opta-se pelo negligenciamento desse aspecto nas análises posteriormente abordadas neste trabalho. 


\section{TÓPICOS SOBRE AS IMPLEMENTAÇÕES}

\subsection{Introdução}

Este capítulo tem o objetivo de apresentar aspectos relevantes das implementações no sistema computacional para ANáliSe de Estruturas Reticuladas (ANSER), evidenciando os modelos efetivamente empregados.

\subsection{Modelos para as vigas}

Foram implementados dois modelos para a análise não-linear das vigas. Os modelos não-estratificados propostos pelo CEB-FIP MC90, e por CORRÊA (1990), além do modelo estratificado. Neste ponto, vale a pena tecer alguns comentários sobre o campo de aplicabilidade dos modelos desenvolvidos e implementados.

Segundo as normas brasileiras e européias, o conceito de segurança na análise estrutural deve ser introduzido pelos ponderadores de resistência dos materiais concreto e aço, individualmente. Esse procedimento, denominado por método semi-probabilístico, por si só inviabiliza a utilização dos elementos nãoestratificados. Além disso, o fato de ser vedado aos modelos não-estratificados a introdução de relações de interação entre os materiais, torna inviável a abordagem consistente da aderência. Diante desse quadro, este trabalho prima pelos modelos estratificados em detrimento de um maior desenvolvimento daqueles referidos ao campo dos momentos fletores e das curvaturas.

\subsubsection{Não-estratificado}

A formulação básica apresentada no item 3.2, e depois particularizada para a representação do aço (item 3.3) pelo modelo elastoplástico perfeito, descreve a evolução das variáveis através de taxas de variações no tempo. 
Para a obtenção de um modelo constitutivo passível de implementação em programas de cálculo, torna-se evidente a necessidade de integrá-lo em um intervalo de interesse $\Delta \mathrm{t} \in[0, \mathrm{~T}] \subset \mathrm{R}$. Empregando a integração numérica, o modelo passa a ser descrito de forma incremental, o que possibilita atualizar as variáveis de estado uniaxiais $\left[\sigma, \varepsilon^{p}, \alpha\right]_{j}$ do instante inicial $t_{j}$, para os valores $\left[\sigma, \varepsilon^{p}, \alpha\right]_{j+1}$ no instante de tempo final $t_{j+1}=t_{j}+\Delta t$, após um incremento de forças.

\subsubsection{Formulação incremental do modelo elastoplástico}

Dentre os procedimentos de integração numérica existentes destacam-se, para esse fim, o procedimento de integração explícito e o procedimento de integração implícito (utilizado neste trabalho). OWEN;HINTON (1980) apresentam algoritmos baseados em integração explícita, enquanto que em trabalhos mais atuais, autores como SIMO;HUGHES (1988) aplicam a integração implícita para a obtenção dos algoritmos, e evidenciam as sua vantagens em relação ao explícito. Uma breve discussão sobre as características destes procedimentos pode ser encontrada também na dissertação de OLIVEIRA (1997).

Da aplicação do procedimento de integração implícito às expressões do item 3.2 resultam, para a iteração $\mathrm{j}+1$ :

da lei de evolução das deformações plásticas: $\dot{\varepsilon}^{p}=\dot{\gamma} \cdot \sin (\sigma)$,

$$
\varepsilon_{\mathrm{i}+1}^{\mathrm{p}}=\varepsilon_{\mathrm{i}}^{\mathrm{p}}+\Delta \mathrm{t} \cdot \dot{\gamma}_{\mathrm{i}+1} \cdot \sin \left(\sigma\left(\mathrm{t}_{\mathrm{i}+1}\right)\right)=\varepsilon_{\mathrm{i}}^{\mathrm{p}}+\Delta \gamma \cdot \sin \left(\sigma\left(\mathrm{t}_{\mathrm{i}+1}\right)\right)
$$

onde: $\quad \Delta \gamma=\Delta \mathrm{t} \cdot \dot{\gamma}_{\mathrm{i}+1}$;

$\sin (\sigma)$ - indica o sinal da variável.

da lei de evolução da variável interna de encruamento: $\dot{\alpha}=\dot{\gamma}$,

$$
\alpha_{i+1}=\alpha_{i}+\Delta \text { t. } \dot{\alpha}_{i+1}=\alpha_{i}+\Delta t . \dot{\gamma}_{i+1}=\alpha_{i}+\Delta \gamma
$$

do critério de plastificação: $f: \operatorname{Linx}^{m} \rightarrow R$,

$$
f\left(\sigma_{i+1}\right)=\left|\sigma_{i+1}\right|-\left(\sigma_{y}+k \cdot \alpha_{i+1}\right) \leq 0
$$

da condição de Kuhn-Tucker: $\dot{\gamma} \cdot f=0$,

$$
\dot{\gamma}_{i+1} \cdot f\left(\sigma_{i+1}\right)=\Delta \gamma \cdot f\left(\sigma_{i+1}\right)=0, \text { pois } \Delta t \geq 0
$$


Para que o processo iterativo possa ser iniciado, as expressões 6.1 a 6.4 devem estar relacionadas a um estado de tensões originário de uma tentativa inicial que será tomada, por simplicidade, como o resultado da aplicação da lei de Hooke. As variáveis relativas a esse estado de tensões serão assinaladas pelo superíndice t. Com a hipótese de comportamento elástico linear, resultam:

$$
\begin{aligned}
& \varepsilon_{i+1}^{p(t)}=\varepsilon_{i}^{p} \text { (passo elástico) } \\
& \sigma_{i+1}^{t}=E \cdot\left[\varepsilon_{i+1}-\varepsilon_{i}^{p}\right] \\
& \alpha_{i+1}^{t}=\alpha_{i} \\
& f_{i+1}^{t}=\left|\sigma_{i+1}^{t}\right|-\left(\sigma_{y}+k \cdot \alpha_{i}\right)
\end{aligned}
$$

As variáveis de estado $\left[\sigma, \varepsilon^{p}, \alpha\right]_{j+1}$ podem agora ser relaionadas aos seus próprios valores originados da tentativa em regime elástico linear, através de uma expressão para $\Delta \gamma \geq 0$ obtida pela imposição da condição $\mathbf{f}_{\mathrm{i}+1}=\mathbf{0}$.

$$
\Delta \gamma=\frac{\mathrm{f}_{\mathrm{i}+1}^{\mathrm{t}}}{(\mathrm{E}+\mathrm{k})}
$$

A partir de $\Delta \gamma \geq 0$, podem ser obtidas as demais variáveis de estado, de acordo com as expressões 6.10 a 6.12. A expressão 6.10 pode também ser empregada para provar que: $\sin \left(\sigma_{i+1}^{t}\right)=\sin \left(\sigma_{i+1}\right)$.

$$
\begin{aligned}
& \sigma_{i+1}=\sigma_{i+1}^{t}-E \cdot \Delta \gamma \cdot \sin \left(\sigma_{i+1}^{t}\right) \\
& \varepsilon_{i+1}^{p}=\varepsilon_{i}^{p}+\Delta \gamma \cdot \sin \left(\sigma_{i+1}^{t}\right) \\
& \alpha_{i+1}=\alpha_{i}+\Delta \gamma
\end{aligned}
$$

\subsubsection{O procedimento incremental-iterativo}

A análise não-linear de estruturas é efetuada, na prática, através de um procedimento incremental-iterativo oriundo da integração do modelo constitutivo, como o obtido nas equações 6.9 a 6.12. A Figura 6.1 ilustra as fases envolvidas no procedimento para o caso uniaxial, no campo dos momentos fletores e das curvaturas e aplicado a um elemento finito apenas. Para estados multiaxiais de tensão, como é o caso das lajes, por exemplo, ocorre a generalização das curvas para superfícies no espaço bidimensional das tensões. 

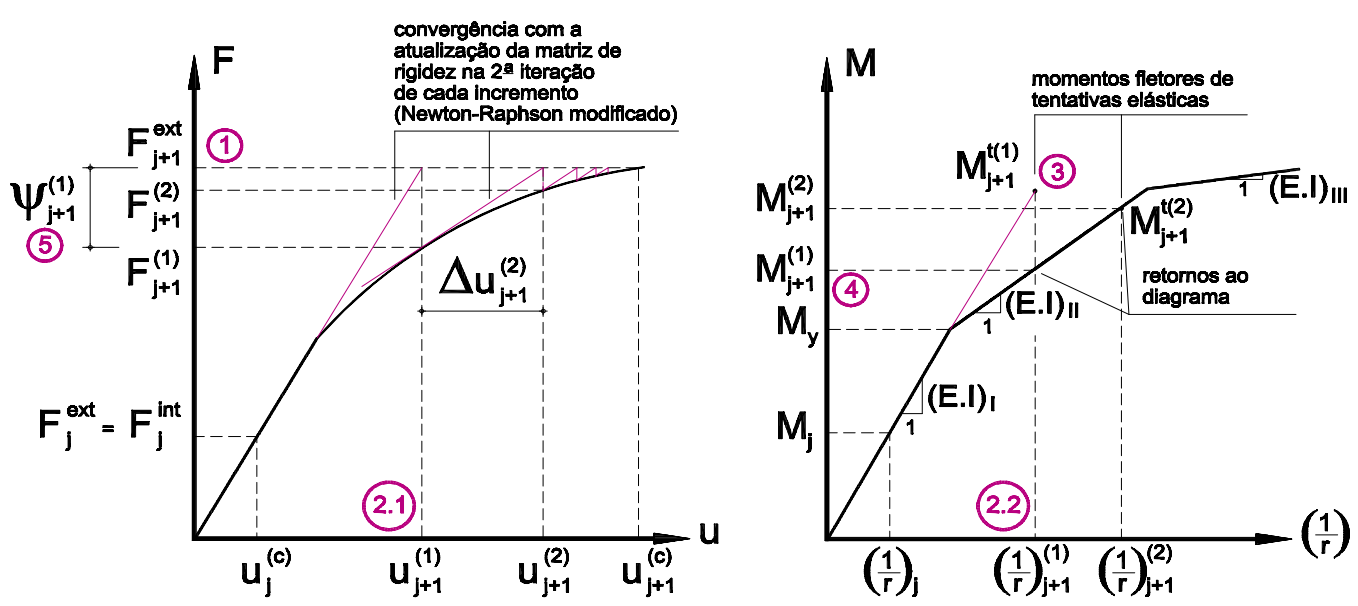

Figura 6.1 - Procedimento incremental-iterativo para o modelo momento-curvatura

Com o objetivo de facilitar a compreensão do processo, genericamente abordado para o incremento de forças ' $\mathrm{j}+1$ ' ilustram-se, na Figura 6.1, os passos descritos a seguir:

passo 1 - aplica-se o incremento de forças ' $j+1$ ' somado ao resíduo de forças do incremento anterior 'j' à estrutura, quando existir. Isto caracteriza o início da primeira iteração do incremento 'j+1'. O não abandono do resíduo de forças final do incremento anterior melhora a precisão sobre o equilíbrio final da estrutura.

do equilíbrio no incremento 'j' , tem-se: $\Psi_{j}=K_{j} \cdot u_{j}^{c}+F_{j}^{e x t}$

no incremento 'j+1', aplicar-se-á o vetor de forças:

$$
\Delta \mathrm{F}_{\mathrm{j}+1}^{\mathrm{ext}}=\Delta \mathrm{F}_{\mathrm{j}+1}^{\mathrm{ext}}+\psi_{\mathrm{j}}
$$

onde : $\Psi_{\mathrm{j}}$ - vetor resíduo de forças do incremento de forças 'j';

$\mathrm{K}_{\mathrm{j}}$ - matriz de rigidez da estrutura, que pode ser variável $\mathrm{K}_{\mathrm{j}}=\mathrm{K}_{\mathrm{j}}\left(\mathrm{u}_{\mathrm{j}}\right)$

$u_{j}^{c}$ - vetor deslocamentos nodais na iteração final do incremento 'j';

$\Delta F_{j+1}^{\text {ext }}$ - vetor de incremento de forças de 'j' a ' $j+1$ ';

$F_{j}^{e x t}$ - vetor de forças nodais aplicadas à estrutura no incremento 'j', (correspondente àsoma dos $\Delta \mathrm{F}^{\text {ext }}$ aplicados até o incremento 'j');

passo 2 - assume-se comportamento elástico linear entre o vetor de forças aplicado, e o de deslocamentos obtidos. Através dos deslocamentos, determina-se o estado de curvaturas (ou de tensões, para uma análise no campo das tensões e deformações):

$$
\Delta \mathrm{u}_{\mathrm{j}+1}=\left[\mathrm{K}_{\mathrm{j}}\right]^{-1} \cdot \Delta \mathrm{F}_{\mathrm{j}+1}^{\mathrm{ext}}
$$




$$
\begin{aligned}
& \text { portanto } \Delta\left(\frac{1}{r}\right)_{j+1}=\left[B_{i}\right] \cdot \Delta u_{j+1} \\
& \text { e } \Delta M_{j+1}^{t}=(E . I)_{j} \cdot \Delta\left(\frac{1}{r}\right)_{j+1}
\end{aligned}
$$

onde : $\Delta \mathrm{u}_{\mathrm{i}+1}$ - vetor de incrementos dos deslocamentos nodais de 'j' a 'j+1';

$\Delta\left(\frac{1}{r}\right)_{j+1}$ - incremento das curvaturas globais de 'j' a 'j+1';

$\Delta \mathrm{M}_{\mathrm{j}+1}^{\mathrm{t}}$ - incremento elástico dos momentos fletores globais de 'j' a 'j+1';

$\left[\mathrm{B}_{\mathrm{i}}\right]$ - matriz que relaciona as curvaturas aos deslocamentos (elemento i);

$(E . I)_{i}$ - módulo de rigidez àflexão da seção transversal do elemento i.

passo 3- acumula-se o momento fletor total $M_{j+1}^{t}=M_{j}+\Delta M_{j+1}^{t}$

onde : $\mathrm{M}_{\mathrm{j}+1}^{\mathrm{t}}$ - momento fletor de tentativa, a ser analisado.

passo 4- verifica-se o escoamento dos pontos de Gauss do elemento através da aplicação do critério:

$$
M_{j+1}^{e f} \geq M_{y j}
$$

onde : $M_{j+1}^{e f}=M_{j+1}^{t}$ - momento fletor efetivo ( $M_{x}$ para o caso uniaxial);

$M_{y j}=\left(M_{y_{j-1}}+k \cdot \alpha_{j}\right)$ - momento fletor de escoamento para o caso uniaxial.

Se ocorreu o escoamento, ou seja, $M_{j+1}^{e f} \geq M_{y j}$, faz-se a redução do momento fletor $M_{j+1}^{t}$ para o diagrama momento-curvatura, obtendo-se $M_{j+1}$ de acordo com o modelo constitutivo imposto. Se não ocorreu o escoamento durante o incremento ' $\mathrm{j}+1$ ', ou seja, $\mathrm{M}_{\mathrm{j}+1}^{\mathrm{ef}}<\mathrm{M}_{\mathrm{yj}}$, conclui-se verdadeira a hipótese inicial de incremento elástico, e o momento fletor ao final do incremento 'j+1' é: $M_{j+1}=M_{j+1}^{t}$.

passo 5- através de integração dos momentos fletores no domínio do elemento, calculam-se as forças nodais internas, que comparadas ao vetor de forças externas, determinam o resíduo $\Psi_{j+1}$. Se a norma deste for superior, em módulo, à tolerância estipulada na análise, retorna-se ao passo 1, aplicando-se apenas o vetor resíduo. Com isso, inicia-se a $2^{\mathrm{a}}$ iteração do incremento 'j+1'. Caso 
contrário, se este for menor que a tolerância estipulada, conclui-se este incremento 'j+1' de forças, e parte-se para um novo incremento 'j+2', caso exista.

O estabelecimento da convergência é de grande importância para o processo incremental-iterativo, e pode ser determinado de diversas formas: convergência de forças, de deslocamentos, e de energia (convergência do par força-deslocamento). O campo de verificação das convergências também pode variar desde um grau de liberdade, até a verificação de todos os graus de liberdade da estrutura conjuntamente. Neste trabalho, toma-se a convergência de forças e de deslocamentos, considerando todos os graus de liberdade da estrutura.

O vetor resíduo de forças em um elemento na iteração ' $k$ ' do incremento 'j', resulta da diferença entre as componentes do vetor de forças aplicado e do vetor de forças internas obtido pela expressão 6.13. A integração é efetuada segundo dois pontos de Gauss. Para a estrutura, o vetor de resíduos de forças é determinado pela expressão 6.20 , e deve contar com a contribuição de todos os elementos, como segue:

$$
\psi_{j+1}=F_{j+1}^{i n t}+F_{j+1}^{e x t}=\sum_{i=1}^{n}[A]\left(\int_{0}^{l_{i}}\left[B_{i}\right]\left\{M_{i}\right\} \cdot d x\right)+F_{j+1}^{e x t}
$$

onde : $l_{i}$ - comprimento do elemento analisado;

[A] - matriz de mapeamento entre os graus de liberdade locais e globais;

$\mathrm{n}$ - número de elementos finitos.

A convergência de forças é atingida no instante em que a razão entre a norma do vetor de resíduos de forças e a norma do vetor de forças aplicadas até aquele instante seja igual ou inferior à tolerância estipulada. Do mesmo modo, a convergência em deslocamentos é atingida quando a razão entre norma do incremento de deslocamentos (globais) entre duas iterações consecutivas, e a norma do respectivo vetor global esteja dentro da tolerância pré-estabelecida.

$$
\frac{\left\|\psi_{i}^{\mathrm{j}}\right\|}{\left\|F_{i}^{\text {ext }}\right\|} \leq \mathrm{t}_{\mathrm{F}} \quad \text { e } \frac{\left\|\Delta \mathrm{u}_{\mathrm{i}}^{\mathrm{j}}\right\|}{\left\|\mathrm{u}_{\mathrm{i}}^{\mathrm{j}}\right\|} \leq \mathrm{t}_{\mathrm{u}}
$$

onde : || - representa a norma Euclidiana de um vetor;

$\psi_{\mathrm{j}}^{k}$ - vetor resíduo de forças na iteração ' $k$ ' do incremento 'j';

$F_{j}^{\text {ext }}$ - vetor de forças no incremento 'j'; 
$u_{j}^{k}$ - vetor deslocamentos da iteração ' $k$ ' do incremento 'j';

$\Delta u_{j}^{k}$ - vetor dos incrementos de deslocamentos na iteração ' $k$ ';

$t_{F}$ e $t_{u}$ - tolerâncias em força e deslocamento respectivamente.

\subsubsection{Estratificado}

O modelo estratificado, como apresentado no item 2.2.1.2 do capítulo 2, exige a adoção de duas relações constitutivas em campo uniaxial: uma para o concreto, e outra para o aço. De acordo com as investigações apresentadas no capítulo 3 deste trabalho, adota-se a relação constitutiva do CEB-FIP MC90 para o concreto solicitado à compressão. Para a tração, implementa-se a relação constitutiva dotada do ramo de amolecimento proposta por FIGUEIRAS (1983). Alternativamente, optou-se também pela implementação do modelo de dano de Mazars (Figura 6.2). Diferentemente do que se observa na análise das lajes, o modelo implementado às vigas não se mostra sensível ao problema da dependência de malha. Apesar dessa observação, o ramo de amolecimento pósruptura à tração pode ser determinado com base nas mesmas prescrições da energia de fratura $\left(G_{f}\right)$ empregadas para o caso das lajes de concreto armado.

As barras de aço, sob solicitação uniaxial, são modeladas segundo uma relação constitutiva elastoplástica perfeita (Figura 6.2). Além da modelagem básica dos materiais, encontram-se implementados também, modelos específicos para a descrição do escorregamento das armaduras longitudinais, e para a quantificação dos efeitos do tempo sobre a estrutura, de acordo com os itens 3.7 e 3.8 do capítulo 3.

A abordagem do problema não-linear para o modelo estratificado segue 0 mesmo procedimento incremental-iterativo apresentado no item 6.2.1, com a diferença de atender a duas relações constitutivas no campo das tensões e das deformações, ao invés de uma, no campo dos momentos fletores e das curvaturas.

\subsection{Modelos para os pilares}

Para a análise dos pilares utiliza-se a seção transversal filamentada. Além dos modelos constitutivos para o aço e o concreto, são também incorporados os modelos de aderência, e os efeitos do tempo sobre o comportamento, seguindo as mesmas premissas adotadas para as vigas. 


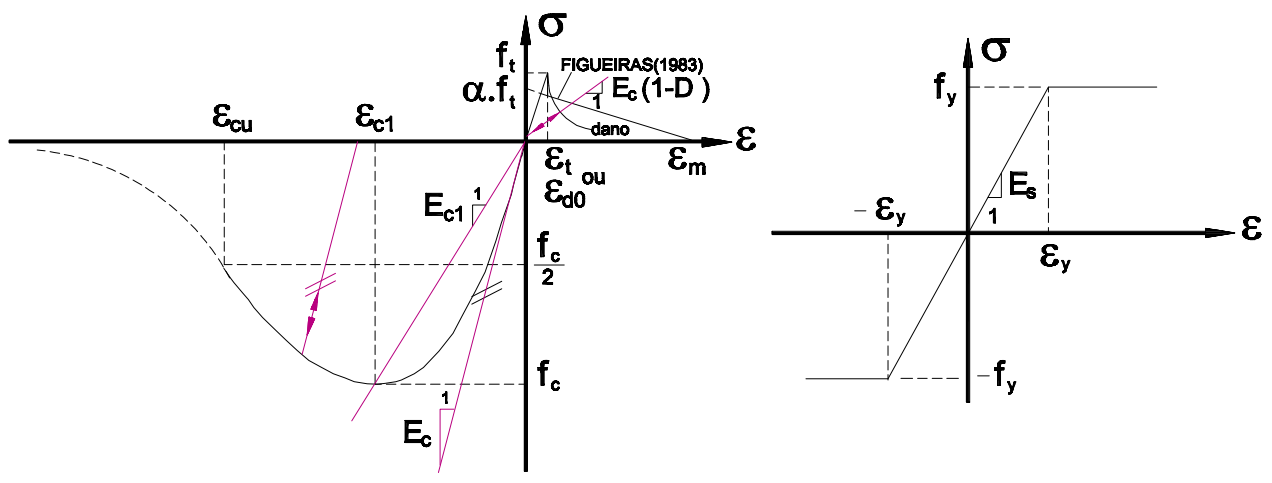

Figura 6.2 - Modelos constitutivos uniaxiais para o concreto e o aço

onde: $f_{y}$ - resistência de escoamento do aço àtração;

$\varepsilon_{y}=f_{y} / E_{s}-$ deformação específica de escoamento do aço;

$E_{s}$ - módulo de deformação longitudinal do aço.

Os parâmetros dos modelos podem ser calculados pelo CEB-FIP MC90, ou mesmo pela NBR-6118, de acordo com a classe de resistência de cada material (Tabela 6.1). Já os parâmetros do modelo de dano não são relacionáveis à resistência característica do concreto e, por esse motivo, devem ser obtidos experimentalmente. Esse fato prejudica a aplicabilidade prática do modelo de dano, pois a realização de ensaios prévios nem sempre é viável na prática.

Tabela 6.1 - Valores dos parâmetros do concreto e do aço

\begin{tabular}{|c|c|c|}
\hline parâmetro & CEB-FIP Model Code 1990 & NBR-6118 \\
\hline$\epsilon_{\mathrm{c} 1}$ & 0,0022 & 0,0020 \\
\hline$\epsilon_{\text {cu }}$ & $\sigma_{\mathrm{c}}=0,5 . \mathrm{f}_{\mathrm{c}}$ na expressão $3.31^{\mathrm{a}}$ & não consta \\
\hline$\epsilon_{\mathrm{m}}$ & 0,0020 & não consta \\
\hline$f_{c}=f_{c m}$ & $\mathrm{f}_{\mathrm{ck}}+\Delta \mathrm{f}(\mathrm{com} \Delta \mathrm{f} \cong 8 \mathrm{MPa})$ & $\mathrm{f}_{\mathrm{ck}}+\Delta \mathrm{f}(\mathrm{com} \Delta \mathrm{f} \cong 3,5 \mathrm{MPa})$ \\
\hline $\mathrm{f}_{\mathrm{t}}=\mathrm{f}_{\mathrm{ctm}}$ & $0,30 .\left(f_{\mathrm{ck}}\right)^{\frac{2}{3}} \quad(\mathrm{MPa})$ & $\begin{array}{c}\mathrm{k} \cdot\left(\frac{\mathrm{f}_{\mathrm{ck}}}{10}\right) \text { para } \mathrm{f}_{\mathrm{ck}} \leq 18 \mathrm{MPa} \\
\mathrm{k} \cdot\left(0,06 . \mathrm{f}_{\mathrm{ck}}+0,7\right) \text { para } \mathrm{f}_{\mathrm{ck}}>18 \mathrm{MPa} \\
\mathrm{k}=\left\{\begin{array}{c}1,2 \rightarrow \text { sec. re tan gular } \\
1,5 \rightarrow \text { sec. " } \mathrm{T} "\end{array}\right.\end{array}$ \\
\hline $\mathrm{E}_{\mathrm{c}}$ & $2,15 \times 10^{4}\left(\frac{f_{\mathrm{cm}}}{10}\right)^{\frac{1}{3}}(\mathrm{MPa})$ & $6600 \cdot \sqrt{f_{c k}+3,5}(\mathrm{MPa})$ \\
\hline$E_{c 1}$ & $\frac{f_{c m}}{0,0022}$ & $\frac{f_{c m}}{0,0020}$ (não consta) \\
\hline$f_{y}$ & $f_{\mathrm{yk}}$ (sugestão deste autor) & $\mathrm{f}_{\mathrm{yk}}$ (sugestão deste autor) \\
\hline$E_{s}$ & $210000 \mathrm{MPa}$ & $210000 \mathrm{MPa}$ \\
\hline$\alpha$ & $0,5 \leq \alpha \leq 0,7$ & não consta \\
\hline
\end{tabular}


Um aspecto bastante importante, e que vale a pena ser discutido, diz respeito ao posicionamento da linha neutra na seção transversal durante a história de carregamento do elemento estrutural. Para facilitar a compreensão, será tomado o caso de um elemento de viga submetido à flexão simples, na $1^{\underline{a}}$ iteração do $1^{0}$ incremento de um carregamento externo que lhe impõe um estado de deslocamentos e, conseqüentemente, um campo de curvaturas. A cada um dos pontos de integração ou, simplesmente PGs, deverá corresponder um valor de curvatura, e um estado de deformações associado a cada uma dessas curvaturas. Admitindo-se, inicialmente, que a linha neutra corte a seção transversal na metade da sua altura geométrica, e empregando os modelos constitutivos dos materiais, determinam-se as tensões e as forças internas correspondentes a cada PG.

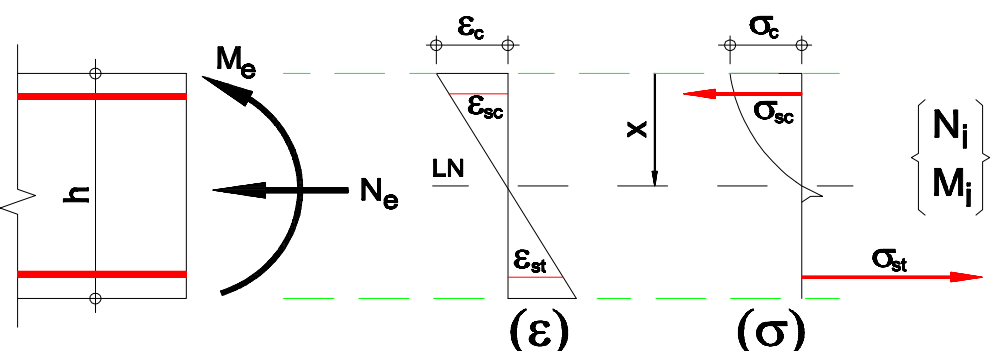

Figura 6.3 - Estados de deformação, tensão e forças ( $1^{a}$ iteração do $1^{\circ}$ incremento)

Esse vetor de forças internas $\left\{\mathrm{N}_{\mathrm{i}}, \mathrm{M}_{\mathrm{i}}\right\}$, comparado ao vetor das forças externas $\left\{N_{e}, M_{e}\right\}$, resulta em um vetor de resíduos $\Psi=\{\Delta N, \Delta M\}$ composto por força normal e momento fletor, já que a força cortante é obtida pelo equilíbrio dos momentos fletores. Como se trata de flexão simples $(\mathrm{N}=0)$, o resíduo de normal nos dois PGs deve ser levado a zero através de um dos procedimentos a seguir:

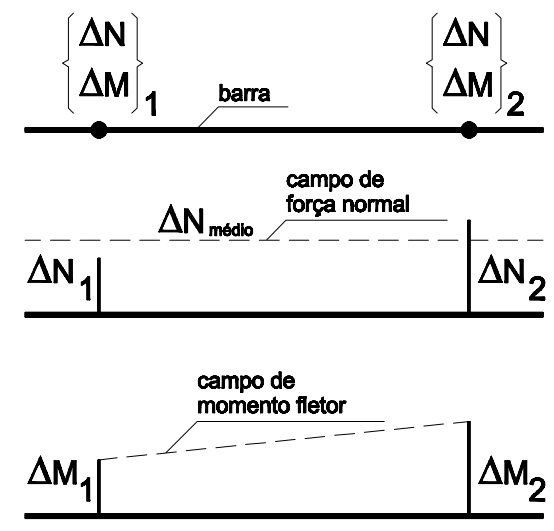

Figura 6.4 - Ilustração do vetor resíduo sobre o domínio da barra

- a primeira alternativa, consiste em manter a curvatura obtida para a iteração em função do estado de deslocamentos, e movimentar a LN para até que 
seja satisfeita a condição de $\mathrm{N}_{\mathrm{i}}=0$ (uma vez que $\mathrm{N}_{\mathrm{e}}=0$ ). Estabelecida essa condição calcula-se, para a posição atualizada da $L N$, o vetor de forças internas e o respectivo vetor resíduo $\Psi=\{\Delta \mathrm{M}\}$ (pois $\Delta \mathrm{N}=0$ ). Obedecendo a esse procedimento são acertadas, independentemente, as posições das linhas neutras nos dois PGs;

- a segunda é mais simples, e consiste na reaplicação do vetor resíduo $\Psi=\{\Delta \mathrm{N}, \Delta \mathrm{M}\}$ à estrutura. Desse modo, a própria parcela do resíduo referente à normal $(\Delta N)$ fica responsável pelo reposicionamento da LN na seção transversal.

Ambas as alternativas apresentam aspectos positivos e negativos. A primeira delas apresenta convergência com um menor número de iterações (cerca de $70 \%$ ) em relação à segunda. No entanto, a sua aplicação à casos de flexão oblíqua se torna mais complexa devido à inclinação da LN com os eixos principais de inércia da seção transversal. A segunda alternativa é mais simples de ser implementada, porém apresenta convergência com maior número de iterações comparativamente à primeira alternativa. A utilização de um campo de deslocamentos longitudinais linear para o elemento finito gera um campo constante de forças normais. Desse modo, ao se realizarem as integrações das tensões normais no domínio do elemento segundo os dois PGs, chega-se a um resíduo de normal equivalente àmédia obtida nos dois PGs.

$$
\Delta N=\int_{V}\left[B_{i}\right]^{\top}\left\{\sigma_{i}\right\} d V=\int_{0}^{I_{i}}\left[\begin{array}{c}
-\frac{1}{l_{i}} \\
\frac{1}{l_{i}}
\end{array}\right]\left\{\begin{array}{ll}
\Delta N_{1} & \Delta N_{2}
\end{array}\right\}=\left\{\begin{array}{ll}
\frac{-N_{1}-N_{2}}{2} & \frac{N_{1}+N_{2}}{2}
\end{array}\right\}
$$

Esse valor médio, no entanto, é maior, em módulo, que o resíduo verificado no PG menos solicitado (Figura 6.4), o que na prática deve provocar um novo resíduo nessa seção transversal, de sinal contrário ao anterior. Sucessivamente, para o PG menos solicitado, há a inversão do sinal do resíduo a cada iteração mas sempre convergindo para a solução. Por outro lado, sendo o valor médio menor, em módulo, que o resíduo observado no PG mais solicitado, este torna-se insuficiente para colocar a LN em uma posição capaz de anular o resíduo de normal nessa seção. Esse PG mais solicitado apresenta uma convergência monotônica para a LN, já que não ocorre a inversão de sinal do resíduo para essa seção transversal. Por esse motivo torna-se a convergência para o elemento e para a própria estrutura torna-se mais dispendiosa em termos do número de iterações comparativamente àprimeira alternativa. 


\subsubsection{Atualização da matriz de rigidez}

A análise dos elementos lineares de concreto armado pode ser efetuada de acordo com três procedimentos de solução: matriz de rigidez inicial, método de Newton-Raphson, ou Newton-Raphson modificado. Os dois últimos métodos adotam a atualização da matriz de rigidez como efeito exclusivo da variação do módulo de deformação longitudinal dos materiais. Para o N-R modificado, a matriz de rigidez é atualizada apenas na $2^{\underline{a}}$ iteração de cada incremento (Figura 6.1).

\subsection{Modelos para as lajes}

Para a análise das lajes de concreto armado cabem os mesmos comentários tecidos no segundo parágrafo do item 6.2 sobre a aplicabilidade de ambos os modelos: não-estratificados e estratificados. No campo dos momentos fletores e das curvaturas foram implementados, de acordo com o item 6.2.1, os modelos propostos pelo CEB-FIP MC90 e por CORRÊA (1991), adotando o momento equivalente dado por von Mises $\left(M_{e q}=\sqrt{\frac{2}{3} \cdot\left(M_{x}^{2}+M_{y}^{2}-M_{x} \cdot M_{y}\right)+2 \cdot M_{x y}^{2}}\right)$.

No entanto, especial destaque é dado doravante à implementação do modelo estratificado com base na teoria introduzida no capítulo 3. As armaduras longitudinais estão submetidas exclusivamente à ação de tensões normais e, como no caso das vigas, respondem àrelação constitutiva elastoplástica perfeita.

As camadas de concreto simples têm o comportamento mecânico regido por um modelo misto. Para os estados de compressão biaxial, aplica-se o critério de von Mises que, como observado no capítulo 3, apresenta resultados bastante razoáveis na representação desse comportamento. Para os estados envolvendo a tração, emprega-se o modelo de fissuração dispersa fixa, monitorado pelo critério de Rankine, responsável pelo cut-off da superfície de von Mises (Figura 6.5).

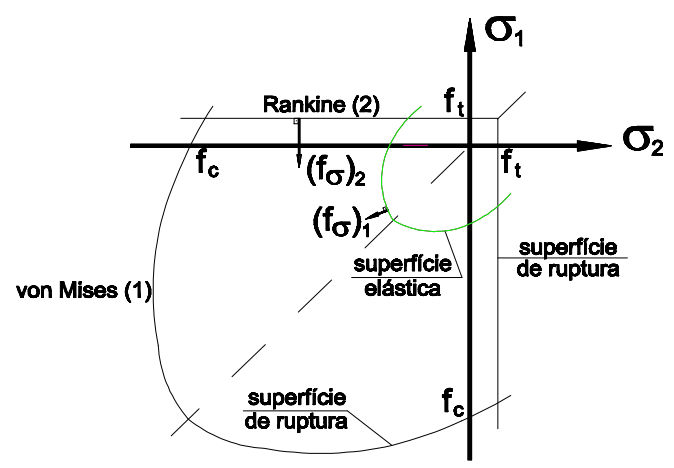

Figura 6.5 - Superfícies do modelo implementado: von Mises e Rankine 
Como indicado na maioria das referências consultadas, a superfície elástica para o critério de von Mises (superfície 1) pode ser adotada no limite de 30\% da resistência à ruptura $\left(f_{c}\right)$. $O$ encruamento é do tipo positivo isótropo, estabelecido em função da deformação plástica equivalente (strain-hardening), e a evolução (encruamento) das superfícies de carregamento até o limite da ruptura é regida pela parábola de Madrid. Vale a pena salientar que, no caso da superfície de von Mises, ZIENCKIEWICZ;TAYLOR(1991) provam que ambos os encruamentos: por trabalho (work-hardening) e por deformação, resultam na mesma formulação incremental. A regra da normalidade do vetor fluxo plástico, na qual $r(\{\sigma\},\{q\})=f_{\sigma}$, é aqui adotada para o encruamento das duas superfícies. Sua aplicabilidade é mais indicada a materiais que não apresentem variação volumétrica com a plastificação, como é o caso do aço anteriormente àruptura. No entanto, o emprego dessa regra à descrição do comportamento do concreto tem proporcionado bons resultados (CHEN;CHEN (1975)).

\subsubsection{Formulação incremental do modelo de von Mises}

As expressões 3.2 a 3.9, que definem o modelo elastoplástico básico, podem ser reescritas em função da parte desviadora do tensor das tensões, aqui denotado por $\{S\}$. O critério de von Mises (expressão 3.3) pode ser reescrito:

$$
f(\{\sigma\},\{q\})=\sqrt{2 \cdot J_{2}}-\sqrt{\frac{2}{3}}\left(\sigma_{y}+\text { k. } \alpha\right)
$$

o invariante $\mathrm{J}_{2}$ pode ser escrito em função do tensor das tensões:

$$
\mathrm{J}_{2}=\frac{1}{2}\|\sigma\|^{2}-\frac{1}{6}(\operatorname{tr}\{\sigma\})^{2}
$$

onde: $\{S\}=\{\sigma\}-\frac{1}{3} \operatorname{tr}\{\sigma\}$

$\{\sigma\}$ - tensor das tensões no espaço tridimensional;

$\operatorname{tr}\{\sigma\}=\sigma_{1}+\sigma_{2}+\sigma_{3}$ - é o traço do tensor das tensões $\{\sigma\}$.

por sua vez, a norma do tensor $\{S\}$ pode ser escrita como:

$$
\|S\|=\sqrt{\|\sigma\|^{2}-\frac{1}{3}(\operatorname{tr}\{\sigma\})^{2}}
$$

a partir das expressões 6.24 e 6.25, o critério é reescrito como: 


$$
f(\{\sigma\},\{q\})=\|S\|-\sqrt{\frac{2}{3}}\left(\sigma_{y}+k . \alpha\right)
$$

e redefine-se a evolução das deformações plásticas:

$$
\left\{\dot{\varepsilon}^{p}\right\}=\dot{\gamma} \frac{\{S\}}{\|S\|}=\dot{\gamma}\{n\}
$$

onde: $\{n\}=\frac{\{S\}}{\|S\|}=r(\{\sigma\},\{q\})$ - corresponde ao vetor unitário que determina a direção do fluxo plástico segundo uma lei associativa $r\{\{\sigma\},\{q\}\}=f_{\sigma}$.

Necessita-se agora, a definição de deformação plástica efetiva $\bar{\alpha}$. Esta variável deve ser definida de tal modo a recuperar-se o caso uniaxial. Deste modo, a partir da definição clássica de deformação plástica efetiva:

$$
\bar{\alpha}(\mathrm{t})=\int_{0}^{\mathrm{t}} \sqrt{\frac{2}{3}} \cdot\left\|\left\{\dot{\varepsilon}^{\mathrm{p}}\right\}(\mathrm{t})\right\| \cdot d \mathrm{t}
$$

obtém-se:

$$
\bar{\alpha}=\sqrt{\frac{2}{3}} \alpha
$$

e, a evolução da deformação plástica efetiva, torna-se:

$$
\dot{\bar{\alpha}}=\dot{\gamma} \cdot \sqrt{\frac{2}{3}}
$$

De modo a adaptar as expressões 6.26 a 6.30, à representação do comportamento relativo ao EPT $\left(\sigma_{z} \equiv \tau_{x z} \equiv \tau_{y z}=0\right)$, necessita-se uma particularização das relações, através da introdução de uma matriz $[P]$ que relaciona o tensor de um estado plano de tensões ao respectivo tensor desviador $\left\{\mathrm{S}^{\star}\right\}$ (incompleto), omitindo-se a representação da componente de tensão desviadora segundo uma terceira direção, aqui denominada direção ' $z$ ' ( $\left.s_{z z}\right)$.

$$
\left\{S^{*}\right\}=[P] \cdot\{\sigma\}
$$

onde: $\{S\}=\left\{S_{x x} S_{x y} S_{y y} S_{z z}\right\}$ - representa o tensor desviador completo;

$$
\begin{aligned}
& S_{z z}=-\sigma_{m}=-\left(\frac{\sigma_{x x}+\sigma_{y y}}{3}\right) ; \\
& \left\{S^{*}\right\}=\left\{S_{x x} S_{y y} S_{x y}\right\} \text { - representa o tensor desviador incompleto; }
\end{aligned}
$$




$$
[P]=\frac{1}{3}\left[\begin{array}{ccc}
2 & -1 & 0 \\
-1 & 2 & 0 \\
0 & 0 & 6
\end{array}\right] \text { - matriz que relaciona }\{S\} \text { a }\{\sigma\}
$$

desse modo, pode-se reescrever $\|S\|$ como:

$$
\begin{aligned}
& \|S\|=\sqrt{\{S\} \cdot\{S\}}=\sqrt{\left\{S^{*}\right\} \cdot\left\{S^{*}\right\}+S_{z z}^{2}}=\sqrt{\left\{S^{*}\right\} \cdot\left\{S^{*}\right\}+\sigma_{m}^{2}} \\
& \|S\|=\sqrt{\left\{S^{*}\right\} \cdot\left\{S^{*}\right\}+\left\{\begin{array}{c}
\sigma_{m} \\
\sigma_{m} \\
0
\end{array}\right\}\left\{S^{*}\right\}}=\sqrt{\left(\left\{S^{*}\right\}+\left\{\begin{array}{c}
\sigma_{m} \\
\sigma_{m} \\
0
\end{array}\right)\left\{S^{*}\right\}\right.}=\sqrt{\left(\left\{S^{*}\right\}+\left\{\begin{array}{c}
\sigma_{m} \\
\sigma_{m} \\
0
\end{array}\right\}\right)[P]\{\sigma\}} \\
& \|S\|=\sqrt{\{\sigma\}^{\top}[P]\{\sigma\}}
\end{aligned}
$$

onde: $\{\sigma\}^{\top}$ - tensor das tensões transposto.

Com base em 6.33, reescrevem-se as expressões 6.26, 6.27 e 6.30 :

$$
\begin{aligned}
& f(\{\sigma\},\{q\})=\sqrt{\{\sigma\}^{\top}[P]\{\sigma\}}-\sqrt{\frac{2}{3}}\left(\sigma_{y}+k \cdot \bar{\alpha}\right) \\
& \left\{\dot{\varepsilon}^{p}\right\}=\dot{\gamma}[P]\{\sigma\} \\
& \dot{\bar{\alpha}}=\dot{\gamma} \sqrt{\frac{2}{3}\{\sigma\}^{\top}[P]\{\sigma\}}
\end{aligned}
$$

Integra-se, a seguir, o modelo triaxial adaptado ao EPT em um intervalo de interesse $\Delta t \in[0, T] \subset R$. A integração é por um procedimento puramente implícito (Backward-Euler Difference Scheme), proposto por SIMO;HUGHES (1988). As relações constitutivas poderão ser escritas de forma incremental, viabilizando-se a atualização das variáveis de estado $\left(\{\sigma\},\left\{\varepsilon^{p}\right\}, \bar{\alpha}\right)_{j}$ do instante $t_{j}$, para seus valores $\left(\{\sigma\},\left\{\varepsilon^{p}\right\}, \bar{\alpha}\right)_{j+1}$ no instante de tempo final $t_{j+1}=t_{j}+\Delta t$. Após a integração, as expressões 6.23 e 6.34 a 6.36 resultam:

$$
\begin{aligned}
& \{\varepsilon\}_{j+1}=\{\varepsilon\}_{j}+\{\dot{\varepsilon}\}_{\Delta t}=\{\varepsilon\}_{j}+\nabla^{s}(\Delta\{u\}) \\
& \left\{\varepsilon^{p}\right\}_{j+1}=\left\{\varepsilon^{p}\right\}_{j}+\left\{\dot{\varepsilon}^{p}\right\}_{j+1} \Delta t=\left\{\varepsilon^{p}\right\}_{j}+\dot{\gamma}_{j+1} \Delta t[P]\{\sigma\}_{j+1}=\left\{\varepsilon^{p}\right\}_{j}+\gamma_{j+1}[P]\{\sigma\}_{j+1}
\end{aligned}
$$




$$
\begin{aligned}
& \bar{\alpha}_{j+1}=\bar{\alpha}_{j}+\dot{\bar{\alpha}}_{j+1} \Delta t=\bar{\alpha}_{j}+\dot{\gamma}_{j+1} \Delta t \sqrt{\frac{2}{3}} \bar{f}_{j+1}=\bar{\alpha}_{j}+\gamma_{j+1} \sqrt{\frac{2}{3}} \bar{f}_{j+1} \\
& \{\sigma\}_{j+1}=[C]\left(\{\varepsilon\}_{j+1}-\left\{\varepsilon^{p}\right\}_{j+1}\right)
\end{aligned}
$$

onde : $\gamma_{\mathrm{j}+1}=\Delta$ t. $\dot{\gamma}_{\mathrm{j}+1}$ para simplificação da notação utilizada;

$\bar{\alpha}_{j+1}$ - deformação plástica efetiva no incremento 'j+1';

$\bar{f}_{j+1}=\sqrt{\{\sigma\}_{j+1}^{\top}[P]\{\sigma\}_{j+1}} ;$

[C] - matriz dos módulos constitutivos de rigidez para o EPT.

Da condição de complementaridade de Kuhn-Tucker:

$$
\begin{aligned}
& f\left(\{\sigma\}_{j+1},\{q\}_{j+1}\right) \leq 0 \\
& \gamma_{j+1} \geq 0 \\
& \gamma_{j+1} f\left(\{\sigma\}_{j+1},\{q\}_{j+1}\right)=0, \text { pois } \Delta t \geq 0
\end{aligned}
$$

Para que o processo iterativo possa ser iniciado, as expressões 6.37 a 6.41 devem estar relacionadas a um estado de tensões originário de uma tentativa inicial que será tomada, por simplicidade, como o resultado da aplicação de relação elástica linear entre tensão e deformação. A indicação das variáveis relativas a esse estado de tensões será feita através do superíndice t.

$$
\{\sigma\}_{j+1}^{\mathrm{t}}=[C]\left(\{\varepsilon\}_{\mathrm{j}+1}-\left\{\varepsilon^{\mathrm{p}}\right\}_{\mathrm{j}}\right)
$$

que resulta em:

$$
\begin{aligned}
& \{\varepsilon\}_{j+1}=\{\varepsilon\}_{j}+\nabla^{s}\{u\} \\
& \{q\}_{j+1}^{t}=\{q\}_{j} \\
& f_{j+1}^{t}=f\left(\{\sigma\}_{j+1}^{t},\{q\}_{j+1}\right) \\
& {[\Xi]_{j+1}(\gamma)=\left([C]^{-1}+\gamma_{j+1}[P]\right)^{-1}} \\
& \{\sigma\}_{j+1}=[\Xi]_{j+1}(\gamma)[C]^{-1}\{\sigma\}_{j+1}^{t}
\end{aligned}
$$


onde: $[\Xi]_{j+1}(\gamma)$ - representa a matriz elástica tangente modificada.

As expressões 6.41, quando relacionadas ao estado de tentativa, possibilitam verificar uma situação de carregamento em regime elástico ou plástico, com base nas seguintes condições:

a) se $\mathrm{f}_{\mathrm{j}+1}^{\mathrm{t}}<0 \rightarrow \mathrm{f}_{\mathrm{j}+1}<0$

e portanto: $\gamma_{\mathrm{j}+1} \mathrm{f}_{\mathrm{j}+1}=0 \rightarrow \gamma_{\mathrm{j}+1}=0$ (incremento elástico)

b) se $\mathrm{f}_{\mathrm{j}+1}^{\mathrm{t}}>0 \rightarrow\left\{\varepsilon^{\mathrm{e}(\mathrm{t})}\right\}_{\mathrm{j}+1} \neq\{\varepsilon\}_{\mathrm{j}+1} \rightarrow \gamma_{\mathrm{j}+1} \neq 0 \rightarrow \gamma_{\mathrm{j}+1}>0 \quad\left(\gamma_{\mathrm{j}+1} \geq 0 \mathrm{p} /\right.$ def. $)$,

e portanto: $\gamma_{\mathrm{j}+1} \mathrm{f}_{\mathrm{j}+1}=0 \rightarrow \mathrm{f}_{\mathrm{j}+1}=0$ (incremento plástico)

As expressões 6.43 a 6.47 , que representam o estado de tentativa em regime elástico linear, dependem da determinação do parâmetro $\gamma$, o qual pode ser obtido pela imposição do critério $(f=0)$ no instante $t_{j+1}$. Assim, a expressão $f=f(\{\sigma\},\{q\})$, pode ser escrita na forma $f=f(\gamma)$. Supondo $\left(f(\{\sigma\},\{q\}) \in \partial E_{\sigma}\right)$ :

$$
f(\{\sigma\},\{q\})=\bar{f}(\{\sigma\},\{q\})-\sqrt{\frac{2}{3}} \cdot k\left(\bar{\alpha}_{j+1}\right)=0,
$$

onde: $k\left(\bar{\alpha}_{j+1}\right)=\left(\sigma_{y}+k \cdot \bar{\alpha}_{j+1}\right)$.

elevando ao quadrado ambos os membros da expressão:

$f^{2}=\bar{f}^{2}-2 \cdot \bar{f} \cdot \sqrt{\frac{2}{3}} \cdot k\left(\bar{\alpha}_{j+1}\right)+\frac{2}{3} \cdot k^{2}\left(\bar{\alpha}_{j+1}\right)=\frac{1}{2} \bar{f}^{2}-\bar{f} \cdot \sqrt{\frac{2}{3}} \cdot k\left(\bar{\alpha}_{j+1}\right)+\frac{1}{3} \cdot k^{2}\left(\bar{\alpha}_{j+1}\right)=0$

agrupando-se os termos semelhantes, vem:

$$
\frac{1}{2} \cdot \bar{f}^{2}-\frac{1}{3} \cdot k^{2}\left(\bar{\alpha}_{j+1}\right)\left[\sqrt{\frac{2}{3}} \cdot \frac{3 \cdot \bar{f}^{k}\left(\bar{\alpha}_{j+1}\right)}{-1}\right]=0
$$

lembrando-se da expressão 6.48, onde:

$$
\bar{f}=\sqrt{\frac{2}{3}} \cdot k\left(\bar{\alpha}_{j+1}\right)
$$

que, introduzida na expressão 6.49, resulta:

$$
\frac{1}{2} \cdot \bar{f}^{2}-\frac{1}{3} \cdot k^{2}\left(\bar{\alpha}_{j+1}\right)\left[\sqrt{\frac{2}{3}} \cdot \frac{3 \cdot \sqrt{\frac{2}{3}} \cdot k\left(\bar{\alpha}_{j+1}\right)}{k\left(\bar{\alpha}_{j+1}\right)}-1\right]=0
$$


que permite concluir:

$$
\frac{1}{2} \bar{f}_{j+1}^{2}-\frac{1}{3} \cdot k^{2}\left(\bar{\alpha}_{j+1}\right)=0
$$

que pode ser escrita na forma:

$$
\left[f\left(\gamma_{j+1}\right)\right]^{2}=\frac{1}{2}\left[\bar{f}\left(\gamma_{j+1}\right)\right]^{2}-\left[R\left(\gamma_{j+1}\right)\right]^{2}=0
$$

onde: $\left[R\left(\gamma_{j+1}\right)\right]^{2}=\frac{1}{3}\left[k\left(\bar{\alpha}_{j+1}\right)\right]^{2}=\frac{1}{3}\left\{k\left[\bar{\alpha}_{j}+\sqrt{\frac{2}{3}} \cdot \gamma_{j+1} \cdot \bar{f}_{j+1}\left(\gamma_{j+1}\right)\right]\right\}^{2}$

Para o caso de isotropia, a matriz constitutiva [C], e a matriz [P] têm as mesmas características, e podem ser reescritas em função de matrizes diagonalizadas como:

$$
\begin{aligned}
& {[P]=[Q][\Lambda p][Q]^{\top}} \\
& {[C]=[Q][\Lambda c][Q]^{\top}}
\end{aligned}
$$

onde: $[Q]=\frac{1}{\sqrt{2}} \cdot\left[\begin{array}{ccc}1 & 1 & 0 \\ -1 & 1 & 0 \\ 0 & 0 & \sqrt{2}\end{array}\right] ; \quad[C]=\frac{E}{1-v^{2}} \cdot\left[\begin{array}{ccc}1 & v & 0 \\ v & 1 & 0 \\ 0 & 0 & \frac{1-v}{2}\end{array}\right]$;

$$
[\Lambda \mathrm{p}]=\left[\begin{array}{ccc}
\frac{1}{3} & 0 & 0 \\
0 & 1 & 0 \\
0 & 0 & 2
\end{array}\right] ; \quad[\Lambda c]=\left[\begin{array}{ccc}
\frac{E}{1-v} & 0 & 0 \\
0 & 2 \mu & 0 \\
0 & 0 & \mu
\end{array}\right]
$$

reescrevendo-se a expressão para $\bar{f}^{2}$ :

$$
\left(\overline{\mathfrak{f}}_{\mathrm{j}+1}\right)^{2}=\{\sigma\}^{\top}[\mathrm{P}][\sigma\}=\{\sigma\}^{\top}[\mathrm{Q}][\Lambda \mathrm{p}][\mathrm{Q}]^{\top}\{\sigma\}
$$

e, utilizando-se a diagonalização dada em 6.53 e 6.54, manipula-se a expressão 6.55 que pode, então, ser escrita para um estado de tensão de tentativa:

$$
\left[\bar{f}\left(\gamma_{j+1}\right)\right]^{2}=\frac{\left(\sigma_{x}^{t}+\sigma_{y}^{t}\right)^{2}}{6 \cdot\left[1+\left(\frac{E}{3(1-v)}\right) \gamma_{j+1}\right]^{2}}+\frac{\left(\sigma_{x}^{t}-\sigma_{y}^{t}\right)^{2}+4\left(\tau_{x y}^{t}\right)^{2}}{2 \cdot\left[1+2 \cdot G \gamma_{j+1}\right]^{2}}
$$


Em resumo, o procedimento de atualização das variáveis de estado $\left(\{\sigma\},\left\{\varepsilon^{p}\right\}, \bar{\alpha}\right)_{j}$, para seus valores $\left(\{\sigma\},\left\{\varepsilon^{p}\right\}, \bar{\alpha}\right)_{j+1}$, devido a um acréscimo de carregamento, pode ser descrito como:

- imposição de incremento em regime elástico linear (6.42 a 6.45);

- resolução da equação 6.51 , com $\left[\bar{f}\left(\gamma_{j+1}\right)\right]^{2}$ dado pela expressão 6.56, obtendo-se o valor de $\gamma_{\mathrm{j}+1}$;

- a partir de $\gamma_{j+1}$, determinam-se as variáveis de estado no instante ' $\mathrm{j}+1$ ', pelas expressões $6.46,6.47,6.39$ e 6.38 (na ordem indicada).

\subsubsection{Atualização da matriz de rigidez (von Mises)}

Assim como na análise dos elementos lineares, a solução incrementaliterativa das lajes pode ser efetuada de acordo com os três procedimentos: matriz de rigidez inicial, método de Newton-Raphson, ou Newton-Raphson modificado. A parcela da atualização da matriz de rigidez referente às camadas de concreto que satisfazem ao critério de von Mises é obtida através da matriz elástica tangente modificada (expressão 6.57).

$$
\left.\frac{d\{\sigma\}}{d\{\varepsilon\}}\right|_{j+1}=[\Xi]_{j+1}(\gamma)-\frac{\left([\Xi]_{j+1}(\gamma)[P]\{\sigma\}_{j+1}\right)\left([\Xi]_{j+1}(\gamma)[P]\{\sigma\}_{j+1}\right)^{\top}}{\{\sigma\}_{j+1}^{\top}[P][\Xi]_{j+1}(\gamma)[P]\{\sigma\}_{j+1}+\bar{\beta}_{j+1}}
$$

onde: $\bar{\beta}_{\mathrm{j}+1}=\frac{2}{3 \theta_{2}}\left(\mathrm{k}_{\mathrm{j}+1}\right)\{\sigma\}_{\mathrm{j}+1}^{\top}[P]\{\sigma\}_{\mathrm{j}+1}$;

$\theta_{2}=1-\frac{2}{3} \mathrm{k}_{\mathrm{j}+1} \cdot \gamma \quad$ (para o caso de $\mathrm{k}$ variável).

\subsubsection{Aspectos sobre a formulação da superfície de Rankine}

A superfície elástica de Rankine (superfície 2) é definida pela resistência à tração do concreto $\left(f_{t}\right)$. FEENSTRA;DE BORST (1995) trazem a formulação completa para o critério de Rankine, incluindo o amolecimento a partir da superfície de ruptura. No entanto, este trabalho apresenta um enfoque peculiar à análise das camadas de concreto submetidas a estados de tração.

Admita-se uma camada de concreto solicitada por um determinado estado plano de tensões que gerem, pelo menos, uma tensão principal positiva superior ao limite de ruptura $\mathrm{f}_{\mathrm{t}}$, promovendo o surgimento de uma ou mais fraturas do tipo $\mathrm{I}$. 
Nessas condições, de acordo com a teoria de fissuras dispersas, a placa de concreto perde as características de comportamento bidimensional acoplado (pois $v \rightarrow 0$ ), e passa a se comportar independentemente nas duas direções principais. O comportamento mecânico segundo essas direções passa a ser governado por relações uniaxiais. Esse comportamento pós-fissuração também é previsto por autores cujos trabalhos estão ligados estritamente ao projeto de lajes de concreto armado. ROCHA (1972) e PARK;GAMBLE (1980), reforçam que as próprias tabelas de Marcos e Czerny, para a determinação de esforços em lajes, foram obtidas desprezando-se o comportamento bidimensional acoplado.

Além da hipótese de desacoplamento do comportamento biaxial apresentada no parágrafo anterior, observa-se que a superfície de Rankine é delimitada paralelamente aos eixos principais. Pela regra da normalidade, então, o retorno de um estado de tentativa elástica à superfície de carregamento se dá paralelamente a um desses eixos. No caso de o estado de tentativa exceder o limite $f_{t}$ nas duas direções principais, o retorno se daria ao vértice da superfície de carregamento, o que está de acordo com o proposto por FEENSTRA;DE BORST (1995), com base na generalização de KOITER (1953) ${ }^{1}$ apud PROENÇA(1988) para a abordagem do escoamento de pontos com derivada indefinida (Figura 6.6).

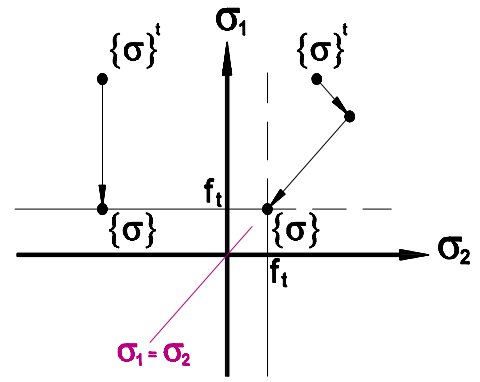

Figura 6.6 - Retornos à superfície de Rankine (ÆEENSTRA;DE BORST(1995))

A curva de amolecimento adotada para a superfície de Rankine é idêntica à do modelo uniaxial (Figura 6.2). No entanto essa curva deve agora ser calibrada com base no conceito de energia de fratura. O comprimento equivalente $h_{\text {eq }}$ é calculado de acordo com o proposto por FEENSTRA;DE BORST (1996):

$$
\mathrm{h}_{\mathrm{eq}}=\alpha_{\mathrm{h}} \cdot \sqrt{\mathrm{A}}
$$

onde: $\alpha_{h}=\left\{\begin{array}{l}\sqrt{2} \text { para elementos com campos lineares } \\ 1 \text { para elementos com campos quadraticos }\end{array}\right.$;

\footnotetext{
${ }^{1}$ KOITER,W.T.(1953). Stress-strain relations, uniqueness and variational theorems for elastic-plastic materials with a singular yield surface. Q. Appl. Math. n. 11, p.350-354. apud PROENÇA(1988).
} 
A - área do elemento finito.

A energia de fratura $G_{f}$ utilizada para calcular os parâmetros da curva de amolecimento são os sugeridos pelo CEB-FIP MC90 (Tabela 6.2) de acordo com a classe do concreto e o diâmetro máximo do agregado graúdo.

Tabela 6.2 - Energia de fratura $G_{f}\left(\mathrm{~N} . \mathrm{m} / \mathrm{m}^{2}\right)$

\begin{tabular}{|c|c|c|c|c|c|c|c|c|}
\hline $\begin{array}{c}\text { tamanho máximo } \\
\text { do agregado }\end{array}$ & \multicolumn{7}{|c|}{ classes do concreto } \\
\hline (mm) & C12 & $\mathbf{C 2 0}$ & $\mathbf{C 3 0}$ & $\mathbf{C 4 0}$ & $\mathbf{C 5 0}$ & $\mathbf{C 6 0}$ & $\mathbf{C 7 0}$ & $\mathbf{C 8 0}$ \\
\hline 8 & 30 & 40 & 50 & 60 & 70 & 75 & 85 & 90 \\
\hline 16 & 50 & 60 & 75 & 90 & 105 & 115 & 125 & 135 \\
\hline 32 & 80 & 105 & 130 & 150 & 170 & 190 & 200 & 220 \\
\hline
\end{tabular}

Cabe observar que a determinação do comprimento equivalente através da expressão 6.58 ameniza, mas não resolve o problema da dependência de malha. Os próprios autores advertem que a expressão tem proporcionado bons resultados para malhas consideradas usuais, o que não é garantido para refinamentos acima de determinados níveis.

Definidas as características de cada superfície separadamente, cabe então a análise do ponto de intersecção entre ambas, que se constitui um ponto de derivada indefinida. A esse vértice, cujas características são similares às do vértice da superfície de Rankine, é aplicada a generalização proposta por Koiter. Como resultado, o retorno de um estado de tentativa inicial pertencente à região delimitada pelos versores normais às duas superfícies concorrentes (Figura 6.7) se dá indiretamente ao vértice. Primeiro, há uma projeção intermediária do estado de tentativa $\{\sigma\}^{\dagger}$ sobre a bissetriz do ângulo formado pelas direções dos vetores de fluxo plástico das duas superfícies naquele ponto. Em seguida, esse estado intermediário retorna ao vértice das superfícies de carregamento.

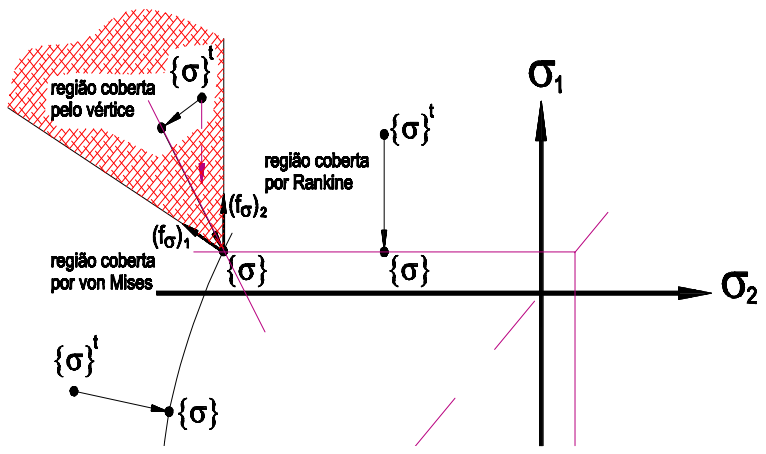

Figura 6.7 - Procedimentos de retorno às superfícies - caso do vértice 
Em termos práticos, na análise de lajes de concreto armado, são raros os estados de tentativa pertencentes à região coberta pelo vértice, tanto que durante as várias simulações numéricas apresentadas neste trabalho, não registrou-se um caso sequer a esse respeito. Apesar disso, o modelo implementado prevê essa possibilidade e, de modo simplificado, executa o retorno apenas à superfície de Rankine (Figura 6.7). Com a adoção desse procedimento, pelo qual a superfície de Rankine exerce predominância na verificação da ruptura para qualquer estado envolvendo a tração, a hipótese de retorno ao vértice formado pelas duas superfícies não é mais obedecida.

\subsubsection{Atualização da matriz de rigidez (Rankine)}

A atualização da matriz de rigidez referente æ̀s camadas de concreto que respondem ao critério de Rankine, assim como para o critério de von Mises, se dá pela alteração da matriz constitutiva [C], então denominada $[\mathrm{C}]^{\mathrm{ep}}$. Por ocasião da fissuração, o concreto passa a apresentar ortotropia, cuja orientação coincide com a dos eixos principais (1 e 2). A cada um dos eixos estão relacionados valores tangentes dos módulos de deformação do concreto $\left(E_{T, 1}, E_{T, 2}\right.$ e $\left.\beta_{c r} \cdot G_{T, 12}\right)$, obtidos da análise uniaxial de cada direção principal isoladamente (lembrando que, neste caso, $v \rightarrow 0$ ) segundo os mesmos procedimentos empregados àanálise uniaxial. $O$ ponderador $\beta_{\mathrm{cr}}$ é introduzido com o objetivo de estimar a contribuição do engrenamento dos agregados na transmissão da tensão de cisalhamento na fissura.

$$
[C]_{12}^{\mathrm{ep}}=\left[\begin{array}{ccc}
\mathrm{C}_{11} & 0 & 0 \\
0 & \mathrm{C}_{22} & 0 \\
0 & 0 & \mathrm{C}_{33}
\end{array}\right]
$$

Com o objetivo de reavaliar a matriz de rigidez de cada elemento, interessa obter a matriz $[\mathrm{C}]_{\mathrm{xy}}^{\mathrm{ep}}$ referida ao sistema cartesiano original $\mathrm{xy}$, relacionável ao sistema de eixos principais através da seguinte transformação linear:

$$
[\mathrm{C}]_{\mathrm{xy}}^{\mathrm{ep}}=[\mathrm{T}]^{\mathrm{T}}[\mathrm{C}]_{12}^{\mathrm{ep}}[\mathrm{T}]
$$

onde: $[T]=\left[\begin{array}{ccc}\cos ^{2}(\alpha) & \operatorname{sen}^{2}(\alpha) & \operatorname{sen}(\alpha) \cos (\alpha) \\ \operatorname{sen}^{2}(\alpha) & \cos ^{2}(\alpha) & -\operatorname{sen}(\alpha) \cos (\alpha) \\ -2 \cdot \operatorname{sen}(\alpha) \cos (\alpha) & 2 . \operatorname{sen}(\alpha) \cos (\alpha) & \left(\cos ^{2}(\alpha)-\operatorname{sen}^{2}(\alpha)\right)\end{array}\right]$; 
$\alpha$ - ângulo formado entre o eixo principal 1 e o eixo $x$ (>0 se anti-horário).

\subsubsection{Estratégia de implementação}

A implementação do modelo envolvendo as superfícies de von Mises e de Rankine pode ser otimizada através da ordenação das tensões principais $\left(\sigma_{2}<\sigma_{1}\right)$. Esse procedimento possibilita a análise dos estados de tensão tirando partido da simetria das superfícies com relação ao eixo $\left(\sigma_{1}=\sigma_{2}\right)$. 


\section{EXEMPLOS PARA AFERIÇÃO DOS MODELOS}

\subsection{Introdução}

Anteriormente ao emprego dos modelos e das implementações discutidas nos capítulos anteriores, há que se aferir sobre a eficácia destes relativamente à correta previsão sobre o comportamento dos elementos estruturais presentes em um pavimento de concreto armado. Com esse objetivo, relaciona-se, a seguir, uma série representativa de exemplos cujos resultados previstos pelos modelos são comparados, tanto àqueles obtidos experimentalmente, quanto aos resultados numéricos apresentados por outros autores.

\subsection{Modelos aplicados à análise de vigas}

Com o objetivo de comprovar o desempenho dos modelos implementados foram escolhidas duas séries de vigas ensaiadas por ÁLVARES (1993), cujos resultados são considerados de boa confiabilidade. Além dos experimentos relativos ao comportamento das vigas, o autor realizou ensaios preliminares dos materiais concreto e aço, tendo obtido os valores apresentados na Tabela 7.1.

Tabela 7.1 - Parâmetros mecânicos dos materiais - experimentais

\begin{tabular}{|c|c|c|}
\hline \multicolumn{2}{|c|}{ concreto } & \multirow{2}{*}{ aço } \\
\cline { 1 - 2 } elastoplástico & dano & \\
\hline$\varepsilon_{\mathrm{c} 1}=0,0032$ & $\varepsilon_{\mathrm{d} 0}=0,00007$ & - \\
\hline$\varepsilon_{\mathrm{cu}}=0,007$ & $\mathrm{~A}_{\mathrm{c}}=0,85$ & - \\
\hline$\varepsilon_{\mathrm{m}}=0,0020$ & $\mathrm{~B}_{\mathrm{c}}=1050$ & - \\
\hline $\mathrm{f}_{\mathrm{c}}=2,55 \mathrm{kN} / \mathrm{cm}^{2}$ & $\mathrm{~A}_{\mathrm{T}}=0,995$ & $\mathrm{f}_{\mathrm{y}}=50,0 \mathrm{kN} / \mathrm{cm}^{2}$ \\
\hline $\mathrm{f}_{\mathrm{t}}=0,2044 \mathrm{kN} / \mathrm{cm}^{2}$ & $\mathrm{~B}_{\mathrm{T}}=8000$ & - \\
\hline $\mathrm{E}_{\mathrm{c}}=2920 \mathrm{kN} / \mathrm{cm}^{2}$ & & $\mathrm{E}_{\mathrm{s}}=19600 \mathrm{kN} / \mathrm{cm}^{2}$ \\
\hline
\end{tabular}


As duas séries apresentam as mesmas características geométricas, de materiais e condições de apoio, mas diferem na quantidade de armadura de flexão. As vigas do grupo I têm armadura longitudinal de tração composta por $3 \Phi 10 \mathrm{~mm}$, enquanto que as do grupo II possuem $5 \Phi 10 \mathrm{~mm}$ dispostos em duas camadas.

Para a análise, procedeu-se a divisão da viga através de 12 elementos finitos com $20 \mathrm{~cm}$ de comprimento cada um, como pode ser observado na Figura 7.1. A seção transversal foi discretizada por 10 camadas de concreto superpostas às armaduras longitudinais de flexão.

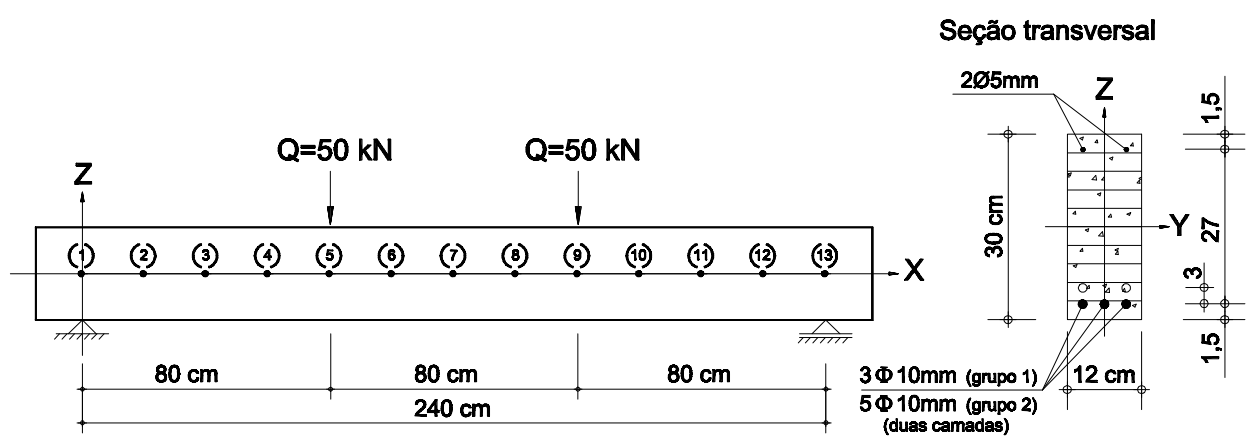

Figura 7.1 - Esquema dos grupos de vigas (grupos I e II)

Foram utilizados incrementos correspondentes a 5,0 kN para cada uma das forças $Q(10,0 \mathrm{kN}$ no total de cada incremento), tolerância de $1 \%$ em forças e $0,5 \%$ em deslocamentos, e permitido um máximo de 20 iterações por incremento.

Os resultados estão representados nos diagramas de força por deslocamento (Figura 7.2 e Figura 7.3). Em ambas as análises numéricas com o modelo estratificado elastoplástico, foi empregado um coeficiente de enrijecimento $\alpha=0,7$ ao modelo de Figueiras (Figura 7.2).

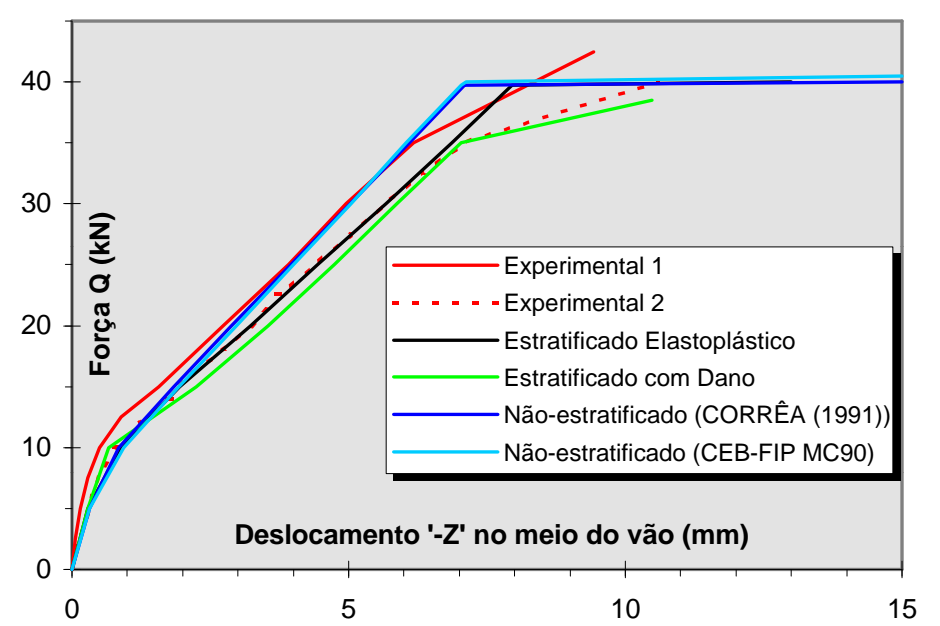

Figura 7.2 - Diagrama força-deslocamento para as vigas do grupo I 


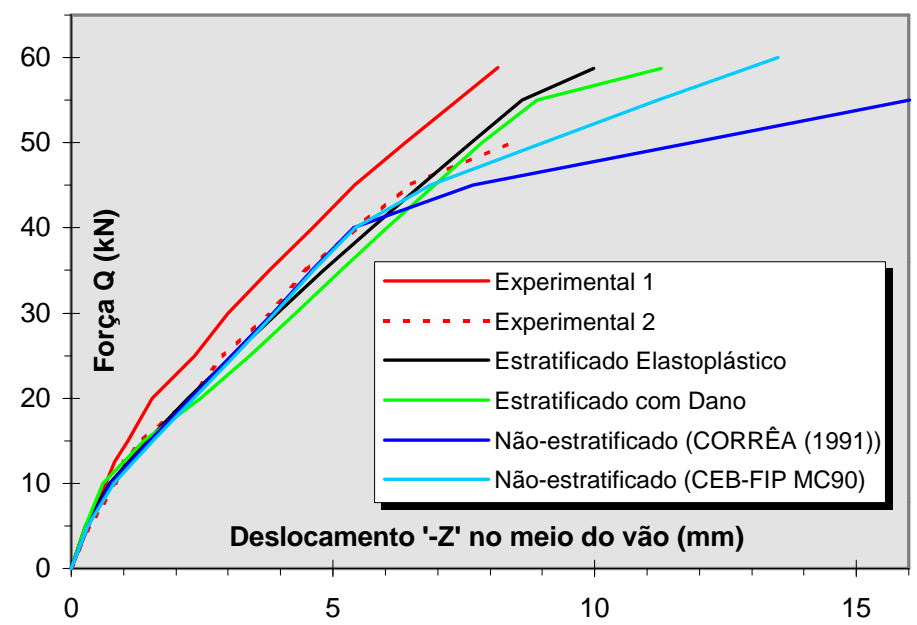

Figura 7.3- Diagrama força-deslocamento para as vigas do grupo II

A análise dos resultados permite concluir sobre a boa representatividade do modelo estratificado elastoplástico no decorrer de toda a história de carregamento. Os modelos não-estratificados, apesar de simples, apresentam bons resultados de esforços e de deslocamentos, principalmente para carregamentos não muito próximos aos de ruptura. No entanto, outros resultados não são facilmente obtidos por esses modelos como, por exemplo, uma descrição sobre a posição da linha neutra na viga. A Figura 7.4 ilustra aposição da linha neutra para as vigas do grupo I submetidas àanálise elastoplástica e a um carregamento $Q=35 \mathrm{kN}$.

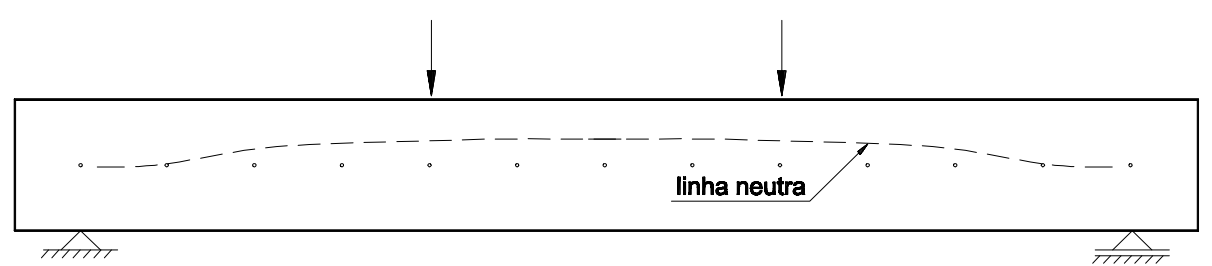

Figura 7.4 - Posição da LN (modelo estratificado elastoplástico)

O modelo de dano de Mazars mostrou-se bastante representativo do comportamento experimental. Para as vigas do grupo I, esse modelo foi capaz de exprimir, com bastante propriedade, os dois pontos de inflexão da curva forçadeslocamento (relativos à fissuração, e ao escoamento da armadura longitudinal tracionada, respectivamente). $\mathrm{Na}$ análise numérica das vigas do grupo II, os modelos estratificados elastoplástico e de dano apresentaram um comportamento semelhante, ambos bastante próximos dos resultados experimentais.

A seguir, estuda-se o problema da dependência de malha para as vigas do grupo I. Para tal, promovem-se duas outras análises, respectivamente com a metade (6), e com o dobro (24) de elementos finitos da malha original (12). Os 
resultados, apresentados na Figura 7.5, evidenciam uma fraca e inexpressiva dependência de malha.

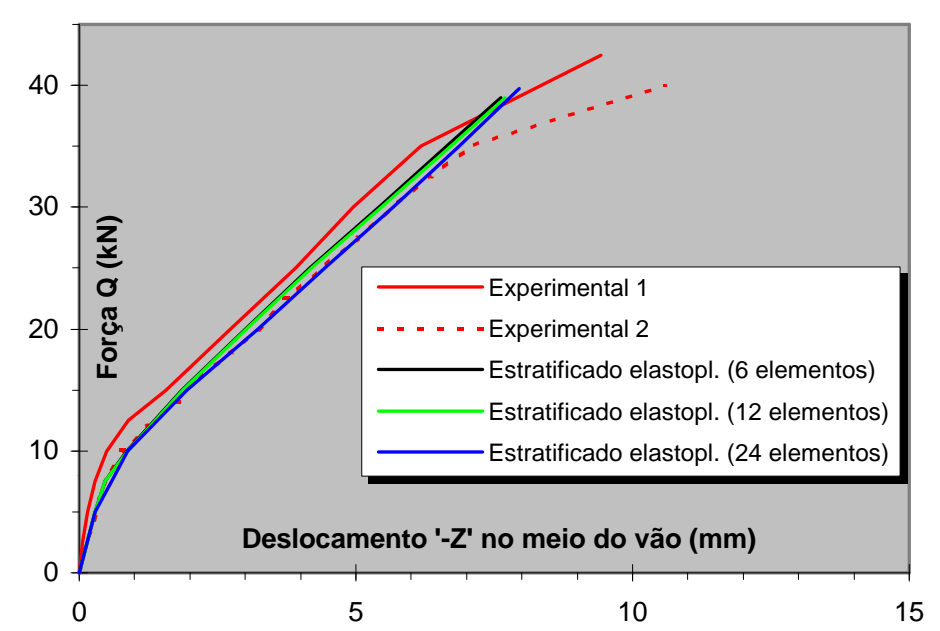

Figura 7.5 - Estudo da dependência de malha - vigas do grupo I

O aspecto da curva força-deslocamento é fortemente influenciado pela tensão de ruptura do concreto à tração que, por sua vez, não exerce grande influência sobre o valor do carregamento limite (ruptura). As simulações numéricas foram efetuadas utilizando-se a tensão de ruptura à tração na flexão $\left(\mathfrak{f}_{t, F}\right)$ de 0,24 $\mathrm{kN} / \mathrm{cm}^{2}$, obtida pela seguinte relação com a tensão de ruptura àtração dada por um ensaio de compressão diametral $\left(\mathfrak{f}_{\mathrm{t}, \mathrm{D}}\right)$, como sugere o CEB-FIP MC90:

$$
f_{t, F}=\frac{0,90 \cdot f_{t, D}}{0,06 \cdot h^{0,7}} \cdot\left(1+0,06 \cdot h^{0,7}\right)
$$

onde: $\mathrm{h}$ - altura da viga em "mm".

Cabe ainda analisar o desempenho do modelo no que se refere ao tempo de processamento requerido para a solução do sistema não-linear. A utilização da matriz de rigidez secante, neste caso, não oferece vantagens, pois leva a uma convergência mais lenta que o procedimento Newton-Raphson, porém consumindo o mesmo tempo para os recálculos das matrizes e vetores do sistema de equações. Os dados da Tabela 7.2 ilustram os desempenhos para processamentos efetuados em computador equipado com microprocessador Pentium de $100 \mathrm{MHz}$.

Tabela 7.2 - Comparativo entre os tempos de processamento (em segundos)

\begin{tabular}{|c|c|c|c|}
\hline exemplo & $\begin{array}{c}\text { matriz de rigidez } \\
\text { inicial }\end{array}$ & Newton-Raphson & $\begin{array}{c}\text { Newton-Raphson modif. } \\
\left(\mathbf{2}^{\mathbf{a}} \text { iter. de cada incr.) }\right.\end{array}$ \\
\hline grupo I & 24,55 & 15,54 & 13,46 \\
\hline grupo II & 30,16 & 16,97 & 14,50 \\
\hline
\end{tabular}


Analisando os dados da tabela anterior, tem-se a tendência de concluir que os dois procedimentos Newton apresentam-se mais eficientes, com alguma vantagem para o NR-Modificado. No entanto, a posterior análise de estruturas compostas por um número maior de elementos permitirão concluir, com maior propriedade, sobre o procedimento mais eficiente.

\subsection{Exemplos de aferição do modelo de pilar}

O elemento finito de pórtico tridimensional, aliado à discretização da seção transversal em filamentos, permite a análise de pilares sob flexão oblíqua composta. São apresentados, a seguir, um exemplo de pilar sob flexão normal, e outros dois sob flexão oblíqua composta analisados por ABDEL-SAYED; GARDNER (1975) ${ }^{1}$ apud EL-METWALLY;EL-SHAHHAT;CHEN (1990). Neste último trabalho, El-Metwally et al., utilizam uma seção filamentada, incorporando ainda as não-linearidades física dos materiais e geométrica da estrutura deslocada. Os modelos constitutivos adotados para os materiais são bastante semelhantes aos empregados neste trabalho. Os pilares ensaiados por Abdel-Sayed e Gardner são medianamente esbeltos, e apresentam as mesmas características geométricas. Com o objetivo de estudar a convergência da análise, os autores realizam três análises distintas, discretizando a seção transversal em 36, 100 e 400 filamentos de concreto superpostos às armaduras longitudinais de flexão. Não tendo observado uma diferença relevante entre os resultados das três análises, os autores apresentam aqueles referentes àuma discretização por 8 elementos finitos, com a seção transversal dividida em $100(10 \times 10)$ filamentos de concreto.

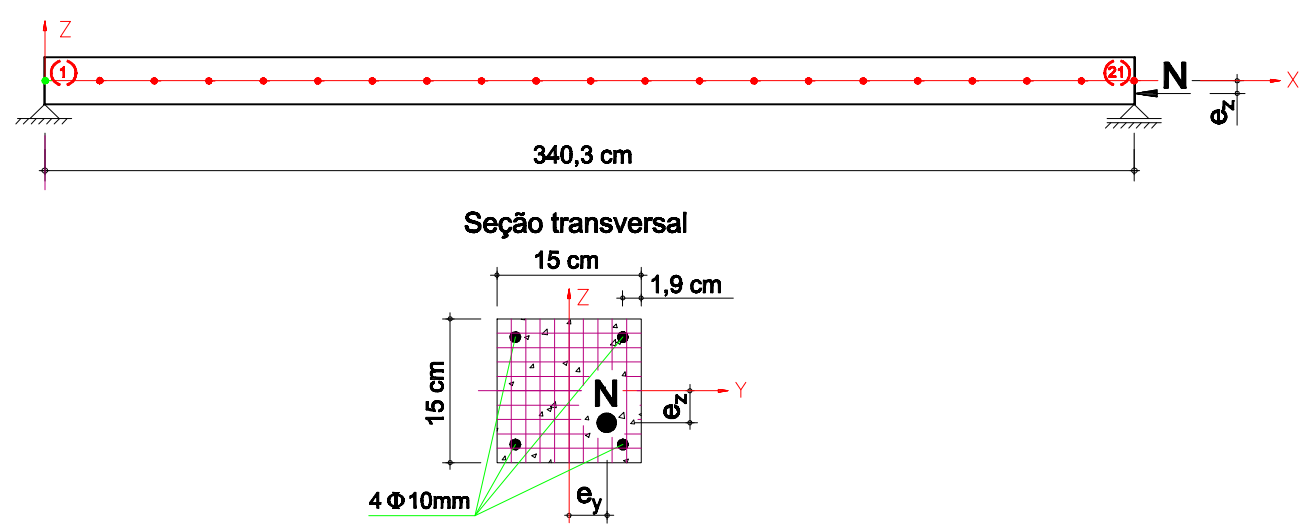

Figura 7.6 - Ilustração do pilar típico de ABDEL-SAYED;GARDNER (1975)

\footnotetext{
${ }^{1}$ ABDEL-SAYED,S.I.;GARDNER,N.J. (1975). Design of symmetric square slender reinforced concrete columns under biaxially eccentric loads. ACI Symposium, Detroit p.149-164. apud EL-METWALLY;ELSHAHHAT;CHEN (1990).
} 
Os autores divulgam apenas a tensão de escoamento do aço e a tensão de ruptura do concreto à compressão. As demais propriedades mecânicas dos materiais foram, neste trabalho, obtidas indiretamente com o auxílio da Tabela 4.1:

aço: $E_{s}=21000 \mathrm{kN} / \mathrm{cm}^{2} ; f_{y}=44,8 \mathrm{kN} / \mathrm{cm}^{2}$.

concreto: $E_{c}=3101 \mathrm{kN} / \mathrm{cm}^{2}\left(^{*}\right) ; f_{c}=3,0 \mathrm{kN} / \mathrm{cm}^{2} ; f_{t}=0,3 \mathrm{kN} / \mathrm{cm}^{2}$.

São analisados os resultados para três pilares submetidos à compressão excêntrica, cujas respectivas excentricidades são apresentadas na Tabela 7.3.

Tabela 7.3 - Excentricidades das forças normais nos pilares

\begin{tabular}{|c|c|c|}
\hline pilar & $\mathbf{e}_{\mathbf{x}}(\mathbf{c m})$ & $\mathbf{e}_{\mathbf{y}}(\mathbf{c m})$ \\
\hline 1 & 12,700 & 0,000 \\
\hline 2 & 6,350 & 3,175 \\
\hline 3 & 12,700 & 12,700 \\
\hline
\end{tabular}

Para as análises, foram utilizados incrementos correspondentes a 12,0 kN para a força $N$, tolerâncias de $0,1 \%$ em forças e $0,1 \%$ em deslocamentos, e permitido um máximo de 10 iterações por incremento (empregando o procedimento Newton-Raphson). Os pilares foram divididos em 20 elementos finitos, e a seção transversal, discretizada em $100(10 \times 10)$ filamentos de concreto superpostos æ̀ barras da armadura longitudinal. Os resultados são apresentados nos diagramas de força axial contra deslocamento transversal do meio do vão.

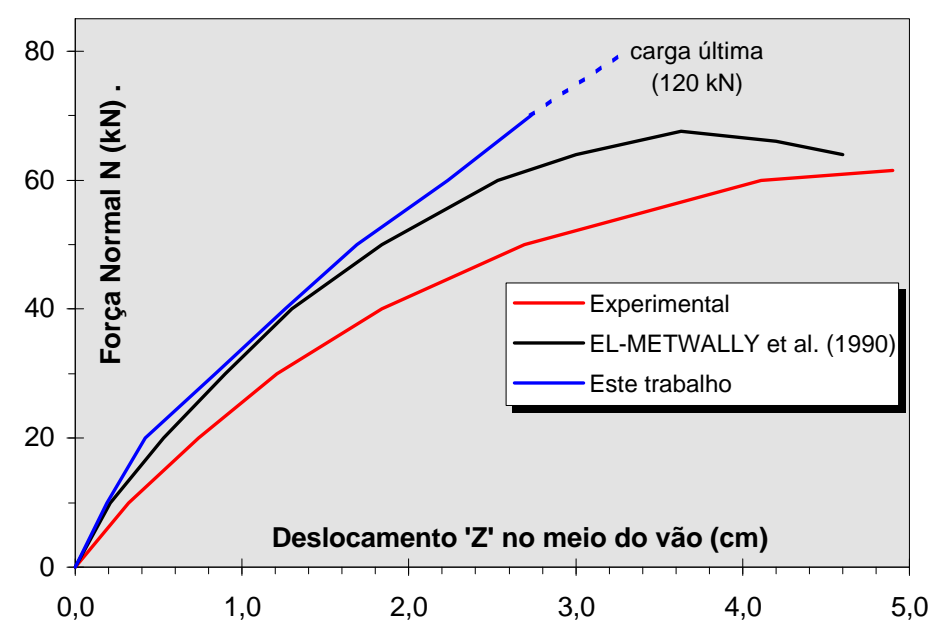

Figura 7.7 - Diagrama de força normal por deslocamento - pilar 1

\footnotetext{
* O módulo de deformação longitudinal do concreto $\left(E_{c}\right)$ foi adotado, para cada um dos ensaios, de modo a reproduzir a rigidez inicial da estrutura segundo as simulações de EL-METWALLY;ELSHAHHAT;CHEN (1990). Assim, para o pilar 1, adotou-se $E_{c}=2000 \mathrm{kN} / \mathrm{cm}^{2}$, para o pilar 2, $\mathrm{E}_{\mathrm{c}}=3100$ $\mathrm{kN} / \mathrm{cm}^{2}$, e para o pilar $3, \mathrm{E}_{\mathrm{c}}=1700 \mathrm{kN} / \mathrm{cm}^{2}$.
} 


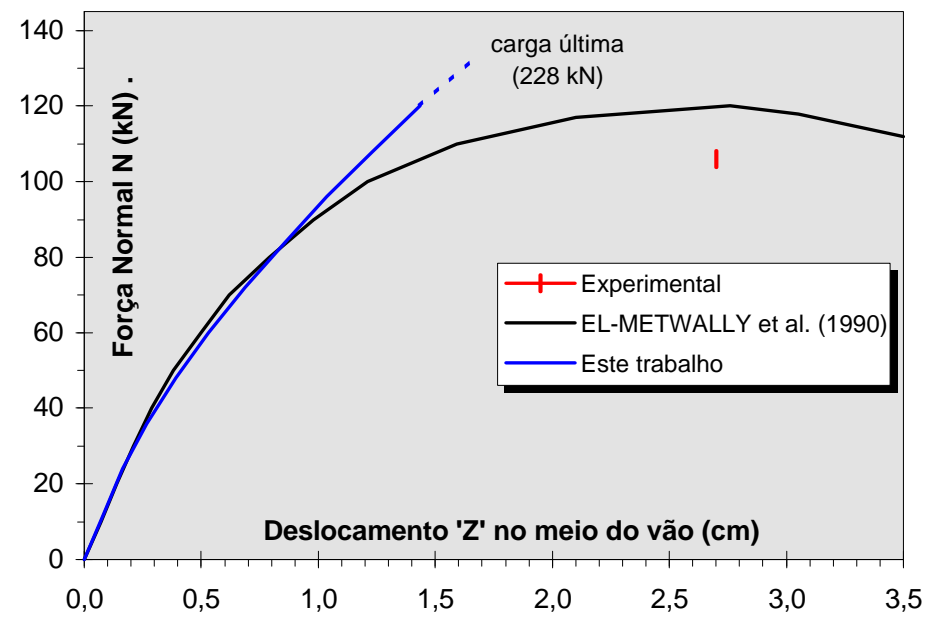

Figura 7.8- Diagrama de força normal por deslocamento - pilar 2

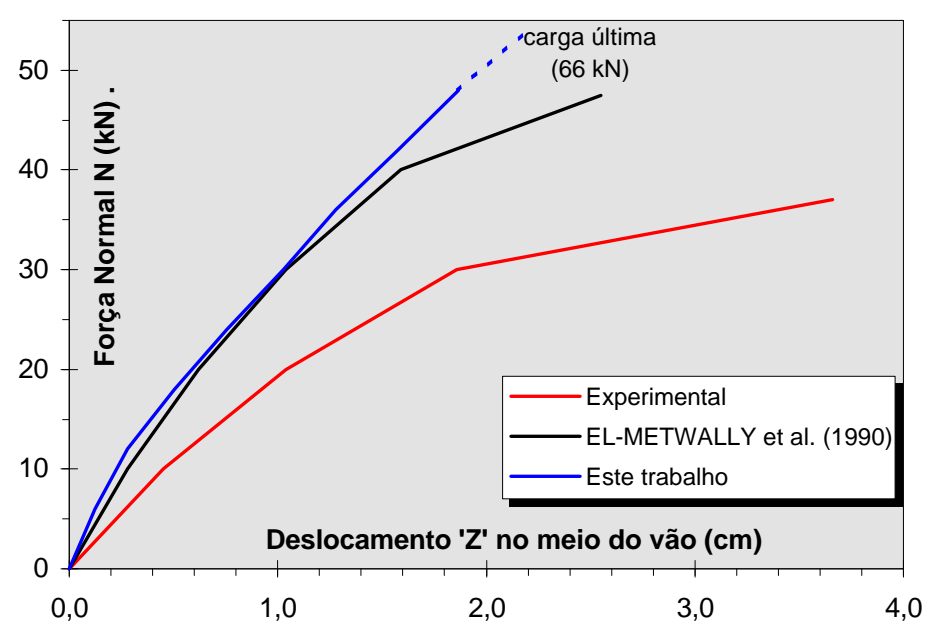

Figura 7.9- Diagrama de força normal por deslocamento - pilar 3

Por se tratarem de pilares medianamente esbeltos $(\lambda=79)$, os efeitos da não-linearidade geométrica (NLG) são bastante acentuados, principalmente nas proximidades da carga de ruptura. O modelo proposto neste trabalho não incorpora a NLG e, por esse motivo, não pode representar com fidelidade o comportamento mecânico do elemento flexo-comprimido para carregamentos próximos aos de ruína. No entanto, a representatividade do comportamento dos pilares ao longo da história de carregamento, até aproximadamente $80 \%$ da carga última, pode ser considerada muito boa, e suficiente para a análise de pavimentos de edifícios.

\subsection{Exemplo de aferição do modelo de aderência}

Apresenta-se, na Figura 7.10, o exemplo de uma das vigas estudadas por KWAK;FILIPPOU (1997). Os autores realizam análise experimental acompanhada 
de uma análise numérica através do modelo apresentado no item 3.7.1. A viga foi discretizada por 24 elementos de chapa de oito nós, perfazendo 6 divisões (elementos) longitudinais por 4 elementos ao longo de sua altura.

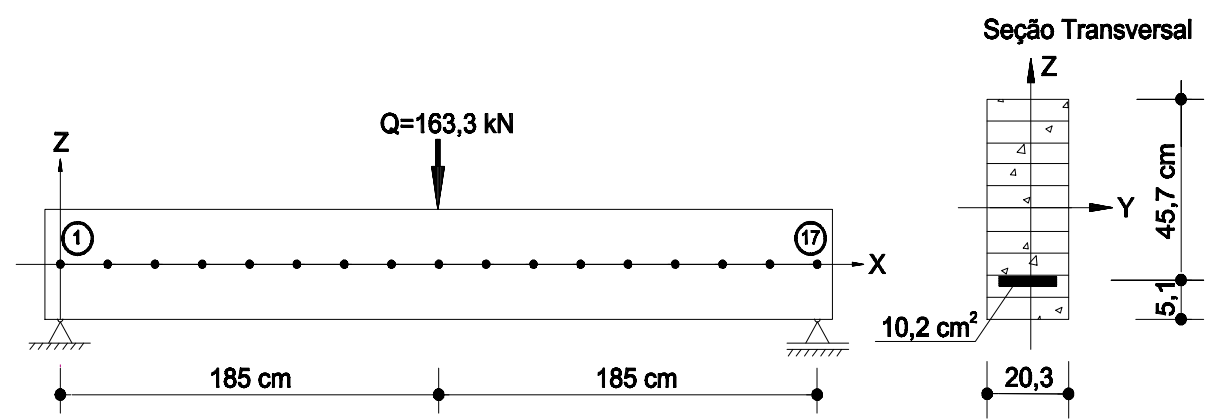

Figura 7.10 - Esquema da viga estudada por KWAK;FILIPPOU (1997)

As propriedades dos materiais empregados na análise são:

aço: $E_{s}=20742 \mathrm{kN} / \mathrm{cm}^{2} ; f_{y}=31,60 \mathrm{kN} / \mathrm{cm}^{2}$.

concreto: $E_{c}=2672 \mathrm{kN} / \mathrm{cm}^{2} ; f_{c}=3,39 \mathrm{kN} / \mathrm{cm}^{2} ; f_{t}=0,36 \mathrm{kN} / \mathrm{cm}^{2}$ (adotado).

Para confrontar os resultados obtidos por Kwak e Filippou, procedeu-se uma análise com o modelo sugerido no item 3.7.2, dividindo-se a viga em 16 elementos finitos de barra de grelha discretizados, cada um, por 10 camadas de concreto superpostas à armadura equivalente à empregada pelos autores (9Ф12 $\mathrm{mm}$ ). A Figura 7.11 ilustra os resultados obtidos pelo modelo proposto neste trabalho e, para efeito de comparação, o resultado omitindo-se totalmente o efeito de enrijecimento àtração, além dos obtidos por Kwak e Filippou.

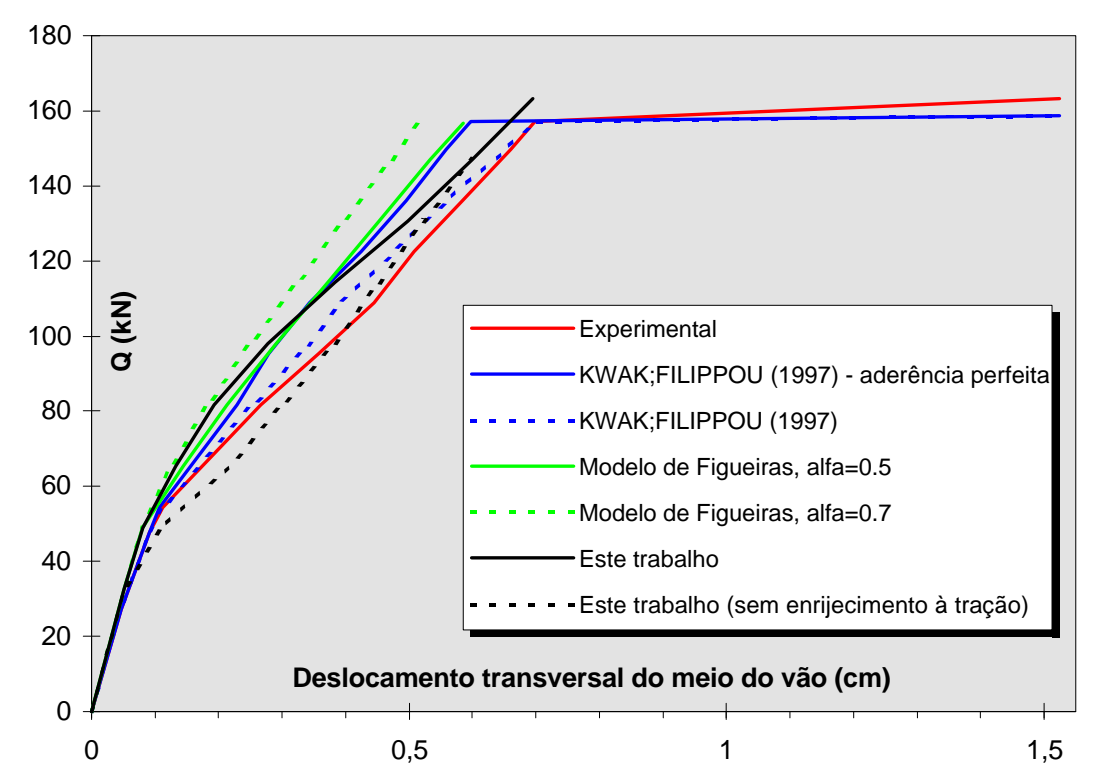

Figura 7.11 - Deslocamentos para a viga de KWAK;FILIPPOU (1997) 
Os resultados obtidos com o modelo proposto estão bastante próximos aos apresentados por KWAK;FILIPPOU (1997). As curvas referentes ao modelo de enrijecimento de FIGUEIRAS (1983) foram calibradas para os valores extremos do parâmetro $\alpha$.

Através de um procedimento análogo ao empregado no exemplo 7.5 efetuam-se duas outras análises empregando-se, respectivamente, a metade e o dobro do número de elementos finitos da malha original. Os resultados (Figura 7.12) demonstram uma moderada dependência da malha. Essa constatação sugere cuidados na elaboração da malha de elementos finitos.

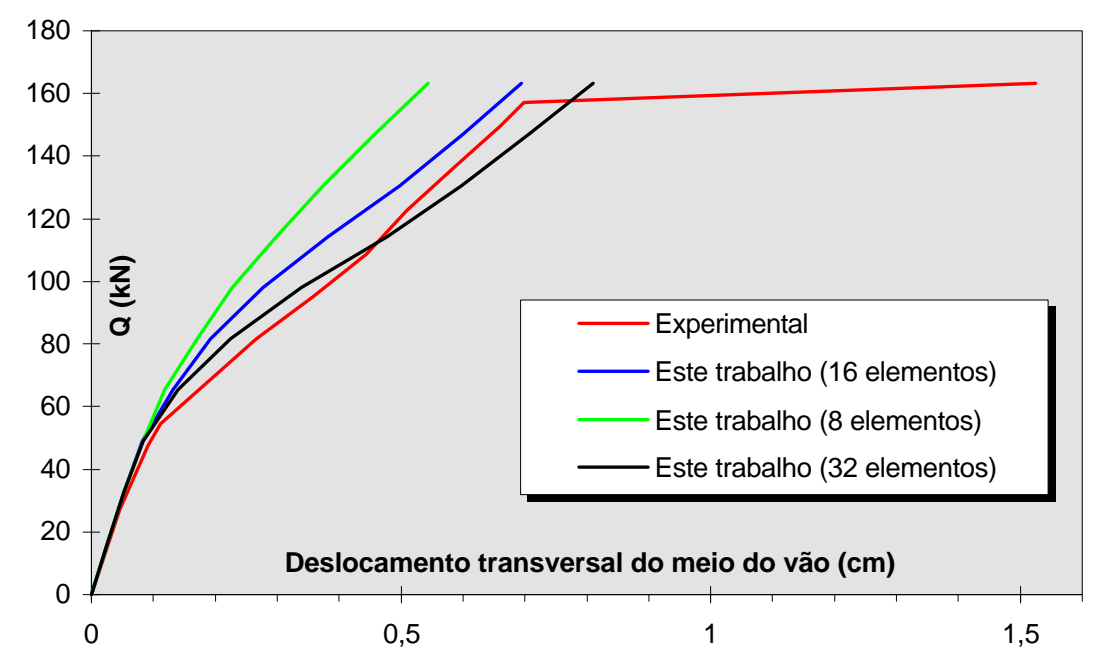

Figura 7.12 - Estudo da dependência de malha - modelo de aderência

A Figura 7.13 exibe um acompanhamento da evolução quantitativa do estado de fissuração da viga com o carregamento. A fissuração inicia-se, no ponto médio da viga, com um carregamento de cerca de $30 \%$ do último $(158,4 \mathrm{kN})$, e propaga-se em direção aos apoios àmedida em que o carregamento é acrescido.

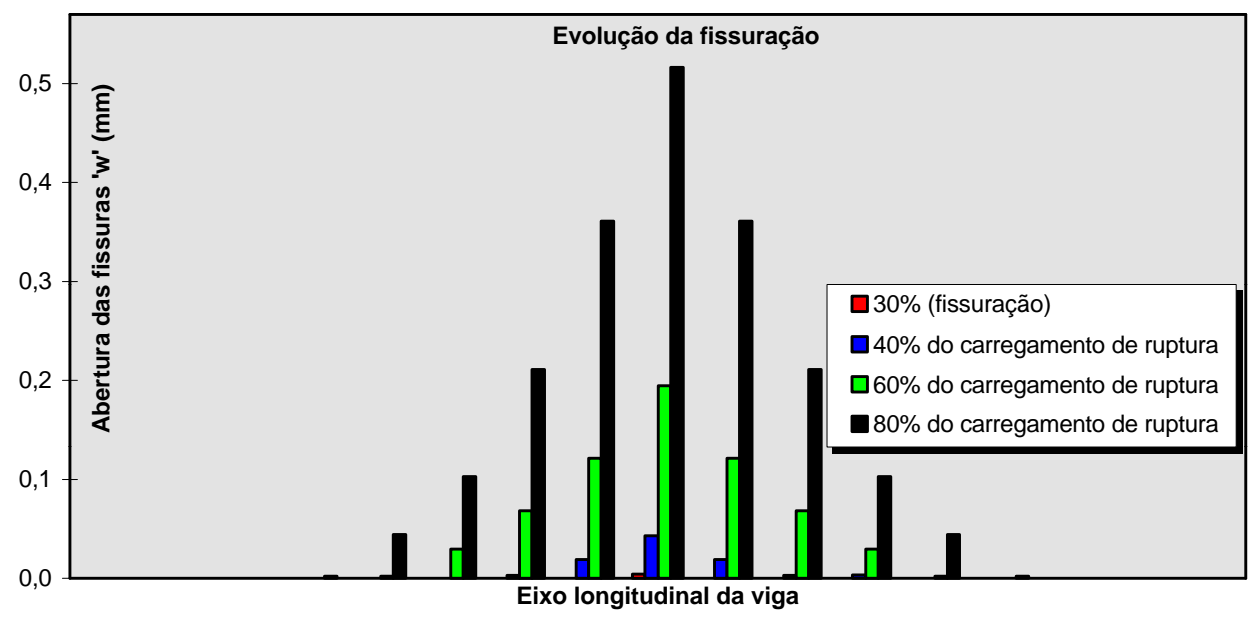

Figura 7.13 - Abertura de fissuras para a viga de KWAK;FILIPPOU (1997) 
O modelo proposto neste trabalho pode ser também aplicado à análise de vigas que apresentem corrosão de suas armaduras longitudinais de flexão, com conseqüente perda de seção transversal e de aderência com o concreto. Com o objetivo de abordar essa aplicação do modelo, OLIVEIRA et al. (1999) apresentam um artigo em que são estudados os aspectos mecânicos dessa patologia, e chegam a resultados consistentes sobre a influência da corrosão de armaduras no comportamento mecânico de uma viga biapoiada.

\subsection{Exemplo de aferição do modelo de fluência (teórico)}

O modelo proposto para a incorporação dos efeitos da fluência do concreto sobre o comportamento das estruturas lineares teve os seus resultados confrontados aos apresentados pelo CEB-FIP MC90 para o caso de vigas biapoiadas (Figura 7.14) submetidas àfluência, através de um coeficiente $\varphi=2,5$. São abordadas diversas configurações de armaduras longitudinais de tração $\left(\rho=A_{s} / A_{c}\right)$ e compressão $\left(\rho^{\prime}=A_{s}^{\prime} / A_{c}\right)$, e várias situações de carregamento uniformemente distribuído $(\mathrm{g}+\mathrm{q})$ (Tabela 7.4).

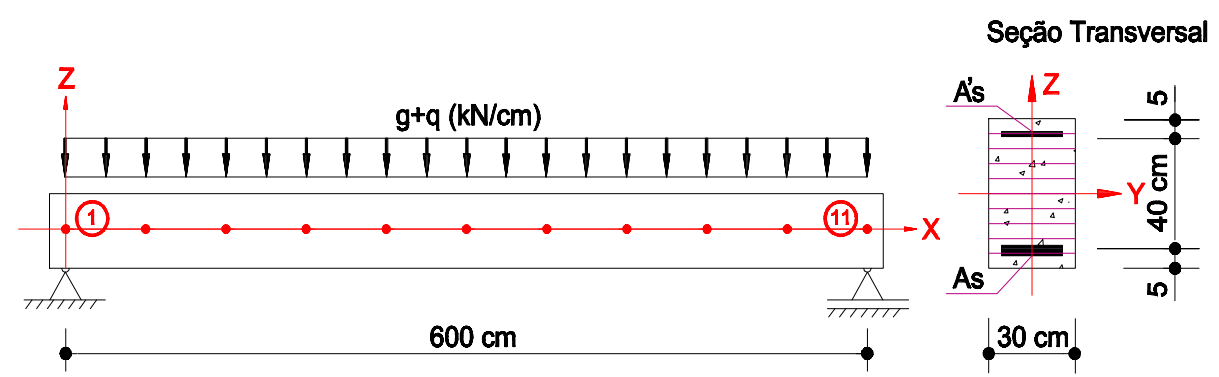

Figura 7.14 -Viga biapoiada (exemplo CEB-FIP MC90)

As características mecânicas dos materiais empregados na análise são:

aço: $E_{s}=20000 \mathrm{kN} / \mathrm{cm}^{2} ; f_{y}=50 \mathrm{kN} / \mathrm{cm}^{2}$.

concreto: $E_{c}=3050 \mathrm{kN} / \mathrm{cm}^{2} ; f_{c}=2,50 \mathrm{kN} / \mathrm{cm}^{2} ; f_{t}=0,25 \mathrm{kN} / \mathrm{cm}^{2}$.

Outras características necessárias à composição do modelo elastoplástico são obtidas substituindo-se o valor de $\mathrm{f}_{\mathrm{c}}$ nas formulações da Tabela 7.4.

Tabela 7.4 - Taxas de armadura e carregamentos (exemplo CEB-90)

\begin{tabular}{|c|c|c|c|c|c|}
\hline caso & 1 & 2 & 3 & 4 & 5 \\
\hline$g+q(\mathrm{kN} / \mathrm{cm})$ & 0,089 & 0,169 & 0,169 & 0,169 & 0,250 \\
\hline$\rho^{\prime}(\%)$ & 0 & 0 & 0,15 & 0,30 & 0 \\
\hline$\rho(\%)$ & 0,3 & \multicolumn{5}{|c|}{0,6} & 0,9 \\
\hline
\end{tabular}


Os resultados numéricos de deslocamentos transversais para o meio do vão das vigas nos instantes $t_{0}$ e $t$ são apresentados na Tabela 7.5. Comparativamente colocam-se, ainda, os resultados apresentados pelo CEB-FIP MC90 segundo 3 métodos (Exato, Bi-linear, e dos Coef. Globais), e por SANCHES (1998) para os modelos de Debernardi e de Ghali e Favre. Para as análises efetuadas com o modelo proposto neste trabalho, a viga foi discretizada em 10 elementos finitos, e a seção transversal em 10 camadas de concreto. O carregamento específico para cada viga foi aplicado em 5 incrementos de força correspondentes, cada um, a $20 \%$ do carregamento total. O critério para a convergência foi estabelecido em $0,1 \%$ em forças e em deslocamentos, e não permitidas mais que 40 iterações por incremento empregando-se o procedimento NR.

Tabela 7.5 - Deslocamentos para os instantes to e t (exemplo CEB-FIP MC90)

\begin{tabular}{|c|c|c|c|c|c|c|}
\cline { 2 - 7 } \multicolumn{2}{c|}{} & \multicolumn{7}{c|}{ CEB - Model Code 1990 } & \multicolumn{2}{c|}{ SANCHES(1998) } & Presente \\
\hline Caso & $\begin{array}{c}\text { Exato } \\
(\mathrm{mm})\end{array}$ & $\begin{array}{c}\text { Bi-linear } \\
(\mathrm{mm})\end{array}$ & $\begin{array}{c}\text { Coef. Globais } \\
(\mathrm{mm})\end{array}$ & $\begin{array}{c}\text { Debernardi } \\
(\mathrm{mm})\end{array}$ & $\begin{array}{c}\text { Ghali \& Favre } \\
(\mathrm{mm})\end{array}$ & $\begin{array}{c}\text { Estratificado } \\
(\mathrm{mm})\end{array}$ \\
\hline 1 & 4,20 & 3,80 & 3,80 & 3,15 & 3,09 & 3,51 \\
\hline 2 & 10,00 & 8,20 & 8,40 & 8,90 & 8,84 & 9,25 \\
3 & 10,00 & 8,20 & 8,40 & 8,79 & 8,73 & 9,09 \\
4 & 9,90 & 8,20 & 8,40 & 8,68 & 8,63 & 8,95 \\
\hline 5 & 12,10 & 10,60 & 10,60 & 11,01 & 10,99 & 10,40 \\
\hline \multicolumn{7}{|c|}{ instante to } \\
\hline 1 & 10,90 & 11,20 & 11,00 & 9,25 & 9,30 & 6,45 \\
\hline 2 & 16,20 & 15,00 & 15,60 & 16,18 & 14,97 & 14,36 \\
3 & 15,50 & 14,40 & 15,00 & 15,38 & 14,29 & 13,44 \\
4 & 14,90 & 14,00 & 14,30 & 14,69 & 13,72 & 12,68 \\
\hline 5 & 19,20 & 18,50 & 18,60 & 20,20 & 18,00 & 16,92 \\
\hline
\end{tabular}

Os resultados de deslocamentos obtidos com o presente modelo, no instante t, se mostraram inferiores aos demais apresentados. Embora considerados de boa confiabilidade, os outros modelos também apresentaram discrepâncias entre si. No sentido de melhor aferir o presente modelo, propõe-se a análise de outros exemplos que disponham de resultados experimentais.

\subsection{Exemplo de aferição do modelo de fluência (experimental)}

BAKOSS et al. (1982) apresentam resultados experimentais e numéricos relativos ao comportamento mecânico de uma viga biapoiada Figura 7.15 submetida aos efeitos da fluência e da retração por um período de até 500 dias. 
Foram realizados 2 ensaios com o objetivo de quantificar, separadamente, os efeitos da retração e da deformação lenta. O primeiro protótipo de viga é submetido ao carregamento ilustrado na Figura 7.15 durante todo o período de tempo analisado. O segundo protótipo, com as mesmas características físicas e geométricas do primeiro, é submetido ao mesmo carregamento (o objetivo é estabelecer um estado de fissuração compatível ao desenvolvido no primeiro protótipo no instante $t_{0}$ ) e, em seguida, é descarregado, e passa a sofrer apenas os efeitos da retração. Com isso, ao final de cada período de análise, são obtidos os deslocamentos totais (fluência e retração) do primeiro protótipo, e os deslocamentos promovidos exclusivamente (em tese, admitindo-se a superposição dos efeitos) pela retração do segundo protótipo. Também são obtidos, experimentalmente, o coeficiente de fluência e a retração específica para as diversas idades do concreto analisadas nos estudos da viga.

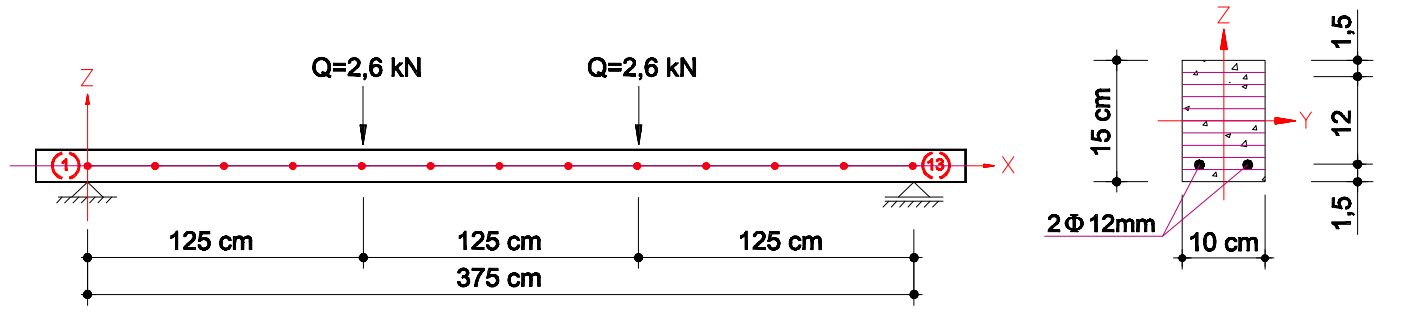

Figura 7.15 - Viga biapoiada analisada por BAKOSS et al. (1982)

Os autores perfazem duas análises numéricas distintas. Na primeira delas, são efetuadas aplicações diretas das formulações propostas pelos códigos modelo britânico $(\mathrm{CP} 110: 1972)^{2}$ e norte americano $\left(\mathrm{ACl}\right.$, comitê $\left.435^{3}\right)$ para a quantificação dos efeitos do tempo sobre os deslocamentos transversais da viga.

Em seguida, os autores determinam o coeficiente de fluência de acordo com o ACl-209 ${ }^{4}$ e o CEB-FIP $1978^{5}$, e os aplicam à análise das vigas através de um modelo numérico. O objetivo é o de alertar para a discordância entre os valores experimentais (Tabela 7.6) e os calculados com os códigos, e verificar qual a implicação disto nos resultados das análises. A viga é dividida em 12 elementos

\footnotetext{
2 British Standards Institution (1972). The structural use of concrete, Part 1; Design, materials, workmanship. CP 110, London, p.155.

${ }^{3} \mathrm{ACl}$ Committee 435 (1966). Deflections of reinforced concrete flexural members. Journal of the American Concrete Institute. Proceedings v.63, n.6, p.637-674. June

${ }^{4} \mathrm{ACl}$ Committee 209 (1971). Prediction of creep, shrinkage and temperature effects in concrete structures. Designing for effects of creep, shrinkage, temperature in concrete structures. American Concrete Institute (ACI SP27-3). p.51-93.

${ }^{5}$ CEB-FIP Model code for concrete structures. Cement and concrete association, p. 384; London.
} 
finitos com seção transversal discretizada em 8 camadas. As características mecânicas divulgadas pelos autores se resumem no módulo de deformação longitudinal do concreto, e suas resistências àcompressão e àtração na flexão.

Para as análises efetuadas com 0 modelo proposto neste trabalho, emprega-se a mesma discretização definida por BAKOSS et al. (1982). As características dos materiais empregados no modelo numérico são:

aço: $E_{s}=20000 \mathrm{kN} / \mathrm{cm}^{2} ; f_{y}=50 \mathrm{kN} / \mathrm{cm}^{2}$ (adotados).

concreto: $E_{c}=3120 \mathrm{kN} / \mathrm{cm}^{2} ; f_{c}=3,90 \mathrm{kN} / \mathrm{cm}^{2} ; f_{t}=0,49 \mathrm{kN} / \mathrm{cm}^{2}$.

O procedimento de solução empregado é o de Newton-Raphson, não sendo permitidas mais de 10 iterações para cada incremento de forças (equivalentes, cada um, a $10 \%$ do total). O controle da convergência é estabelecido com tolerâncias de $0,1 \%$ em forças e em deslocamentos.

Tabela 7.6 - Flechas máximas medidas e previstas para a viga biapoiada

\begin{tabular}{|c|c|c|c|c|c|c|}
\hline \multirow{2}{*}{ método de determinação } & \multirow{2}{*}{ origem dos dados } & \multicolumn{5}{|c|}{ flecha máxima (mm) } \\
\cline { 3 - 7 } & & \multicolumn{4}{|c|}{ tempo sob carregamento (dias) } \\
\cline { 3 - 7 } & & 0 & 25 & 95 & 260 & 500 \\
\hline medido experimentalmente & ACl-209 & 11,60 & 15,70 & 19,10 & 22,50 & 24,30 \\
\hline ACl-435 & C\&CA (CP110:1972) & 13,30 & 15,10 & 18,50 & 18,90 & 19,30 \\
\hline CP 110:1972 & ACl-209 & 7,20 & 9,50 & 11,60 & 13,30 & 14,80 \\
\hline \multirow{2}{*}{ mef (BAKOSS et al. (1982)) } & CEB-FIP 1978 & 7,20 & 10,40 & 13,40 & 16,00 & 18,30 \\
\cline { 2 - 7 } & experimental & 7,20 & 10,00 & 12,50 & 14,80 & 16,70 \\
\hline \multirow{2}{*}{ mef (presente trabalho) } & experimental & 7,95 & 10,96 & 13,56 & 15,20 & 16,72 \\
\hline método de determinação & origem dos dados & \multicolumn{5}{c|}{ coeficiente de fluência $(\varphi 28)$} \\
\hline \multicolumn{2}{|c|}{ medido experimentalmente } & 0,00 & 0,78 & 1,44 & 2,00 & 2,41 \\
\hline
\end{tabular}

Neste exemplo, para que fosse obtida a melhor aproximação para o deslocamento inicial (em $t_{0}$ ), foi empregado o valor máximo para $\alpha(=0,7)$. O objetivo é o de proporcionar uma avaliação coerente dos deslocamentos no instante t. Empregando-se os coeficientes de fluência medidos experimentalmente, verifica-se que os resultados obtidos pelo presente modelo estão bastante próximos aos conseguidos por BAKOSS et al. (1982). Já os deslocamentos calculados pelos códigos modelo estiveram um pouco acima do medido experimentalmente, principalmente devido àsuperestimativa do coeficiente de fluência.

Dando prosseguimento àaferição do modelo numérico colocam-se, a seguir, duas análises importantes para a verificação de sua consistência. A primeira delas refere-se àposição da linha neutra nos instantes $t_{0} e$ t. Conforme colocado na teoria 
do capítulo 3, há de se esperar que a linha neutra migre no sentido da armadura longitudinal de flexão tracionada à medida que o concreto sofra os efeitos da fluência. A Figura 7.16 ilustra as posições da LN obtidas numericamente para os instantes $\mathrm{t}_{0}=28$, e $\mathrm{t}=500$ dias.

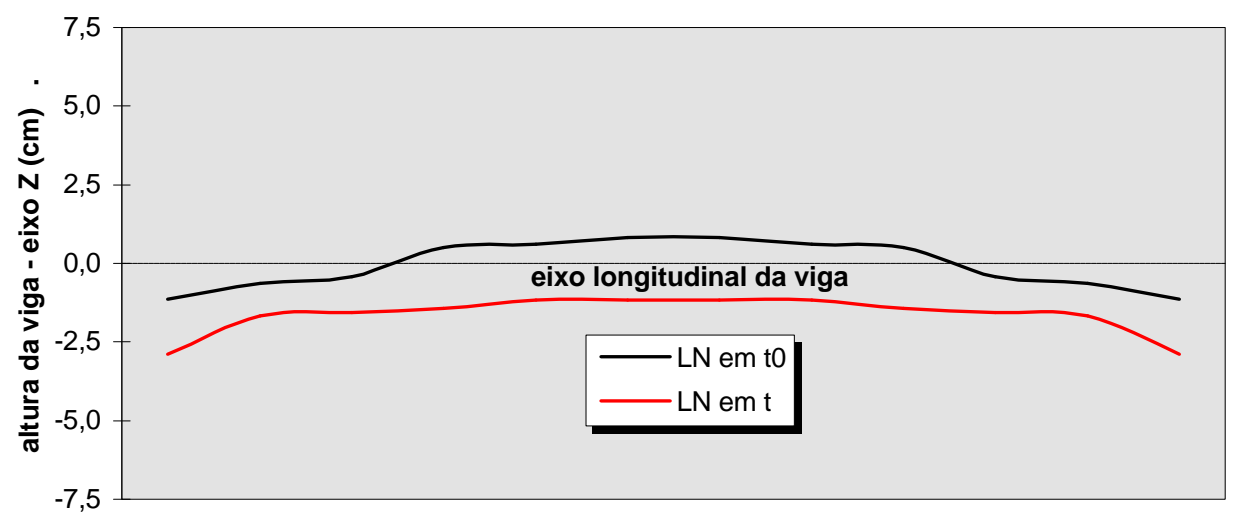

Figura 7.16 - Posição da linha neutra $(L N)$ nos instantes $t_{0}=28$ e $t=500$ dias

Como pode ser observado, a linha neutra ao longo de toda a viga sofreu um traslado médio de 2,0 cm em direção àarmadura longitudinal tracionada.

Finalmente, cabe a análise das deformações longitudinais da armadura tracionada entre os instantes $t_{0}$ e $t=500$ dias. Na Figura 7.17 observa-se que as diferenças entre as deformações nos instantes $t_{0}$ e $t$ são razoavelmente grandes para as regiões próximas aos apoios, onde as deformações são de pequena magnitude em relação æ̀s demais, mas decaem àmedida que se observam seções mais próximas do centro do vão, onde as deformações são mais significativas. BAKOSS et al. (1982) mediram, experimentalmente, para o caso de uma viga contínua com dois tramos de mesmo comprimento, uma diferença próxima aos $55 \%$ para as deformações da armadura longitudinal de flexão no meio do vão livre entre os instantes $t_{0}$ e $t=500$ dias.

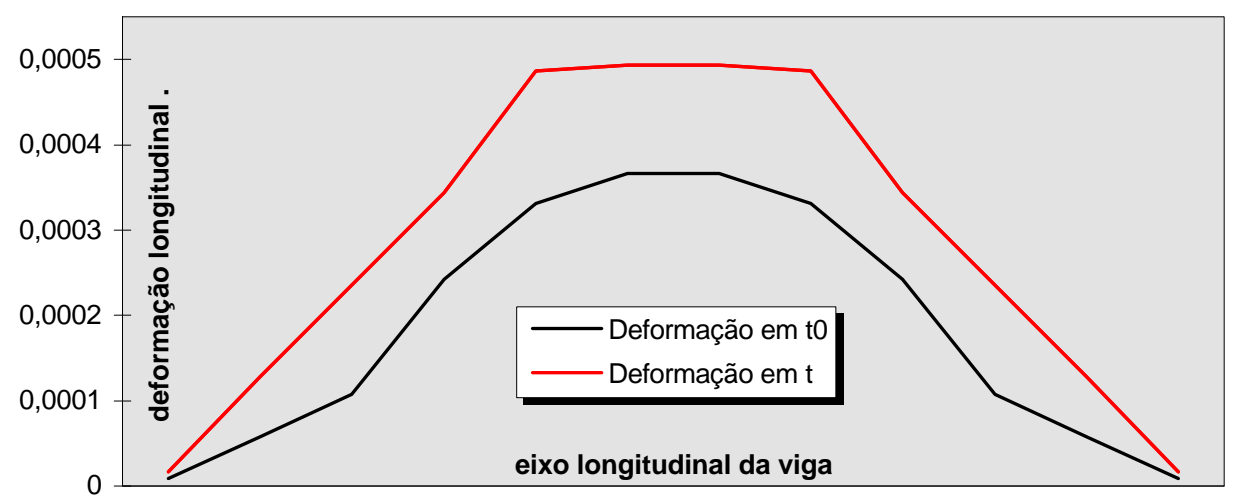

Figura 7.17 - Deformação longitudinal da armadura tracionada 


\subsection{Primeiro exemplo de aferição dos modelos para as lajes}

Este primeiro exemplo refere à análise de uma laje quadrada de concreto armado estudada por DOTTREPE et al. (1973) ${ }^{6}$ apud CORRÊA (1991). A laje é apoiada continuamente ao longo de seus lados, e submetida a uma carga distribuída em uma pequena extensão em torno do ponto central da laje. Os autores empregam elemento finito de placa discretizado em camadas de concreto que obedecem ao critério de Kupfer, Hilsdorf e Rüsh, enquanto o aço é representado por um modelo elastoplástico perfeito uniaxial. Um quarto da placa é dividido em 64 elementos quadrilaterais de placa, discretizados por 6 camadas, e a carga total de 355,84 kN (80 kips) é aplicada em dez incrementos iguais.

As características mecânicas dos materiais, supostas na análise, são:

$$
\begin{gathered}
\text { aço: } E_{s}=20685 \mathrm{kN} / \mathrm{cm}^{2}\left(30 \times 10^{6} \mathrm{psi}\right) ; f_{y}=30,3 \mathrm{kN} / \mathrm{cm}^{2}(44000 \mathrm{psi}) \text {. } \\
\text { concreto: } E_{c}=2758 \mathrm{kN} / \mathrm{cm}^{2}\left(4 \times 10^{6} \mathrm{psi}\right) ; f_{c}=4,8 \mathrm{kN} / \mathrm{cm}^{2}(6920 \mathrm{psi}) ; \\
f_{t}=0,43 \mathrm{kN} / \mathrm{cm}^{2} \text { (adotado por Corrêa); } v=0,15 ; \alpha=0,6 .
\end{gathered}
$$

A Figura 7.18 traz uma ilustração da laje, juntamente com a proposta de malha inicial para a análise aqui efetuada.

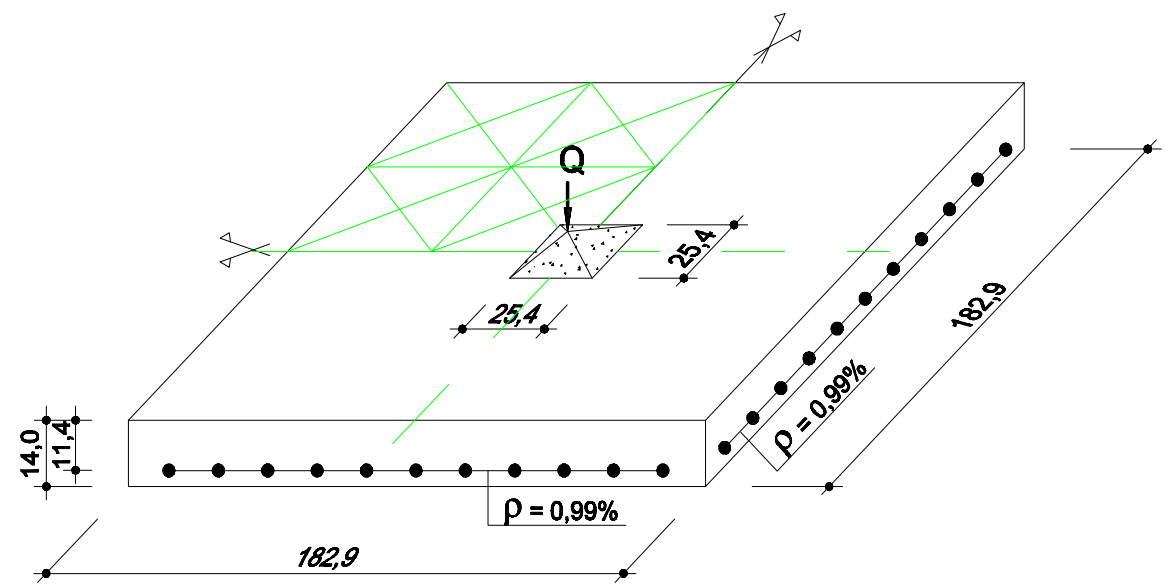

Figura 7.18 - Laje simplesmente apoiada e malha inicial

Como pode ser notado na Figura 7.18, inicialmente um quarto da laje foi dividido em 16 elementos triangulares, ou 4 elementos quadrilaterais de placa (malha 1). Posteriormente, para possibilitar a verificação do problema da dependência de malha, a quantidade de elementos foi quadruplicada (malha 2). A

\footnotetext{
${ }^{6}$ DOTTREPE,J.C.;SCHNOBRICH,W.C.;PECKNOLD,D.A.(1973). Layered finite element procedure for inelastic analysis of reinforced concrete slabs. IABSE Publications, v. 33-11, p. 53-68. apud CORRÊA(1991).
} 
altura da laje foi discretizada por 10 camadas, assim como já havia sido adotado para a análise das vigas de concreto armado.

A superfície de von Mises obedeceu a um modelo elastoplástico perfeito delimitado pela resistência à compressão do concreto $\left(f_{c}\right)$. Também foram realizadas simulações desprezando-se a resistência à tração do concreto, e negligenciando o ramo de amolecimento do concreto para a superfície de Rankine (Figura 7.19). De um modo geral, a aplicação da força, considerada concentrada, foi prevista para 16 incrementos, de valores: $30 \%, 3 \times(10 \%), 4 \times(5 \%)$ e $8 \times(2,5 \%)$.

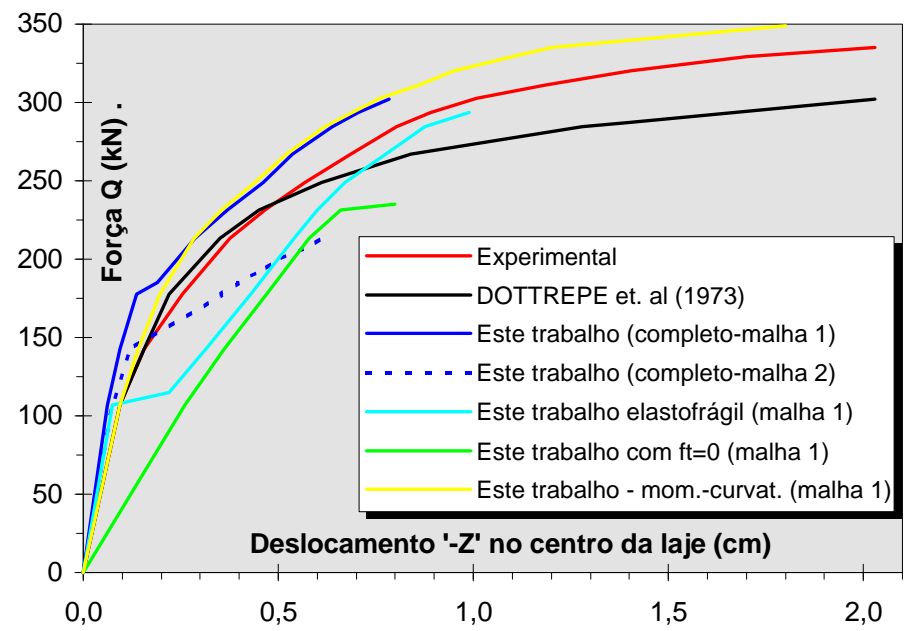

Figura 7.19 - Diagrama de força $Q$ por deslocamento transversal

A malha 1 resulta em um comprimento equivalente $\left(h_{e q}\right) 3,27$ vezes a espessura da laje (h), enquanto que, com a malha 2 , essa relação cai para 1,63 vezes. Para a análise das lajes deve-se evitar a utilização de malhas muito refinadas, que levem a relações $h_{e q} / h$ baixas (inferiores a 2,5). Isso não é uma regra, mas sim um procedimento que pode ser seguido na tentativa de se evitarem problemas com a resposta do modelo, devido àdependência de malha.

Neste exemplo, foram realizadas duas outras simulações com o objetivo de se estabelecerem comparações. Uma delas refere-se à modelagem do concreto à tração (Rankine) segundo um modelo elastofrágil, como o proposto por Rashid no início do desenvolvimento da teoria das fissuras dispersas. A outra simulação despreza a resistência à tração do concreto desde o início da análise (ou seja, hipótese de estádio II puro). Neste caso é interessante observar que, após a fissuração, essas duas curvas seguem pela mesma tangente, o que é coerente com os diagramas propostos pelo CEB-FIP MC90. No entanto, o modelo que despreza a resistência à tração impõe uma ruptura com carregamentos inferiores àqueles obtidos pelo modelo elastofrágil. 
O modelo momento-curvatura segundo as hipóteses de CORRÊA (1991) apresenta resultados bastante satisfatórios e, pelo menos até onde foi investigado, independentes do refinamento da malha.

A título de ilustração, a Figura 7.20 apresenta o estado de fissuração previsto para um carregamento $\mathrm{Q}=213,5 \mathrm{kN}$, que equivale a cerca de $70 \%$ do carregamento de ruptura para o modelo completo $(Q=302,0 \mathrm{kN})$.

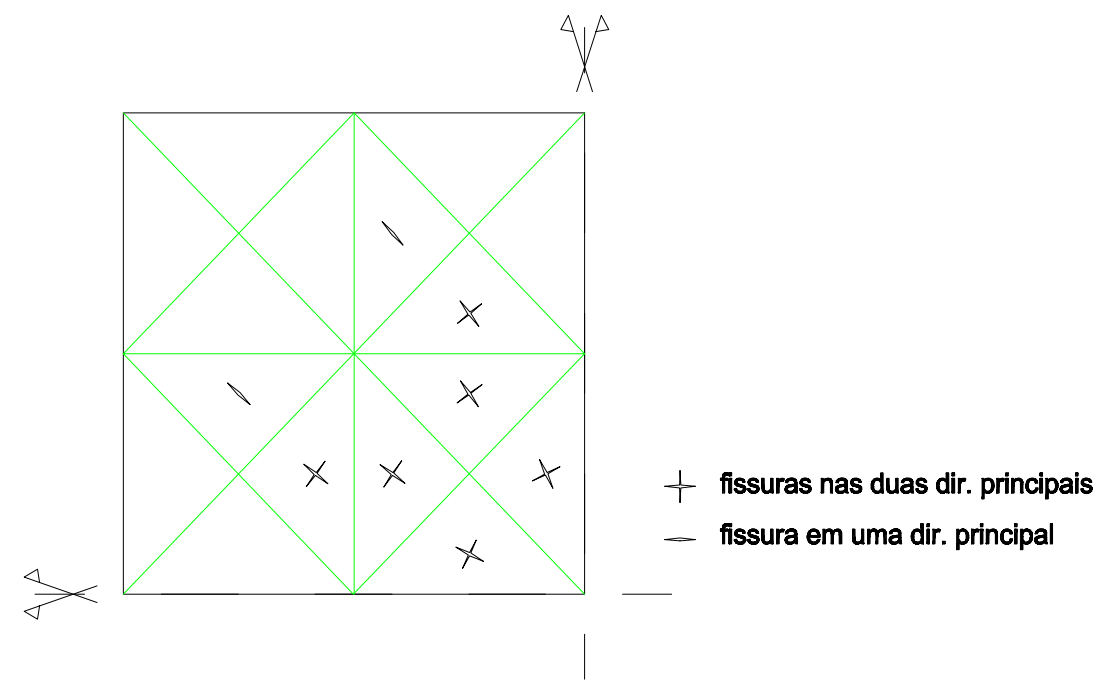

Figura 7.20 - Estado de fissuração do fundo da laje, porém visto de cima (malha 1)

\subsection{Segundo exemplo de aferição dos modelos para as lajes}

Neste são analisados os deslocamentos de uma laje plana pertencente a um edifício comercial, e comparados aos resultados medidos in-loco na estrutura real. O pano de laje, denominado por laje plana de Taylor, foi também objeto de investigações por parte de RANGAN (1976,1986), que apresenta uma proposta simplificada para a determinação dos deslocamentos desse tipo de estrutura considerando-se os efeitos da fluência. A laje é apoiada nos quatro vértices, e submetida a uma carga distribuída, considerada constante durante os 850 dias após os quais mediram-se os deslocamentos transversais.

Além das características geométricas da laje, do carregamento mantido, e do módulo de deformação longitudinal e coeficiente de fluência do concreto, nada mais foi divulgado sobre os materiais. Assim, algumas dessas características tiveram que ser obtidas indiretamente, ou até mesmo criteriosamente arbitradas. As características mecânicas dos materiais, supostas na análise, são:

aço: $E_{s}=21000 \mathrm{kN} / \mathrm{cm}^{2} ; f_{y}=30,0 \mathrm{kN} / \mathrm{cm}^{2}$ (ambas arbitradas). 
concreto: $E_{c}=2448 \mathrm{kN} / \mathrm{cm}^{2} ; f_{c}=1,5 \mathrm{kN} / \mathrm{cm}^{2} ; f_{t}=0,18 \mathrm{kN} / \mathrm{cm}^{2}\left(f_{c}\right.$ e $f_{t}$ obtidos indiretamente pela formulação do CEB-FIP MC90 a partir de $\mathrm{E}_{\mathrm{c}}$ ); $v=0,15 ; \varphi=1,65$ (coeficiente de fluência pata $t=850$ dias); $\alpha=0,6$.

O carregamento de projeto e as especificações das armaduras não foram divulgados. Neste caso, foram adotadas as hipóteses de carregamento e de cálculo previstas pelas normas brasileiras, na obtenção das armaduras nas duas direções. Por simplicidade, as taxas geométricas de armadura (somente armadura positiva) de cada direção $\left(A_{s x}=11,4 \mathrm{~cm}^{2} / \mathrm{m} ; A_{\text {sy }}=8,9 \mathrm{~cm}^{2} / \mathrm{m}\right)$ foram mantidas por toda a extensão da laje.

A Figura 7.21 traz uma ilustração da laje, da proposta de malha, e do carregamento uniformemente distribuído considerado na análise da fluência.

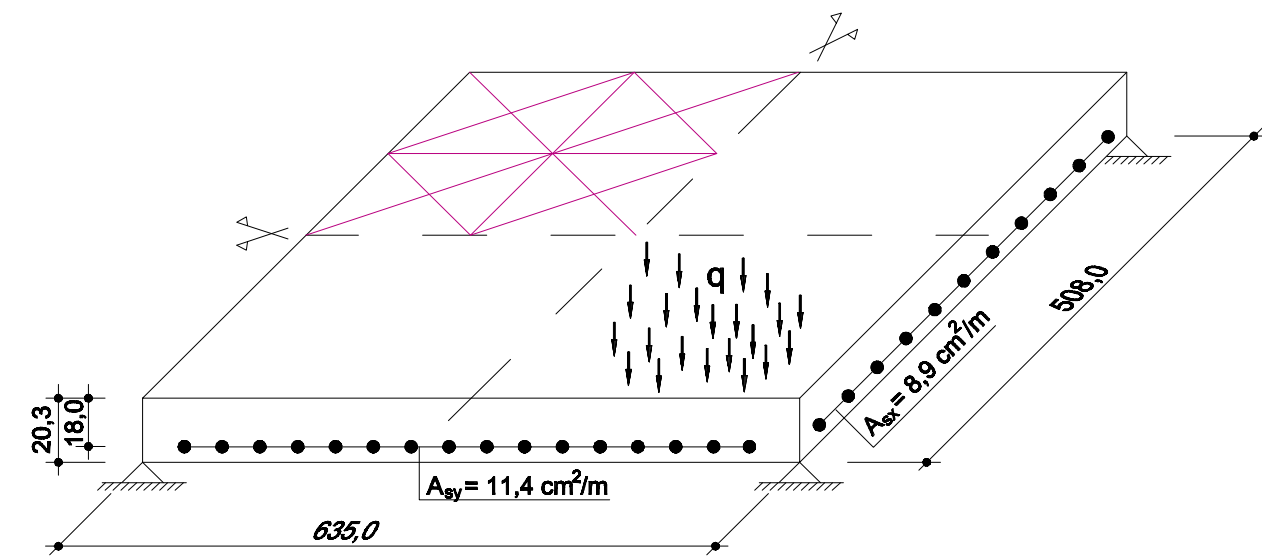

Figura 7.21 - Laje plana de Taylor. Ilustração da malha e do carregamento considerado para calcular o efeito da fluência

Foi processada a análise de um quarto da laje, dividido em 4 elementos quadrilaterais de placa. A altura da laje foi discretizada por 10 camadas. Assim como no exemplo anterior, a superfície de von Mises obedeceu a um modelo elastoplástico perfeito delimitado pela resistência à compressão do concreto. A aplicação do carregamento uniformemente distribuído foi prevista para 10 incrementos, de valores: $30 \%$, e $7 \times(10 \%)$. O efeito da fluência foi considerado de acordo com a teoria exposta no Capítulo 4, e com base no coeficiente de fluência experimental supra mencionado para a idade $\mathrm{t}=850$ dias.

Os resultados de deslocamentos para o centro da laje obtidos para os instantes $t_{0}$ e $t$ com 0 presente modelo estão apresentados na Tabela 7.7 juntamente com aqueles previstos por Rangan. O deslocamento medido na estrutura real no instante t também está colocado a título ilustrativo. Esse resultado 
refere-se à ação de ambos os efeitos principais do tempo sobre as estruturas de concreto armado: a retração e a fluência.

Tabela 7.7 - Deslocamentos para a laje de Taylor (cm)

\begin{tabular}{|c|c|c|c|c|}
\hline & $\Delta_{\mathrm{t} 0}$ & $\Delta_{\text {fluência }}$ & $\begin{array}{c}\Delta_{\text {retraçã }} \\
\circ\end{array}$ & $\Delta_{\text {total }}$ \\
\hline experimental & - & - & - & 1,83 \\
\hline Rangan & 0,51 & 0,58 & 0,61 & 1,70 \\
\hline este trabalho & 0,46 & 0,44 & - & $0,90^{*}$ \\
\hline
\end{tabular}

Apesar de o resultado experimental referir-se ao deslocamento total no instante $\mathrm{t}$, a sua proximidade com o valor total apresentado por Rangan, nesse mesmo instante $t$, permite inferir sobre a também possível proximidade entre os respectivos valores relativos exclusivamente à ação da fluência. Seguindo esse raciocínio pode-se afirmar que, para o presente exemplo, os resultados foram satisfatórios. Em termos percentuais, o presente modelo revelou um deslocamento adicional devido à fluência de $96 \%$ sobre o deslocamento inicial, enquanto que Rangan obteve algo em torno de $113 \%$.

Para o objetivo final à qual se destina a aplicação do modelo proposto, na determinação do estado limite de utilização relativo às deformações excessivas, parecem ser de suficiente precisão os resultados por ele determinados.

Como comentário final deste capítulo, vale salientar que apenas uma parte das aferições impostas aos modelos implementados estão relatadas. Vários outros exemplos foram empregados com o objetivo de se estabelecer um mínimo de segurança com relação àconfiabilidade dos modelos. 


\section{ASPECTOS SOBRE O DIMENSIONAMENTO}

\subsection{Introdução}

O dimensionamento de estruturas empregando-se modelos constitutivos mais representativos para os materiais tem sido, nos últimos anos, objeto de grande interesse dentre os órgãos internacionais de regulamentação.

De acordo com o CEB: Bulletin d'Information nํ227, “ . . . a aplicação da não-linearidade física (NLF) é o corolário lógico do estado limite semi-probabilístico. $\mathrm{Na}$ realidade, para desenvolver-se uma correta análise probabilística não é possível confiar em uma representação grosseira das correlações entre os materiais". $\mathrm{Na}$ seqüência, reafirma-se uma posição crítica com relação ao emprego da análise elástico-linear no dimensionamento de elementos estruturais, principalmente no que se refere à impossibilidade de representar possíveis redistribuições de esforços, o que, em muitos casos, piora as condições de segurança: " . . dados teóricos e experimentais atualmente demonstram que a hipótese da análise elástico-linear pode se apresentar tanto a favor como contra a segurança. Esse aspecto é inaceitável para a execução de um projeto seguro e econômico".

Segundo o ACI Building Code - Committee 318 (cap. 5), sobre os métodos de análise: “ . . . a análise não-linear é uma descrição realista do comportamento físico, e portanto, um método completamente consistente com as hipóteses usadas para a verificação local e dimensionamento de elementos estruturais; deve ser utilizada como uma referência para outras aproximações mais simplificadas".

A revisão da norma brasileira (NB1-revisão 2000), ainda não aprovada, também aborda aspectos da análise não-linear obedecendo a alguns dos preceitos enfocados pelo CEB Model Code 1990 (CEB-FIP MC90).

É fato que a introdução da análise não-linear no processo de dimensionamento de uma estrutura possa trazer benefícios relacionados àprecisão na determinação do comportamento mecânico. Outro aspecto bastante favorável, e 
que merece ser destacado, diz respeito à eliminação de atividades conjugadas ao próprio dimensionamento, como na imposição dos estádios para a verificação dos estados limites de serviço, ou mesmo nas análises adicionais requeridas pela imposição de plastificações localizadas de maneira não consistente.

\subsubsection{Objetivos}

Como já mencionado neste texto, muitas são as vantagens vislumbradas pelo emprego da análise não-linear no dimensionamento de estruturas de concreto armado. Essa perspectiva de avanço, no entanto, parece ainda não ter encontrado o seu merecido espaço, uma vez que é evidente a falta de procedimentos que possibilitem o emprego dessa potencial ferramenta na prática. Atualmente, não existe consenso sobre uma metodologia para o dimensionamento considerando-se relações constitutivas não-lineares. A utilização do método semi-probabilístico, e mesmo a introdução de outras julgadas mais adequadas, ainda estão em estudo, principalmente no seio dos comitês de trabalho do CEB-FIP (FIB).

O objetivo desta parte do trabalho é o de estabelecer o estado da arte sobre a aplicação da análise não-linear física ao projeto de estruturas. São descritas as principais metodologias cujo emprego ao dimensionamento tem sido estudado e, com o objetivo de estabelecerem-se comparações apresentam-se, ao final, exemplos práticos simples envolvendo o dimensionamento de elementos isolados.

\subsubsection{Campo de aplicação e validade}

Em princípio, de acordo com o CEB: Bulletin d'Information $n^{\circ} 227$, o campo de aplicação da análise não-linear física pode ser considerado ilimitado, com exceção feita aos casos em que a não-linearidade geométrica (NLG) exerça influência predominante sobre a redistribuição de esforços antes que seja atingida a capacidade portante da estrutura (por exemplo, na análise de pilares esbeltos). Neste trabalho não são considerados os efeitos das solicitações de torção e de cortante sobre o comportamento não-linear dos elementos estruturais lineares.

\subsection{Disposições normativas}

São apresentadas, a seguir, definições normativas gerais relacionadas à segurança das estruturas, de acordo com as normas nacionais em vigor. 


\subsubsection{Ponderadores das ações}

As ações características devem ser ponderadas por $\gamma_{f}=\gamma_{\uparrow 1} \times \gamma_{\uparrow 2} \times \gamma_{\uparrow 3}$. O fator

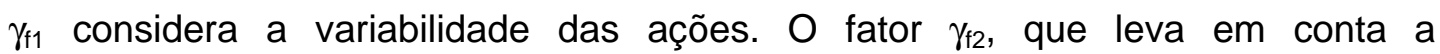
probabilidade de ocorrência simultânea das ações, é substituído pelos fatores de combinação ou de redução $\left(\psi_{i}\right)$, de acordo com o estado limite analisado, e a combinação empregada. Por último, $\gamma_{\mathrm{f} 3}$ está relacionado aos desvios gerados nas construções e nas aproximações feitas em projeto do ponto de vista das solicitações. A princípio, os fatores $\gamma_{f 1}$ e $\gamma_{f 3}$ deveriam ser aplicados respectivamente na majoração das ações e dos esforços internos. Na prática, ambos são aplicados simultaneamente pois, a análise elástico linear resulta nos mesmos esforços internos, qualquer que seja a ordem de aplicação dos fatores. Exceção à essa regra é feita explicitamente pela NBR-8681/84 que, com o objetivo de impedir a amplificação dos efeitos de segunda ordem nas análises onde a NLG deva ser considerada, indica o desdobramento do fator de carregamento.

$\mathrm{Na}$ composição do carregamento para a verificação do estado limite último, toma-se $\gamma_{\mathrm{t} 2}=1,0$ para as cargas permanentes e para a carga variável principal. Para as demais cargas variáveis, toma-se $\gamma_{\mathrm{t} 2}=\psi_{0}$ (fator de combinação das cargas variáveis). O produto $\gamma_{f}=\gamma_{\mathrm{f} 1} \times \gamma_{\mathrm{f3}}$, de acordo com a norma NBR 8681/84 - Ações e segurança nas estruturas (e mantido na NB1 - revisão 2000) consta da Tabela 8.1.

Tabela 8.1 - Coeficiente $\gamma_{f}=\gamma_{f 1} \times \gamma_{f 3}$

\begin{tabular}{|c|c|c|c|c|}
\cline { 2 - 5 } \multicolumn{1}{c|}{} & \multicolumn{2}{c|}{ permanentes $\left(\gamma_{\mathbf{f}}=\gamma_{\mathbf{g}}\right)$} & \multicolumn{2}{c|}{ variáveis $\left(\gamma_{\mathbf{f}}=\gamma_{\mathbf{q}}\right)$} \\
\cline { 2 - 5 } & desfavoráveis & favoráveis & geral & temperatura \\
\hline normais & 1,4 & 0,9 & 1,4 & 1,2 \\
\hline especiais ou de construção & 1,3 & 0,9 & 1,2 & 1,0 \\
\hline excepcionais & 1,2 & 0,9 & 1,0 & 0,0 \\
\hline
\end{tabular}

Como este trabalho analisa as condições de projeto de pavimentos de concreto armado sob condições usuais, empregam-se apenas as combinações últimas normais na verificação do estado limite último (expressão 8.1).

$$
F_{d}=\gamma_{g} F_{g k}+\gamma_{q}\left(F_{q 1 k}+\sum_{j=1}^{n} \psi_{0 j} F_{q j k}\right) 1
$$

\footnotetext{
${ }^{1}$ Foram consideradas apenas as cargas presentes no pavimento. Também não foi considerada a parcela referente à retração.
} 
$\mathrm{Na}$ verificação dos ELS, o produto $\left(\gamma_{\mathrm{f} 1} \times \gamma_{\mathrm{f3}}\right)$ passa a valer 1,0 , e $\gamma_{\mathrm{f} 2}$ é substituído por um dos fatores de redução $\left(1, \psi_{1}\right.$ ou $\left.\psi_{2}\right)$. Para a análise de pavimentos onde não há predominância de pesos de equipamentos que permaneçam fixos por longos períodos de tempo, nem de elevadas concentrações de pessoas, os fatores de utilização e de combinação assumem os seguintes valores: $\psi_{0}=0,4 ; \psi_{1}=0,3$; e $\psi_{2}=0,2$. De acordo com o estado limite de serviço a ser verificado, devem ser empregadas uma das combinações indicadas na Tabela 8.2.

A NB1-78 não indica quais as combinações a serem utilizadas para a verificação de cada um dos ELS. A NB1 - revisão 2000, no entanto, faz algumas indicações a esse respeito.

Tabela 8.2 - Combinações de serviço

\begin{tabular}{|c|c|c|}
\hline $\begin{array}{c}\text { combinações } \\
\text { de serviço }\end{array}$ & ELS a verificar & Composição \\
\hline $\begin{array}{c}\text { quase- } \\
\text { permanente } \\
\text { (CQP) }\end{array}$ & $\begin{array}{c}\text { deformações. } \\
\text { excessivas }\end{array}$ & $\mathrm{F}_{\mathrm{d}, \mathrm{ser}}=\sum_{\mathrm{i}=1}^{\mathrm{m}} \mathrm{F}_{\mathrm{gi,k}}+\sum_{\mathrm{j}=1}^{\mathrm{n}} \psi_{2 \mathrm{j}} \cdot \mathrm{F}_{\mathrm{qj}, \mathrm{k}}$ \\
\hline freqüente (CF) & $\begin{array}{c}\text { formação e abertura } \\
\text { de fissuras e vibrações } \\
\text { excessivas }\end{array}$ & $\mathrm{F}_{\mathrm{d}, \mathrm{ser}}=\sum_{\mathrm{i}=1}^{\mathrm{m}} \mathrm{F}_{\mathrm{gi,k}}+\psi_{1} \cdot \mathrm{F}_{\mathrm{q} 1, \mathrm{k}}+\sum_{\mathrm{j}=2}^{\mathrm{n}} \psi_{2 \mathrm{j}} \cdot \mathrm{F}_{\mathrm{qj}, \mathrm{k}}$ \\
\hline rara (CR) & formação de fissuras & $\mathrm{F}_{\mathrm{d}, \mathrm{ser}}=\sum_{\mathrm{i}=1}^{\mathrm{m}} \mathrm{F}_{\mathrm{gi}, \mathrm{k}}+\mathrm{F}_{\mathrm{q} 1, \mathrm{k}}+\sum_{\mathrm{j}=2}^{\mathrm{n}} \psi_{2 \mathrm{j}} \cdot \mathrm{F}_{\mathrm{qj}, \mathrm{k}}$ \\
\hline
\end{tabular}

\subsubsection{Ponderadores dos materiais}

Os materiais que compõem a estrutura do pavimento, de acordo com o método semi-probabilístico, devem ter suas propriedades de resistência minoradas pelo coeficiente $\gamma_{m}$ na verificação do ELU. Analogamente ao coeficiente de ponderação das ações, este último também é composto por 3 parcelas $\gamma_{\mathrm{m}=} \gamma_{\mathrm{m} 1 \times} \gamma_{\mathrm{m} 2 \times}$ $\gamma_{\mathrm{m} 3}$. No entanto, a NBR 8681/84 e a NB1-revisão 2000, que também incorpora os conceitos de segurança nas estruturas, não apresentam valores para essas parcelas. Os valores de $\gamma_{m}$ indicados pela NB1-revisão 2000 estão na Tabela 8.3.

Tabela 8.3 - Valores dos coeficientes $\gamma_{c}$ e $\gamma_{s}$

\begin{tabular}{|c|c|c|}
\hline combinações & concreto $\left(\gamma_{\mathbf{c}}\right)$ & aço $\left(\gamma_{\mathbf{s}}\right)$ \\
\hline normais & 1,4 & 1,15 \\
\hline especiais & 1,2 & 1,15 \\
\hline excepcionais & 1,2 & 1,0 \\
\hline
\end{tabular}


A NB1-78 não indica claramente quais as propriedades dos materiais empregadas nas verificações relativas aos ELS. A NB1-revisão 2000, no entanto, é clara nesse aspecto, e indica um coeficiente de minoração $\gamma_{m}=1,0$ para os materiais, e propõe o emprego de suas propriedades características de resistência.

\subsection{Métodos disponíveis}

Apesar de ainda não se dispor de uma metodologia suficientemente fundamentada para o dimensionamento em regime não-linear físico, existem, no entanto, boas propostas com esse objetivo, mas que necessitam ser ainda bastante discutidas. Basicamente, são duas as correntes de pensamento que fundamentam as metodologias. A primeira delas, liderada pelo pesquisador Giorgio Macchi, defende a continuidade do método semi-probabilístico, apesar de não descartar a necessidade de algumas adaptações necessárias. A segunda linha de pensamento, tendo à frente Gert König e Josef Eibl, adota uma postura revolucionária, e defende o conceito de um coeficiente de segurança global relativo aos materiais. Apesar de ambas as propostas ainda estarem em desenvolvimento no âmbito do CEB Task Group 2.1 Non-linear design methods and safety concepts, nota-se, principalmente após a edição do CEB: Bulletin d'Information $n^{\circ} 239$, um fortalecimento das idéias de König e Eibl em relação às de Macchi.

\subsubsection{Método semi-probabilístico}

No CEB: Bulletin d'Information $n^{\circ}$ 229, MACCHI (1995) desenvolve uma série de raciocínios em prol da manutenção do método semi-probabilístico, apesar de admitir a necessidade de adaptações de modo a contemplar os novos conhecimentos e atender às novas necessidades. O principal apelo do pesquisador diz respeito ao aproveitamento do extenso conhecimento já incorporado ao método desde a sua criação, em 1964. Ele alerta para o fato de que novos métodos ainda necessitariam ser calibrados através de extensas análises de confiabilidade, considerando-se a influência das variáveis inerentes à segurança. Por fim, Macchi tece críticas ao método dos coeficientes globais, e questiona sobre a (atual) real capacidade de modelagem da ruptura de estruturas complexas.

Os membros do CEB Task Group 2.1 esclarecem que a probabilidade de ruptura de uma estrutura só pode ser corretamente avaliada através de estudos que envolvam a distribuição aleatória das variáveis envolvidas (propriedades dos 
materiais, carregamento e geometria), como o que se procede nas análises de confiabilidade. No entanto, a complexidade desse tipo de análise inviabiliza a sua utilização corrente, e abre espaço para o desenvolvimento de uma metodologia determinística aplicada ao dimensionamento e à avaliação da segurança.

A aplicação do método semi-probabilístico ao dimensionamento de estruturas considerando-se o comportamento não-linear esbarra na definição dos itens 8.2.1 e 8.2.3. Os aspectos que dificultam a aplicação e, de certo modo, o entendimento da lógica implícita no método, estão relatados a seguir.

\subsubsection{Composição do carregamento}

Os resultados de uma análise não-linear geralmente contemplam uma apreciável redistribuição dos esforços internos da estrutura. Quando o objetivo da análise é o de dimensionamento, essa redistribuição também é fortemente influenciada pelo modo como é considerado o carregamento, uma vez que o conceito de proporcionalidade entre ações e esforços deixa de existir.

Uma possibilidade para a consideração do carregamento surge da analogia com a análise de estruturas considerando-se a não-linearidade geométrica (NLG), onde é comum o particionamento de $\gamma_{\mathrm{f}}$, empregando-se $\gamma_{\mathrm{f} 1}$ na majoração do

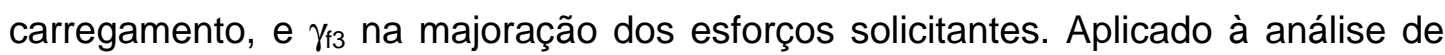
estruturas cujos comportamentos atendam a uma lei constitutiva limitada por um valor último, esse procedimento pode levar ao estado ilustrado na Figura 8.1.

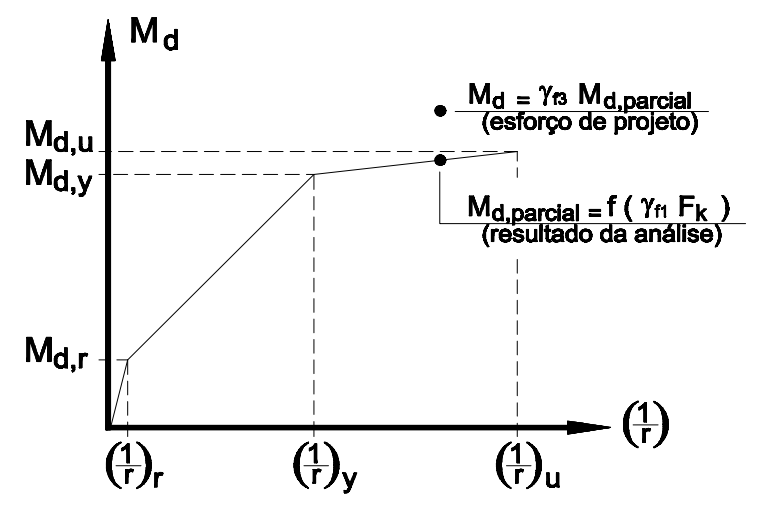

Figura 8.1 - Aspecto da majoração do esforço parcial de projeto ( $\left.M_{d, \text { parcial }}\right)$

Supondo que, ao final da análise, a seção esteja submetida a um esforço suficientemente próximo a $M_{u}$, tal que a pós-multiplicação desse esforço por $\gamma_{+3}$ possa conduzir a $M>M_{u}$, significa admitir que a capacidade resistente préestabelecida para a seção é incompatível com o valor do carregamento aplicado. Esse problema, já observado por OLIVEIRA (1997), gera um procedimento iterativo 
na busca da convergência entre o momento fletor de projeto $\left(M_{d}\right)$, e o valor da capacidade última resistente arbitrada para a seção transversal de acordo com suas características geométricas e de resistência $\left(M_{d, u}\right)$.

Procedimento idêntico, e preconizado pelo Eurocode 2: Design of concrete structures (Part 1: General rules and rules for buildings), recebe a designação de procedimento de linearização (linearization procedure), pois admite uma majoração linear dos esforços na seção analisada. Essa proposta surgiu com LEVI (1970) ${ }^{2}$ apud CEB: Bulletin d'Information nํ2ㄱ juntamente com as primeiras idéias sobre o problema da incerteza da segurança na análise não-linear. De acordo com o Boletim $n^{\circ} 227$, esse procedimento foi abandonado posteriormente para a análsie não-linear física pois, a interrupção do processo de carregamento da estrutura em um nível intermediário, quando a rigidez da estrutura é ainda bastante efetiva, reduz excessivamente a possibilidade de redistribuição dos esforços internos.

Ainda com maior intensidade, a aplicação de todo o coeficiente $\gamma_{f}$ a posteriori, ou seja, na majoração exclusiva dos esforços, incorre nos impedimentos assinalados para o procedimento de linearização.

A opção mais plausível, então, parece ser a aplicação do carregamento total de projeto (majorado por $\gamma_{\mathrm{f}}$ ) para a obtenção dos esforços. Com isso, elimina-se o problema da possível superação de $M_{d, u}$ uma vez que, ao final da análise, não devem ser observados esforços superiores ao máximo permitido pelo modelo nãolinear. Contrariamente à crítica tecida ao procedimento de linearização, pesa contra este último, o fato de proporcionar uma excessiva redistribuição de esforços, somente atingidos com a ocorrência de um carregamento com pouca probabilidade de ser atingido (definição do carregamento de projeto). De qualquer forma, apesar das críticas, parece ser esta última opção a mais aceita atualmente (SANTOS (1997), e CEB: Bulletin d'Information nº 229).

\subsubsection{Valores para as propriedades dos materiais}

A composição das propriedades dos materiais pode, assim como na determinação do carregamento, levar a problemas de superação do esforço de projeto, ou mesmo proporcionar uma excessiva redistribuição esforços. Admita-se, inicialmente, a estrutura definida pelos valores médios de resistência dos materiais. Em se tratando de análises referentes aos ELS, essa opção parece ser a mais

\footnotetext{
${ }^{2}$ LEVI, F. (1970). II problema della sicurezza delle costruzioni iperstatiche. Giornale del Genio Civile. Roma, fasc.4, Aprile.
} 
acertada, uma vez que a estrutura real deva apresentar um comportamento próximo daquele obtido de uma análise considerando-se as propriedades médias dos materiais. Valores característicos, ou de projeto, envolvem aspectos probabilísticos ligados à segurança da estrutura no ELU, e por isso não exprimem o comportamento em serviço esperado. No ELU, no entanto, de acordo com o método semi-probabilístico, as características mecânicas dos materiais devem ser minoradas pelos coeficientes de segurança. Isso pode levar, na maioria dos casos, ao mesmo problema assinalado na Figura 8.2 pois, ao final da análise respeitandose os valores dos esforços obtidos considerando-se as propriedades médias dos materiais, estes devem ser minorados pelos coeficientes de segurança, e assim, apresentarem-se inferiores aos observados na análise.

Por outro lado, a adoção das propriedades de projeto dos materiais em toda a estrutura pode conduzir a resultados pouco confiáveis e fisicamente distorcidos, uma vez que a análise contemplaria uma estrutura mais deformável que a estrutura real, prejudicando o aspecto da redistribuição de esforços.

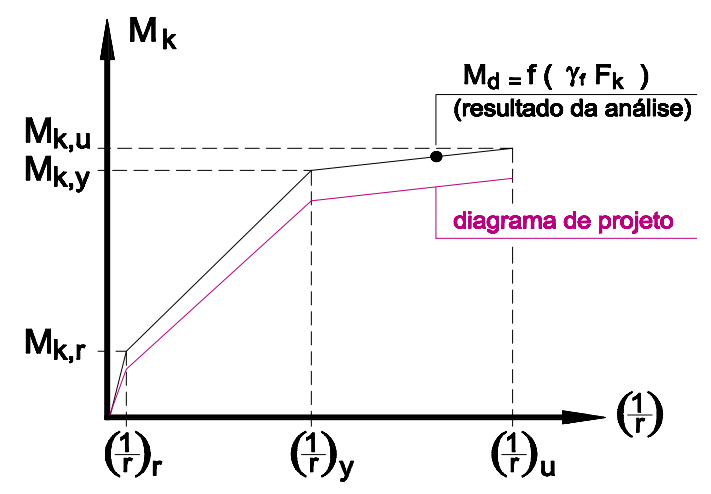

Figura 8.2 - Aspecto da minoração do esforço característico $\left(M_{k}\right)$

Com o objetivo de contornar esse problema, o CEB: Bulletin d'Information $n^{\circ}$ 227 propõe o emprego dos valores médios das propriedades dos materiais em toda a estrutura, exceto nas seções críticas, onde seriam utilizadas as propriedades de projeto. Com isso, eliminar-se-ia o inconveniente da Figura 8.2, pois as seções críticas é que seriam utilizadas nas verificações do ELU. Como a princípio não se conhecem quais são as seções críticas da estrutura, a proposta é de que se proceda a análise até o instante em que uma ou mais seções atinjam, no diagrama referente às propriedades médias, o valor de início da plastificação determinado com valores de projeto. A partir desse instante, o comportamento momento fletor por curvatura para essas seções apresenta uma descontinuidade, e passa a obedecer ao diagrama momento fletor por curvatura de projeto (Figura 8.3). 


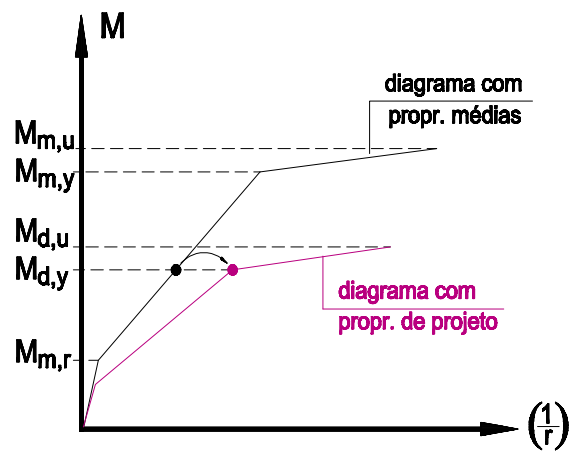

Figura 8.3 - Diagramas de momento fletor por curvatura para análise não-linear (CEB - Boletim $n^{\circ}$ 227)

Apesar de apresentar-se como uma solução possível para o problema, essa proposta não parece ser consistente, e muito menos genérica, uma vez que sua aplicabilidade é restrita apenas ao campo dos momento fletores e das curvaturas.

\subsubsection{Propostas para o dimensionamento}

Ao definir as propriedades de projeto do concreto altera-se, além da capacidade resistente teórica ( $f_{c k} \rightarrow f_{c d}$ ), também a relação constitutiva do material. Isso inviabiliza a caracterização de uma relação constitutiva que seja capaz de ambos: representar coerentemente as redistribuições de esforços (de acordo com as propriedades médias), e ainda estar limitada a um valor convencional ( $\left.f_{c d}\right)$.

A definição de uma relação constitutiva para o aço é menos conflitante, haja visto a invariabilidade (mesmo que convencional) de seu módulo de deformação longitudinal $\left(E_{s}\right)$ com a resistência ao escoamento (Figura 8.4).

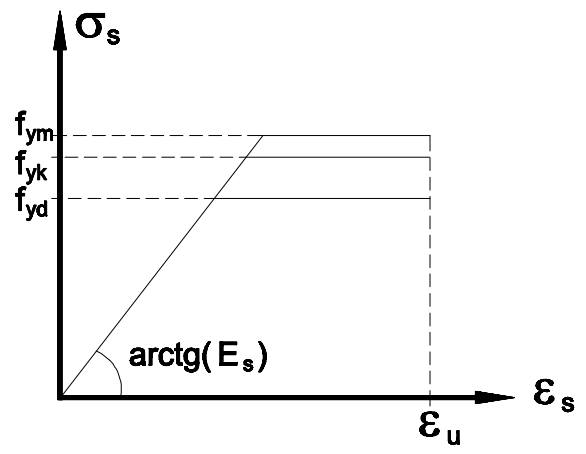

Figura 8.4 - Diagrama tensão-deformação para o aço CA-50A

\subsubsection{Proposta de alteração da rigidez inicial}

Essa proposta, apresentada por CÂMARA et al. (1994) e depois adotada por SANTOS (1997) mantém, para o aço, o valor de projeto convencional obtido 
com $\gamma_{s}=1,15$, mas promove uma modificação da lei constitutiva do concreto. $O$ módulo de elasticidade, calculado na origem com base no valor médio da resistência, é afetado por um fator $\gamma_{c}=1,20$ como preconiza o CEB-FIP MC90 consoante à determinação dos deslocamertos. A tensão de ruptura é a de projeto convencional $\left(f_{c d}=f_{c k} / \gamma_{c}\right.$, com $\left.\gamma_{c}=1,50\right)$, como mostra a Figura 8.5 devidamente adaptada ao $\gamma_{c}=1,40$. Através desse artifício, objetiva-se a melhoria da análise relativa aos ELS (principalmente na previsão de deslocamentos), sobre a qual repousa grande parte das críticas quanto ao emprego do método semiprobabilístico. Segundo os autores, esse artifício exerce influência desprezível sobre o comportamento à ruptura e, consequentemente, na previsão do ELU.

\subsubsection{Proposta da limitação da tensão máxima}

Neste trabalho, propõe-se a composição de duas relações constitutivas, ou seja, uma lei baseada no valor médio de resistência até que seja atingida a tensão de projeto $\left(f_{c d}\right)$. Em seguida, a curva tensão-deformação segundo os valores médios é substituída por uma relação elastoplástica perfeita até que seja atingida a deformação limite (Figura 8.5).

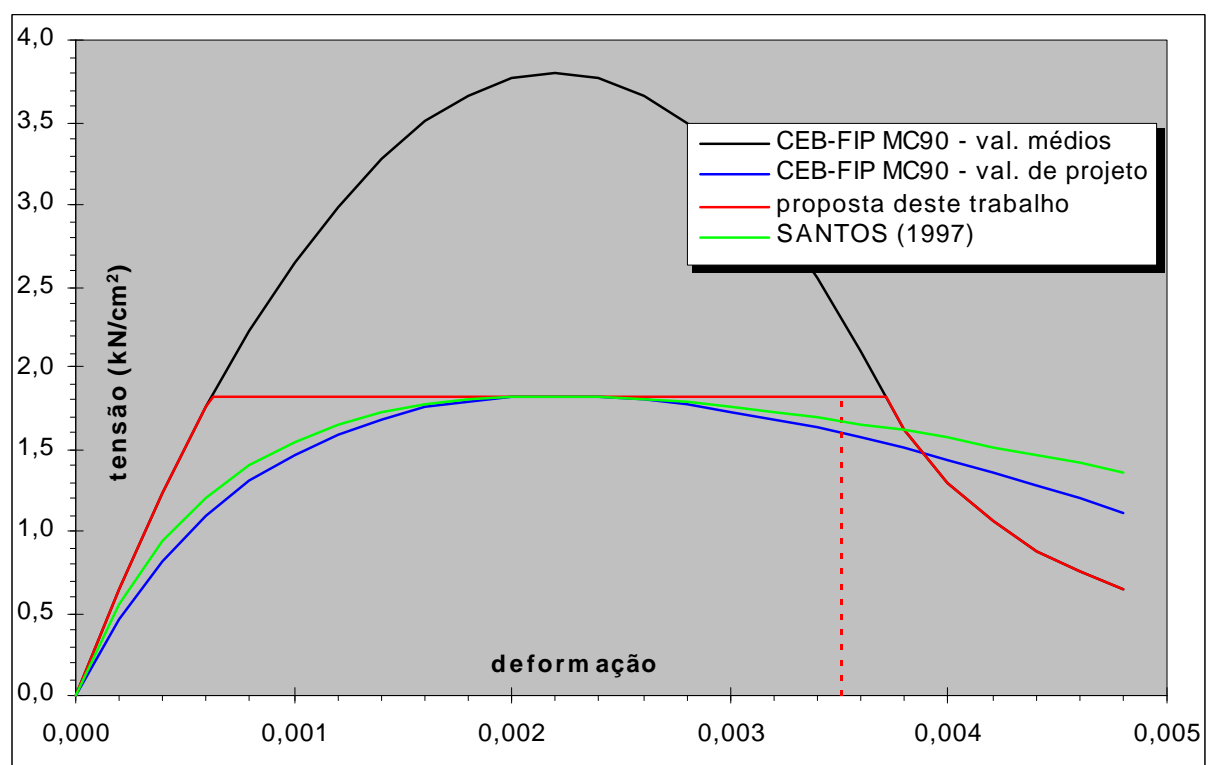

Figura 8.5 - Diagramas para o concreto C-30 (CEB-FIP MC90)

A aplicação do formato de segurança semi-probabilístico ao dimensionamento de estruturas de concreto armado apresenta apreciáveis pontos favoráveis, destacando-se: o grau de conhecimento acumulado ao longo dos anos, além da consagração de seu emprego em diversos países. Portanto, a extensão de sua aplicação ao dimensionamento em regime não-linear seria mais facilmente 
aceita, e não existiria a necessidade da verificação de muitos dos coeficientes empregados. No entanto, como se procurou destacar neste texto, é praticamente impossível compatibilizar a aplicação desse método com uma boa representação do comportamento estrutural, que é o principal objetivo a que se destina o emprego das relações não-lineares. Pelo contrário, ao se adotarem propostas baseadas na alteração da relação constitutiva do concreto, o objetivo da representatividade fica prejudicado, e dá margem à grande crítica quanto ao emprego da metodologia semi-probabilística para esse tipo de dimensionamento.

\subsubsection{Método dos coeficientes globais}

A proposta de emprego do método dos coeficientes globais tem o objetivo, segundo o texto do CEB: Bulletin d'Information $\mathrm{n}^{\circ}$ 239, de estabelecer uma metodologia consistente que seja aplicável a todo tipo de modelo ou de estrutura. $A$ partir das relações constitutivas dos materiais e, obviamente, das características geométricas, de vinculação, e de carregamento, é possível inferir sobre a segurança de uma estrutura de concreto armado, e não apenas daquelas onde o conceito da seção transversal seja aplicável.

O conceito de coeficiente global $\left(\gamma_{g l}\right)$ doravante empregado quer referir-se apenas à parcela da segurança relativa à resistência da estrutura, de modo que:

$$
\left(\gamma_{q} \cdot Q+\gamma_{g} \cdot G\right) \leq \frac{R}{\gamma_{g l}}
$$

onde: $\mathrm{R}$ é a capacidade resistente da estrutura empregando-se as propriedades médias dos materiais.

A maior discussão quanto ao emprego do método restringe-se à definição do valor do coeficiente global a ser empregado. Se as propriedades médias dos materiais forem definidas simplificadamente como:

$$
\begin{aligned}
& f_{c m}=1,1 \cdot f_{c k} \\
& f_{y m}=1,1 \cdot f_{y k}
\end{aligned}
$$

pode-se mostrar que o $\gamma_{\mathrm{gl}}$ para uma seção transversal de concreto armado situa-se, aproximadamente, entre 1,265 (quando a ruptura se dá pela armadura de flexão) e 1,650 (quando a ruptura se dá pelo concreto), se for empregado $\gamma_{c}=1,5$. No entanto, quando a ruptura da seção se dá pela concomitância dos dois modos, não existe uma descrição para o coeficiente (Figura 8.6). 


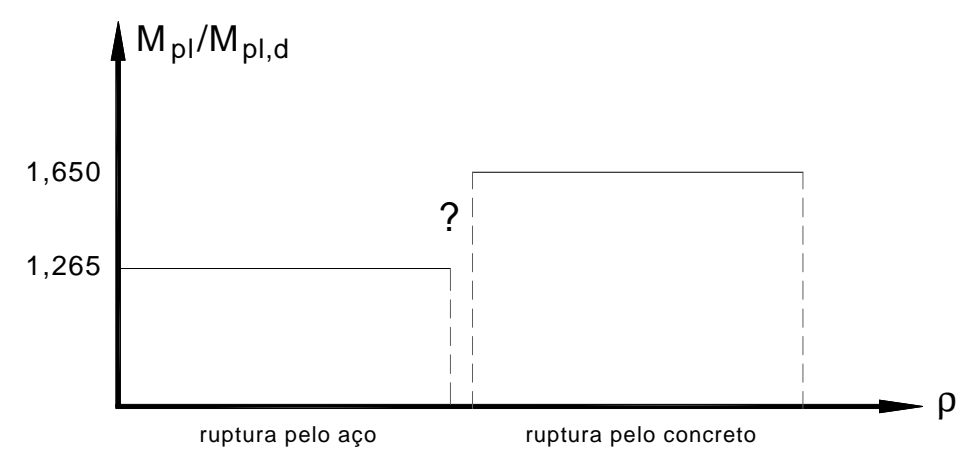

Figura 8.6 - Diagrama idealizado para o $\gamma_{g l}$ esperado para uma estrutura de concreto armado submetida à flexão. Carregamento proporcional

onde: $\mathrm{M}_{\mathrm{pl}}$ - momento de plastificação obtido com os valores médios dos materiais; $M_{p l, d}$ - momento de plastificação obtido com as propriedades de projeto.

Esses valores, apresentados por EIBL;SCHMIDT-HURTIENNE (1997), também podem ser caracterizados analiticamente:

$$
\begin{aligned}
& \text { aço concreto } \\
& f_{y d}=\frac{f_{y k}}{1,15} ; f_{y m}=1,10 . f_{y k} \quad f_{c d}=\frac{f_{c k}}{1,5} ; f_{c m}=1,10 . f_{c k} \\
& \text { onde: } \frac{f_{y m}}{f_{y d}}=1,10.1,15=1,265 \quad \frac{f_{c m}}{f_{c d}}=1,10.1,5=1,650
\end{aligned}
$$

É importante salientar o fato de que o conceito do coeficiente global relativo æ̀s cargas só pode ser empregado uma vez admitida a hipótese de carregamentos proporcionais. A sua extensão ao dimensionamento de elementos submetidos a esforços de $2^{\underline{a}}$ ordem deve ser vista com muita cautela sabido que, nesses casos, não se verifica a proporcionalidade da relação $\mathrm{M} / \mathrm{N}$ (excentricidade).

$\mathrm{O}$ fato de existirem dois conhecidos coeficientes de segurança, de acordo com o tipo de ruptura (ou ELU), e outros desconhecidos para o caso de ruptura concomitante, dificulta a adoção de uma metodologia para o dimensionamento. De um modo geral, as vigas são projetadas para um ELU definido pela deformação excessiva das armaduras de flexão, enquanto que os pilares, preferencialmente, pelo esmagamento do concreto. Nessa linha de raciocínio, LOURENÇO et al. (1992) propõem uma análise global segmentada, de acordo com o modo de ruptura: $\gamma_{\mathrm{gl}}=1,5$ se a ruptura for pelo concreto $(1,5$ pois os autores propõem $\mathrm{f}_{\mathrm{cm}}=\mathrm{f}_{\mathrm{ck}}$ ), e $\gamma_{\mathrm{gl}}=1,15$ se a ruptura se der por deformação excessiva da armadura.

A solução encontrada pelos membros do CEB Task Group 2.1 Non-linear design methods and safety concepts, e sobre a qual pesam as maiores críticas, foi a de adaptar o valor da resistência média do concreto $\left(f_{\mathrm{cm}}\right)$ de acordo com 
pesquisas finalizadas e em andamento na Universidade de Leipzig (KÖNIG et al. $(1997)^{3}$ apud CEB: Bulletin d'Information $n^{\circ}$ 239). Segundo os autores, o valor da resistência média do concreto, medido in-situ é de 0,85 do respectivo valor característico medido em laboratório.

$$
f_{c m}=0,85 . f_{c k}
$$

Essa relação apresenta precedente semelhante. Na definição do coeficiente $\gamma_{c}$ pelo código CEB-FIP MC90 existem 3 parcelas assim definidas:

$$
\gamma_{c}=\gamma_{R d} \cdot \eta \cdot \frac{f_{c, 0,005}}{f_{c, 0,05}}
$$

onde: $\gamma_{\mathrm{Rd}}=1,10$ (refere-se às incertezas quanto ao material);

$\eta=1,10$ (relação entre as resistências do concreto: laboratório / in-situ);

$\frac{f_{c, 0,005}}{f_{c, 0,05}}=1,24$ (refere-se à mudança do quantil de $5 \%$ para o de $0,5 \%$ ).

$\mathrm{Na}$ definição de $\eta$, no entanto, a relação é feita entre as resistências médias, e não entre uma média e outra característica. De qualquer modo, uma vez aceita a validade da relação 8.5 , os coeficientes referidos a ambos os tipos de ruptura passam a ser bastante próximos e, para efeito prático, iguais a 1,27. A Figura 8.7 traz uma ilustração da composição de $\gamma_{c}$.

$$
\begin{array}{cl}
\text { aço } & \text { concreto } \\
f_{y d}=\frac{f_{y k}}{1,15} ; f_{y m}=1,10 . f_{y k} & f_{c d}=\frac{f_{c k}}{1,5} ; f_{c m}=0,85 \cdot f_{c k} \\
\text { onde: } \frac{f_{y m}}{f_{y d}}=1,10 \cdot 1,15=1,265 & \frac{f_{c m}}{f_{c d}}=0,85 \cdot 1,5=1,275
\end{array}
$$

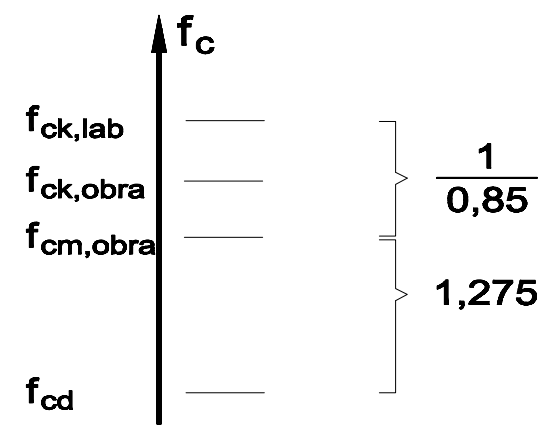

Figura 8.7 - Desdobramento do coeficiente de segurança $\gamma_{c}=1,5$

\footnotetext{
${ }^{3}$ KÖNIG,G.;SHOUKOV,D.;JUNGWIRTH,F.(1997). Sichere beton production für stahlbetontragwerke, Intermediate report 2, March. apud CEB: Bulletin d'Information nํㅜ 239.
} 
No texto do CEB: Bulletin d'Information nํ 239 apresentam-se os resultados teóricos da análise de uma seção retangular de concreto armado supostamente sob flexão. Nos diagramas da Figura 8.8 constam os resultados de duas análises tendo sido empregados, a cada uma delas, valores distintos para a resistência média do concreto. Pode-se observar a pequena variabilidade da proporção $\left(\gamma_{\mathrm{gl}}\right)$ entre o momento resistente empregando-se as propriedades médias (com $\left.\mathrm{f}_{\mathrm{cm}}=0,85 . \mathrm{f}_{\mathrm{ck}}\right)$, e aqueles onde foram adotadas as propriedades de projeto. Esse aspecto é bastante favorável para o emprego de um coeficiente de segurança fixo.

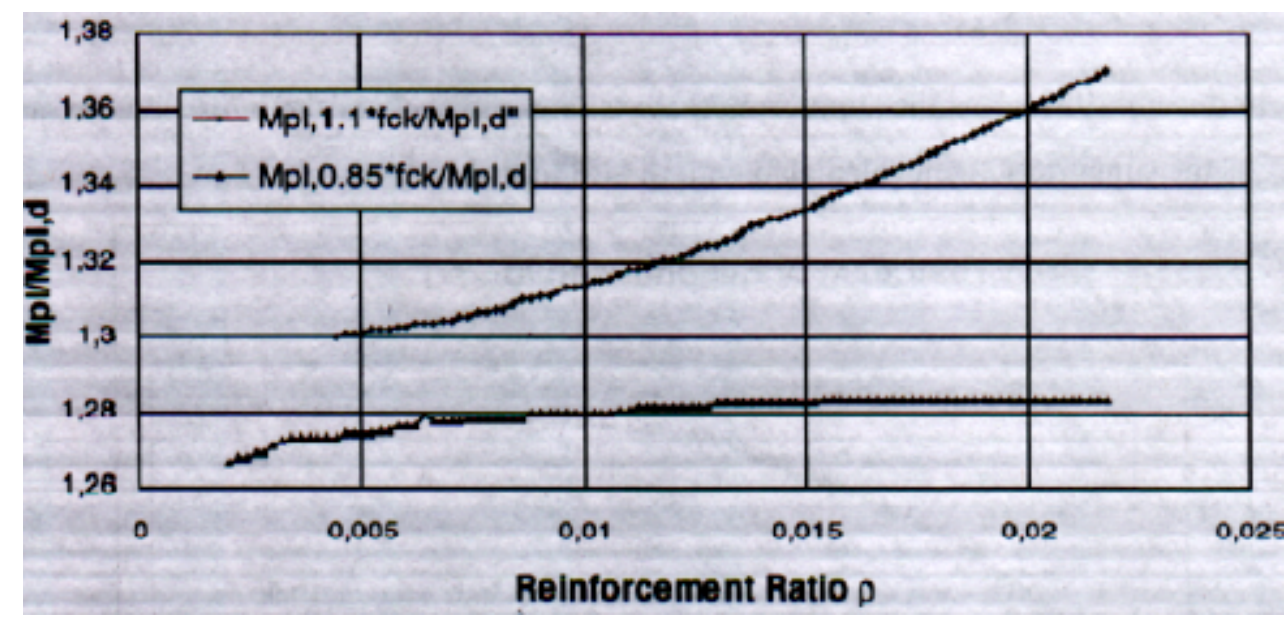

Figura 8.8 - Proporção entre os momentos de plastificação $\left(\gamma_{g l}\right)$ : CEB-FIP

onde: $\mathrm{M}_{\mathrm{pl}}-$ momento de plastificação obtido com as propriedades médias:

$$
\mathrm{f}_{\mathrm{yd}}=1,10 . \mathrm{f}_{\mathrm{yk}} ; \mathrm{f}_{\mathrm{cd}}=0,85 . \mathrm{f}_{\mathrm{ck}} \text { ou } \mathrm{f}_{\mathrm{yd}}=1,10 . \mathrm{f}_{\mathrm{yk}} ; \mathrm{f}_{\mathrm{cd}}=1,10 . \mathrm{f}_{\mathrm{ck}} \text {; }
$$

$\mathrm{M}_{\mathrm{pl}, \mathrm{d}}$ - momento de plastificação obtido com as propriedades de projeto: $\mathrm{f}_{\mathrm{yd}}=\mathrm{f}_{\mathrm{yk}} / 1,15 ; \mathrm{f}_{\mathrm{cd}}=\mathrm{f}_{\mathrm{ck}} / 1,50$.

Com o objetivo de confirmar os resultados apresentados pelo CEB-FIP (obtidos com $\gamma_{c}=1,5$ ), bem como estender o estudo às principais solicitações que se podem apresentar em um pavimento, foram elaboradas breves análises (Figura 8.10, Figura 8.11 e Figura 8.12) com as seções transversais apresentadas na Figura 8.9, e admitido o concreto C-30.
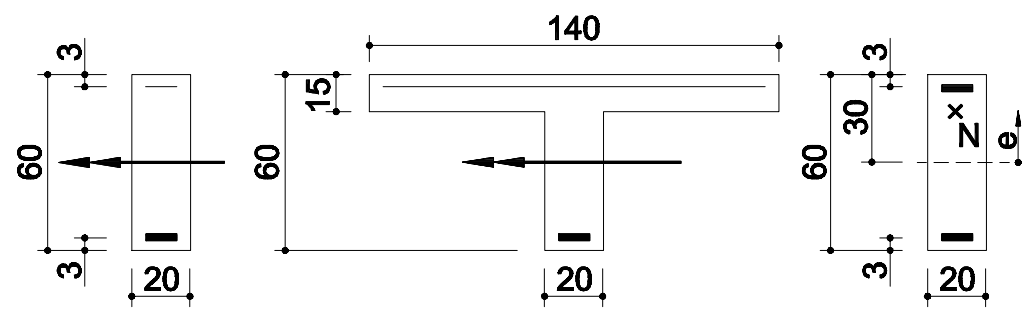

Figura 8.9 - Geometria das seções analisadas 


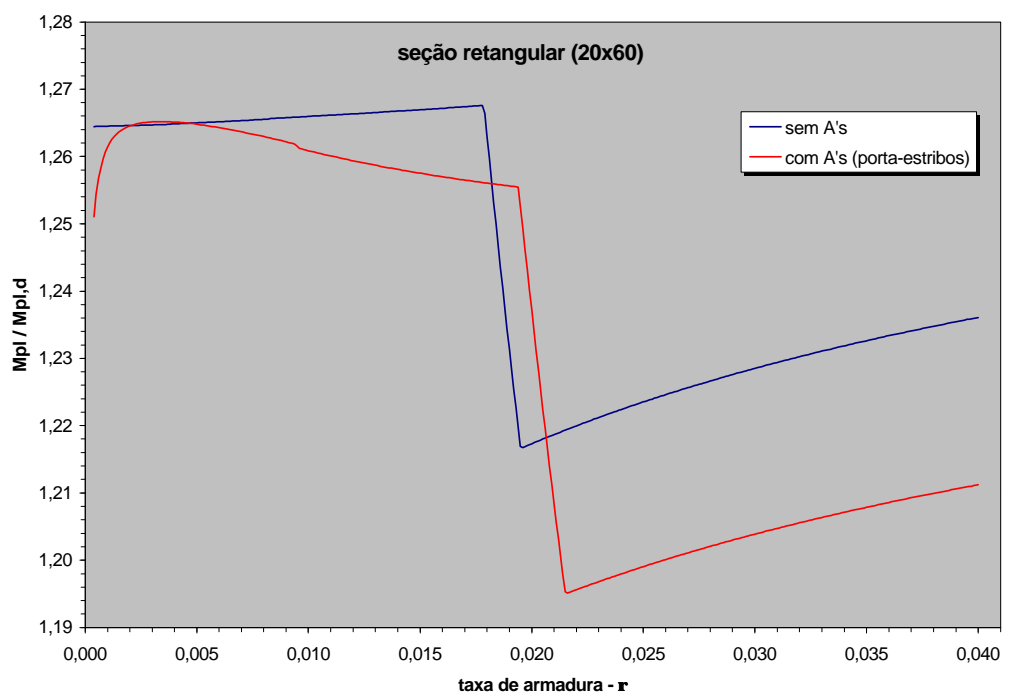

Figura 8.10 - $\gamma_{g^{\prime}}$. Seção retangular sob flexão simples

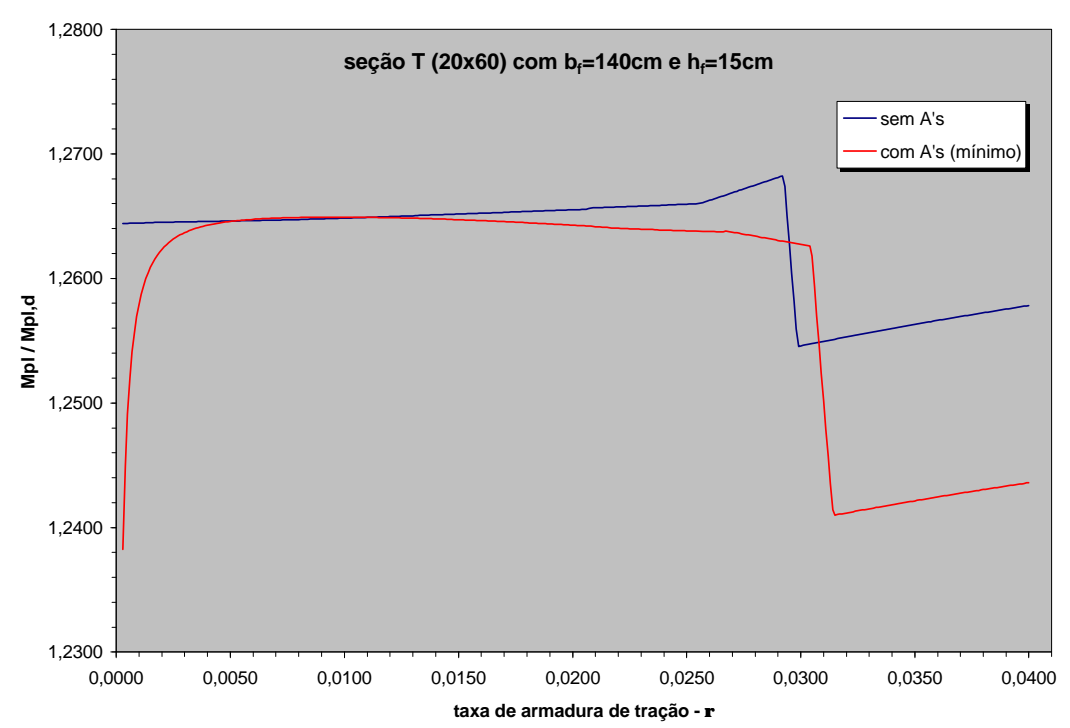

Figura 8.11 - $\gamma_{g l}$. Seção T sob flexão simples

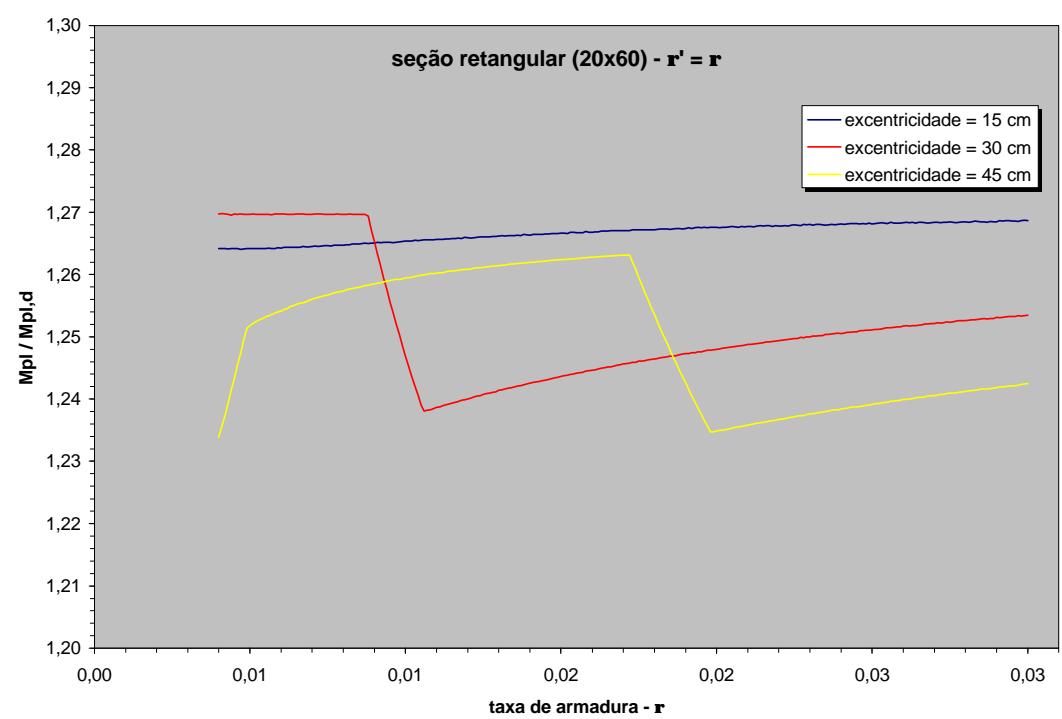

Figura 8.12 - $\gamma_{g^{\prime}}$. Seção retangular sob FNC 
As curvas obtidas confirmam, com restrições, a previsão para o coeficiente de segurança global em torno de 1,27. O comportamento das seções retangulares submetidas à flexão simples pode ser considerado dentro de limites toleráveis para taxas de armadura de até 1,8\%, partir da qual o coeficiente sofre uma sensível queda para em torno de 1,194. Já as vigas de seção T apresentam um coeficiente de segurança global bastante bem enquadrado (em torno de 1,265) para toda a gama de armadura de flexão permitida, pela atual norma brasileira. O valor mínimo ficou em 1,24, o que significa menos de $2 \%$ do valor pretendido. A seção sob flexão normal composta apresentou, como era de se esperar, comportamentos diferenciados de acordo com a excentricidade da força normal (medida na maior direção a partir do eixo baricêntrico da seção). As 3 curvas apresentarem dentro de uma tolerância razoável, porém, o melhor comportamento se deu para uma excentricidade inferior aos limites do núcleo central de inércia.

Uma vez constatada a razoável aproximação dos resultados obtidos para as seções e solicitações analisadas, cabe a adaptação do método aos coeficientes indicados pelos códigos de normalização brasileiros. O coeficiente de segurança aplicado ao aço é o mesmo indicado pelo CEB-FIP MC90, ou seja, $\gamma_{s}=1,15$. No entanto, o coeficiente aplicado ao concreto, de acordo com a NBR-8681/84 deve valer $\gamma_{c}=1,4$, o que leva a um coeficiente para a ruptura pelo concreto de:

$$
\frac{f_{c m}}{f_{c d}}=0,85 \cdot 1,4=1,19
$$

Se o objetivo final é o de manter fixo o coeficiente de segurança, quer seja a ruptura pelo concreto ou pelo aço, deve-se agora alterar o valor médio para o escoamento do aço, de modo a se obter um coeficiente de 1,19.

$$
f_{y m}=\frac{1,19}{1,15} \cdot f_{c k}=1,035 \cdot f_{c k}
$$

Neste ponto vale a pena tecer um breve comentário sobre o valor adotado para a resistência média de escoamento do aço. O CEB: Bulletin d'Information no 239 não justifica a adoção do valor $f_{y m}=1,10 . f_{y k}$, e mesmo as pesquisas elaboradas com o objetivo de se estabelecer tal valor não obtiveram sucesso. De qualquer modo, por se tratar de um material cujo avanço tecnológico de produção é muito superior ao do concreto, por exemplo, o valor de 10\% parece estar superestimado, pois corresponde a um coeficiente de variação $C V=6,1 \%$. Resultados obtidos no laboratório do Departamento de Estruturas, da EESC-USP, não divulgados 
formalmente, sugerem resistências médias bastante próximas ao valor característico. Assim sendo, mesmo não dispondo de um maior embasamento formal, parece ser razoável o emprego dos 3,5\% (CV=2,1\%) para relacionar o valor médio ao valor característico da resistência ao escoamento do aço.

Do mesmo modo como procedido à verificação do coeficiente de segurança indicado pelo CEB: Bulletin d'Information $n^{\circ} 239(1,27)$ procede-se, a seguir, uma série de aferições com o objetivo de explorar melhor as respostas mecânicas das seções transversais da Figura 8.9, agora empregando-se $\gamma_{c}=1,4$. A amplitude dos estudos procedidos constam da Tabela 8.4, e os resultados apresentados, convém ressaltar, dão apenas um indicativo sobre o comportamento estrutural. Conclusões mais fundamentadas, que permitam uma aplicação prática do método, só devem ser tomadas mediante análises envolvendo o caráter estocástico das variáveis inerentes à segurança, através das simulações sobre a confiabilidade estrutural. Exemplos desse tipo de análise podem ser encontrados nos trabalhos de HENRIQUES (1998), e de SOARES (2001).

Tabela 8.4 - Resumo dos casos analisados com $\gamma_{c}=1,4$

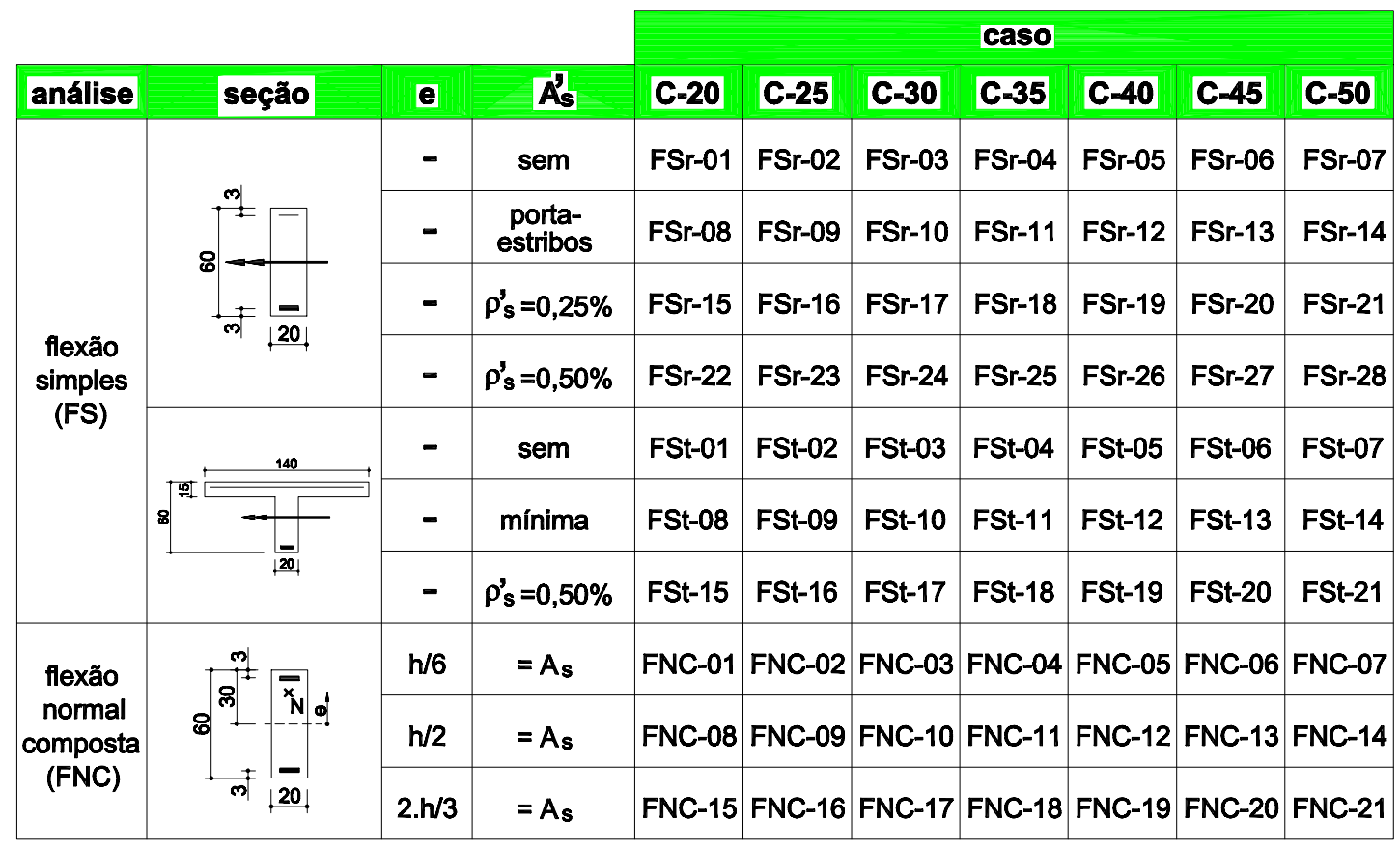

Os resultados obtidos com as simulações propostas na Tabela 8.4 são apresentados nas figuras a seguir. Uma série de outras simulações, objeto de uma investigação sobre a influência da geometria da seção transversal no comportamento do coeficiente $\gamma_{\mathrm{gl}}$, estão apresentadas no Anexo B. 


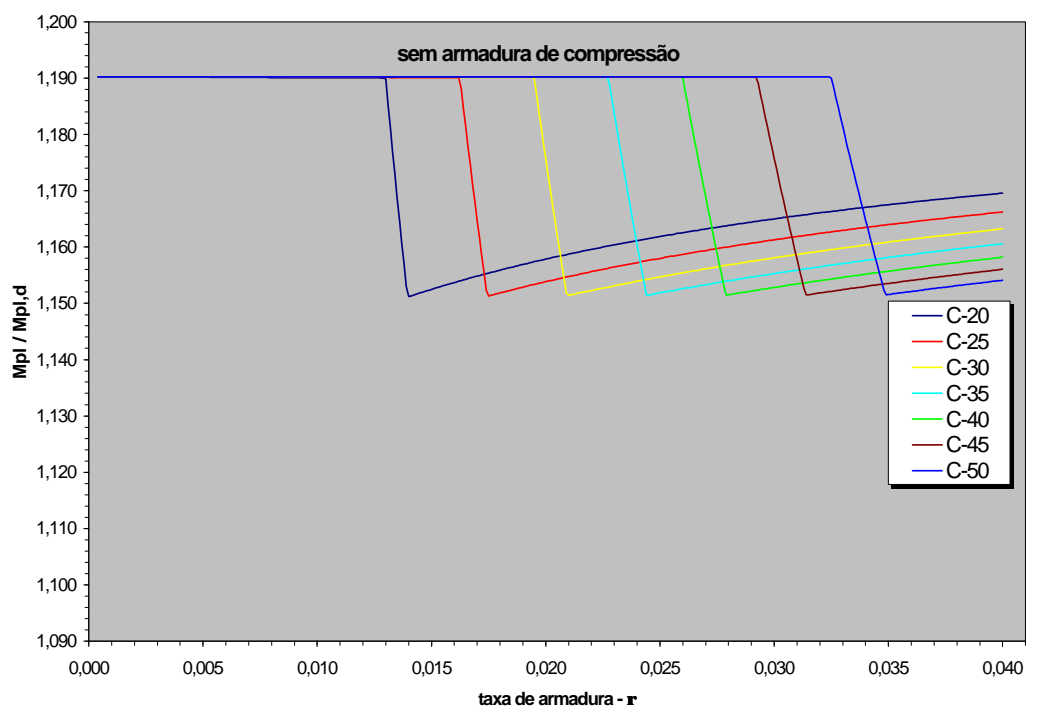

Figura $8.13-\gamma_{g l .}$ FSr-01 a FSr-07

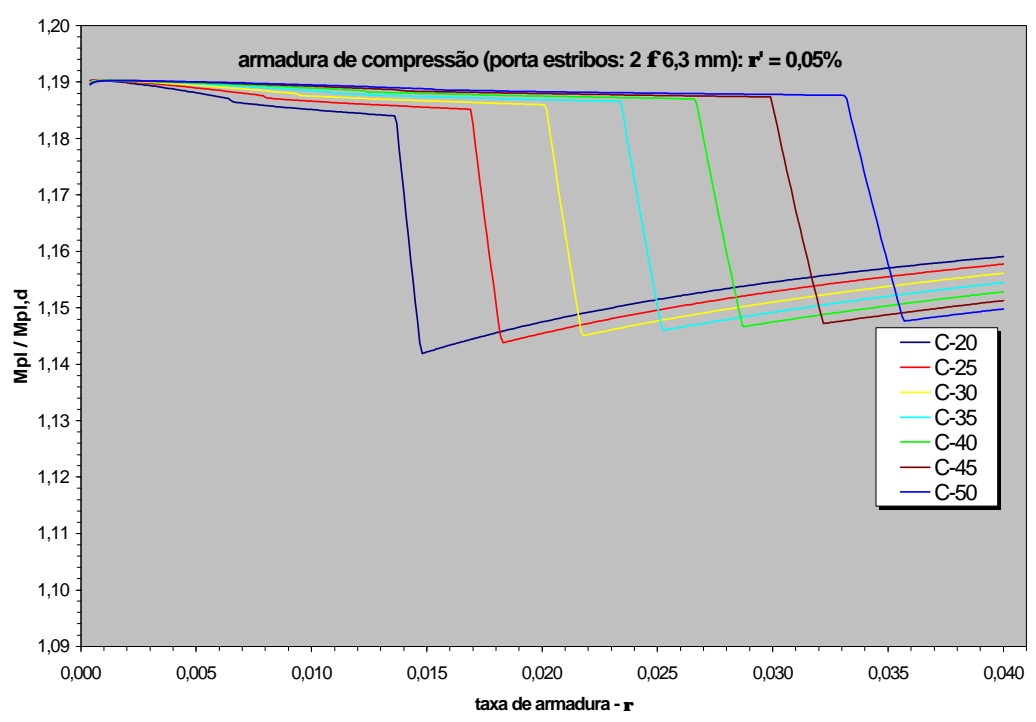

Figura 8.14 - $\gamma_{g l .}$ FSr-08 a FSr-14

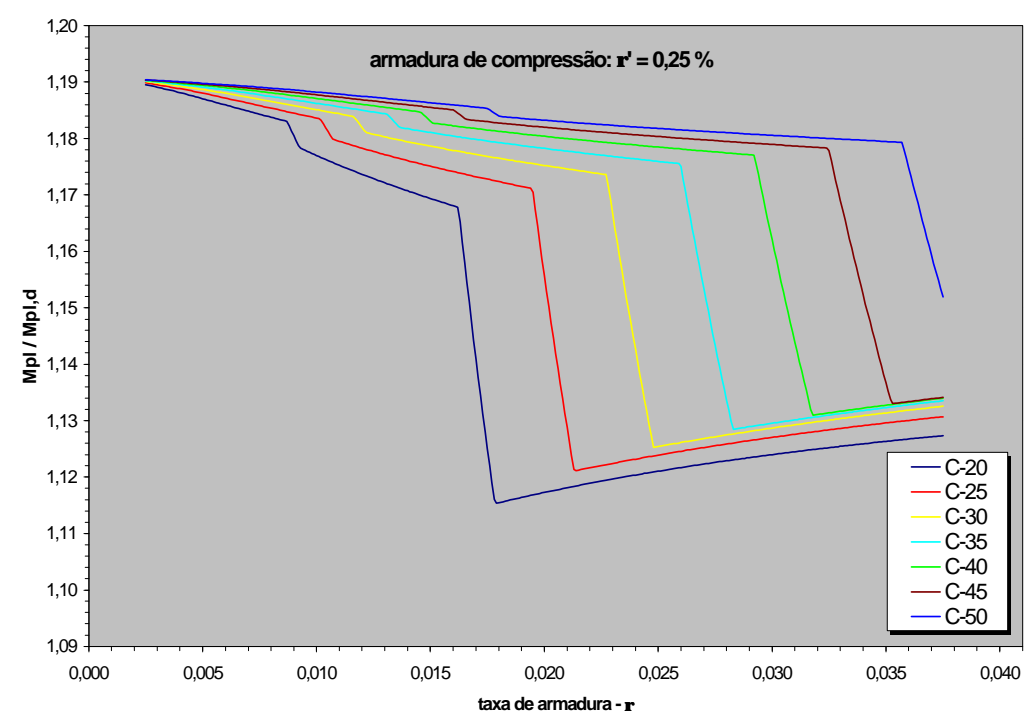

Figura 8.15 - $\gamma_{g \mid}$. FSr-15 a FSr-21 


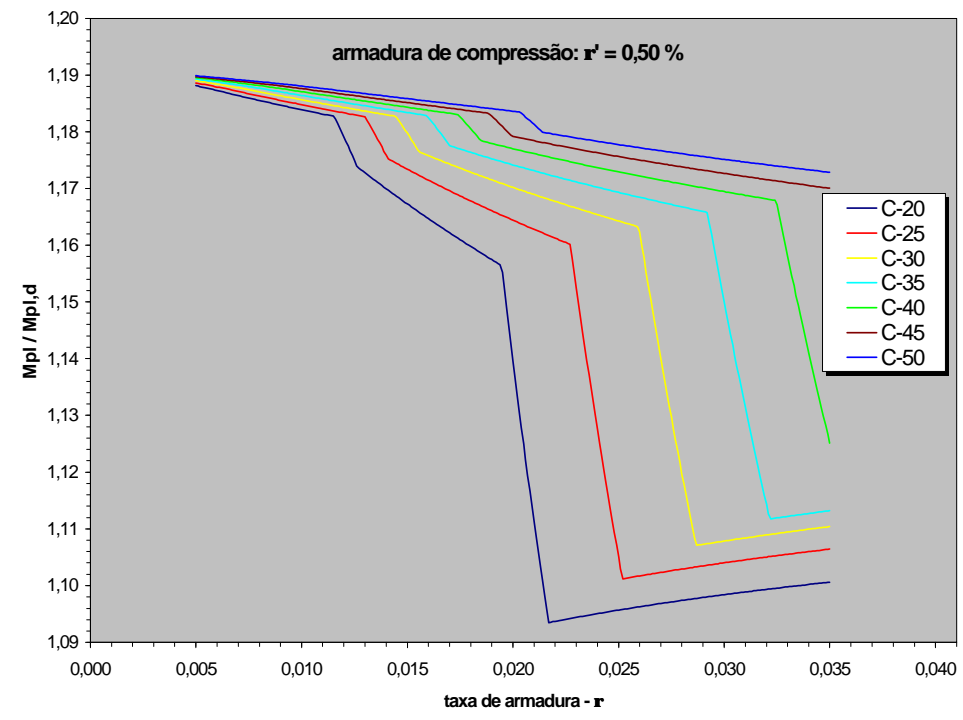

Figura 8.16 - $\gamma_{g l .}$ FSr-22 a FSr-28

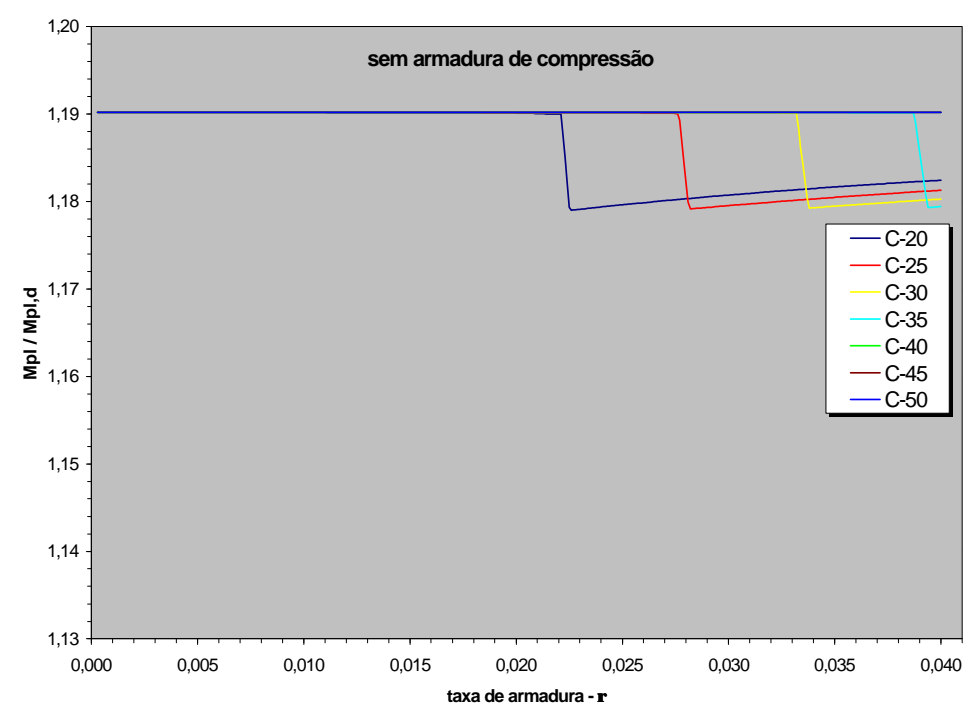

Figura $8.17-\gamma_{g \mid}$. FSt-01 a FSt-07

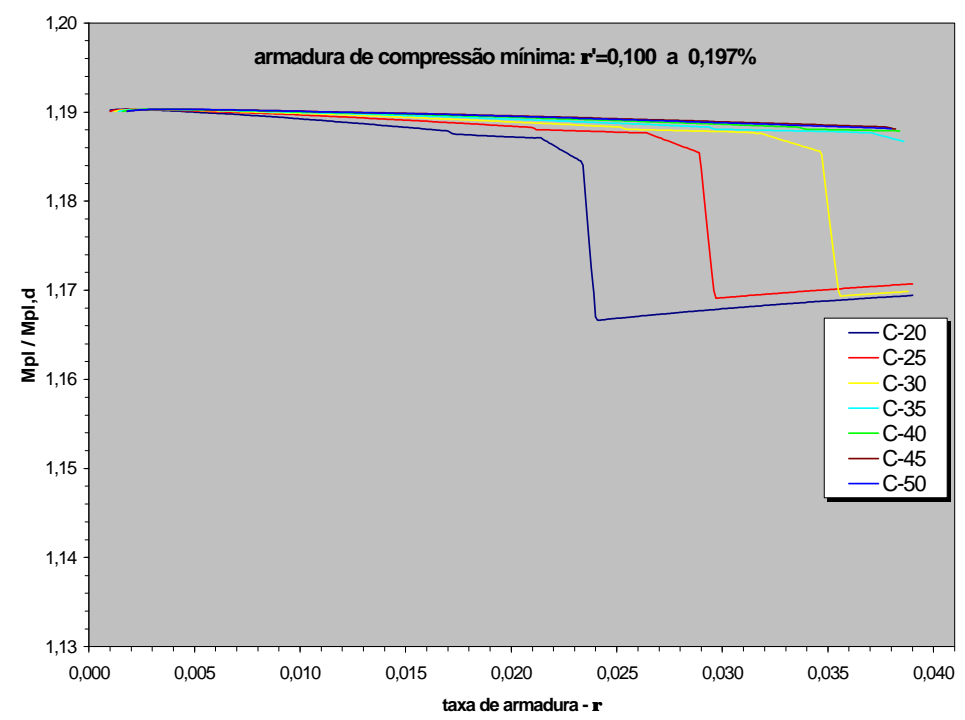

Figura $8.18-\gamma_{g \mid .}$ FSt-08 a FSt-14 


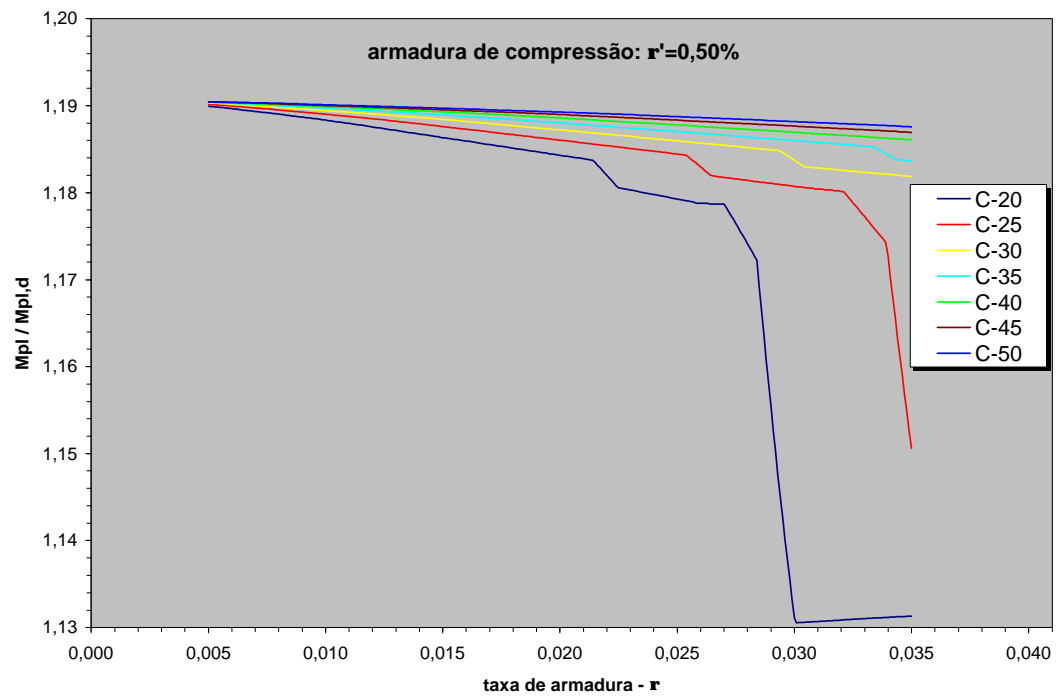

Figura $8.19-\gamma_{g \mid .}$ FSt-15 a FSt-21

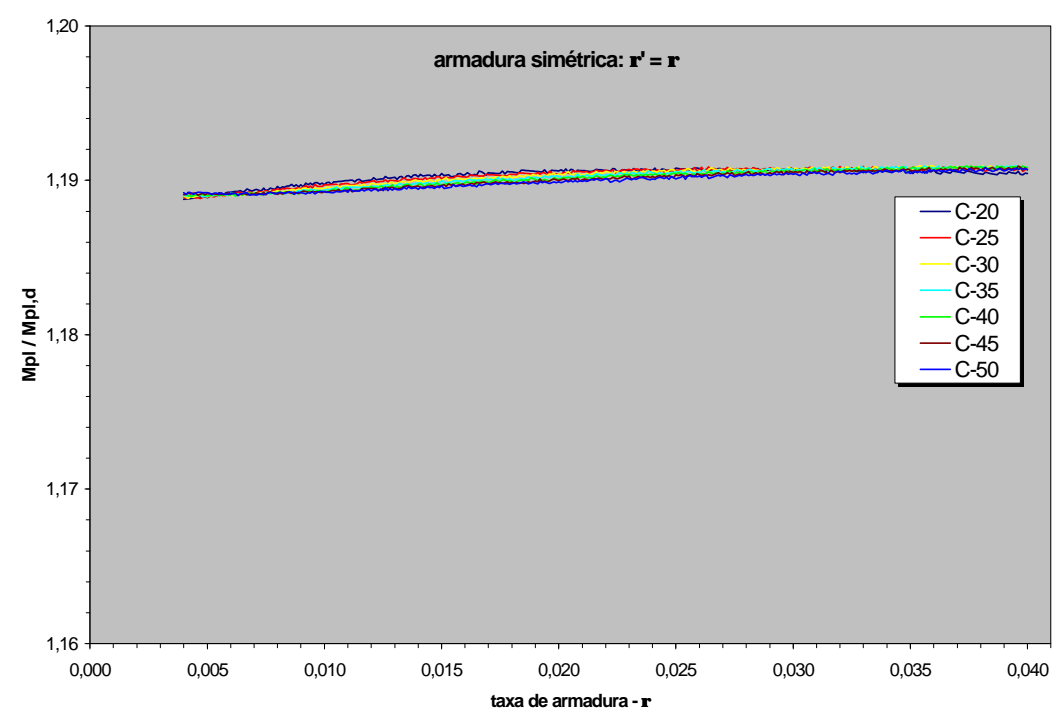

Figura $8.20-\gamma_{g l} . F N C, e=10 \mathrm{~cm}$

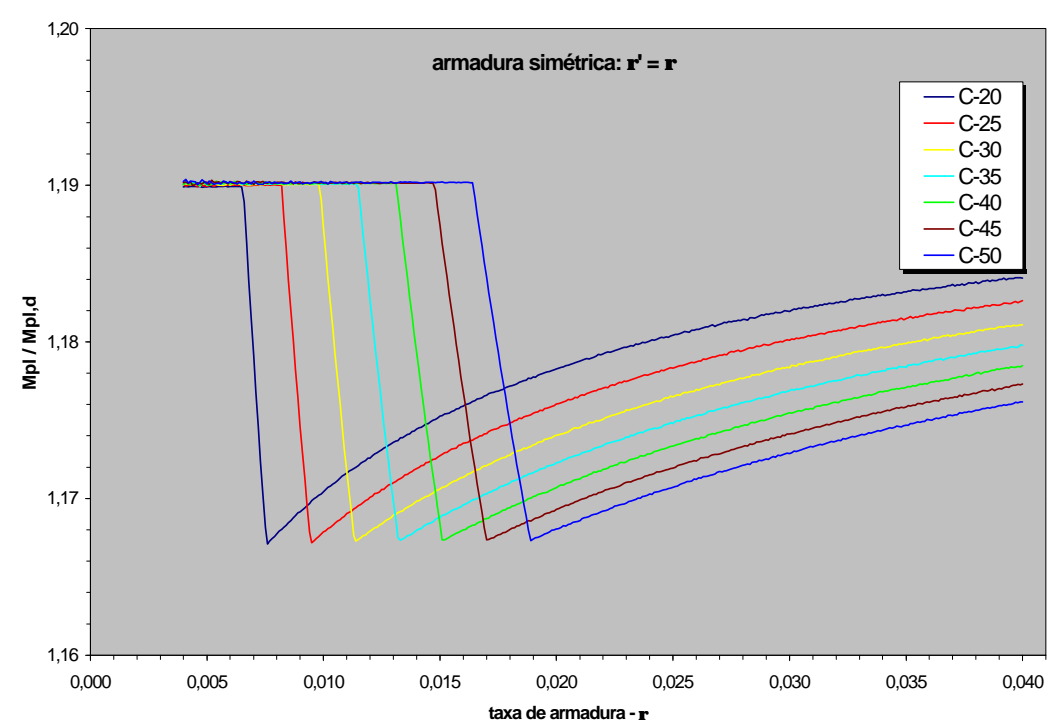

Figura $8.21-\gamma_{g l .} F N C, e=30 \mathrm{~cm}$ 


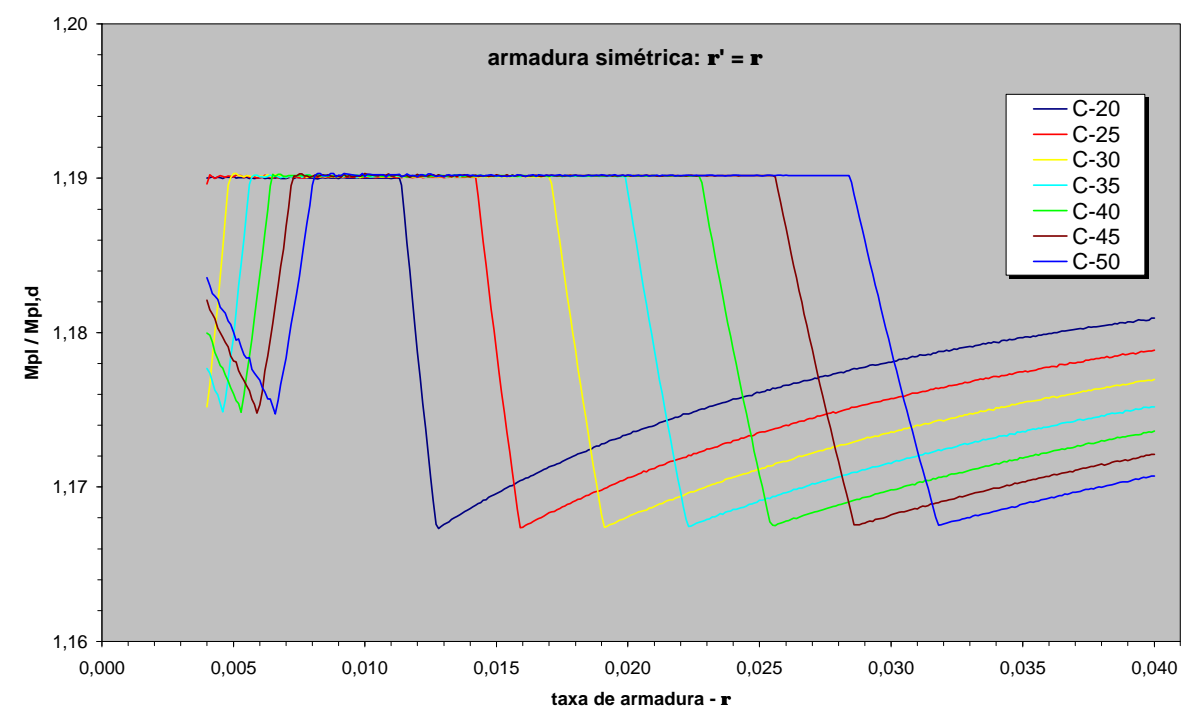

Figura $8.22-\gamma_{g l} . F N C, e=40 \mathrm{~cm}$

De um modo geral, os diagramas indicam que o emprego do coeficiente global de segurança relativo aos materiais apresenta um bom potencial a ser explorado, principalmente se resolvidos alguns dos problemas aqui observados. As seções submetidas à flexão simples mostraram-se bastante sensíveis à introdução de armadura negativa, revelando-se, para as seções retangulares, o menor coeficiente $\gamma_{\mathrm{gl}}\left(1,092\right.$ para $\left.\rho^{\prime}=0,5 \%\right)$. Nas seções $T$ submetidas à flexão simples, o efeito da introdução da armadura foi menos intenso, e o coeficiente $\gamma_{\mathrm{gl}}$ apresentou um valor mínimo igual a 1,13 para $\rho^{\prime}=0,5 \%$. As seções sob flexão normal composta apresentaram tanto maior variabilidade do coeficiente $\gamma_{\mathrm{gl}}$ quanto maior a excentricidade da força normal. Há que se ressaltar que, em todos os casos estudados, houve uma maior estabilidade de $\gamma_{g l}$ à medida em foram empregados concretos de classes superiores.

O comportamento descrito para $\gamma_{\mathrm{gl}}$, bem como as conclusões parciais, são aplicáveis tão somente à análise de seções ou de estruturas isostáticas cujo comportamento no ELU coincide com o de uma seção transversal típica. O emprego dessas idéias ao dimensionamento de estruturas hiperestáticas, onde a redistribuição dos esforços seja possível, pode levar a um comportamento ainda melhor para $\gamma_{\mathrm{g}}$, mas que deve ser corretamente qualificado e quantificado através de análises de confiabilidade estrutural. HENRIQUES (1998) analisa dois casos de vigas de concreto armado sob o enfoque da confiabilidade empregando o método de simulação de Monte Carlo: viga biengastada e viga apoiada-engastada. Foram consideradas como variáveis aleatórias as resistências à compressão do concreto e de escoamento do aço à tração, além da altura da viga (podendo variar até $0,7 \mathrm{~cm}$ ). 
A resistência média à compressão do concreto foi considerada de acordo com a CEB-FIP MC90, ou seja: $\mathrm{f}_{\mathrm{cm}}=\mathrm{f}_{\mathrm{ck}}+8,0 \mathrm{MPa}$. Os resultados, para diversas classes de concreto, e diversas taxas de armadura, mostram que a relação entre o coeficiente global (referido aos materiais) para a estrutura $\left(\gamma_{g l, e s t .}\right)$ e para a seção $\left(\gamma_{g l}\right)$, dentre os casos analisados, é igual ou superior a 1 (parâmetro a). Um resumo das curvas propostas por Henriques, relativamente à profundidade da linha neutra $(x / d)$ na seção onde ocorre o ELU, é apresentado na Figura 8.23. Nota-se que o parâmetro a supera a unidade para $\mathrm{x} / \mathrm{d}$ entre 0,35 e 0,52.
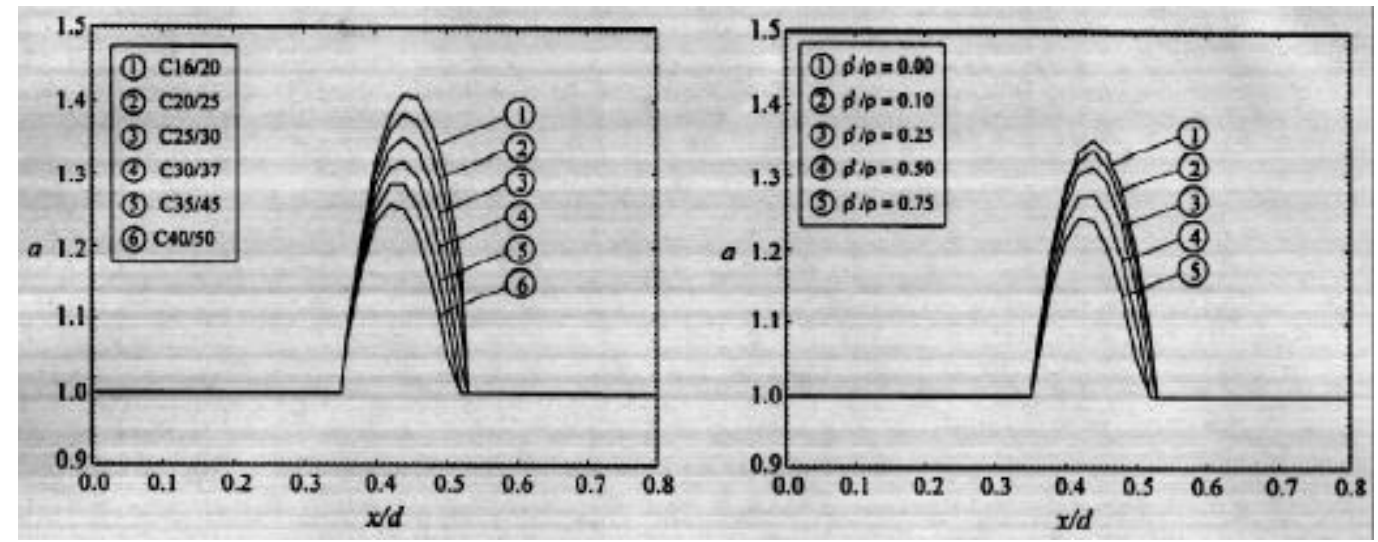

Figura 8.23 - Relação $a=\gamma_{g l, e s t} / \gamma_{g l}$

\subsubsection{Particularização às lajes}

A natureza tensorial dos esforços observados nas lajes, que acabam por impossibilitar a caraterização de um comportamento mecânico típico de seção transversal, dificulta o avanço no estudo do coeficiente global de segurança relativo aos materiais para esse elemento estrutural. Um estudo (determinístico) sobre a segurança envolvendo as lajes de concreto armado deveria contemplar uma gama razoável de variáveis fartamente combinadas entre si, destacando-se: relação entre os lados, condições de apoio, espessura, resistência característica do concreto e do aço, e taxas de armadura. Obviamente, um estudo com essas características consumiria um período de tempo tal que, por si só, inviabilizaria a sua inclusão neste trabalho. O que se faz, paleativamente, com o objetivo único de mostrar a aplicabilidade do método também com relação às lajes, é estabelecer alguns valores para $\gamma_{\mathrm{gl}}$ relacionados a uma laje quadrada $(400 \mathrm{~cm} \times 400 \mathrm{~cm})$ apoiada nos quatro lados. O concreto empregado é o C-30; o aço é o CA-50A. Foram empregadas apenas armaduras positivas, com as mesmas praticadas nas direções $x$ e y. 


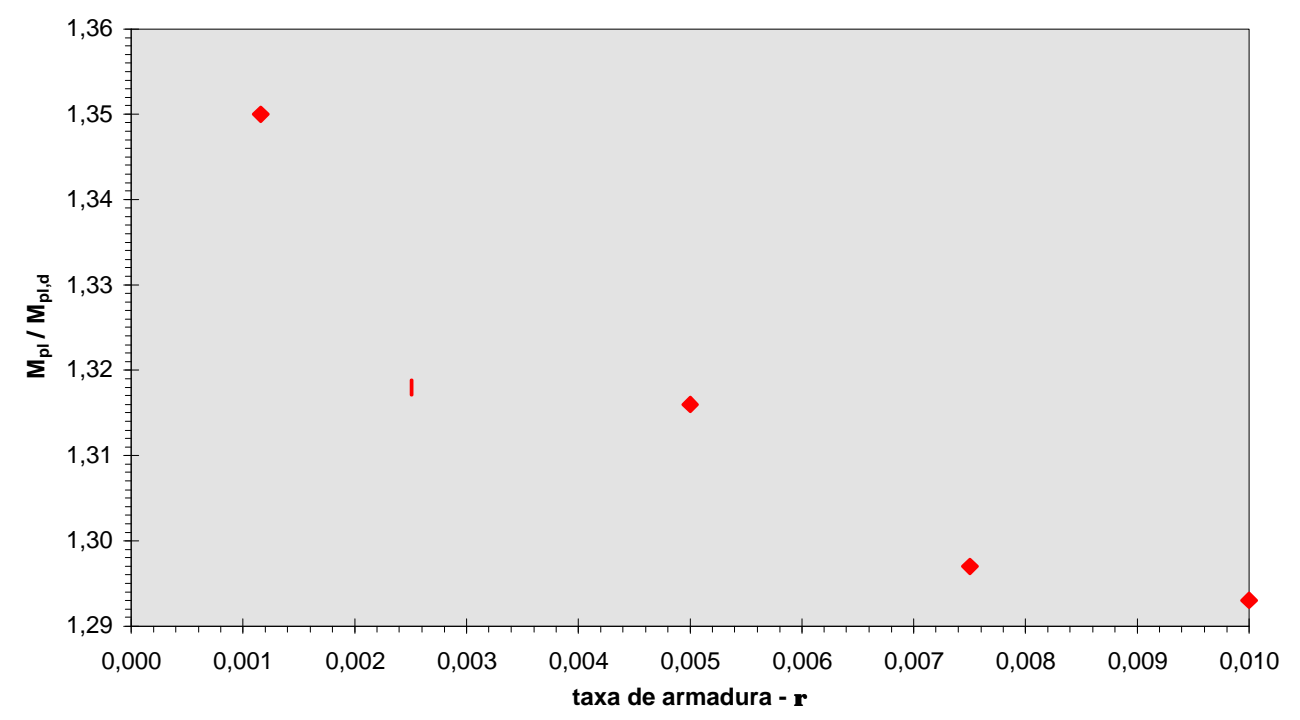

Figura 8.24 - $\gamma_{g l}$ para uma laje quadrada apoiada

Os resultados, assinalados em forma de pontos no diagrama da Figura 8.24, retratam um bom comportamento de $\gamma_{g l}$ para a estrutura analisada (laje apoiada). O menor valor observado, de 1,293 (para uma taxa $\rho=1,0 \%$ ), é cerca de $5 \%$ inferior ao maior deles: 1,350 para $\rho=\rho_{\min }=0,116 \%$.

Apesar de ter sido apresentado como uma solução para o dimensionamento de estruturas de concreto armado, o método do coeficiente global de segurança relativo aos materiais apresenta ainda, como anteriormente relatado neste texto, algumas deficiências que necessitam ser sanadas. O mau comportamento de $\gamma_{\mathrm{gl}}$ para taxas de armadura de tração superiores a 1,8\% em seções transversais sob flexão simples, bem como a piora desse comportamento ao se incrementarem as armaduras de compressão, devem ainda ser objeto de estudos. Faz-se necessária, ainda, uma consistente avaliação da relação " $a$ " para outros elementos e arranjos estruturais, como as lajes, por exemplo.

\subsection{Exemplos de aplicação}

Com o objetivo de fixar as idéias expostas, e de promover uma boa compreensão dos aspectos intrínsecos à análise nãolinear de estruturas de concreto armado são colocados, a seguir, alguns exemplos simples de aplicação prática. Todos os exemplos são baseados nas características mecânicas dos materiais: concreto $\mathrm{C}-30\left(\mathrm{f}_{\mathrm{ck}}=30 \mathrm{MPa}\right)$; e aço $\mathrm{CA}-50 \mathrm{~A}$, cujas propriedades médias e de projeto constam da Tabela 8.5. Para o aço, na falta de referências utiliza-se, como valores médios de resistência à tração e à compressão, os próprios valores 
característicos, uma vez que essas propriedades apresentam pequena variabilidade. O módulo de elasticidade, como já mencionado, pode ser considerado invariável. Os valores relativos ao concreto são obtidos através das relações do CEB-FIP MC90 sendo que, para o valor da resistência à tração característica $\left(f_{c t k}\right)$, adota-se a média entre os valores superior e inferior indicados, o que na prática corresponde à própria resistência à tração médỉ $\left(\mathfrak{f}_{\mathrm{ctm}}\right)$.

Tabela 8.5 - Características mecânicas dos materiais empregados nos exemplos

\begin{tabular}{|c|c|c|c|}
\cline { 3 - 4 } \multicolumn{2}{c|}{} & concreto & aço \\
\hline \multirow{2}{*}{$\begin{array}{c}\text { propr. } \\
\text { médias }\end{array}$} & módulo de def. longitudinal & $E_{c}=3355 \mathrm{kN} / \mathrm{cm}^{2}$ & $E_{s}=21000 \mathrm{kN} / \mathrm{cm}^{2}$ \\
\cline { 2 - 4 } & resistência à compressão & $\mathrm{f}_{\mathrm{cm}}=3,80 \mathrm{kN} / \mathrm{cm}^{2}$ & $\mathrm{f}_{\mathrm{yk}}=50,00 \mathrm{kN} / \mathrm{cm}^{2}$ \\
\cline { 2 - 4 } & resistência à tração & $\mathrm{f}_{\mathrm{ctm}}=0,29 \mathrm{kN} / \mathrm{cm}^{2}$ & $\mathrm{f}_{\mathrm{yk}}=50,00 \mathrm{kN} / \mathrm{cm}^{2}$ \\
\hline \multirow{2}{*}{$\begin{array}{c}\text { propr. } \\
\text { de }\end{array}$} & módulo de def. longitudinal & $\mathrm{E}_{\mathrm{c}}=3355 \mathrm{kN} / \mathrm{cm}^{2}$ & $\mathrm{E}_{\mathrm{s}}=21000 \mathrm{kN} / \mathrm{cm}^{2}$ \\
\cline { 2 - 4 } & resistência à compressão & $\mathrm{f}_{\mathrm{cd}}=1,82 \mathrm{kN} / \mathrm{cm}^{2}$ & $\mathrm{f}_{\mathrm{yd}}=43,48 \mathrm{kN} / \mathrm{cm}^{2}$ \\
\cline { 2 - 4 } & resistência à tração & $\mathrm{f}_{\mathrm{ctd}}=0,21 \mathrm{kN} / \mathrm{cm}^{2}$ & $\mathrm{f}_{\mathrm{yd}}=43,48 \mathrm{kN} / \mathrm{cm}^{2}$ \\
\hline
\end{tabular}

O carregamento considerado em todos os exemplos é o mesmo, e composto apenas de cargas uniformemente distribuídas: uma carga permanente $\mathrm{g}=25,0 \mathrm{kN} / \mathrm{m}$, e uma sobrecarga $\mathrm{q}=5,0 \mathrm{kN} / \mathrm{m}$. Na composição dos carregamentos de cálculo para o ELS e o ELU, ter-se-iam ${ }^{4}$ :

ELS (CQP): $\quad F_{\mathrm{d}, \text { serv }}=(1,0 \times 25,0+0,2 \times 5,0) \mathrm{kN} / \mathrm{m}$

$$
F_{d, \text { serv }}=26,0 \mathrm{kN} / \mathrm{m}
$$

ELS (CR): $\quad F_{\text {d,serv }}=(1,0 \times 25,0+1,0 \times 5,0) \mathrm{kN} / \mathrm{m}$

$$
F_{d, \text { serv }}=30,0 \mathrm{kN} / \mathrm{m}
$$

ELU (última): $F_{d, u}=1,4 \times 25,0+1,4 \times 5,0 \mathrm{kN} / \mathrm{m}$

$$
F_{\mathrm{d}, \mathrm{u}}=42,0 \mathrm{kN} / \mathrm{m}
$$

Em todos os exemplos que se seguem, procura-se empregar a mesma metodologia para a solução. O dimensionamento em regime não-linear é dependente das taxas de armadura pré-estabelecidas de alguma forma. Desta forma, o dimensionamento nada mais é que um processo interativo de tentativa e correção ou, do ponto de vista técnico, um procedimento de verificação de taxas de armadura ou de dimensões de seção transversal pré-determinados. As plastificações podem ser impostas pelo projetista tanto através da diminuição da

\footnotetext{
${ }^{4}$ Supondo: $\psi_{0}=0,4 ; \psi_{1}=0,3 ;$ e $\psi_{2}=0,2$.
} 
taxa de armadura de flexão ou da altura (ou da largura) de determinadas seções transversais, como também através de ambas as soluções conjuntamente.

Convém relembrar que, ao diminuir a taxa de armadura de flexão, a seção passa a trabalhar próxima ao domínio 2 , o que é desejável sob o aspecto da segurança. No entanto, se for empregada a diminuição da área de concreto, a seção transversal passa a se comportar mais proximamente ao domínio 4. Isso não é desejável sob o aspecto da segurança pois, nesse domínio, a perda da capacidade portante se dá pelo esmagamento do concreto comprimido, que caracteriza a ruptura frágil sob incrementos de deformação não controlada.

A bem da simplicidade opta-se, neste trabalho, pela alteração única e exclusiva das taxas de armadura de flexão tracionadas. A porcentagem de plastificação imposta estará sempre referida à porcentagem de diminuição da armadura de flexão tracionada.

O efeito positivo dos porta-estribos sobre o comportamento do elemento também será computado e, invariavelmente deve referir-se a $2 \Phi 6,3 \mathrm{~mm}$. Os elementos são armados pelo cobrimento simples dos diagramas de momentos fletores. A armadura de flexão é única para a região submetida a momentos de mesmo sinal, e calculada com base no momento fletor máximo para essa região. $O$ cobrimento das armaduras utilizado é de $2,5 \mathrm{~cm}$, o que está em acordo com o que sugere NB1-revisão 2000 para a classe de agressividade I.

A flecha limite, também estabelecida de acordo com a NB1-revisão 2000 é de $1 / 250$, calculada com todo o carregamento de serviço referente à combinação quase-permanente de utilização. Cabe salientar que todas as demais verificações de deslocamentos indicadas na NB1-revisão 2000 podem ser efetuadas segundo o mesmo procedimento indicado.

\subsubsection{Viga biapoiada}

Este primeiro exemplo refere-se à estrutura elementar daFigura 8.25.
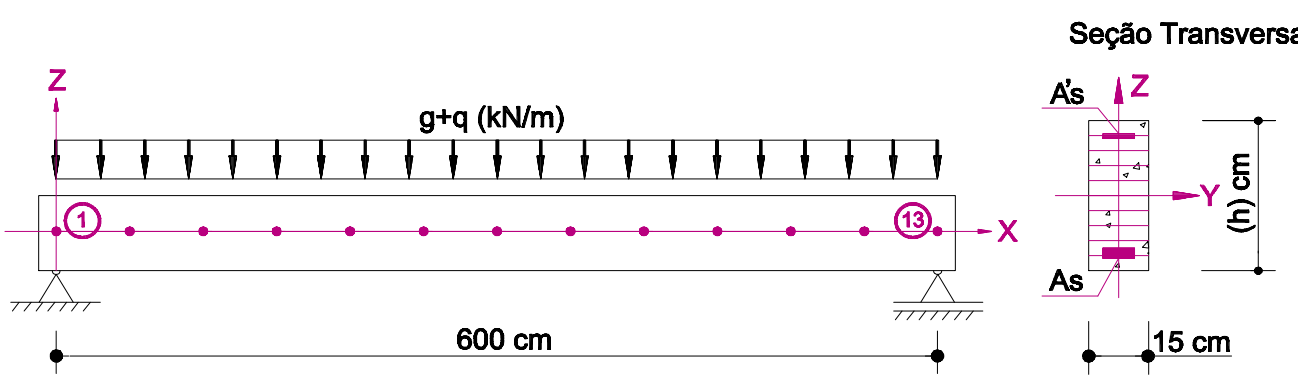

Figura 8.25 - Viga biapoiada: exemplo 1 
Em seguida, são descritos os passos que poderiam ser seguidos para 0 dimensionamento e a verificação de uma estrutura em regime não-linear segundo o método semi-probabilístico, e com a relação constitutiva proposta para o concreto:

a) dimensiona-se a estrutura em regime elástico-linear atendendo ao ELU e, se possível, entre os domínios 3 e 4. Neste exemplo, no entanto, o ELS relativo às deformações excessivas foi determinante:

$M_{d}=18900 \mathrm{kN} . \mathrm{cm} \rightarrow \mathrm{d}=47 \mathrm{~cm} ; \mathrm{h}=50 \mathrm{~cm}$

portanto, $A_{s}=11,46 \mathrm{~cm}^{2} ; A_{s}^{\prime}=0,62 \mathrm{~cm}^{2}$ (porta estribos)

b) determina-se a flecha instantânea e, principalmente, a flecha no tempo infinito, considerando-se:

- a armadura do item a);

- propriedades médias dos materiais;

- carregamento de serviço (combinação quase-permanente)

- por simplicidade, $\varphi_{28}=2,5$ (adotado).

$\mathrm{f}_{0}=1,39 \mathrm{~cm}$ (flecha no instante de aplicação do carregamento)

$\mathrm{f}_{\infty}=2,26 \mathrm{~cm}<\mathrm{l} / 250(=2,40 \mathrm{~cm})$

c) para a combinação última normal utilizando, para o concreto, o diagrama tensão-deformação da Figura 8.5 (diagrama com as propriedades médias, seccionado no valor de $f_{c d}$ ) e, para o aço, as propriedades de projeto, verificam-se as deformações máximas obtidas (na seção do meio do vão):

concreto: $\varepsilon_{\mathrm{c}}^{\min }=-0,00159$; aço: $\varepsilon_{\mathrm{s}}^{\max }=0,00204$

Como ambas as deformações estão dentro do espectro permitido para o ELU, admite-se que a estrutura esteja segura para a configuração de armaduras longitudinais adotada. A viga, armada com os esforços obtidos em regime elástico linear, já apresenta um estado de deslocamentos bastante próximo ao máximo permitido, o que impossibilita a tentativa de qualquer tipo de redução de armaduras longitudinais que atendam ao ELS de deformações excessivas.

A título ilustrativo coloca-se, a seguir, uma segunda análise desconsiderando-se a contribuição dos porta estribos para o comportamento mecânico da viga. Como pode ser observado, essas barras de aço, geralmente não consideradas no cálculo, exercem influência (ainda que pequena) no sentido de melhoria da rigidez do elemento estrutural. A presença dessas barras auxilia na 
diminuição das flechas instantâneas e no tempo infinito (neste, com maior eficiência), além de proporcionar uma melhoria no estado de deformações da armadura de flexão tracionada e das fibras de concreto comprimidas.

concreto: $\varepsilon_{\mathrm{c}}^{\min }=-0,00203$; aço: $\varepsilon_{\mathrm{s}}^{\max }=0,00240$

$\mathrm{f}_{0}=1,42 \mathrm{~cm}$

$f_{\infty}=2,35 \mathrm{~cm}<\mathrm{l} / 250$

Outra análise foi efetuada com o objetivo de se estabelecer a carga de ruína para a viga. A capacidade resistente última foi cerca de $2 \%$ superior ao carregamento último de projeto, o que significa dizer que não há reservas de resistência além da necessária para satisfazer ao ELU.

A seguir, coloca-se uma comparação entre os resultados para as flechas calculadas de acordo com a NB1-78, e pelas expressões de Branson incorporadas à NB1-revisão 2000.

$$
\begin{gathered}
\text { NB1-78: } E_{c s}=(0,9) \cdot\left[660 \cdot(30+3,5)^{1 / 2}\right]=3438 \mathrm{kN} / \mathrm{cm}^{2} ; \therefore \alpha_{e}=\frac{E_{s}}{E_{c}}=6,11 \\
f_{0 e}=\frac{5}{384} \cdot \frac{0,26 \cdot 600^{4}}{3438 \cdot \frac{15 \cdot 50^{3}}{12}}=0,82 \mathrm{~cm} \text { (flecha elástica inicial); } \\
\mathrm{f}_{\infty}=\mathrm{f}_{0 \mathrm{e}} \cdot \frac{\left(\frac{1}{r}\right)_{\infty}}{\left(\frac{1}{r}\right)_{0}}=\frac{\frac{3 \cdot\left|\varepsilon_{\mathrm{c}}\right|+\varepsilon_{\mathrm{s}}}{\mathrm{d}}}{\frac{\left|\varepsilon_{\mathrm{c}}\right|+\varepsilon_{\mathrm{s}}}{\mathrm{d}}}=\frac{3 \cdot\left|\varepsilon_{\mathrm{c}}\right|+\varepsilon_{\mathrm{s}}}{\left|\varepsilon_{\mathrm{c}}\right|+\varepsilon_{\mathrm{s}}} \text { (supondo estádio II) }
\end{gathered}
$$

profundidade da LN no estádio II:

$$
x=-\frac{\alpha_{e}\left(A s+A_{s}^{\prime}\right)}{b_{w}}+\sqrt{\left[\frac{\alpha_{e}\left(A s+A_{s}^{\prime}\right)}{b_{w}}\right]^{2}+\frac{2 \alpha_{e}}{b_{w}}\left(d A s+d^{\prime} A_{s}^{\prime}\right)}
$$

$x=16,63 \mathrm{~cm}$

momento de inércia no estádio II:

$I_{I I}=\frac{b_{w} x^{3}}{3}+\alpha_{e} A_{s}(d-x)^{2}+\alpha_{e} A_{s}^{\prime}\left(x-d^{\prime}\right)^{2}=88282 \mathrm{~cm}^{4}$

deformações específicas máximas no estádio II:

$$
\varepsilon_{c}=\frac{M \cdot x}{E_{c} \cdot I_{I I}}=0,00064
$$




$$
\begin{aligned}
& \varepsilon_{s}=\frac{M(d-x)}{E_{c} \cdot I_{\|}}=0,00117 \\
& \therefore f_{\infty}=0,82 \cdot 1,707=1,40 \mathrm{~cm}
\end{aligned}
$$

NB1-78 (revisão): $E_{c s}=0,85 \cdot\left(4760 \mathrm{f}_{\mathrm{ck}}^{1 / 2}\right)=2216 \mathrm{kN} / \mathrm{cm}^{2} ; \therefore \alpha_{e}=\frac{E_{s}}{E_{c}}=9,48$. $\mathrm{f}_{0 \mathrm{e}}=\frac{5}{384} \cdot \frac{0,26 \cdot 600^{4}}{(\mathrm{EI})_{\mathrm{eq}}}$ (flecha elástica inicial); rigidez equivalente para a seção fissurada (expressão de Branson): $(E I)_{\text {eq }}=E_{c s}\left\{\left(\frac{M_{r}}{M_{a}}\right)^{3} \cdot I_{0}+\left[1-\left(\frac{M_{r}}{M_{a}}\right)^{3}\right] I_{I I}\right\} \leq E_{c s} \cdot I_{0}$ momento de inércia da seção bruta de concreto $I_{0}=156250 \mathrm{~cm}^{4}$; momento de inércia no estádio II: $I_{\|}=88282 \mathrm{~cm}^{4}$; momento de fissuração: $M_{r}=\frac{f_{c t m} \cdot I_{0}}{y_{t}}=1812,5 \mathrm{kN} \cdot c m$ momento fletor na seção crítica: $M_{a}=11700,0 \mathrm{kN} . \mathrm{cm}$ $\therefore(\mathrm{El})_{\mathrm{eq}}=196192864 \mathrm{kN} \cdot \mathrm{cm}^{2}$. $\mathrm{f}_{0}=2,24 \mathrm{~cm}$; $\mathrm{f}_{\infty}=\mathrm{f}_{0} \cdot \alpha_{\mathrm{f}}=\mathrm{f}_{0} \cdot \frac{\Delta \xi}{1+50 \rho^{\prime}}=2,24 \cdot \frac{2-0,66}{1+50 \cdot \frac{0,62}{15 \times 47}}=2,87 \mathrm{~cm}$ (supondo 0 carregamento de longa duração aplicado aos 28 dias).

A análise numérica (considerando-se $\Phi \cong 12 \mathrm{~mm}$ ) revelou que, para uma combinação freqüente de ações, a viga deverá apresentar um estado de fissuração caracterizado por uma abertura máxima no meio do vão de aproximadamente 0,33 mm. A NB1-78 permite, para as vigas de edifícios em geral, uma abertura máxima de 0,3 mm. Esse valor também é compartilhado pela NB1-78 (revisão 2000) que, no entanto, faculta a possibilidade de esse valor atingir até $0,4 \mathrm{~mm}$ se o elemento estrutural estiver em um ambiente Classe I de agressividade (peças protegidas com UR $\leq 65 \%$ em zona urbana, ou peça protegida em zona rural).

De acordo com o método do coeficiente global de segurança relativo aos materiais, o fator $\gamma_{g l}$, definido pela relação entre os carregamentos de ruptura adotando-se, respectivamente, as propriedades médias e de projeto, deve ser igual ou superior a 1,19. Valores inferiores significam que a viga não atende à segurança estabelecida. Para este exemplo, $\gamma_{\mathrm{gl}}$ manteve-se em 1,236, pois os carregamentos 
relativos à ruptura foram de: $52,67 \mathrm{kN} / \mathrm{m}$ considerandose as propriedades médias; e de $42,63 \mathrm{kN} / \mathrm{m}$ considerando-se as propriedades de projeto dos materiais.

\subsubsection{Viga apoiada-engastada}

O segundo exemplo refere-se à viga apresentada naFigura 8.26.

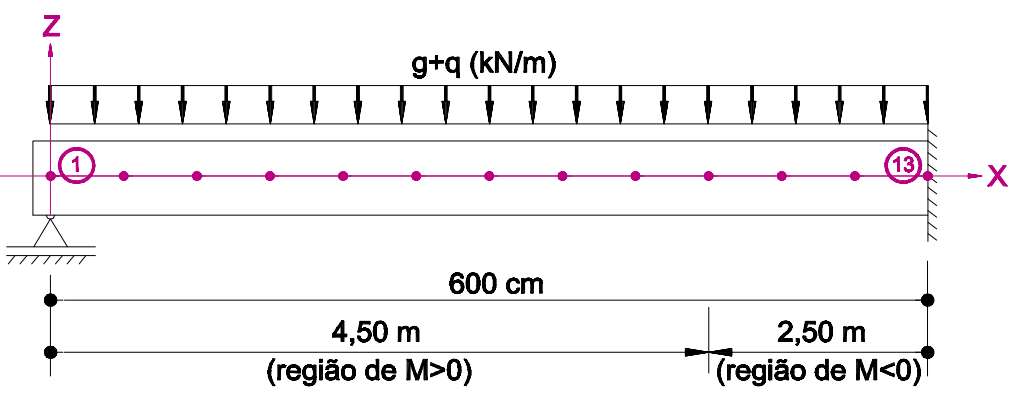

Seção Transversal

Figura 8.26 - Viga apoiada-engastada - exemplo 2

Por ser hiperestática, essa viga possibilita uma redistribuição de esforços internos, ditado pelas suas características mecânicas, geométricas e de vinculação.

O pré-dimensionamento da viga é feito a partir das tabelas de dimensionamento (por exemplo, as tabelas de Kzerny ou, mais atualmente, as tabelas que empregam $k_{c}$ e $k_{s}$ ) aplicadas aos esforços obtidos em regime elástico linear: A armadura de pré-dimensionamento é tomada como o valor inicial de um problema com solução iterativa, e a partir dessa configuração inicial é que se propõem plastificações localizadas através de alterações nas taxas de armadura.

É importante ressaltar que as referidas tabelas de dimensionamento são formuladas a partir de várias hipóteses simplificadoras, dentre as quais a desconsideração do concreto tracionado para o equilíbrio da seção transversal, e a imposição dos domínios de deformação na obtenção das taxas de armadura figuram como as principais. Consequentemente, as armaduras obtidas com o emprego dessas tabelas, bem como os momentos máximos aos quais se referem essas armaduras, podem, provavelmente, apresentar distorções quando comparados aos obtidos pelo modelo não-linear aqui empregado.

a) dimensiona-se a estrutura em regime elástico-linear atendendo ao ELU entre os domínios 3 e 4 .

$$
\begin{aligned}
& M_{d}^{-}=18900 \mathrm{kN} . \mathrm{cm} \rightarrow d=44 \mathrm{~cm} ; \mathrm{h}=47 \mathrm{~cm} ; A_{s}^{\prime}=13,19 \mathrm{~cm}^{2} ; A_{s}=0,62 \mathrm{~cm}^{2} \\
& M_{d}^{+}=10631 \mathrm{kN} . \mathrm{cm} \rightarrow d=44 \mathrm{~cm} ; \mathrm{h}=47 \mathrm{~cm} ; A_{s}^{\prime}=0,62 \mathrm{~cm}^{2} ; A_{s}=6,28 \mathrm{~cm}^{2}
\end{aligned}
$$


b) determina-se a flecha instantânea e, principalmente, a flecha no tempo infinito, considerando-se:

- a armadura do item a);

- propriedades médias dos materiais;

- carregamento de serviço (combinação quase-permanente)

- por simplicidade, $\varphi_{28}=2,5$ (adotado).

$\mathrm{f}_{0}=0,77 \mathrm{~cm}$ (flecha no instante de aplicação do carregamento)

$\mathrm{f}_{\infty}=1,23 \mathrm{~cm}<\mathrm{l} / 250(=2,4 \mathrm{~cm})$

c) para a combinação última normal, utilizando o diagrama tensãodeformação para o concreto proposto na Figura 8.5 (diagrama com as propriedades médias, seccionado no valor de $\mathrm{f}_{\mathrm{cd}}$ ) e as propriedades de projeto do aço, verificam-se as deformações máximas (nas seções críticas):

seção de $\mathbf{M}_{\text {máx }}^{+}$: concreto: $\varepsilon_{\mathrm{c}}^{\min }=-0,00077$; aço: $\varepsilon_{\mathrm{s}}^{\max }=0,00189$

seção de $\mathbf{M}_{\text {máx }}^{-}$: concreto: $\varepsilon_{\mathrm{c}}^{\min }=-0,00210$; aço: $\varepsilon_{\mathrm{s}}^{\max }=0,00228$

Como ambas as deformações estão dentro do espectro permitido para o ELU, admite-se que a estrutura esteja segura para a configuração de armaduras longitudinais adotada.

A NB1-revisão 2000 traz uma proposta para a verificação de possíveis redistribuições impostas à estrutura. "Reduzindose um momento fletor de $M$ para $\delta \mathrm{M}$ em uma determinada seção transversal, a relação entre o coeficiente de redistribuição $\delta$ e a posição da $L N$ nessa seção $(x / d)$, para o momento reduzido $\delta M$, deve ser dada por:

$$
\begin{aligned}
& \delta \geq 0,44+1,25 .(\mathrm{x} / \mathrm{d}) \text { para concretos } \operatorname{com} \mathrm{f}_{\mathrm{ck}} \leq 35 \mathrm{MPa} \\
& \delta \geq 0,56+1,25 .(\mathrm{x} / \mathrm{d}) \text { para concretos com } \mathrm{f}_{\mathrm{ck}}>35 \mathrm{MPa}
\end{aligned}
$$

O coeficiente de redistribuição deve, ainda, obedecer aos seguintes limites: $\delta \geq 0,75$ em qualquer caso;

$\delta \geq 0,90$ para estruturas de nós móveis.

E a posição da linha neutra deve, no ELU, satisfazer aos seguintes limites: $\mathrm{x} / \mathrm{d} \leq 0,50$ para concretos com $\mathrm{f}_{\mathrm{ck}} \leq 35 \mathrm{MPa}$ $\mathrm{x} / \mathrm{d} \leq 0,40$ para concretos com $\mathrm{f}_{\mathrm{ck}}>35 \mathrm{MPa}$ 
Supondo que a seção do engaste esteja solicitada no estádio III, a profundidade da $L N$ deve valer: $x=21,40 \mathrm{~cm}$, ou seja, $x / d=0,486$. Essa posição de LN satisfaz aos quesitos mínimos mas, de acordo com a expressão 8.13, não permite redistribuições, pois $\delta=1,05$.

Estabelecendo uma a análise não-linear, no entanto, torna-se possível a imposição de plastificações à viga quantificandose, coerentemente, as redistribuições decorrentes dessa imposição, e estabelecendo a nova configuração de equilíbrio. Esse procedimento está em acordo com a NB1-revisão 2000, onde indica-se que, para toda e qualquer plastificação imposta à estrutura devem, obrigatoriamente, ser reestabelecidas as suas condições de equilíbrio sob o novo estado de solicitação.

d) como foi dimensionada com os esforços obtidos em regime elásticolinear, a viga deve apresentar reservas quanto aos aspectos de flechas e de deformações. Isso pode viabilizar a imposição de plastificações em determinadas regiões, buscando um melhor aproveitamento das características geométricas e mecânicas da viga. Com esse objetivo, propõe-se uma plastificação de $18 \%$ (o que eqüivaleria a uma redução de $12 \%$ no momento de cálculo segundo as tabelas de dimensionamento) para a seção do engaste, mantendo-se a armadura da região de momento positivo.

$$
\begin{aligned}
& M_{d}^{-}=16700 \mathrm{kN} . \mathrm{cm} \rightarrow d=44 \mathrm{~cm} ; \mathrm{h}=47 \mathrm{~cm} ; A_{s}^{\prime}=10,81 \mathrm{~cm}^{2} ; A_{s}=0,62 \mathrm{~cm}^{2} \\
& M_{d}^{+} \rightarrow A_{s}^{\prime}=0,62 \mathrm{~cm}^{2} ; A_{s}=9,30 \mathrm{~cm}^{2}
\end{aligned}
$$

A partir dessa nova distribuição de armaduras imposta, retorna-se ao procedimento normal de verificação, especificamente ao item b), agora denominado b1) (primeira iteração):

b1) $\mathrm{f}_{0}=0,67 \mathrm{~cm}$ (flecha no instante de aplicação do carregamento)

$$
\mathrm{f}_{\infty}=1,11 \mathrm{~cm}<\mathrm{l} / 250(=2,4 \mathrm{~cm})
$$

c1) seção de $\mathbf{M}^{+}{ }_{\text {máx }}$ : concreto: $\varepsilon_{\mathrm{c}}^{\min }=-0,00086$; aço: $\varepsilon_{\mathrm{s}}^{\max }=0,00207$ seção de $\mathbf{M}^{-}{ }_{\text {máx }}$ : concreto: $\varepsilon_{c}^{\min }=-0,00331$; aço: $\varepsilon_{\mathrm{s}}^{\max }=0,00391$

Essa plastificação de $18 \%$ corresponde à máxima absorvida pela estrutura. Outras tentativas, impondo-se níveis maiores de plastificação, levaram a estrutura ao colapso convencional na simulação numérica $\left(\varepsilon_{c}<-0,0035\right.$ ou $\left.\varepsilon_{c}>0,010\right)$. 
Sob o ponto de vista teórico, no entanto, as plastificações na região do engaste poderiam estender-se até o limite de 100\%, desde que as características mecânicas da viga permitissem-na responder ao novo esquema estático, agora biapoiado. No sentido de promover uma maior plastificação na região do engaste mediante o reforço da armadura na região submetida a momento positivo, sugerese um decréscimo de aproximadamente $37 \%$ na taxa de armadura, ou de $29 \%$ em relação ao momento fletor (de acordo com a NB1-revisão 2000) para a região do engaste, que passaria a estar submetida à ação de um momento fletor $M_{b}=13387$ $\mathrm{kN} . \mathrm{cm}\left(\Delta \mathrm{M}_{d}=13387-18900=-5513 \mathrm{kN} . \mathrm{cm}\right)$. Essa plastificação acresce o momento fletor máximo positivo de aproximadamente $\Delta \mathrm{M}_{\mathrm{d}} / 2=2756,5 \mathrm{kN} . \mathrm{cm}$.

$$
\begin{aligned}
& M_{d}^{-}=13387 \mathrm{kN} . \mathrm{cm} \rightarrow d=44 \mathrm{~cm} ; \mathrm{h}=47 \mathrm{~cm} ; A_{\mathrm{s}}^{\prime}=8,22 \mathrm{~cm}^{2} ; A_{s}=0,62 \mathrm{~cm}^{2} ; \\
& M_{d}^{+}=13387 \mathrm{kN} . \mathrm{cm} \rightarrow d=44 \mathrm{~cm} ; h_{=}=47 \mathrm{~cm} ; A_{s}^{\prime}=0,62 \mathrm{~cm}^{2} ; A_{s}=8,22 \mathrm{~cm}^{2} ;
\end{aligned}
$$

Como procedido anteriormente, retorna-se ao item b):

b2) $f_{0}=0,76 \mathrm{~cm}$ (flecha no instante de aplicação do carregamento) $\mathrm{f}_{\infty}=1,21 \mathrm{~cm}<\mathrm{l} / 250(=2,4 \mathrm{~cm})$

c2) seção de $\mathbf{M}^{+}{ }_{\text {máx }}$ : concreto: $\varepsilon_{\mathrm{c}}^{\min }=-0,00088$; aço: $\varepsilon_{\mathrm{s}}^{\max }=0,00172$ seção de $\mathbf{M}^{-}{ }_{\text {máx }}$ : concreto: $\varepsilon_{c}^{\min }=-0,00304$; aço: $\varepsilon_{\mathrm{s}}^{\max }=0,00425$

Essa última configuração de armaduras confere à viga um comportamento mecânico bastante próximo ao apresentado pela configuração inicial (item a)).

Por último, apresentam-se as flechas máximas para a viga da configuração a), calculadas de acordo com a NB1-78 e com a NB1-revisão 2000:

$$
\begin{aligned}
& \text { NB1-78: } E_{\mathrm{cs}}=3438 \mathrm{kN} / \mathrm{cm}^{2} ; \therefore \alpha_{\mathrm{e}}=\frac{\mathrm{E}_{\mathrm{s}}}{\mathrm{E}_{\mathrm{c}}}=6,11 \\
& \mathrm{f}_{0 \mathrm{e}}=\frac{3}{554} \cdot \frac{0,26 \cdot 600^{4}}{3438 \cdot \frac{15 \cdot 50^{3}}{12}}=0,34 \mathrm{~cm} \text { (flecha elástica inicial); } \\
& \mathrm{f}_{\infty}=\mathrm{f}_{0 \mathrm{e}} \cdot \frac{3 \cdot\left|\varepsilon_{\mathrm{c}}\right|+\varepsilon_{\mathrm{s}}}{\left|\varepsilon_{\mathrm{c}}\right|+\varepsilon_{\mathrm{s}}} \text { (supondo estádio II) } \\
& \text { profundidade da LN no estádio II: } \mathrm{x}=13,98 \mathrm{~cm} \\
& \text { momento de inércia no estádio II: } \mathrm{I}_{\mathrm{II}}=59380 \mathrm{~cm}{ }^{4} ; \\
& \text { deformações específicas máximas no estádio II: }
\end{aligned}
$$




$$
\begin{aligned}
& \varepsilon_{c}=\frac{M \cdot x}{E_{c} \cdot I_{\| l}}=0,00080 \\
& \varepsilon_{s}=\frac{M(d-x)}{E_{c} \cdot I_{\| l}}=0,00172 \\
& \therefore f_{\infty}=0,34 \cdot 1,637=0,56 \mathrm{~cm}
\end{aligned}
$$

$\mathrm{NB} 1-78$ (revisão): $\mathrm{E}_{\mathrm{cs}}=2216 \mathrm{kN} / \mathrm{cm}^{2} ; \therefore \alpha_{\mathrm{e}}=\frac{\mathrm{E}_{\mathrm{s}}}{\mathrm{E}_{\mathrm{c}}}=9,48$.

$$
f_{0 e}=\frac{3}{554} \cdot \frac{0,26 \cdot 600^{4}}{(E I)_{\mathrm{eq}}} \text { (flecha elástica inicial); }
$$

rigidez equivalente para a seção fissurada (expressão de Branson):

$(E I)_{\text {eq }}=E_{c s}\left\{\left(\frac{M_{r}}{M_{a}}\right)^{3} \cdot I_{0}+\left[1-\left(\frac{M_{r}}{M_{a}}\right)^{3}\right] I_{I I}\right\} \leq E_{c s} \cdot I_{0}$

momento de inércia da seção bruta de concreto $I_{0}=129779 \mathrm{~cm}^{4}$;

momento de inércia no estádio $\|$ : $I_{\|}=59380 \mathrm{~cm}^{4}$;

momento de fissuração: $M_{r}=\frac{f_{c t m} \cdot I_{0}}{y_{t}}=1601,5 \mathrm{kN} . \mathrm{cm}$

momento fletor na seção crítica: $M_{a}=11700,0$ kN.cm

$\therefore(\mathrm{El})_{\mathrm{eq}}=131986172 \mathrm{kN} \cdot \mathrm{cm}^{2}$.

$f_{0}=1,38 \mathrm{~cm}$;

$f_{\infty}=f_{0} \cdot \alpha_{f}=f_{0} \cdot \frac{\Delta \xi}{1+50 \rho^{\prime}}=1,38 \cdot \frac{2-0,66}{1+50 \cdot \frac{0,62}{15 \times 44}}=1,77 \mathrm{~cm}$ (supondo o carregamento de longa duração aplicado aos 28 dias).

As aberturas de fissuras para as três opções analisadas (considerando-se $\Phi \cong 12 \mathrm{~mm}$ ), e para as regiões do vão e do engaste, constam da Tabela 8.6.

Tabela 8.6 - Abertura de fissuras para a viga apoiada-engastada $(\mathrm{mm})$

\begin{tabular}{|c|c|c|}
\hline opção & $\mathbf{w}_{\mathbf{r}}$ - vão & $\mathbf{w}_{\mathbf{r}}$ - engaste \\
\hline inicial & 0,16 & 0,17 \\
\hline 1 & 0,13 & 0,17 \\
\hline 2 & 0,15 & 0,21 \\
\hline
\end{tabular}


As aberturas das fissuras apresentaram-se com diferentes valores para os três casos analisados. De um modo geral, a pior condição foi observada para a opção 2 na região do engaste, que apresentou uma abertura de 0,21 mm.

Para esse exemplo, também foram calculados três coeficientes globais $\gamma_{g l}$, de acordo com as possíveis taxas de armadura empregadas no dimensionamento e verificação. Os resultados, apresentados na Tabela 8.7 confirmam a armadura inicial como uma das possíveis ao projeto seguro, e habilitam as demais opções como sendo seguras.

Tabela 8.7 - Valores de $\gamma_{g l}$ para a viga apoiada-engastada

\begin{tabular}{|c|c|c|c|c|c|}
\hline opção & \multicolumn{2}{|c|}{ armaduras $\mathbf{( c m}^{2}$ ) } & carregamento & carregamento & $\gamma_{\mathbf{g l}}$ \\
& $\mathbf{A}_{\mathbf{s}}$ & $\mathbf{A}_{\mathbf{s}} \mathbf{s}$ & caract. médias & caract. de proj. & \\
\hline inicial & 6,28 & 13,19 & $55,0 \mathrm{kN} / \mathrm{m}$ & $43,6 \mathrm{kN} / \mathrm{m}$ & 1,26 \\
\hline 1 & 9,30 & 10,81 & $63,0 \mathrm{kN} / \mathrm{m}$ & $45,2 \mathrm{kN} / \mathrm{m}$ & 1,39 \\
\hline 2 & 8,22 & 8,22 & $58,1 \mathrm{kN} / \mathrm{m}$ & $41,6 \mathrm{kN} / \mathrm{m}$ & 1,40 \\
\hline
\end{tabular}

É interessante observar que a configuração que apresentou o menor $\gamma_{g l}$ foi aquela obtida a partir do dimensionamento considerando-se o regime elásticolinear (opção inicial). Isso se deve ao fato de, para as opções 1 e 2, a ruptura ocorrer pela deformação excessiva da armadura longitudinal tracionada, enquanto que para a configuração inicial, essa ruptura se dá pelo esmagamento do concreto. Os carregamentos relativos à ruptura da viga empregandose as características de projeto dos materiais estiveram iguais ou superiores ao carregamento de projeto (42 kN/m), exceto a opção 2 que ficou cerca insignificantemente abaixo do referido valor (cerca de 1\%).

\subsubsection{Viga engastada-engastada}

A Figura 8.27 ilustra a viga do terceiro exemplo.
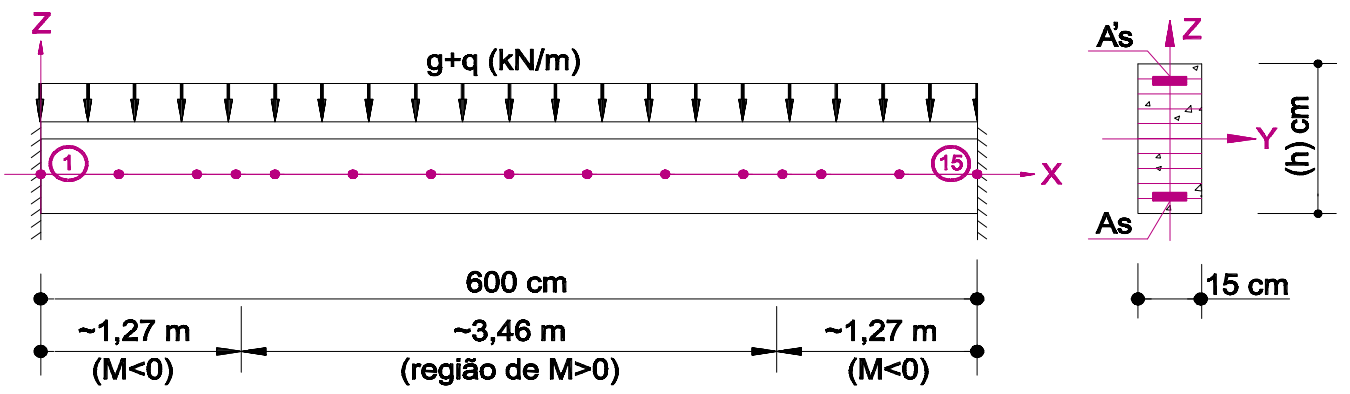

Figura 8.27 - Viga engastada-engastada - exemplo 3 
O pré-dimensionamento, e a verificação da viga seguem os passos de a a d já apresentados nos exemplos anteriores:

a) dimensionamento atendendo ao ELU entre os domínios 3 e 4.

$M_{d}{ }^{-}=12600 \mathrm{kN} . \mathrm{cm} \rightarrow \mathrm{d}=37 \mathrm{~cm} ; \mathrm{h}=40 \mathrm{~cm} ; A_{\mathrm{s}}^{\prime}=10,56 \mathrm{~cm}^{2} ; A_{s}=0,62 \mathrm{~cm}^{2}$

$M_{d}^{+}=6300 \mathrm{kN} . \mathrm{cm} \rightarrow \mathrm{d}=37 \mathrm{~cm} ; \mathrm{h}=40 \mathrm{~cm} ; A_{\mathrm{s}}^{\prime}=0,62 \mathrm{~cm}^{2} ; A_{s}=4,26 \mathrm{~cm}^{2}$

b) flecha instantânea e flecha no tempo infinito, considerando-se:

- a armadura do item a);

- propriedades médias dos materiais;

- carregamento de serviço (combinação quase-permanente)

- por simplicidade, $\varphi_{28}=2,5$ (adotado).

$\mathrm{f}_{0}=0,61 \mathrm{~cm}$ (flecha no instante de aplicação do carregamento)

$\mathrm{f}_{\infty}=1,00 \mathrm{~cm}<\mathrm{l} / 250(=2,4 \mathrm{~cm})$

c) para a combinação última normal, empregando o diagrama tensãodeformação para o concreto proposto na Figura 8.5 e as propriedades de projeto do aço, verificam-se as deformações máximas (nas seções críticas):

seção de $\mathbf{M}_{\text {máx }}^{+}$: concreto: $\varepsilon_{\mathrm{c}}^{\min }=-0,00057$; aço: $\varepsilon_{\mathrm{s}}^{\max }=0,00156$ (seguro!)

seção de $\mathbf{M}_{\text {máx }}^{-}$: concreto: $\varepsilon_{\mathrm{c}}^{\min }=-0,00168$; aço: $\varepsilon_{\mathrm{s}}^{\max }=0,00194$ (seguro!)

A profundidade da LN nas seções correspondentes aos engastes é de: $x=18,24 \mathrm{~cm}$, ou seja, $x / d=0,49$. Essa posição de $L N$, apesar de satisfazer aos quesitos mínimos da NB1-revisão 2000, de acordo com a expressão 8.13 não permite redistribuições, pois $\delta=1,06$.

d) com o objetivo de igualar as armaduras positiva e negativa, propõe-se uma plastificação de $35 \%$ na taxa de armadura negativa (o que eqüivaleria a uma redução de $25 \%$ no momento de cálculo segundo as tabelas de dimensionamento), e um acréscimo de cerca de $60 \%$ na armadura positiva.

$$
\begin{aligned}
& M_{d}{ }^{-}=9450 \mathrm{kN} . \mathrm{cm} \rightarrow d=37 \mathrm{~cm} ; \mathrm{h}=40 \mathrm{~cm} ; A_{s}^{\prime}=6,90 \mathrm{~cm}^{2} ; A_{s}=0,62 \mathrm{~cm}^{2} \\
& M_{d}{ }^{+}=9450 \mathrm{kN} . \mathrm{cm} \rightarrow d=37 \mathrm{~cm} ; \mathrm{h}=40 \mathrm{~cm} ; A_{s}^{\prime}=0,62 \mathrm{~cm}^{2} ; A_{s}=6,90 \mathrm{~cm}^{2}
\end{aligned}
$$

A partir dessa nova distribuição de armaduras (imposta), retorna-se ao procedimento normal de verificação, mais especificamente ao item $\mathbf{b}$ ): 
b1) $\mathrm{f}_{0}=0,64 \mathrm{~cm}$ (flecha no instante de aplicação do carregamento) $\mathrm{f}_{\infty}=1,02 \mathrm{~cm}<\mathrm{l} / 250(=2,4 \mathrm{~cm})$

c1) seção de $\mathbf{M}^{+}{ }_{\text {máx }}$ : concreto: $\varepsilon_{\mathrm{c}}^{\min }=-0,00067$; aço: $\varepsilon_{\mathrm{s}}^{\max }=0,00132$ seção de $\mathbf{M}^{-}{ }_{\text {máx }}$ : concreto: $\varepsilon_{\mathrm{c}}^{\min }=-0,00184$; aço: $\varepsilon_{\mathrm{s}}^{\max }=0,00268$

As aberturas de fissuras para as duas opções analisadas (considerando-se $\Phi \cong 12 \mathrm{~mm}$ ), e para as regiões do vão e dos engastes, constam da Tabela 8.8.

Tabela 8.8 - Abertura de fissuras para a viga engastada-engastada ( $\mathrm{mm}$ )

\begin{tabular}{|c|c|c|}
\hline opção & $\mathbf{w}_{\mathbf{r}}$ - vão & $\mathbf{w}_{\mathbf{r}}$ - engaste \\
\hline inicial & 0,16 & 0,17 \\
\hline 1 & 0,13 & 0,17 \\
\hline
\end{tabular}

Como pode ser observado, as aberturas das fissuras na região do engaste permaneceram as mesmas para os dois casos, enquanto que no vão, a opção inicial apresentou um valor de abertura superior à da opção 1, provavelmente em virtude de sua menor taxa de armadura nessa região.

De acordo com as duas possibilidades para as taxas de armadura, foram calculados os coeficientes globais $\gamma_{\mathrm{gl}}$ apresentados na Tabela 8.9.

Tabela 8.9 - Valores de $\gamma_{g l}$ para a viga engastada-engastada

\begin{tabular}{|c|c|c|c|c|c|}
\hline \multirow{2}{*}{ opção } & \multicolumn{2}{|c|}{ armaduras $\left(\mathbf{c m}^{2}\right)$} & $\begin{array}{c}\text { carregamento } \\
\text { caract. médias }\end{array}$ & $\begin{array}{c}\text { carregamento } \\
\text { caract. de proj. }\end{array}$ & $\gamma_{\mathbf{g l}}$ \\
\hline inicial & 10,56 & 4,26 & $60,9 \mathrm{kN} / \mathrm{m}$ & $45,4 \mathrm{kN} / \mathrm{m}$ & 1,34 \\
\hline 1 & 6,90 & 6,90 & $58,8 \mathrm{kN} / \mathrm{m}$ & $41,7 \mathrm{kN} / \mathrm{m}$ & 1,41 \\
\hline
\end{tabular}

Novamente, a configuração que apresentou o menor $\gamma_{g l}$ foi a proporcionada pelas armaduras obtidas com os esforços do regime elástico-linear. No entanto, neste exemplo, bem como no anterior, a opção inicial foi a que proporcionou o maior carregamento considerando-se as características de projeto dos materiais (cerca de $45,5 \mathrm{kN} / \mathrm{m}$ ).

\subsubsection{Laje apoiada}

A laje empregada neste exemplo é aquela apresentada na Figura 8.28. 


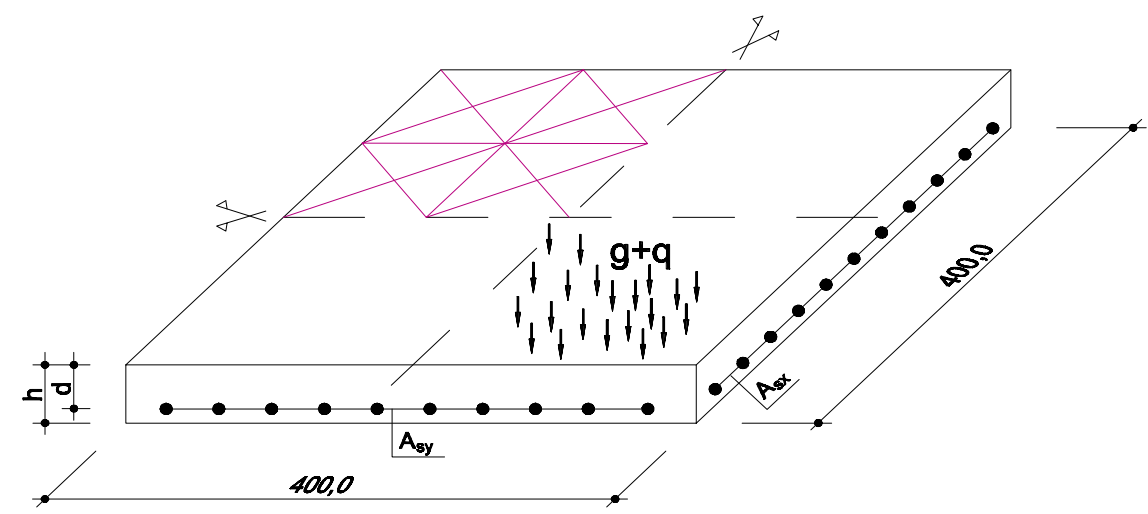

Figura 8.28 - Laje apoiada nos quatro lados - exemplo 4

Supondo ser uma laje de pavimento usual de concreto armado, o carregamento convencional, bem como a combinações empregadas para 0 dimensionamento no ELU e a verificação dos ELS devem ser:

g: $\quad 2,5 \mathrm{kN} / \mathrm{cm}^{2}$ (peso próprio, supondo $\mathrm{h}=10 \mathrm{~cm}$ );

$1,0 \mathrm{kN} / \mathrm{cm}^{2}$ (revestimento);

q: $\quad 3,0 \mathrm{kN} / \mathrm{cm}^{2}$ (sobrecarga).

ELU: $\quad 1,4 \times(2,5+1,0)+1,4 \times 3,0=9,1 \mathrm{kN} / \mathrm{m}^{2}$;

ELS: $1,0 \times(2,5+1,0)+0,2 \times 3,0=4,1 \mathrm{kN} / \mathrm{m}^{2}$.

Com relação às estruturas de edfícios, a NB1-78 dispensa o cálculo das flechas quando a altura útil da laje 'd' for igual ou superior à relação $1 /\left(\psi_{2} \cdot \psi_{3}\right)$, onde: I corresponde ao menor vão para as lajes armadas em cruz; $\psi_{2}$ e $\psi_{3}$ são valores tabelados, respectivamente, de acordo com as vinculações e com a tensão de cálculo na armadura $\left(\sigma_{\mathrm{sd}}\right)$. Para a laje em questão, e admitindo-se $\sigma_{\mathrm{sd}}=43,5 \mathrm{kN} / \mathrm{cm}^{2}$, os valores seriam: $I=400 \mathrm{~cm} ; \psi_{2}=1,5$ e $\psi_{3}=30$. Isso significa que, para uma laje cuja altura útil seja superior a $8,9 \mathrm{~cm}$, são dispensadas as verificações de flecha. Supondo que a armadura da laje seja composta de ferros com diâmetro máximo $\Phi=8,0 \mathrm{~mm}$ e que, a NB1-78 estabelece que o cobrimento mínimo para as lajes no interior de edifícios seja de $0,5 \mathrm{~cm}$, uma espessura $\mathrm{h}=10 \mathrm{~cm}$ implicaria em uma altura útil $\mathrm{d}=9,1 \mathrm{~cm}(>8,9 \mathrm{~cm})$.

O pré-dimensionamento, a partir dos esforços obtidos a partir das hipóteses da elasticidade, é feito de acordo com as tabelas de PINHEIRO(1996).

$$
\begin{aligned}
& M_{x}=M_{y}=6,15 \mathrm{kN} \cdot \mathrm{m} / \mathrm{m} ; \\
& A_{s x}=A_{s y}=1,62 \mathrm{~cm}^{2} / \mathrm{m} .
\end{aligned}
$$


Considerando essa configuração de armaduras, as flechas calculadas nos instantes $t_{0}$ e $t=\infty$ foram (considerando-se, simplificadamente, $\varphi_{28}=2,5$ ):

$$
\begin{aligned}
& \mathrm{f}_{0}=0,15 \mathrm{~cm} \text { (flecha no instante de aplicação do carregamento) } \\
& \mathrm{f}_{\infty}=0,50 \mathrm{~cm}<\mathrm{l} / 250(=2,3 \mathrm{~cm})
\end{aligned}
$$

O dimensionamento considerando-se a espessura $\mathrm{h}=10 \mathrm{~cm}$ leva à uma taxa de armaduras pequena, o que sugere o mau aproveitamento do concreto. Alternativamente, adota-se uma nova espessura para a laje, agora de $9 \mathrm{~cm}$, o que significa uma altura útil $\mathrm{d}=8,1 \mathrm{~cm}$. As novas armaduras são:

$$
A_{s x}=A_{s y}=1,82 \mathrm{~cm}^{2} / \mathrm{m} \text {. }
$$

Para a nova configuração, os deslocamentos calculados são de:

$$
\begin{aligned}
& \mathrm{f}_{0}=0,20 \mathrm{~cm} \\
& \mathrm{f}_{\infty}=0,66 \mathrm{~cm}
\end{aligned}
$$

Para as duas taxas de armadura, foram calculados os coeficientes globais $\gamma_{\mathrm{gl}}$, que ficaram em 1,31 para a opção $\mathrm{h}=10 \mathrm{~cm}$, e 1,30 para $\mathrm{h}=9,0 \mathrm{~cm}$.

Estes exemplos foram apresentados com o objetivo de gerar discussões sobre a consistência dos métodos de dimensionamento estudados. A inclusão de outros exemplos, envolvendo estruturas mais complexas, poderia desviar a atenção dos aspectos básicos aos quais desejam-se de focar as discussões. 


\section{CONCLUSÃO}

O término deste trabalho de pesquisa vem acompanhado de uma série de constatações relacionadas principalmente ao tema dimensionamento. Aquelas julgadas as mais importantes por parte deste autor estão resumidamente comentadas neste capítulo. De qualquer modo, independentemente das conclusões aqui estabelecidas, vale a pena relatar a sensível melhora na representatividade do comportamento mecânico dos elementos estruturais proporcionada pela introdução de leis constitutivas mais adequadas.

Os elementos finitos, bem como os modelos constitutivos empregados na descrição do comportamento mecânico dos elementos estruturais, mostraram-se suficientemente precisos para a representação dos estados limites último e de serviço abordados neste trabalho. Devido àmaior capacidade de representação, os elementos finitos do tipo estratificado receberam uma maior ênfase em detrimento daqueles formulados no campo dos momentos fletores e das curvaturas. $O$ comportamento dos pilares sob flexão oblíqua composta pôde ser modelado através da dupla estratificação da seção transversal do elemento segundo ambas as direções principais de inércia. Essa técnica, também conhecida por filamentação, constitui uma alternativa viável em relação a outras técnicas. Um breve estudo comparativo revelou a boa representatividade desse procedimento comparativamente æ̀s integrações por Gauss-Legendre e Gauss-Lobatto. As análises dos estados limites de serviço de deformações excessivas, e de abertura de fissuras puderam ser melhoradas em virtude da implementação dos modelos que tratam da fluência e do escorregamento das armaduras, respectivamente.

$\mathrm{Na}$ segunda parte do trabalho, onde foram abordados os aspectos relativos ao projeto estrutural, as observações estão mais restritas a críticas às metodologias propostas, do que à consolidação de idéias. Os estudos realizados nesse campo, quer através de bibliografias, quer através do contato com pesquisadores empenhados no assunto, permite concluir que a obtenção de uma 
metodologia segura para o dimensionamento considerando-se as leis constitutivas não-lineares ainda está por ser consolidada. A metodologia semi-probabilística, ou mesmo, mais recentemente, a metodologia do coeficiente global, são ainda passíveis de duras críticas, e necessitam ser melhor estudadas antes que o seu uso prático seja estabelecido. A expectativa é de que, no médio prazo, essas questões sejam sanadas, e a evolução dos procedimentos de cálculo, viabilizada.

O futuro dessa área, que visa o emprego das relações constitutivas ao dimensionamento estrutural, aponta para os estudos sobre a confiabilidade estrutural como ferramenta para a viabilização de uma metodologia determinística segura. Atualmente, apesar de serem vários os trabalhos que tratam da simulação da segurança, existe uma forte tendência de multiplicação dos mesmos, bem como da diversificação de seu emprego. 


\section{REFERÊNCIAS BIBLIOGRÁFICAS}

ÁLVARES,M.S. (1993). Estudo de um modelo para o concreto: formulação, identificação paramétrica e aplicação do método dos elementos finitos. São Carlos. Dissertação (Mestrado) - Departamento de Engenharia de Estruturas, EESC-USP.

ALLWOOD,R.J.;BAJARWAN,A.A.(1996). Modeling nonlinear bond-slip behavior for finite element analyses of reinforced concrete structures. ACI Structural Journal, v.93, n. 5, p. 538-544, September-October.

AMERICAN SOCIETY OF CIVIL ENGINEERS (1982). State-of-the-art report on finite element analysis of reinforced concrete. New York, ASCE.

ASSAN,A.E.(1990). Vigas de concreto armado com não linearidade física. In: CONGRESSO IBERO LATINO-AMERICANO SOBRE MÉTODOS COMPUTACIONAIS PARA ENGENHARIA, 11., Rio de Janeiro. v.2, p.741-749.

ASSOCIAÇÃO BRASILEIRA DE NORMAS TÉCNICAS (1978). NB-1 - Projeto e execução de obras de concreto armado. Rio de Janeiro.

(1984). NBR 8681 - Ações e segurança nas estruturas. Rio de Janeiro.

BAKOSS,S.L.; GILBERT,R.I.; FAULKES,K.A.; PULMANO,V.A. (1982). Long-term deflections of reinforced concrete beams. Magazine of Concrete Research, v.34, n.121, p. 203-212.

BALBO,A.R.(1998). Contribuição àformulação matemática de modelos constitutivos para materiais com dano contínuo. São Carlos. Tese (Doutorado) Departamento de Engenharia de Estruturas, EESC-USP.

BALLAROTTI,C.(1981). Análise elastoplástica de pórticos planos retangulares. São Carlos. Dissertação (Mestrado) - Departamento de Engenharia de Estruturas, EESC-USP.

BASHUR,F.K.; DARWIN,D.(1978). Nonlinear model for reinforced concrete slabs. J. Struct. Div., ASCE, v.104, p.157-170.

BAZANT,Z.P.(1972). Creep and shrinkage in concrete structures. 2.ed. John Willey \& Sons.

BELYTSCHKO,T.;VELEBIT,M.(1972). Finite element method for elastic plastic plates. J. Eng. Mech. Div., ASCE, v.98, p.227-242. 
BRANSON,D.E.(1966). Deflections of reinforced concrete flexural members. ACl Journal, June.

BROMS,B.B.(1965). Crack width and crack spacing in reinforced concrete members. ACl Journal, v. 62, n.10, p.1237-1255.

BUSSAMRA,F.L.;PIMENTA,P.M.(1995). Equações constitutivas do concreto baseadas na mecânica do dano contínuo. Boletim Técnico da EPUSP, BT/PEF/9522, 19p.

CAMARA,J;VINAGRE,J.;PINTO,A.(1994). Metodologia para verificação da segurança em análises não-lineares. In: ENCONTRO NACIONAL - BETÃO ESTRUTURAL 1994, Porto, Portugal, p.373-383.

CARVALHO,R.C. (1994). Análise não-linear de pavimentos de edifícios de concreto através da analogia de grelha. São Carlos. Tese (Doutorado) -Departamento de Engenharia de Estruturas, EESC-USP.

CEB-FIP Model code 1990 - final draft. Bulletin D'Information, n. 203-205; 1991.

CEB-FIP Bulletin D'Information, n. 229 New developments in non-linear analysis methods, 1995.

n. 239 Non-linear analysis / Safety evaluation and monitoring, 1997.

n. 242 (fib) Ductility of reinforced concrete structures, 1998.

CERVERA,M.; HINTON,E.(1986). Nonlinear analysis of reinforced concrete plates and shells using a three dimension model. In: HINTON,E.; OWEN,D.R.J., ed. Computational modeling of reinforced concrete structures. Swansea, Pineridge Press. p.303-326.

CHEN,W.F.(1982). Plasticity in reinforced concrete. New York, McGraw-Hill.

CHEN,A.C.T.;CHEN,W.F.(1975). Constitutive relations for concrete. Journal of the Engineering Mechanics Division, v.101.

CHEN,W.F.;HAN,D.J.(1988). Plasticity for structural engineers. New York, SpringerVerlag.

CHEN,W.F.;YAMAGUCHI,E.;KOTSOVOS,M.D.;PAN,A.D.(1993). Constitutive models. In: INTERNATIONAL WORKSHOP ON FINITE ELEMENT ANALYSIS OF REINFORCED CONCRETE STRUCTURES, 2., New York. Proc. New York, ASCE. p.36-117.

CHEUNG,Y.K.;KING,I.P.;ZIENKIEWICZ,O.C.(1968). Slab bridges with arbitrary shape and support conditions: a general method of analysis based on finite elements. Proceedings of the Institution of Civil Engineers; n. 40, p.9-36.

CLARKE,G.;SCHOLZ,H.;ALEXANDER,M.(1988). New method to predict the creep deflection of cracked reinforced concrete flexural members. ACl Materials Journal, v. 85-M12, p. 95-101, March-April.

CORLEY,W.G.;SOZEN,M.A. (1966). Time-dependent deflections of reinforced concrete beams. ACl Journal, n. 63-17, p. 373-386. 
CORRÊA,M.R.S.(1991). Aperfeiçoamento de modelos usualmente empregados no projeto de sistemas estruturais de edifícios. São Carlos. Tese (Doutorado) Departamento de Engenharia de Estruturas, EESC-USP.

CRISFIELD,M.A.(1991). Non-linear finite element analysis of solids and structures. Chichester, John Wiley \& Sons.

DEBERNARDI,P.G.(1989). Behavior of concrete structures in service. Journal of Structural Engineering, v.115, p. 33-50.

DOTREPPE,J.C., SCHNOBRICH,W.C., PECKNOLD,D.A.(1973). Layered finite element procedure for inelastic analysis of reinforced concrete slabs. IABSE Publications, p.11-33, 53-68.

EIBL,J.;SCHMIDT-HURTIENNE,B.(1997). General outline of a new safety format, In: CEB-FIP Bulletin D'Information, n. 229 New developments in non-linear analysis methods, p.33-48.

ELIGEHAUSEN,R.; BALÁZS,G.L.(1991). Bond and detailing. In: COLLOQUIUM ON THE CEB-FIP MC90, 28-30 August, Rio de Janeiro, 1991. Proceedings. Rio de Janeiro, COPPE/CEB, p.213-261.

ELIGEHAUSEN,R.;POPOV,E.P.;BERTERO,V.V.(1983). Local bond stress-slip relationships of deformed bars under generalized excitations. Berkeley, CA., Earthquake Engineering Research Center, University of California. (Report $\mathrm{n}$. UCB/EERC 83-23)

EL-METWALLY,S.E.;EL SHAHHAT,A.M.;CHEN,W.F(1989). 3-D Nonlinear analysis of R/C slender columns. Computers \& Structures, v.37, n. 5, p. 863-872.

FEENSTRA,P.H.;DE BORST,R.(1995). A plasticity model and algorithm for mode-I cracking in concrete. International Journal for Numerical Methods in Engineering v.38, p. $2509-2529$.

FEENSTRA,P.H.;DE BORST,R.(1996). A composite plasticity model for concrete. International Journal of Solids and Structures v.33, n.5, p. 707-730.

FIGUEIRAS,J.A.(1983). Ultimate load analysis of anisotropic and reinforced concrete plates and shells. Swansea. Ph.D.Thesis, Depart. of Civil Engrg., University College of Swansea.

FLOREZ-LÓPEZ,J.(1993). Modelos de daño concentrado para la simulation numerica del colapso de porticos planos. Revista Internacional de Métodos Numéricos para Cálculo y Diseño en Ingenieria, v.9, n.2, p.123-139.

FOSTER,S.J.;BUDIONO,B.;GILBERT,R.I.(1996). Rotating crack finite element model for reinforced concrete structures. Computers \& Structures, v.58, n.1, p.43-50.

FRANÇA,R.L.S.(1985). Exemplo de cálculo do esforço de segunda ordem global em um edifício de concreto armado. In: COLÓQUIO SOBRE ESTABILIDADE GLOBAL DAS ESTRUTURAS DE CONCRETO ARMADO, IBRACON, São Paulo.

FUSCO, P.B. (1986). Estruturas de concreto: solicitações normais. 2.ed. Rio de Janeiro, Guanabara Dois. 
GHALI,A.;FAVRE,R.(1986). Concrete structures: stress and deformations. London, Chapman and Hall.

HAND,F.R.; PECKNOLD,D.A.; SCHNOBRICH,W.C.(1973). Nonlinear layered analysis of RC plates and shells. Journal of Structural Division, ASCE, v. 99, p.1491-1504.

HENRIQUES,A.A.R.(1998). Aplicação de novos conceitos de segurança no dimensionamento do betão estrutural. Porto, Portugal. Tese (Doutorado) Engenharia Civil, Universidade do Porto, Portugal.

HINTON,E.; OWEN,D.R.J.(1986). Computational modelling of reinforced concrete structures. Swansea, Pineridge Press.

JIANG,D.H.;SHAH,S.P.(1994). Mechanism of bond and slip. In: BORESI, A.P.;CHONG,K.P. Engineering mechanics in Civil Engineering. New York, ASCE - American Society of Civil Engineers,. p.1416-1419.

JOFRIET,J.C.;McNEICE,G.M. (1971). Finite element analysis of reinforced concrete slabs. Journal of Structural Division, ASCE. v. 97, p. 785-806.

KOITER,W.T.(1953). Stress-strain relations, uniqueness and variational theorems for elastic-plastic materials with a singular yield surface. Q. Appl. Math. n. 11, p.350-354.

KOMATSU,J.S.(1985). Cálculo elastoplástico de estruturas lineares de concreto. São Carlos. Dissertação (Mestrado) - Departamento de Engenharia de Estruturas, EESC-USP.

KUPFER,H.B.;HILSDORF,H.K.;RUSH,H.(1969). Behavior of concrete under biaxial stresses. American Concrete Journal, v. 66, p. 656-666.

KUPFER,H.B.;GERSTLE,K.H.(1973). Behavior of concrete under biaxial stresses. Journal of the Engineering Mechanics Division, v. 99, p. 853-866.

KWAK,H.,G.;FILIPPOU,F.C.(1997). Nonlinear fe analysis of $\mathrm{r} / \mathrm{c}$ structures under monotonic loads. Computers \& Structures, v.65, n. 1, p. 1-16.

LA BORDERIE,C.;PIJAUDIER-CABOT,G.;MAZARS,J.(1991). Response of plain and reinforced concrete structures under cyclic loadings. Cachan, France, Laboratoire de Mécanique et Technologie. (Rapport Interne, n. 123).

LABBANE,M.;SAHA,N.K.;TINGE.C.(1993). Yield criterion and loading function for concrete plasticity. International Journal of Solids \& Structures, v.30, p. 12691288.

LEMAITRE,J.;CHABOCHE,J.C.(1985). Mécanique des Matériaux Solides. Paris, Dunod-Bordas.

LEMAITRE,J.;CHABOCHE,J.C.(1990). Mechanics of Solid Materials. Cambridge University Press.

LIN,C.S.; SCORDELIS,A.C.(1975). Nonlinear analysis of rc shells of general form. Journal of Structural Division, ASCE, v. 101, p. 523-538. 
LOURENÇO,P.B.;PÓVOAS,R.H.C.F.;FIGUEIRAS,J.A.(1992). Compared study of nonlinear finite element analysis and the strut-and-tie model for concrete structures. A designer perspective. In: $4^{\text {th }}$ International Conference on Education, Practice and Promotion of Computer Methods in Engineering using Small Computers. Ed. X. Liao, Dalian, P.R. Proceedings, China, p. 660-667.

MACHADO,C.P.(1989). Tensões, deformações e deslocamentos em estruturas de concreto armado. São Paulo. Dissertação (Mestrado) - Departamento de Engenharia de Estruturas e Fundações - EPUSP.

MACCHI,G.(1995). Nonlinear analysis. The CEB approach, In: CEB-FIP Bulletin D'Information, n. 229 New developments in non-linear analysis methods, p.7-12.

MANFREDI,G.;PECCE,M.(1998). A refined R.C. beam element including bond-slip relationship for the analysis of continuous beams. Computers \& Structures, v.69, p. 53-62.

MARÇAL,P.V.; KING,I.P.(1967). Elasto-plastic analysis of two-dimensional stress systems by the finite element method. International Journal of Mechanical Sciences, v. 9, p. 143-155.

MARTINS,P.C.R.(1991). Bond stress-slip influence on flexural behaviour of PPC elements. In: COLLOQUIUM ON THE CEB-FIP MC90, 28-30 August, Rio de Janeiro, 1991. Proceedings. Rio de Janeiro, COPPE/CEB, p.263-288.

MAZARS,J.(1984). Application de la mécanique de l'endommagement au comportement non lineaire et à la rupture du béton de structure. Thése de Doctorat d'État, Université Paris 6.

MENDELSON,A.(1968). Plasticity: theory and application. Robert E. Krieger Publ.

MENÉTREY,P.;WILLAM,K.J.(1995). Triaxial failure criterion for concrete and its generalization. ACl Structural Journal, v.92, n. 3, p. 311-318, May-June.

MIRZA,S.M.;HOUDE,J.(1979). Study of bond stress-slip relationships in reinforced concrete. ACl Journal, v.76, n. 1, p. 19-46, January.

NAYAK,G.C.; ZIENKIEWICZ,O.C.(1972). Elasto-plastic stress analysis: a generalization for various constitutive relations including strain softening. International Journal for Numerical Methods in Engineering, v. 5, p. 113-135.

NEVILLE,A.M.;DILGER,W.H.;BROOKS,J.J.(1983). Creep of plain and structural concrete. New York. London Construction Press.

NGO,D.;SCORDELIS,A.C.(1967). Finite element analysis of reinforced concrete beams. ACl Journal, v.64, n. 3, p. 152-163, March.

NILSON,A.,H.(1968). Nonlinear analysis of reinforced concrete by the finite element method. ACl Journal, v.65, n. 9, p. 757-766, September.

NILSON,A.,H.(1972). Internal measurement of bond slip. ACI Journal, v.69, n. 7, p. 439-441, July. 
NOVOTNY,A.A.; LUERSEN,M.A.; PEREIRA,J.T.; SELKE,C.A.C.(1994). Análise comparativa entre alguns procedimentos de integração na espessura para problemas elastoplásticos em placas semi-espessas. In: CONGRESSO IBERO LATINO-AMERICANO SOBRE MÉTODOS COMPUTACIONAIS PARA ENGENHARIA, Belo Horizonte, p.1569-1578.

OLIVEIRA,R.S.(1997). Análise de pavimentos de edifícios de concreto armado com a consideração da não-linearidade física. São Carlos. Dissertação (Mestrado) Departamento de Engenharia de Estruturas, EESC-USP.

OLIVEIRA,R.S.;ARAÚJO,D.L.;CORRÊA,M.R.S.;RAMALHO,M.A.(1999). Avaliação da perda da resistência de vigas de concreto armado pelo efeito da corrosão de armaduras. In: CONPAT'99, 18-21 octubre, Montevideo. Proceedings. p.827834.

OÑATE,E.I.N. (1992). Calculo de estructuras por el metodo de elementos finitos. Barcelona, Centro Internacional de Métodos Numéricos en Ingeniería.

OWEN,D.R.J.; HINTON,E.(1980). Finite elements in plasticity: theory and practice. Swansea, Pineridge Press.

PARK,H.;KLINGNER,R.E.(1997). Nonlinear analysis of RC members using plasticity with multiple failure criteria. Journal of Structural Engineering, v.123, n.5, p.643-651.

PEREGO,M.A.(1989). Danneggiamento dei materiali lapidei: leggi costitutive, analisis per elementi finiti ed applicazioni. Tesi di Laurea, Politécnico di Milano

PINHEIRO,L.M.(1996). Concreto armado: tabelas e ábacos. São Carlos, Escola de Engenharia de São carlos - Publicações.

PITUBA,J.J.C.(1998). Estudo e aplicação de modelos constitutivos para o concreto fundamentados na mecânica do dano contínuo. São Carlos. Dissertação (Mestrado) - Departamento de Engenharia de Estruturas, EESC-USP.

PRAGER,W.; HODGE, P.G.(1963). Theory of perfectly plastic solids. New York, John Wiley \& Sons.

PROENÇA,S.P.B.(1988). Sobre modelos matemáticos do comportamento não linear do concreto: análise crítica e contribuições. São Carlos. Tese (Doutorado) - Departamento de Engenharia de Estruturas, EESC-USP.

PROENÇA,S.P.B.(1997). Sobre atividades de pesquisa em mecânica dos materiais $e$ análise não-linear de estruturas. São Carlos. Tese (Livre-docência) Departamento de Engenharia de Estruturas, EESC-USP.

RAHMAN,M.A.; AYANO,T.; SAKATA,K. (1998). The use of physical phenomena to predict time effects in cracked reinforced concrete beams. Magazine of Concrete Research, v.50, n.3, p. 219-227.

SAENZ,L.P.(1964) Discussion of "Equation for the stress-strain curve of concrete", paper by P. Desayi; S. Krishnan. ACI Journal, v.61. 
SANCHES JR.,F. (1998). Cálculo de esforços e deslocamentos em pavimentos de edifícios considerando-se modelos próprios para o concreto armado. São Carlos. Dissertação (Mestrado) - Departamento de Engenharia de Estruturas, EESC-USP.

SANTOS,J.C.V.N.(1997). Avaliação dos efeitos de 2a. ordem em edifícios de betão armado. Lisboa, Portugal. Tese (Doutorado) - Engenharia Civil, Universidade Técnica de Lisboa, Portugal.

SATHURAPPAN,G.; RAJAGOPALAN,N.; KRISHNAMOORTHY,C.S.(1992). Nonlinear finite element analysis of reinforced and prestressed concrete slabs with reinforcement (inclusive of prestressing steel) modelled as discrete integral components. Computers \& Structures, v.44, n. 3, p. 575-584.

SFAKIANAKIS,M.G.;FARDIS,M.N.(1991). Bounding surface model for cyclic biaxial bending of rc sections. Journal of Engineering Mechanics, v. 117, n. 12, Dec.

SHAH,S.P.;SWARTZ,S.E.(1995). Fracture mechanics of concrete. New York, John Wiley \& Sons.

SILVA,R.M.(1996). Análise não-linear de pórticos planos de concreto armado: modelagem numérica e avaliação dos métodos aproximados. São Carlos. Tese (Doutorado) - Departamento de Engenharia de Estruturas, EESC-USP.

SIMO,J.C.; HUGHES,T.J.R.(1988). Elastoplasticity and viscoplasticity: computational aspects.

SKRZYPEK,J.J.(1993). Plasticity and creep: theory, examples, and problems. Trad. by Richard B. Hetnarski. Boca Ranton, CRC Press.

SOMAYAJI,S; SHAH,S.P.(1981). Bond stress versus slip relationship and cracking response of tension members. ACl Journal, v.78, n. 3, p. 217-225, May-June.

TASSIOS,T.P.;YANNOPOULOS,P.J.(1981). Analytical studies on reinforced concrete members under cyclic loading based on bond stress-slip relationships. ACl Journal, v.78, n. 3, p. 206-216, May-June.

WHANG,B.(1969). Elasto-plastic orthotropic plates and shells. In: SYMPOSIUM ON APPLICATIONS ON FINITE ELEMENT METHODS IN CIVIL ENGINEERING, Tennessee, Vanderbilt University. Proc. p. 481-513.

ZIENCKIEWICZ,O.C.; VALLIAPAN,S.; KING,I.P.(1969). Elasto-plastic solutions on engineering problems - 'initial stress', finite element approach. International Journal for Numerical Methods in Engineering, v. 1, p. 75-100. 


\section{Anexo A - INCORPORAÇÃO DAS DIMENSÕES DOS PILARES}

\section{A.1. Introdução}

Pela teoria de placas delgadas (ou teoria de Kirchoff), desprezam-se as deformações por força cortante no domínio do elemento. O resultado são esforços que tendem ao infinito com o refinamento progressivo da malha no entorno de forças concentradas (ou apoios puntuais).

$\mathrm{Na}$ análise das estruturas convencionais de edifícios de concreto armado, os elementos estruturais unidimensionais são representados por uma barra, e a ligação dos pilares às lajes fica caracterizada através de um ponto no plano do pavimento. A presença desse apoio puntual possibilita o surgimento de forças concentradas, e leva àindefinição dos resultados no seu entorno.

Torna-se então, evidente, a necessidade de incorporar o pilar com suas dimensões finitas no modelo numérico, afastando toda a imprecisão decorrente de refinamentos inadequados. Autores como CHEUNG;KING;ZIENKIEWICZ (1968) indicam que, nesses casos, as lajes deveriam ser dimensionadas para os esforços atuantes no limite das faces dos pilares, desprezando-se os valores obtidos em regiões mais próximas ao centro desse apoio.

\section{A.2. Aspectos da formulação}

São resumidos, a seguir, os principais aspectos da formulação envolvendo a translação de graus de liberdade no espaço.

\section{A.2.1. Translação de coordenadas no espaço bidimensional}

Para os estudos apresentados neste capítulo, considera-se o pavimento contido no plano xy. Primeiramente, constituem-se dois sistemas de coordenadas 
ortogonais de referência: o sistema original $\bar{O} x y z$, e um segundo sistema Oxyz, defasado dos valores escalares $\left(d_{x}, d_{y}, 0\right)$, no plano $x y$, em relação ao sistema original, conforme se mostra na Figura A.1.

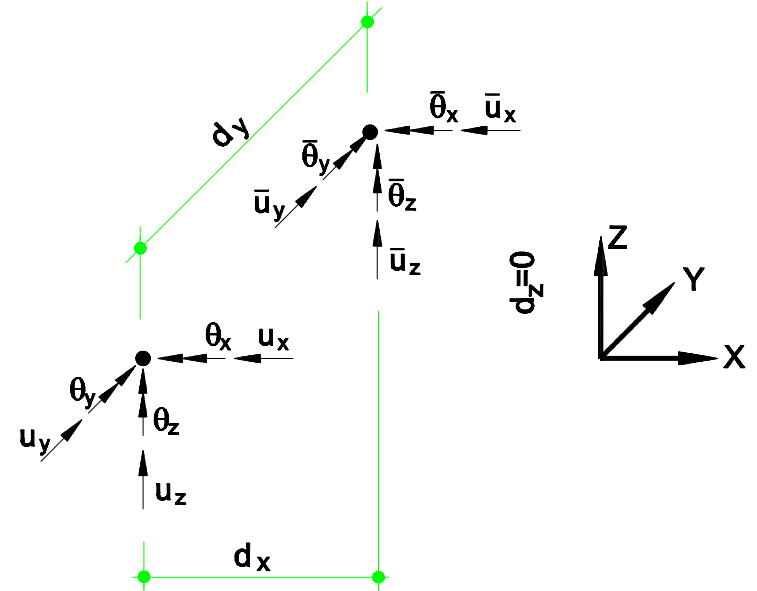

Figura A.1 - Translação de coordenadas no espaço tridimensional

Um deslocamento arbitrário de corpo rígido no plano xy $\left(d_{z}=0\right)$ pode, então, ser descrito independentemente pelos dois sistemas de referência. Pode-se estabelecer, também, uma correlação geométrica entre os dois sistemas de coordenadas de modo que cada um dos deslocamentos segundo o sistema $\overline{\mathrm{O}} \mathrm{xyz}$ possa ser escrito como uma combinação linear dos deslocamentos relativos a Oxyz, e vice-versa. Para isso, no entanto, impõe-se a condição de que as rotações $(\theta)$ de corpo rígido envolvidas sejam tão pequenas que permitam escrever as translações $(u)$ de um ponto como sendo o produto da rotação $(\theta)$ pelo raio $(R)$ que liga o ponto ao centro instantâneo de rotação:

$$
\mathrm{u}=\mathrm{R} \cdot \theta
$$

De acordo com a Figura A.1, os deslocamentos podem ser relacionados pela seguinte transformação linear:

$$
\left\{\begin{array}{l}
\bar{u}_{x} \\
\bar{u}_{y} \\
\bar{u}_{z} \\
\bar{\theta}_{x} \\
\bar{\theta}_{y} \\
\bar{\theta}_{z}
\end{array}\right\}=\left[\begin{array}{cccccc}
1 & 0 & 0 & 0 & 0 & d_{y} \\
0 & 1 & 0 & 0 & 0 & d_{x} \\
0 & 0 & 1 & -d_{y} & d_{x} & 0 \\
0 & 0 & 0 & 1 & 0 & 0 \\
0 & 0 & 0 & 0 & 1 & 0 \\
0 & 0 & 0 & 0 & 0 & 1
\end{array}\right] \cdot\left\{\begin{array}{l}
u_{x} \\
u_{y} \\
u_{z} \\
\theta_{x} \\
\theta_{y} \\
\theta_{z}
\end{array}\right\}
$$

que, em termos matriciais pode ser escrita: 


$$
\{\bar{q}\}=\left[\Lambda^{\top}\right]\{q\}
$$

onde: $\left[\Lambda^{\top}\right]$ - matriz de transformação linear do sistema Oxyz para o $\overline{\mathrm{O}} x y z$;

$\{q\}$ - vetor de deslocamentos descrito no sistema de coord. transladado;

$\{\bar{q}\}$ - vetor de deslocamentos descrito no sistema de coord. original.

\section{A.2.2. Aplicação do PTV}

Admite-se que o movimento de corpo rígido deva estar relacionado a um estado de forças único e também genérico $\{\bar{F}\}$, medido no sistema original, ou $\{F\}$, medido no sistema transladado. Dessa forma, pode-se inferir que a energia $\Pi$ acumulada pela estrutura, quantificada nos dois sistemas descritos, seja rigorosamente a mesma, já que o trabalho é uma grandeza escalar do tipo:

$$
\Pi=\left\{\begin{array}{llllll}
\bar{F}_{x} & \bar{F}_{y} & \bar{F}_{z} & \bar{M}_{x} & \bar{M}_{y} & \bar{M}_{z}
\end{array}\right\} \cdot\left\{\begin{array}{l}
\bar{u}_{x} \\
\bar{u}_{y} \\
\bar{u}_{z} \\
\bar{\theta}_{x} \\
\bar{\theta}_{y} \\
\bar{\theta}_{z}
\end{array}\right\}=\left\{\begin{array}{llllll}
F_{x} & F_{y} & F_{z} & M_{x} & M_{y} & M_{z}
\end{array}\right\} \cdot\left\{\begin{array}{l}
u_{x} \\
u_{y} \\
u_{z} \\
\theta_{x} \\
\theta_{y} \\
\theta_{z}
\end{array}\right\}
$$

ou, matricialmente:

$$
\{\overline{\mathrm{F}}\}^{\top}\{\overline{\mathrm{q}}\}=\{\mathrm{F}\}^{\top}\{\mathrm{q}\}
$$

Substituindo a equação A.3 na A.5, tem-se:

$$
\{\bar{F}\}^{\top}[\Lambda]^{\top}\{q\}=\{F\}^{\top}\{q\}
$$

de onde se conclui que:

$$
\{\mathrm{F}\}=[\Lambda]\{\overline{\mathrm{F}}\}
$$

\section{A.3. Aplicação ao elemento de placa}

A formulação para a incorporação de pilares com dimensões finitas no modelo numérico envolve a translação dos graus de liberdade referentes aos nós 
que fazem fronteira com as faces do pilar para o nó localizado no centro de gravidade (cg) da seção transversal (Figura A.2).

Convém salientar que as hipóteses aqui envolvidas não ferem as hipóteses iniciais de seções planas assim permanecerem após a imposição de deformações.

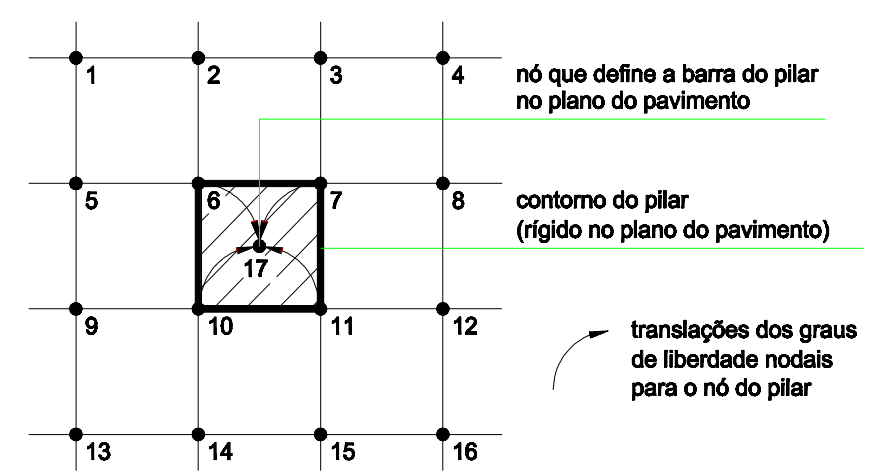

Figura A.2 - Translação dos graus de liberdade dos nós de fronteira do pilar

No entanto, à medida em que transladam-se os graus de liberdade de determinados nós (pertencentes a elementos de placa) para outro modificam-se, não somente o vetor de cargas nodais dos elementos definidos por esses nós, como também a matriz de rigidez. A transformação do vetor de cargas nodais é dada pela expressão A.7. A matriz de rigidez dos elementos de placa $[\bar{k}]$ cujos graus de liberdade foram transladados ao $\mathrm{cg}$ do pilar, expressa em termos das novas coordenadas $[\mathrm{k}]$, deve ser transformada como a seguir, de acordo com o próprio estado de esforços no elemento dado no sistema de coordenadas original:

$$
\{\overline{\mathrm{F}}\}=[\overline{\mathrm{k}}] \cdot\{\overline{\mathrm{q}}\}
$$

Substituindo-se as equações A.3 e A.7 na equação A.8, tem-se:

$$
[\Lambda]^{-1}\{\mathrm{~F}\}=[\overline{\mathrm{k}}] \cdot[\Lambda]^{\top}\{\mathrm{q}\}
$$

Pré multiplicando-se ambos os membros pela matriz de transformação $[\Lambda]$,

$$
\{\mathrm{F}\}=[\Lambda] \cdot[\bar{k}] \cdot[\Lambda]^{\top}\{\mathrm{q}\}
$$

conclui-se que a matriz de rigidez pode ser obtida com base na expressão:

$$
[\mathrm{k}]=[\Lambda] \cdot[\overline{\mathrm{k}}] \cdot[\Lambda]^{\top}
$$

O estado final de esforços no elemento finito deve ser dado em função da matriz momento por deslocamento, de acordo com a expressão: 


$$
\{\overline{\mathrm{T}}\}=\left\{\overline{\mathrm{T}}_{0}\right\}+\left\{\overline{\mathrm{T}}_{\mathrm{D}}\right\}\{\overline{\mathrm{q}}\}
$$

onde: $\{\overline{\mathrm{T}}\}$ - vetor de esforços finais no sistema de coordenadas original;

$\left\{\overline{\mathrm{T}}_{0}\right\}$ - vetor de esforços iniciais no sistema de coordenadas original;

$\left\{\overline{\mathrm{T}}_{D}\right\}$ - matriz força-deslocamento no sistema de coordenadas original.

Substituindo-se a equação A.3 na A.12, tem-se:

$$
\{\overline{\mathrm{T}}\}=\left\{\overline{\mathrm{T}}_{0}\right\}+\left[\overline{\mathrm{T}}_{\mathrm{D}}\right] \cdot[\Lambda]^{\top}\{\mathrm{q}\}
$$

De onde conclui-se que a matriz momento por deslocamento [ $\left.T_{D}\right]$ pode ser obtida através da seguinte transformação:

$$
\left[\mathrm{T}_{\mathrm{D}}\right]=\left[\overline{\mathrm{T}}_{\mathrm{D}}\right] \cdot[\Lambda]^{\top}
$$

Mesmo havendo as translações de coordenadas de nós adjacentes ao pilar para um nó localizado no cg de sua seção transversal, convém observar que tanto o estado de deslocamentos como o estado de esforços dos elementos continuarão sendo relativos aos nós originais.

\section{A.4. Implementação}

Como já sugerido em situação análoga estudada por CORRÊA (1991), quando da implementação de nós de pórtico com dimensões finitas, vale a pena tirar proveito das características da matriz $[\Lambda]$, de modo a tornar mais eficiente a implementação das formulações apresentadas. A matriz $\left[\Lambda_{\mathrm{i}}\right]$ genérica para a translação dos graus de liberdade relativos ao nó i do elemento finito de placa com os seis graus de liberdade apresentados na Figura 1.2, pode ser assim dividida:

$$
\Lambda_{\mathrm{i}}=\left[\begin{array}{cc}
\mathrm{I} & 0 \\
\Omega_{\mathrm{i}} & \mathrm{I}
\end{array}\right]
$$

onde: $\Omega_{\mathrm{i}}=\left[\begin{array}{ccc}0 & 0 & -\mathrm{d}_{\mathrm{y}} \\ 0 & 0 & \mathrm{dx} \\ \mathrm{d}_{\mathrm{y}} & \mathrm{d}_{\mathrm{x}} & 0\end{array}\right] ; \quad I=\left[\begin{array}{ccc}1 & 0 & 0 \\ 0 & 1 & 0 \\ 0 & 0 & 1\end{array}\right] ; \quad 0=\left[\begin{array}{ccc}0 & 0 & 0 \\ 0 & 0 & 0 \\ 0 & 0 & 0\end{array}\right]$;

$(d x)_{i},(d y)_{i}$ - translações no plano xy com relação aos eixos x e y. 
Para a representação dos quatro nós (i, j, k, l) de um elemento quadrilateral, por exemplo, são necessárias 4 submatrizes para compor a matriz $[\Lambda]$ :

$$
\Lambda=\left[\begin{array}{llll}
{\left[\Lambda_{\mathrm{i}}\right]} & & & {[0]} \\
& {\left[\Lambda_{\mathrm{j}}\right]} & & \\
& & {\left[\Lambda_{\mathrm{k}}\right]} & \\
{[0]} & & & {\left[\Lambda_{1}\right]}
\end{array}\right]
$$

\section{A.5. Primeiro exemplo}

Neste primeiro exemplo, objetivando validar as formulações apresentadas, procede-se a análise em regime elástico-linear de uma viga mediante o emprego de elementos finitos de placa (Figura A.3).

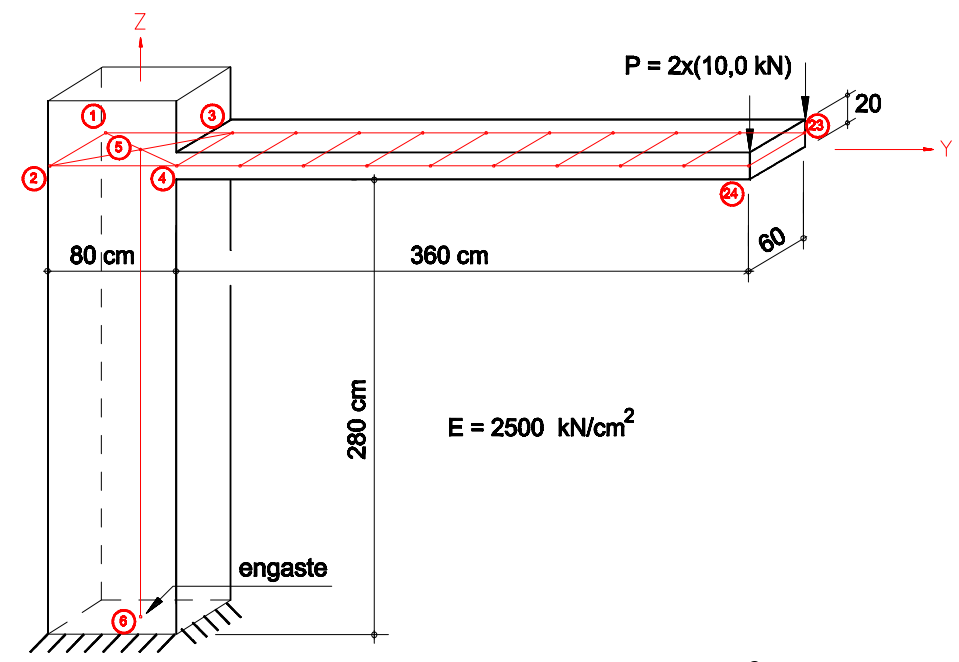

Figura A.3 - Viga engastada em pilar - $1^{\circ}$ exemplo

Admite-se o engaste de uma viga faixa em um pilar de dimensões finitas, e efetuam-se duas análises: na primeira delas, considera-se a viga engastada (na direção X) no plano médio do pilar (representado pela barra 5-6). Em seguida, a viga é analisada considerando-se as reais dimensões desse pilar, operando-se as translações dos graus de liberdade dos nós 3 e 4 para o centro do pilar (nó 5).

A Tabela A.1 apresenta resultados de flechas para as vigas e de esforços solicitantes para o pilar, considerando-se ou não as suas dimensões na análise.

Tabela A.1 - Resultados obtidos para a estrutura

\begin{tabular}{|c|c|c|c|}
\hline \multirow{2}{*}{ análises } & viga & \multicolumn{2}{|c|}{ pilar } \\
\cline { 2 - 4 } & flecha máx. $(\mathrm{cm}) \mathrm{N}(\mathrm{kN})$ & $\mathrm{M}_{\mathrm{x}}(\mathrm{kN} . \mathrm{cm})$ \\
\hline pilar puntual (vão livre=4,0m) & $-0,0415$ & $-20,0$ & $-8000,0$ \\
\hline pilar como apoio extenso & $-0,0315$ & $-20,0$ & $-8000,0$ \\
\hline
\end{tabular}


Analisando os resultados apresentados na Tabela A.1 observa-se que, apesar da diminuição da flecha no segundo caso, os resultados de esforços no pilar não foram afetados, justamente por se tratar de uma estrutura isostática.

\section{A.6. Segundo exemplo}

Este exemplo promove a aplicação do modelo à análise de um pavimento (Figura A.4) também em regime elástico-linear já estudado por FRANÇA(1985), CORRÊA(1991), e OLIVEIRA(1997). O pavimento é composto de laje plana com espessura de $16 \mathrm{~cm}$. As vigas ocorrem apenas na caixa da escada e de elevadores, unindo os pilares-parede.

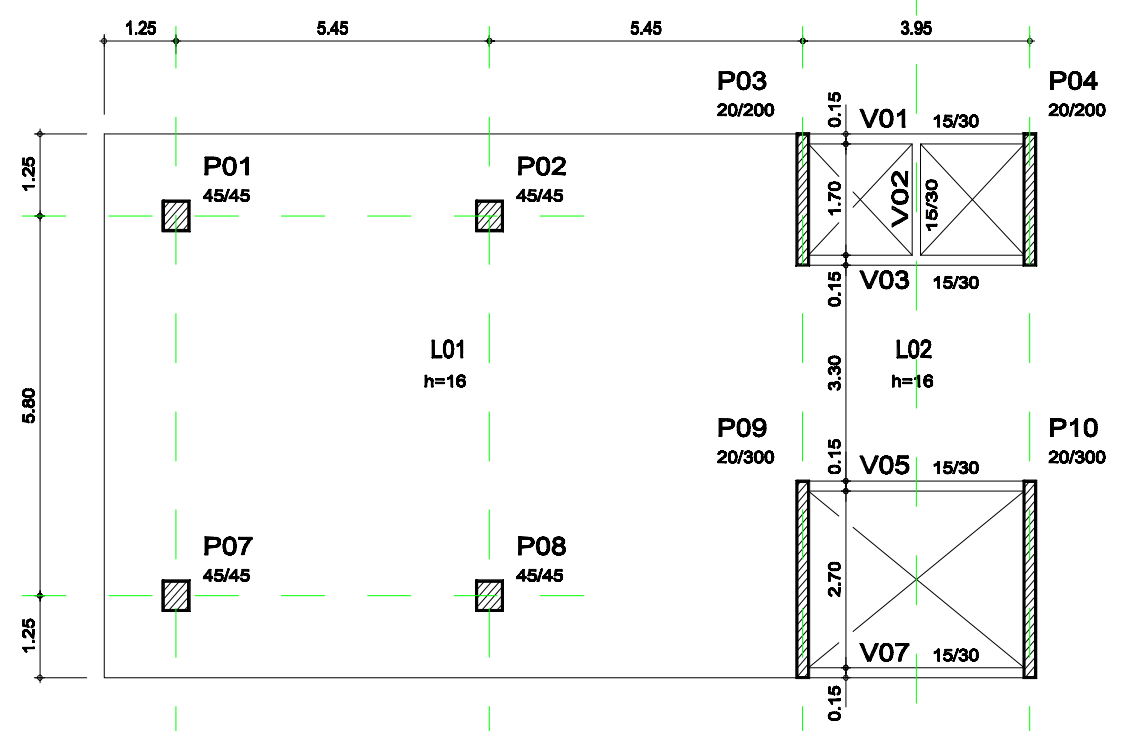

Figura A.4 - Pavimento tipo: laje plana (medidas em cm)

O concreto utilizado apresenta as seguintes características:

$\mathrm{E}_{\mathrm{c}}\left(^{*}\right)=1920 \mathrm{kN} / \mathrm{cm}^{2}$ (módulo de deformação longitudinal reduzido);

$v=0,20$ (coeficiente de Poisson);

$\gamma=25,0 \mathrm{kN} / \mathrm{m}^{3}$ (peso específico).

O carregamento (além do peso próprio) é composto por:

revestimento $=1,0 \mathrm{kN} / \mathrm{m}^{2}$;

divisórias $\quad=1,0 \mathrm{kN} / \mathrm{m}^{2}$;

sobrecarga $=3,0 \mathrm{kN} / \mathrm{m}^{2}$.

* Módulo de elasticidade longitudinal reduzido de modo a incorporar, de maneira indireta e inconsistente, os efeitos do tempo. Prática usual em escritórios de projeto. 
Para a análise de meio pavimento foram empregados 204 elementos finitos quadrilaterais de placa. Empregaram-se 15 barras para a simulação de vigas (3 barras para cada viga ou meia viga), e 4 barras para a representação dos pilares (P01,P02,P07 e P08). Os pilares-parede P03 e P09 foram simulados por 4 e 6 molas de rotação, respectivamente.

De início, os pilares são modelados puntualmente sob a planta do pavimento, resultando nas curvas de isodeslocamento da Figura A.5, e de isomomentos fletores das Figuras A.6 e A.7 na região do pilar P08.

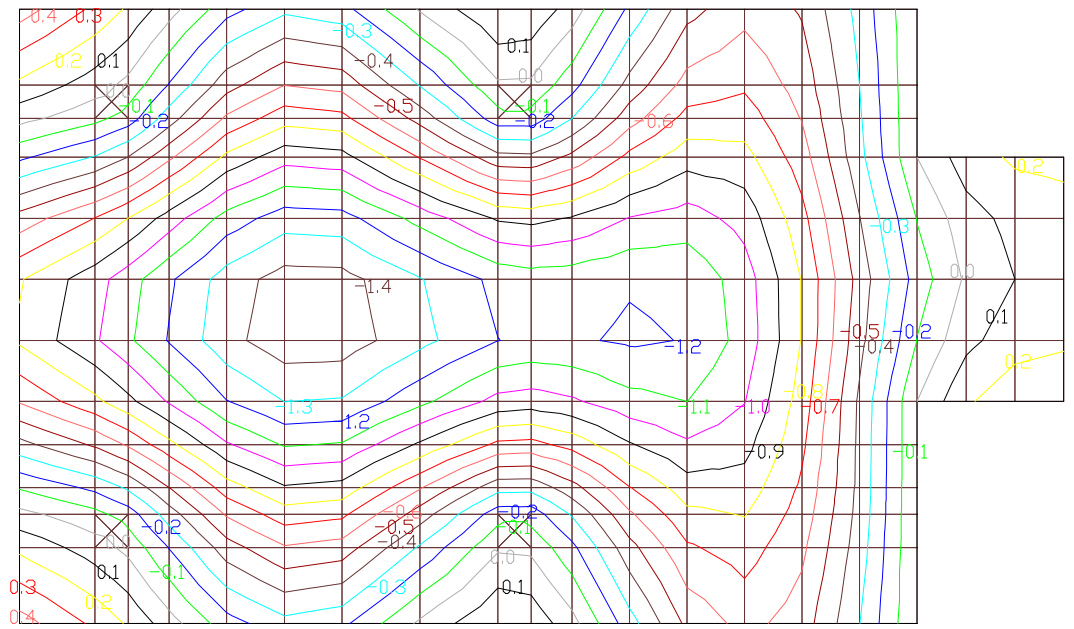

Figura A.5 - Translação segundo o eixo $z$ - apoios puntuais

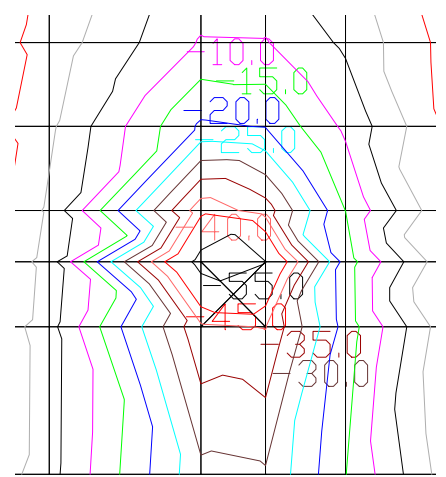

Figura A.6 - Momento fletor $M_{x}$ na região do P08 - apoios puntuais

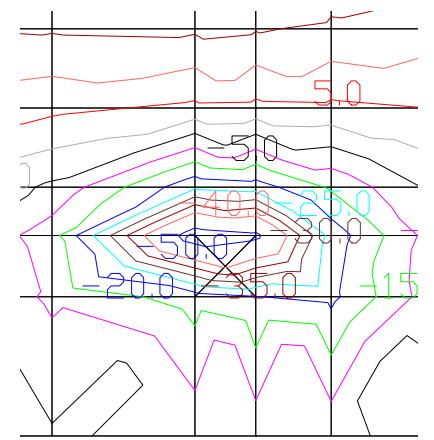

Figura A.7 - Momento fletor $M_{y}$ na região do P08 - apoios puntuais 
Em seguida, os pilares são incorporados com suas dimensões reais, seguindo a mesma malha. Este procedimento, como pode ser observado, melhora bastante a representatividade dos esforços de momento fletor negativo nas regiões dos pilares, eliminando-se os "picos". Os momentos fletores positivos, assim como os deslocamentos transversais das regiões entre os pilares, também diminuem, haja visto o decréscimo dos vãos livres entre os pilares (Figuras A.8 a A.10).

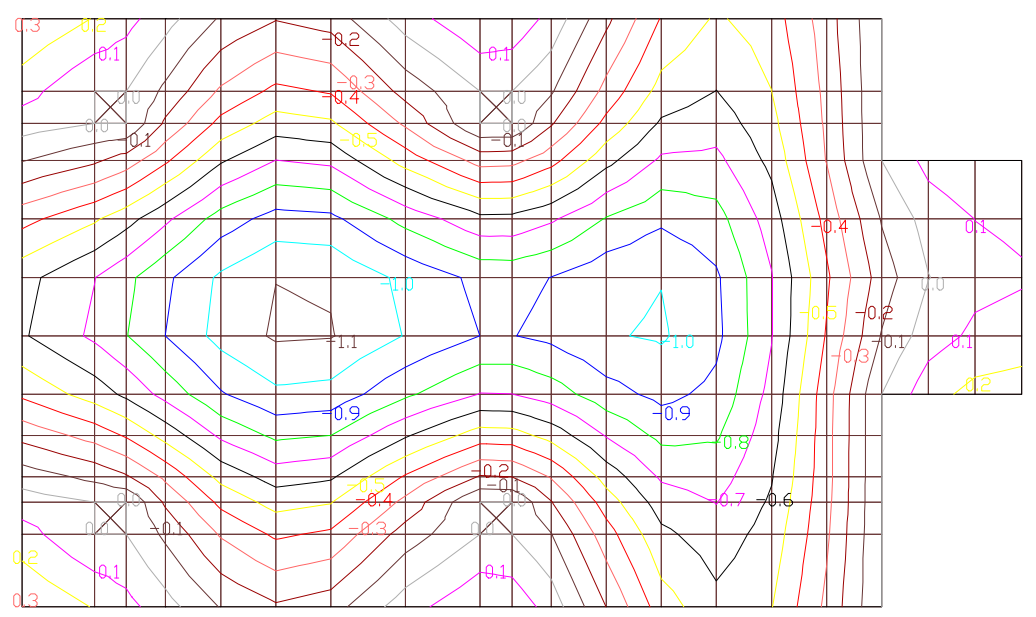

Figura A.8 - Translação segundo o eixo z - apoios extensos

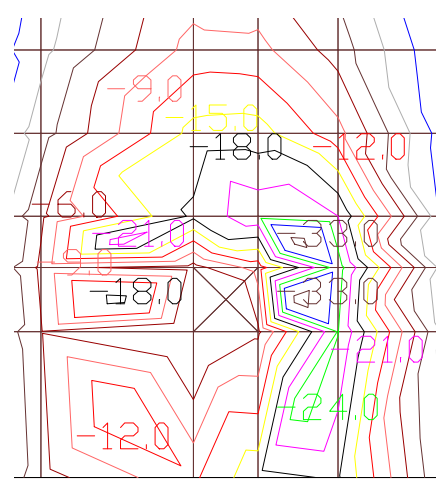

Figura A.9 - Momento fletor $M_{x}$ na região do P08 - apoios extensos

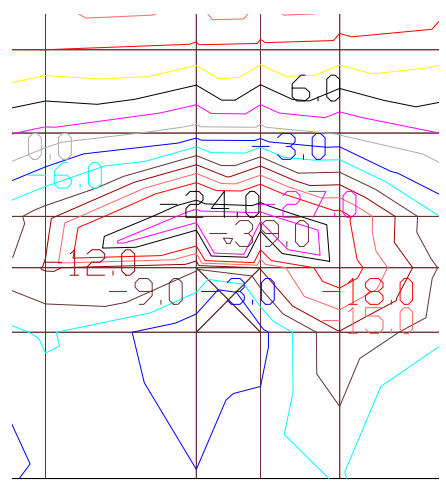

Figura A.10 - Momento fletor $M_{y}$ na região do P08 - apoios extensos 
A Tabela A.2 traz um resumo dos resultados obtidos com as duas análises.

Tabela A.2 - Resultados significativos das análises

\begin{tabular}{|c|c|c|c|c|c|c|}
\hline descrição & \multicolumn{2}{|c|}{ Tz (cm) } & \multicolumn{2}{c|}{ Mx (kN.cm) } & \multicolumn{2}{c|}{ My (kN.cm) } \\
& (mín.) & $($ máx) & (mín.) & $($ máx $)$ & (mín.) & (máx) \\
\hline $\begin{array}{c}\text { análise com trecho } \\
\text { rígido }\end{array}$ & $-1,114$ & 0,303 & $-35,86$ & 19,11 & $-40,69$ & 21,98 \\
\hline $\begin{array}{c}\text { análise sem trecho } \\
\text { rígido }\end{array}$ & $-1,461$ & 0,447 & $-80,69$ & 20,03 & $-80,14$ & 25,33 \\
\hline
\end{tabular}

Os resultados apresentados na Tabela A.2 permitem concluir positivamente sobre os benefícios da incorporação dos pilares com suas dimensões reais na análise do pavimento.

Neste exemplo houve um decréscimo de aproximadamente $24 \%$ nos deslocamentos transversais comparativamente à consideração do pilar puntual. Os esforços de momento negativo na região do pilar tiveram decréscimo de aproximadamente 50\% (sobre os momentos fletores de "pico", considerando-se os apoios puntuais), e os momentos fletores positivos, uma redução de 5 a $15 \%$. 


\section{AneXO B - ESTUDO DO COMPORTAMENTO DO COEFICIENTE $\gamma_{g l}$}

\section{B.1. Introdução}

Este anexo objetiva-se ao suporte de algumas das afirmações estabelecidas no Capítulo 8 no que se refere ao comportamento do coeficiente de segurança global relativo aos materiais $\left(\gamma_{\mathrm{gl}}\right)$. Em complemento æ̀s seções transversais abordadas no Capítulo 8, quais sejam:

a) retangular 20/60 sob flexão simples com e sem armadura de compressão;

b) $T$ 20/60 com $b_{f}=140 \mathrm{~cm}$ e $h_{f}=15 \mathrm{~cm}$ sob flexão simples com e sem armadura de compressão;

c) retangular $20 / 60$ sob flexão normal composta com armadura simétrica;

apresentam-se, neste anexo, uma série de resultados, obtidos a partir de outras seções transversais, e para as duas classes de concreto que delimitaram a análise estabelecida no Capítulo 8 (C-20 e C-30).

Procura-se, com esse procedimento, observar a variação do comportamento do coeficiente $\gamma_{\mathrm{gl}}$ com algumas das principais variáveis relacionadas às seções transversais: classe do concreto e geometria. Não se pretende, obviamente, esgotar a amplitude das variáveis envolvidas, nem muito menos das possíveis combinações pois, como já mencionado no Capítulo 8 , toda a gama de possibilidades só pode, e deve ser levada em consideração, através de modelos capazes de inferir resultados considerando a aleatoriedade das variáveis. A Tabela B.1 apresenta as seções transversais analisadas neste anexo, bem como aquelas cujos resultados foram apresentados no Capítulo 8 (naquele caso, para todas as classes de concreto analisadas).

Apenas a dimensão relativa à altura da seção transversal para as seções retangulares é que foi objeto de investigação, pois é evidente que a outra dimensão 
(largura) interfere proporcionalmente sobre ambas as capacidades resistentes da seção transversal (com valores médios e com valores de projeto) conduzindo, assim, à uma mesma relação para $\gamma_{\mathrm{gl}}$. Manteve-se a mesma largura para todas as seções $(20 \mathrm{~cm})$, e foram experimentadas diversas alturas que abrangessem uma amplitude relativamente grande. Por isso, deve-se notar que a seção 20/10 é puramente teórica, e não constitui uma opção de emprego prático, principalmente para o caso de FNC. Nas análises das seções T, o objetivo foi o de estudar a influência da largura da mesa sobre o comportamento de $\gamma_{\mathrm{gl}}$. O cobrimento teórico empregado nas análises foi estabelecido relativamente à altura de cada uma das seções, e equivalente a 0,05.h. Apesar de não estar contemplada nos estudos deste anexo, há que se destacar que a variável cobrimento também pode apresentar influência sobre o comportamento do coeficiente $\gamma_{\mathrm{gl}}$.

Tabela B.1 - Seções extra analisadas com $\gamma_{c}=1,4$. Casos investigados

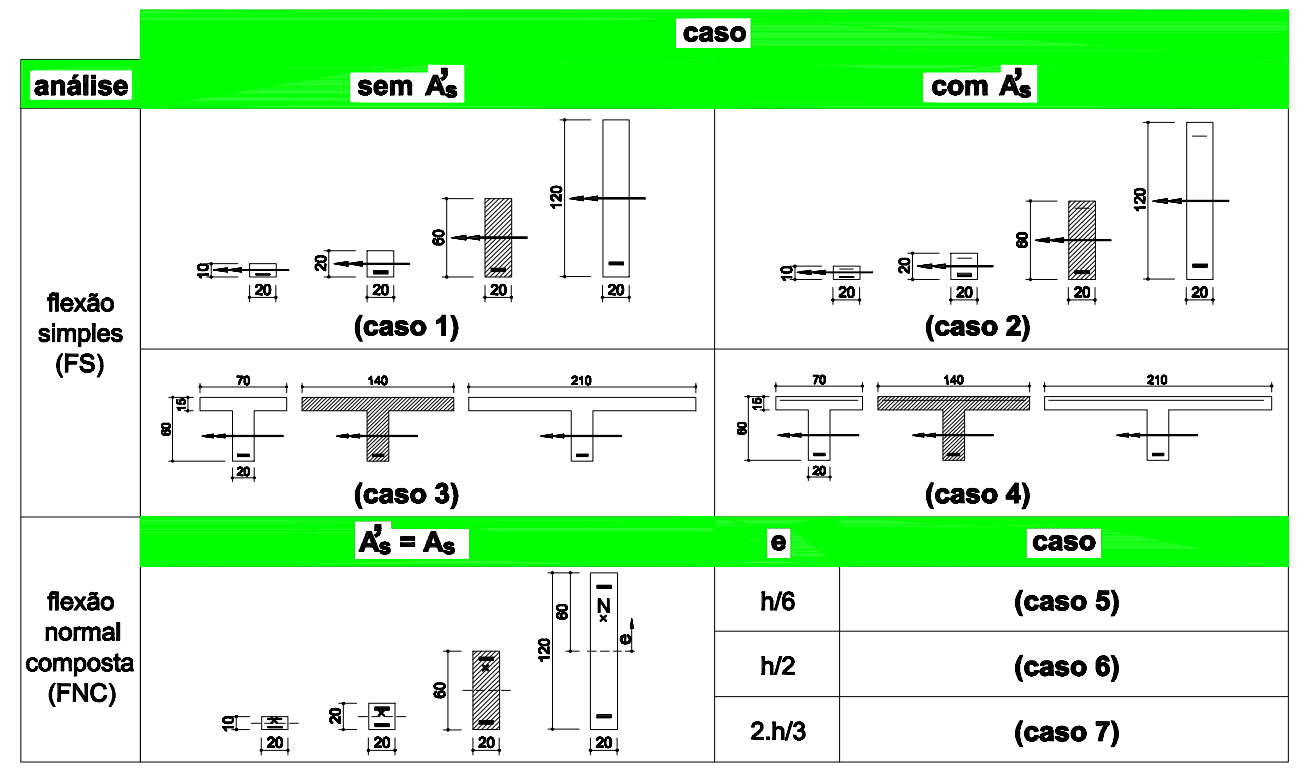

\section{B.2. Resultados}

Os resultados das análises estão apresentados nas figuras a seguir. Para a maioria dos casos, houve uma superposição perfeita das curvas, e por isso notamse apenas duas delas, relativas às duas classes de concreto aqui analisadas (C-20 e C-50). 


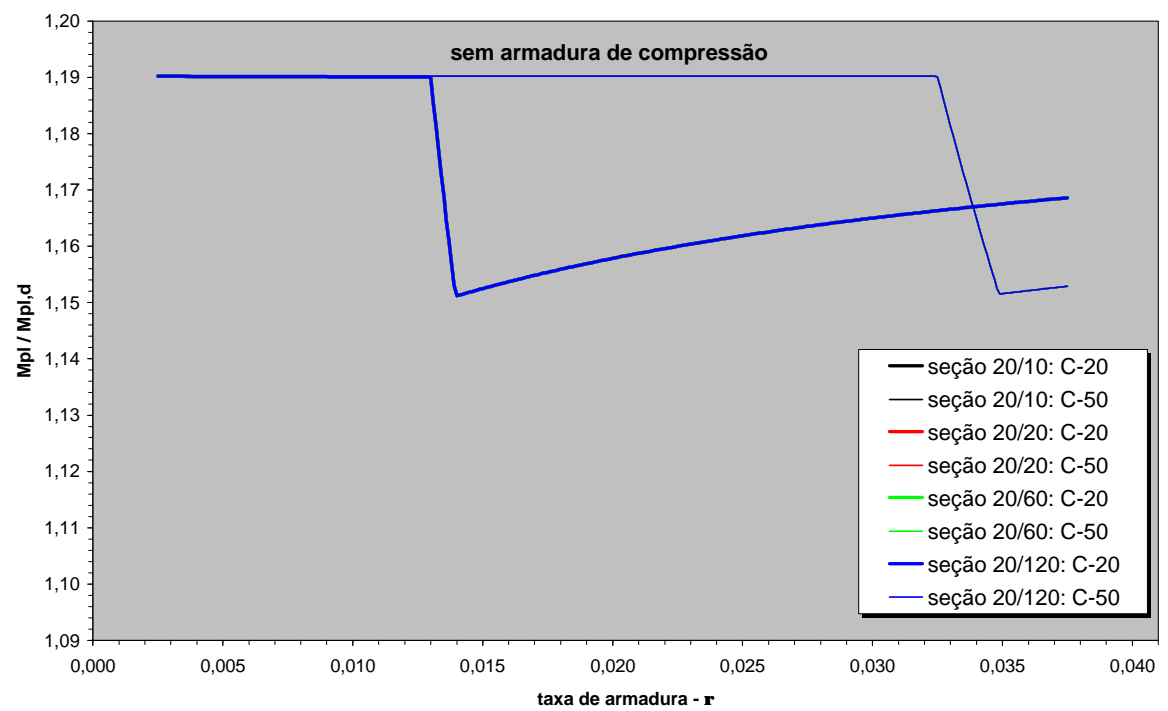

Figura B.1 - $\gamma_{g l .}$ Caso 1

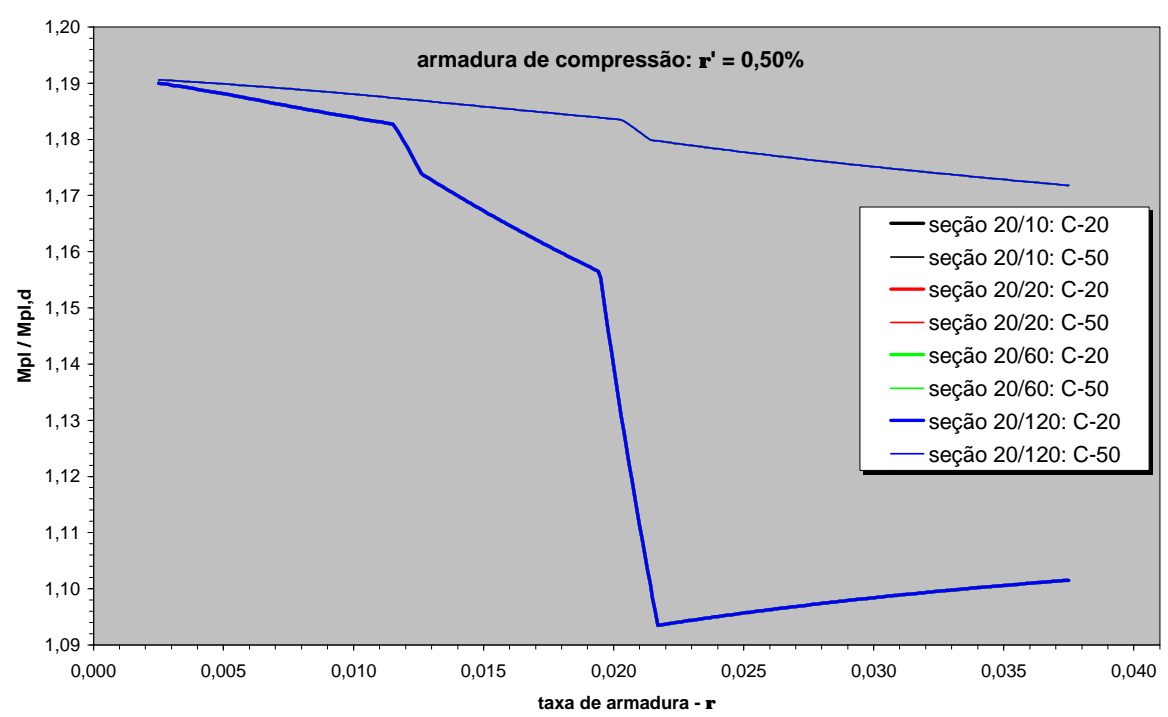

Figura B.2 - $\gamma_{g l .}$ Caso 2

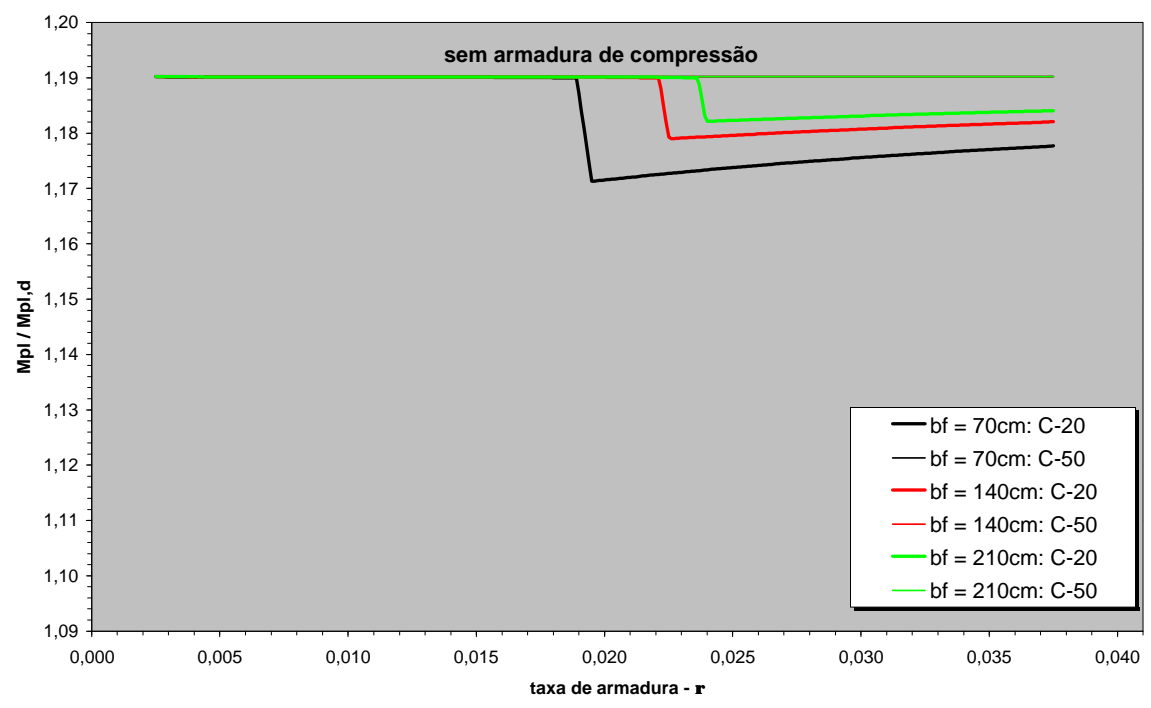

Figura B.3 $-\gamma_{g l .}$ Caso 3 


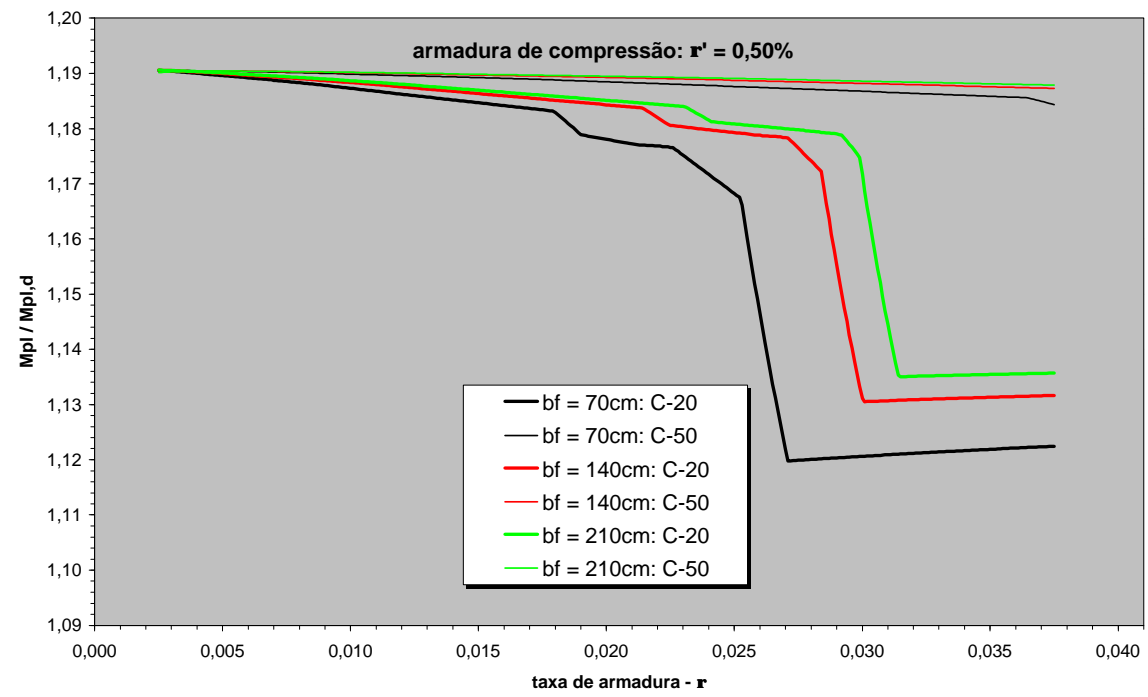

Figura B.4 - $\gamma_{g l .}$. Caso 4

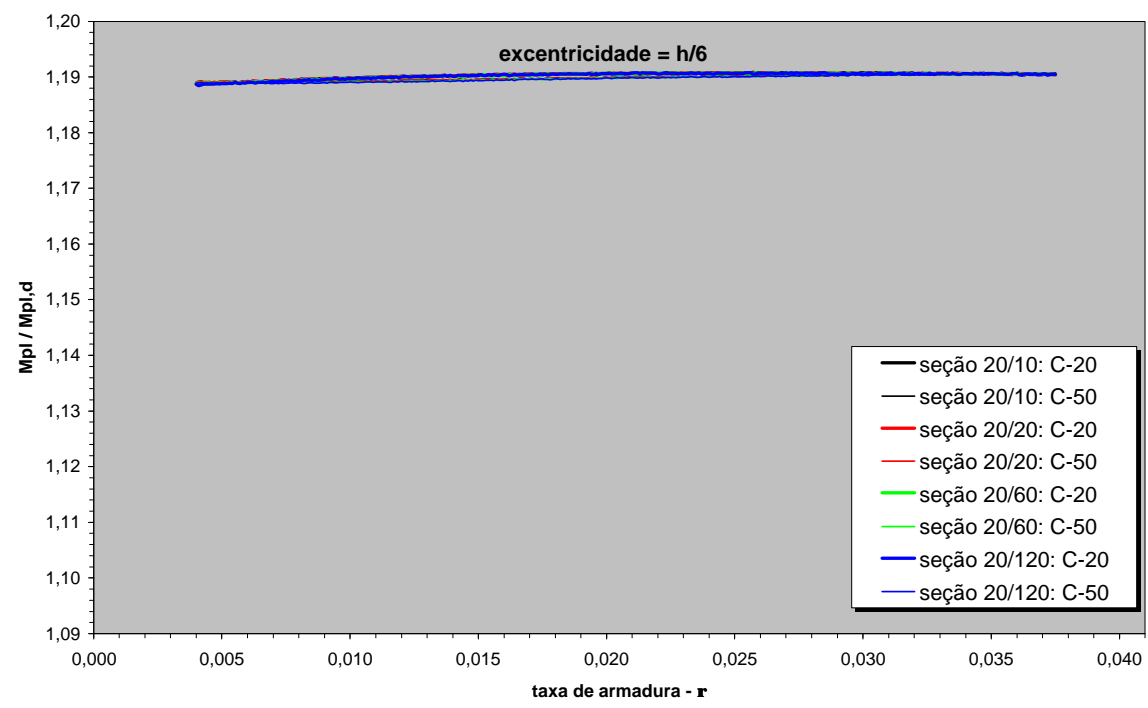

Figura B.5 - $\gamma_{g \mid .}$ Caso 5

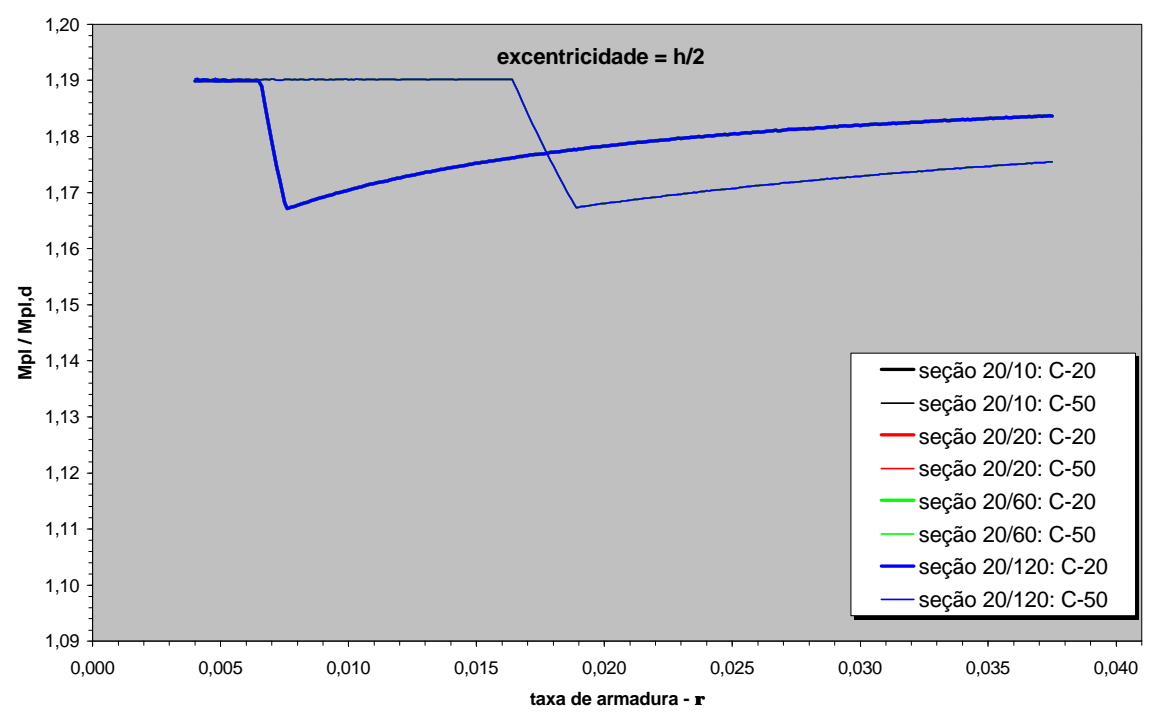

Figura B. $6-\gamma_{g l}$. Caso 6 


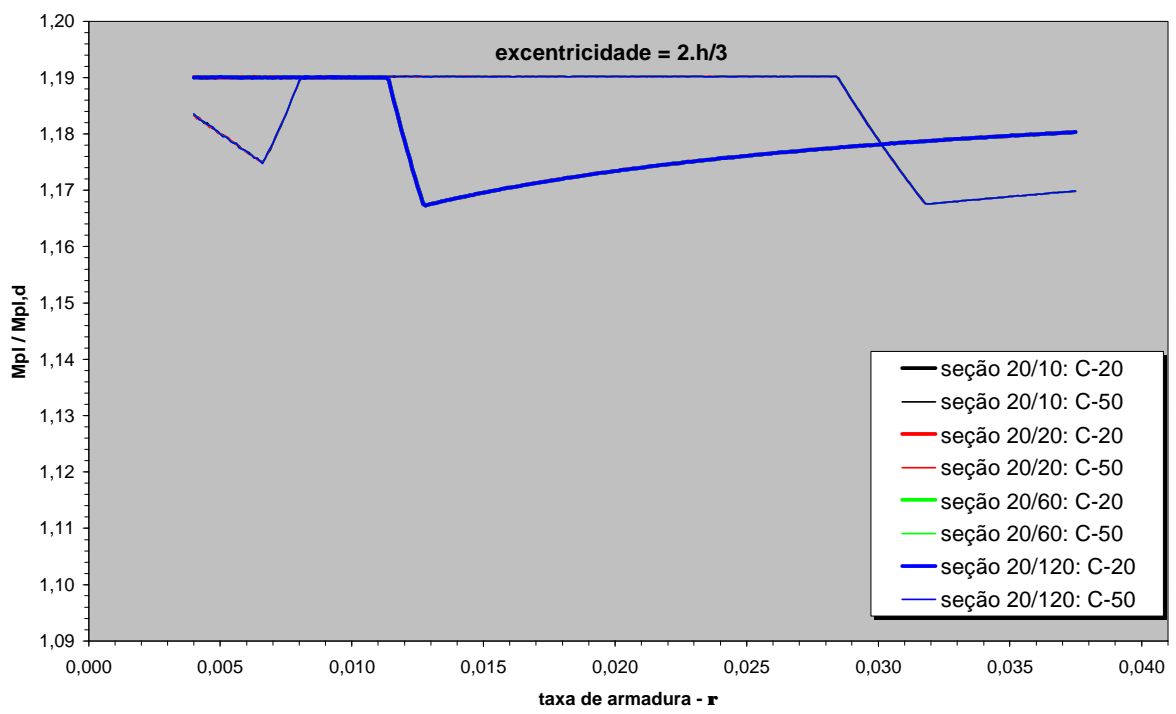

Figura B. 7 - $\gamma_{g l .}$ Caso 7 